\title{
Framing the Adaptation Gap Report
}

\author{
Magnan, Alexandre; Christiansen, Lars; Neufeldt, Henry
}

Published in:

Adaptation Gap Report 2020

Publication date:

2021

\section{Document Version}

Publisher's PDF, also known as Version of record

Link back to DTU Orbit

Citation (APA):

Magnan, A., Christiansen, L., \& Neufeldt, H. (2021). Framing the Adaptation Gap Report. In Adaptation Gap Report 2020 United Nations Environment Programme.

\section{General rights}

Copyright and moral rights for the publications made accessible in the public portal are retained by the authors and/or other copyright owners and it is a condition of accessing publications that users recognise and abide by the legal requirements associated with these rights.

- Users may download and print one copy of any publication from the public portal for the purpose of private study or research.

- You may not further distribute the material or use it for any profit-making activity or commercial gain

- You may freely distribute the URL identifying the publication in the public portal

If you believe that this document breaches copyright please contact us providing details, and we will remove access to the work immediately and investigate your claim 


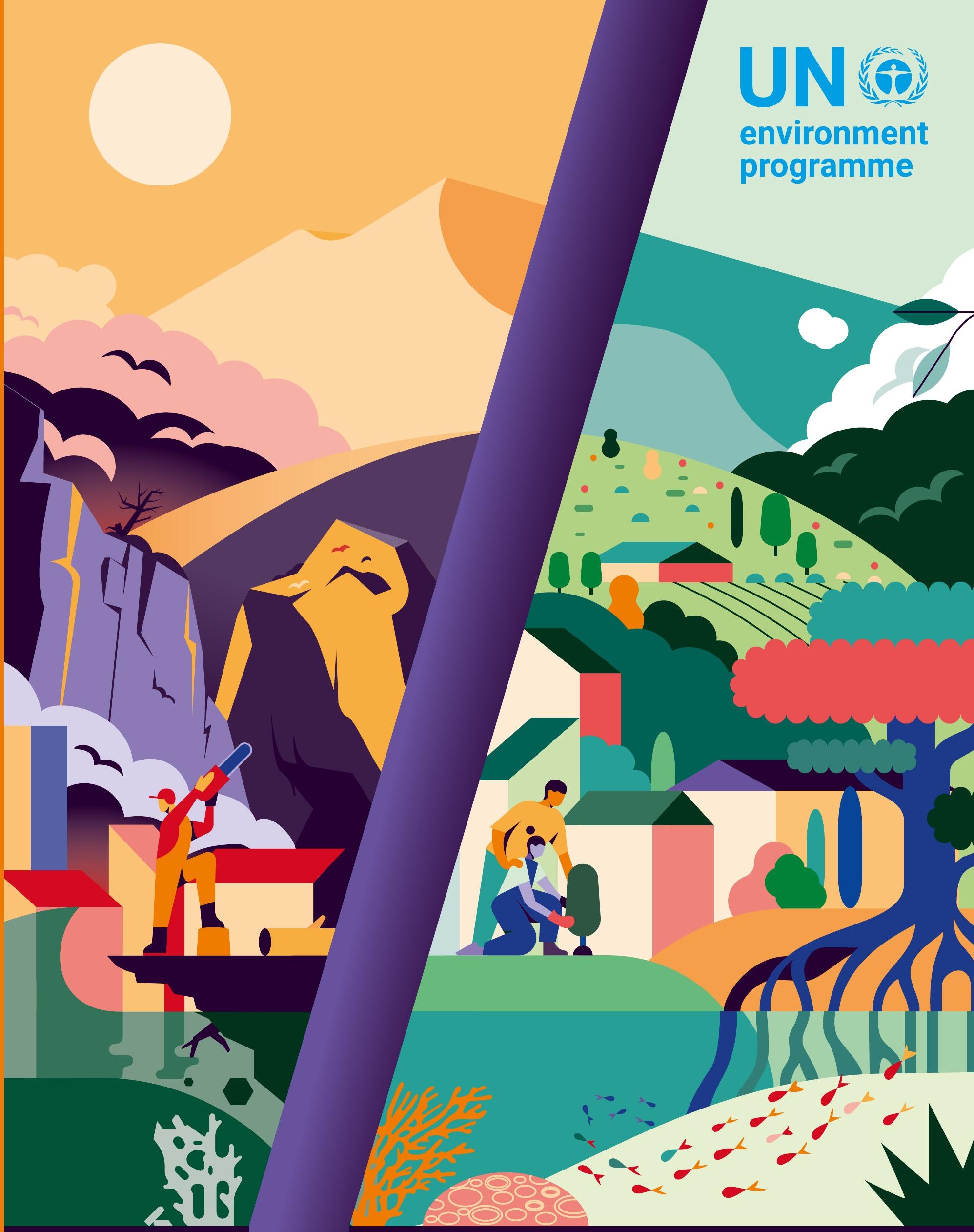

\section{$\because ّ$ UNEP DTU} PARTNERSHIP

\begin{tabular}{|c|}
\hline WASP \\
\hline $\begin{array}{c}\text { WORLD } \\
\text { ADAPTATION } \\
\text { SCIENCE } \\
\text { PROGRAMME }\end{array}$ \\
\hline
\end{tabular}




\section{ISBN: 978-92-807-3834-6}

Job number: DEW/2332/NA

This publication may be reproduced in whole or in part and in any form for educational or non-profit services without special permission from the copyright holder, provided acknowledgement of the source is made. The United Nations Environment Programme would appreciate receiving a copy of any publication that uses this publication as a source.

No use of this publication may be made for resale or any other commercial purpose whatsoever without prior permission in writing from the United Nations Environment Programme. Applications for such permission, with a statement of the purpose and extent of the reproduction, should be addressed to the Director, Communication Division, United Nations Environment Programme, P. O. Box 30552, Nairobi 00100, Kenya.

\section{Disclaimers}

The designations employed and the presentation of the material in this publication do not imply the expression of any opinion whatsoever on the part of the Secretariat of the United Nations concerning the legal status of any country, territory or city or area or its authorities, or concerning the delimitation of its frontiers or boundaries. For general guidance on matters relating to the use of maps in publications please go to http://www.un.org/Depts/Cartographic/ english/htmain.htm

Mention of a commercial company or product in this document does not imply endorsement by the United Nations Environment Programme or the authors. The use of information from this document for publicity or advertising is not permitted. Trademark names and symbols are used in an editorial fashion with no intention on infringement of trademark or copyright laws.

The views expressed in this publication are those of the authors and do not necessarily reflect the views of the United Nations Environment Programme. We regret any errors or omissions that may have been unwittingly made.

() Maps, photos and illustrations as specified

\section{Suggested citation}

United Nations Environment Programme (2021). Adaptation Gap Report 2020. Nairobi.

\section{Production}

United Nations Environment Programme (UNEP), UNEP DTU Partnership (UDP) and the World Adaptation Science Programme (WASP).

\section{Supported by:}

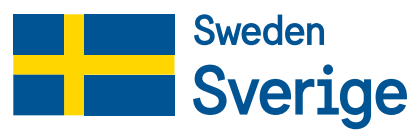

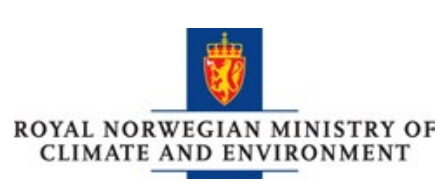

粕 IDRC $\mid$ CRDI

Interemational Development Research Centre
Centre de recherches pour le développement international

Canadăă

\section{UNEP promotes}

environmentally sound

practices globally and

in its own activities. Our

distribution policy aims to reduce

UNEP's carbon footprint. 
Adaptation Gap Report 2020 


\section{Acknowledgements}

The United Nations Environment Programme (UNEP) would like to thank the steering committee members, the lead and contributing authors and the project coordination team for their contribution to the development of this report. The following individuals have provided input to the report Authors and reviewers contributed to this report in their individual capacity and their affiliations are only mentioned for identification purposes.

\section{Steering committee}

Edith Adera (African Development Bank), Barbara Buchner (Climate Policy Initiative), Minpeng Chen (Renmin University of China), Barney Dickson (UNEP), Vincent Gainey (Foreign Commonwealth and Development Office, Government of the United Kingdom), Jian Liu (UNEP), Anil Markandya (Basque Centre for Climate Change), Youssef Nassef (Secretariat of the United Nations Framework Convention on Climate Change), Anne Olhoff (UNEP DTU Partnership), Cynthia Rosenzweig (NASA Goddard Institute for Space Studies and Columbia University), Michiel Schaeffer (Global Centre on Adaptation), Tint Thaung (The Nature Conservancy), Alberto Yanosky (Guyra Paraguay).

\section{Chapter 1. Setting the scene}

Lead Authors: Lars Christiansen (UNEP DTU Partnership) and Alexandre Magnan (IDDRI).

Contributing Authors: Valerie Kapos (United Nations Environment Programme World Conservation Monitoring Centre, UNEP-WCMC), Timo Leiter (Grantham Research Institute on Climate Change and the Environment, London School of Economics and Political Science), Manishka De Mel (Columbia University and NASA Goddard Institute for Space Studies), Annett Moehner (Secretariat of the United Nations Framework Convention on Climate Change), Henry Neufeldt (UNEP DTU Partnership), Pieter Pauw (Frankfurt School of Finance \& Management), Cynthia Rosenzweig (NASA Goddard Institute for Space Studies and Columbia University).

\section{Chapter 2. Framing the Adaptation Gap Report}

Lead Authors: Alexandre Magnan (IDDRI), Lars Christiansen (UNEP DTU Partnership), Henry Neufeldt (UNEP DTU Partnership).

Contributing Authors: Valerie Kapos (UNEP-WCMC), Timo Leiter (Grantham Research Institute on Climate Change and the Environment, London School of Economics and Political Science), Manishka De Mel (Columbia University and NASA Goddard Institute for Space Studies), Annett Moehner (Secretariat of the United Nations Framework Convention on Climate Change), Cynthia Rosenzweig (NASA Goddard Institute for Space Studies and Columbia University).

\section{Chapter 3. Assessing global progress on adaptation planning}

Lead Authors: Annett Moehner (Secretariat of the United Nations Framework Convention on Climate Change), Maryam Navi (Secretariat of the United Nations Framework Convention on Climate Change), Fatin Tawfig (Secretariat of the United Nations Framework Convention on Climate Change).

\section{Chapter 4. Global progress on financing for adaptation}

Lead Authors: Pieter Pauw (Frankfurt School of Finance \& Management), Romain Weikmans (Université Libre de Bruxelles), Charlene Watson (Overseas Development Institute), Henriette Jahns (Frankfurt School of Finance \& Management), Martin Prowse (Independent Evaluation Unit of the Green Climate Fund), Adriana Quevedo (Overseas Development Institute), Jyotsna Puri (International Fund for Agricultural Development).

Chapter 5. Progress in implementing adaptation: insights from project proposals and scientific literature

Lead Author: Timo Leiter (Grantham Research Institute on Climate Change and the Environment, London School of Economics and Political Science).

\section{Chapter 6. Nature-based solutions for adaptation}

Lead Authors: Valerie Kapos (UNEP-WCMC), Manishka De Mel (Columbia University and NASA Goddard Institute for Space Studies), Cynthia Rosenzweig (NASA Goddard Institute for Space Studies and Columbia University), Mathilde Kolenda (UNEP DTU Partnership), Lucy Emerton (Environment Management Group), Henry Neufeldt (UNEP DTU Partnership).

Contributing Authors: Elisabeth Bernhardt (UNEP), Thomas William Dale (UNEP DTU Partnership), Adam Freed (Bloomberg Associates), Julie Greenwalt (Go Green for Climate/Co-chair GEO for Cities), Shaun Martin (World Wildlife Fund), Karen Podvin (International Union for Conservation of Nature), Ali Raza Rizvi (International Union for Conservation of Nature), Anika Terton (International Institute for Sustainable Development), Tint Thaung (The Nature Conservancy), Suyeon Yang (UNEP), Alberto Yanosky (Guyra Paraguay). 


\section{Chapter 7. Global progress on adaptation and outlook}

Lead Authors: Alexandre Magnan (IDDRI), Thomas William Dale (UNEP DTU Partnership).

Contributing Authors: Henry Neufeldt (UNEP DTU Partnership), Lars Christiansen (UNEP DTU Partnership), Valerie Kapos (UNEP-WCMC), Timo Leiter (Grantham Research Institute on Climate Change and the Environment, London School of Economics and Political Science), Annett Moehner (Secretariat of the United Nations Framework Convention on Climate Change), Manishka De Mel (Columbia University and NASA Goddard Institute for Space Studies), Cynthia Rosenzweig (NASA Goddard Institute for Space Studies and Columbia University).

\section{Reviewers}

Mozharul Alam (UNEP), Stephanie Allan (Oxford Policy Management), Ariadna Anisimov (IDDRI), Joanes Atela (African Research and Impact Network), Vidhee Avashia (Indian Institute of Management Ahmedabad), Elisabeth Bernhardt (UNEP), Tania Guillén Bolaños (Climate Service Center Germany - GERICS), Dennis Bours (Adaptation Fund Technical Evaluation Reference Group), Christina Chan (World Resources Institute), Dipesh Chapagain (University of Bonn), Alexandre Chausson (University of Oxford), Sunungurai Dominica Chingarande (University of Zimbabwe), Carlos Smaniotto Costa (Universidade Lusófona), Bruce Currie-Adler (International Development Research Centre), Paul Desanker (United Nations Framework Convention on Climate Change), Gustavo Alberto Fonseca (Global Environment Facility), Francesco Gaetani (UNEP), Amit Garg (Indian Institute of Management Ahmedabad), Oscar Guevara (World Wildlife Fund), Sven Harmeling (CARE International), Fareeha Iqbal (Global Environment Facility), Robert Kay (ICF), Carola Kloeck (Sciences Po), Donna Lagdameo (Red Cross Red Crescent Climate Centre), Nicolina Lamhauge (Organisation for Economic Co-operation and Development), Don Lemmen (unaffiliated), Tabea Lissner (Climate Analytics), Anthony Mills (C4 EcoSolutions and Stellenbosch University), Johanna Nalau (Griffith University), Mark New (University of Cape Town), Marcus Nield (UNEP), Ian Noble (Australian National University), Marta Olazabal (Basque Centre for Climate Change), Mikko Ollikainen (Adaptation Fund), Åsa Persson (Stockholm Environment Institute), Tuan Anh Pham (Viet Nature Conservation Centre), Diana Reckien (University of Twente), Morgan Richmond (Climate Policy Initiative), Miguel Sánchez (University of Granada), Brett Scheffers (University of Florida), Zita Sebesvari (United Nations University), Alessandra Sgobbi (European Commission), Joohun Shin (Green Climate Fund), Chandni Singh (Indian Institute for Human Settlements), Adelle Thomas (Climate Analytics), Jessica Troni (UNEP), Revocatus Twinomuhangi (Makerere University), Sebastian Vicuna (Pontificia Universidad Catolica de Chile), Tatirose Vijitpan (UNEP-International Ecosystem Management Partnership, IEMP), Paul Watkiss (Paul Watkiss Associates), Jaime Webbe (Canadian International Resources and
Development Institute), Bregje van Wesenbeeck (Deltares), Suyeon Yang (UNEP), Jinhua Zhang (UNEP).

\section{Editors}

Henry Neufeldt (UNEP DTU Partnership), Lars Christiansen (UNEP DTU Partnership), Thomas William Dale (UNEP DTU Partnership).

\section{Secretariat and coordination}

Lars Christiansen (UNEP DTU Partnership), Thomas William Dale (UNEP DTU Partnership), Henry Neufeldt (UNEP DTU Partnership), Anne Olhoff (UNEP DTU Partnership), Ying Wang (UNEP), Maarten Kappelle (UNEP), Edoardo Zandri (UNEP).

\section{Media support}

UNEP: Timothy Albone, David Cole, Marie Daher, Florian Fussstetter, Maria Vittoria Galassi, Nancy Groves, Tal Harris, Viola Kup, Beverly McDonald, Pooja Munshi, Elvis Mwaura, Moses Osani, Keishamaza Rukikaire, Laila Saada, Sajni Shah, Mellab Shiluli, Neha Sud.

UNEP DTU Partnership: Monna Hammershøy Blegvad, Lasse Hemmingsen, Mette Annelie Rasmussen.

\section{Language editing and translation of executive summary}

Strategic Agenda

\section{Thanks also to}

Anu Adhikari (IUCN, Nepal), Mirella Gallardo (Instituto de Montaña, Peru), Luciano Mateos (Consejo Superior de Investigaciones Científicas), Alfredo Durán Núñez del Prado (Centro AGUA-Universidad Mayor de San Simón (UMSS)), Sergio Martos-Rosillo (Geological Survey of Spain (Instituto Geológico y Minero de España)) and Nirmal Jivan Shah (Nature Seychelles).

UNEP: Mohamed Atani, Mario Boccucci, Angeline Djampou, Dany Ghafari, Gustavo Mañez Gomis, Anna Maria Kilponen, Anna Maria Kilponen, Sofia Méndez, Abdelmenam Mohamed, Susan Mutebi-Richards, Pinya Sarasas, Ekaterina Tegina, Kaisa Uusimaa

\section{UNEP DTU Partnership: Christian Knudsen}

Finally, UNEP would like to thank the Danish Ministry of Foreign Affairs, the Norwegian Ministry of Climate and Environment, the Norwegian Ministry of Foreign Affairs, the Swedish International Development Authority (SIDA) and the International Development Research Centre (IDRC) of Canada for their support to the work of the Adaptation Gap Report. 


\section{W}

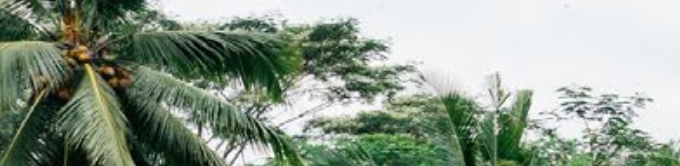

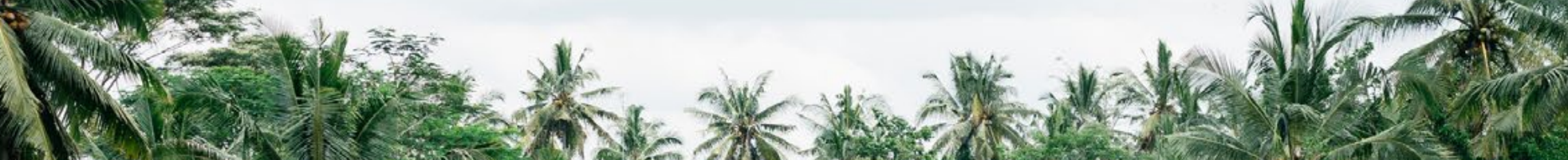

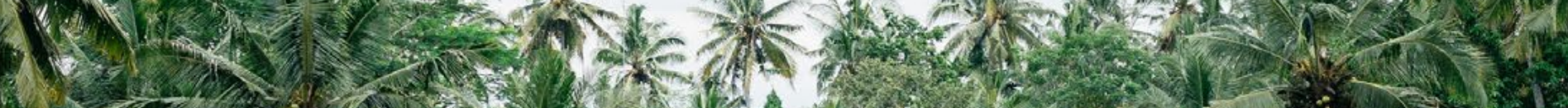

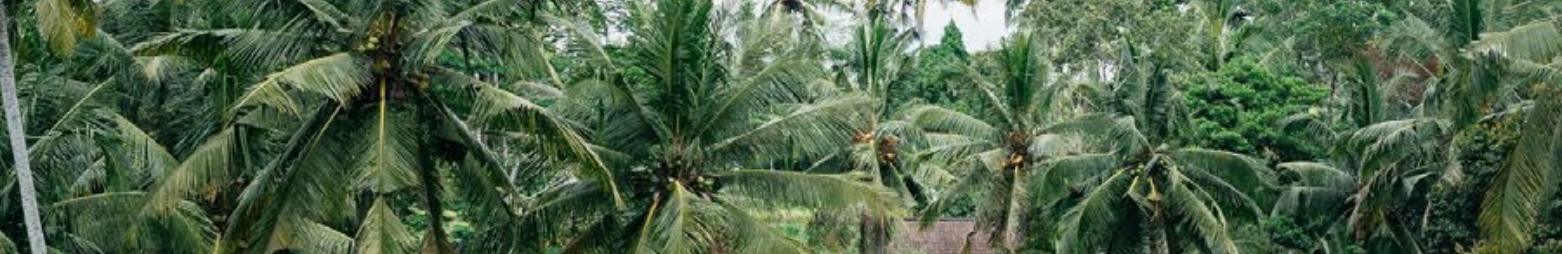

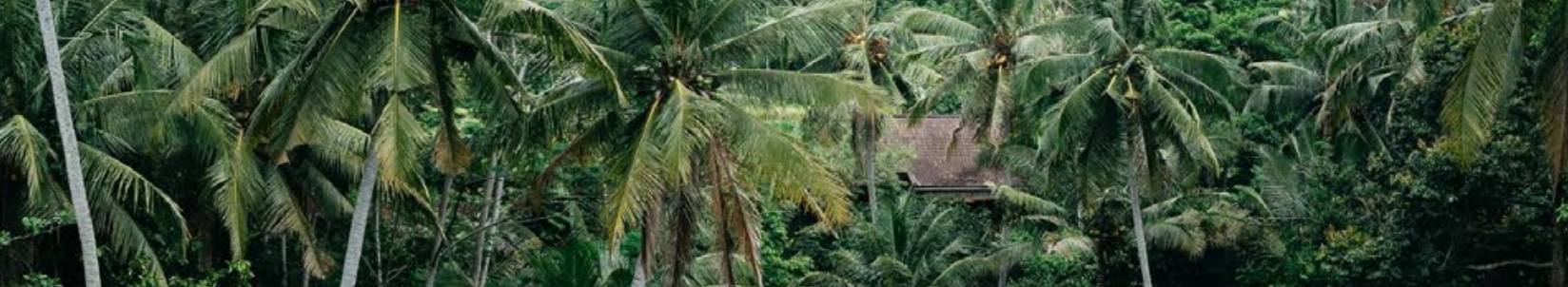

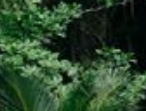

1.

(2) 1.

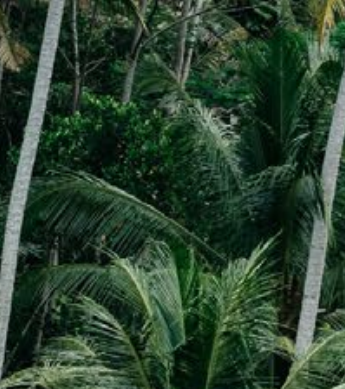

Nins

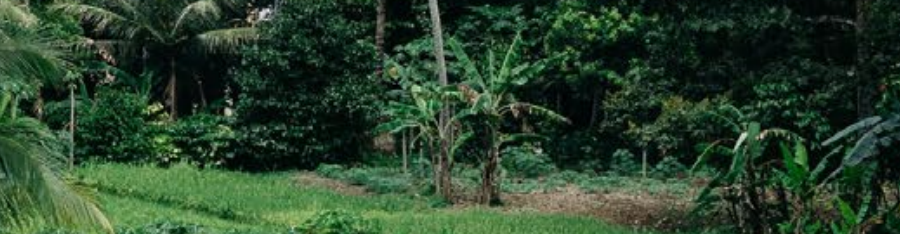

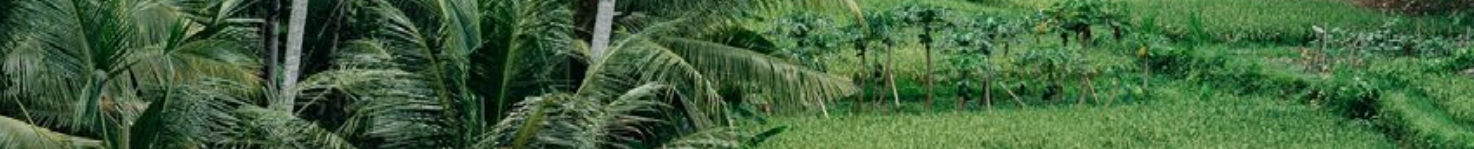

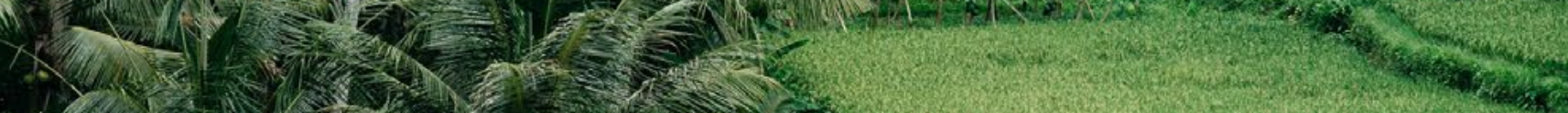

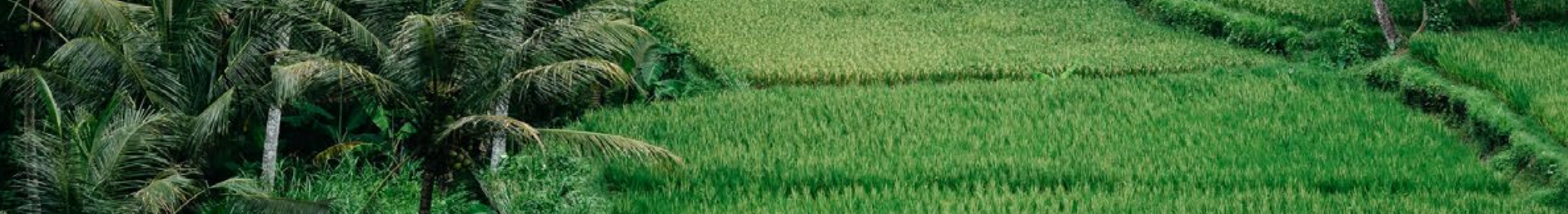

$\frac{1}{4}$

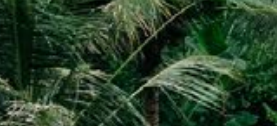

Nest

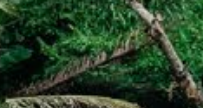

ang

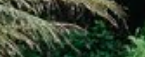




\section{Contents}

Acknowledgements

Contents $\quad$ VII

Glossary

Foreword $\quad$ XI

Executive Summary XIV

Chapter 1 Setting the scene $\quad 1$

1.1 Context 2

1.2 The 2020 Adaptation Gap Report 2

Chapter 2 Framing the Adaptation Gap Report 5

2.1 Introduction 6

$2.2 \quad$ Framing the climate risks context 6

$\begin{array}{lll}2.3 & \text { Understanding progress in adaptation } & 7\end{array}$

Chapter 3 Assessing global progress on adaptation planning 13

$\begin{array}{lll}3.1 & 14\end{array}$

3.2 Methodology 16

$\begin{array}{lll}3.3 & \text { Progress on adaptation planning } & 18\end{array}$

Chapter 4 Global progress on financing for adaptation 23

$4.1 \quad$ Financing of adaptation - introduction 24

4.2 Financing adaptation - status and progress in adaptation finance flows 25

4.3 New trends in the financing of adaptation 29

Chapter 5 Progress in implementing adaptation: insights from project proposals and 33 scientific literature

$5.1 \quad$ Introduction 34

$5.2 \quad$ Scope and data sources 34

5.3 Implemented adaptation actions 36

$5.4 \quad$ Adaptation results 39

$\begin{array}{lll}5.5 & \text { Outlook } & 40\end{array}$

Chapter 6 Nature-based solutions for adaptation 43

$6.1 \quad$ Introduction 44

$6.2 \quad$ Biodiversity and climate risks 48

$6.3 \quad$ Planning 51

6.4 Financing NbS for adaptation $\quad 55$

$6.5 \quad$ Implementation of NbS 63

6.6 Scaling up and moving forward $\quad 76$

$\begin{array}{lll}\text { Chapter } 7 & \text { Global progress on adaptation and outlook } & 79\end{array}$

$7.1 \quad$ Cross-chapter synthesis 80

7.2 Way forward: how to improve the assessment of global adaptation progress 83 


\section{Glossary}

The entries in this glossary are primarily taken or adapted from definitions provided by reports published by the Intergovernmental Panel on Climate Change (IPCC). In cases where the IPCC has not provided a definition for a term, definitions have been sourced from other authoritative sources such as the International Union for Conservation of Nature (IUCN) and the Convention on Biological Diversity (CBD)

Adaptation: The process of adjustment to actual or expected climate and its effects. In human systems, adaptation seeks to moderate or avoid harm or exploit beneficial opportunities. In some natural systems, human intervention may facilitate adjustment to expected climate and its effects. (IPCC, 20141).

Adaptive capacity: The ability of systems, institutions, humans, and other organisms to adjust to potential damage, to take advantage of opportunities, or to respond to consequences (IPCC, 2014').

Adaptation costs: Costs of planning, preparing for, facilitating, and implementing adaptation measures, including transaction costs (IPCC, 20072).

Baseline: The state against which change is measured. It might be a current baseline, in which case it represents observable, present-day conditions. It might also be a 'future baseline', which is a projected future set of conditions excluding the driving factor of interest. Alternative interpretations of the reference conditions can give rise to multiple baselines (IPCC, 2007²).

Ecosystem: A functional unit consisting of living organisms, their non-living environment and the interactions within and between them. The components included in a given ecosystem and its spatial boundaries depend on the purpose for which the ecosystem is defined: in some cases they are relatively sharp, while in others they are diffuse. Ecosystem boundaries can change over time. Ecosystems are nested within other ecosystems and their scale can range from very small to the entire biosphere. In the current era, most ecosystems either contain people as key organisms, or are influenced by the effects of human activities in their environment (IPCC, 2014').

Ecosystem-based Adaptation: The use of biodiversity and ecosystem services as part of an overall adaptation strategy to help people to adapt to the adverse effects of climate change (IPCC, 20143).

Ecosystem services: Ecological processes or functions having monetary or non-monetary value to individuals or society at large. These are frequently classified as (1) supporting services such as productivity or biodiversity maintenance, (2) provisioning services such as food or fibre, (3) regulating services such as climate regulation or carbon sequestration, and (4) cultural services such as tourism or spiritual and aesthetic appreciation (IPCC, 2014').

Exposure: The presence of people, livelihoods, species or ecosystems, environmental functions, services, and resources, infrastructure, or economic, social, or cultural assets in places and settings that could be adversely affected (IPCC, 20141)

Hazard: The potential occurrence of a natural or humaninduced physical event or trend that may cause loss of life, injury, or other health impacts, as well as damage and loss to property, infrastructure, livelihoods, service provision, ecosystems and environmental resources (IPCC, 20141). 
Limits to adaptation: The point at which an actor's objectives (or system needs) cannot be secured from intolerable risks through adaptive actions.

- Hard adaptation limit: No adaptive actions are possible to avoid intolerable risks.

- Soft adaptation limit: Options are currently not available to avoid intolerable risks through adaptive action (IPCC, 2014').

Mitigation (of climate change): A human intervention to reduce the sources or enhance the sinks of greenhouse gases (IPCC, 20141).

Nature-based Solutions ( $\mathrm{NbS}$ ): Actions to protect, sustainably manage and restore natural or modified ecosystems that address societal challenges effectively and adaptively, simultaneously providing human wellbeing and biodiversity benefits (IUCN, 20164).

Representative Concentration Pathways (RCPs): [Climate change] Scenarios that include time series of emissions and concentrations of the full suite of greenhouse gases (GHGs) and aerosols and chemically active gases, as well as land use/land cover. The word representative signifies that each RCP provides only one of many possible scenarios that would lead to the specific radiative forcing characteristics. The term pathway emphasizes the fact that not only the long-term concentration levels but also the trajectory taken over time to reach that outcome (IPCC, 20141).

Resilience: The capacity of social, economic and environmental systems to cope with a hazardous event or trend or disturbance, responding or reorganizing in ways that maintain their essential function, identity and structure, while also maintaining the capacity for adaptation, learning and transformation (IPCC, 2014¹).

Risk: The potential for consequences where something of value is at stake and where the outcome is uncertain, recognizing the diversity of values. Risk is often represented as probability of occurrence of hazardous events or trends multiplied by the impacts if these events or trends occur. Risk results from the interaction of vulnerability, exposure, and hazard (IPCC, 2014').

Vulnerability: The propensity or predisposition to be adversely affected. Vulnerability encompasses a variety of concepts and elements including sensitivity or susceptibility to harm and lack of capacity to cope and adapt (IPCC, 20141).

\footnotetext{
https://archive.ipcc.ch/pdf/assessment-report/ar5/wg2/WGIIAR5-AnnexII_FINAL.pdf https://www.ipcc.ch/site/assets/uploads/2018/02/ar4-wg2-app-1.pdf

https://www.ipcc.ch/site/assets/uploads/2018/02/WGIIAR5-Chap14_FINAL.pdf (p. 846)
}

https://portals.iucn.org/library/sites/library/files/resrecfiles/WCC_2016_RES_069_EN.pdf 
Photo: (c) Eyoel Kahssay (Unsplash) 


\section{Foreword}

2020 was not only the year of the pandemic, it was also the year of intensifying climate impacts. Floods, droughts and storms affected over 50 million people. Wildfires devastated forests and communities. Plagues of locusts devoured vital crops in East Africa.

We have not heeded these warnings. Based on current pledges under the Paris Agreement, the world is heading for at least a $3^{\circ} \mathrm{C}$ temperature rise this century. If this happens, 2020 will seem like a walk in the park. Even if we limit global warming to well below $2^{\circ} \mathrm{C}$, or even $1.5^{\circ} \mathrm{C}$, developing countries will suffer. We are, as the UN Secretary-General said in his 2020 State of the Planet address, in "a race against time to adapt to a rapidly changing climate". The fifth edition of the UNEP Adaptation Gap Report - which looks at the state of play in adaptation planning, finance and implementation - finds that while we may be gathering pace, we are still losing this vital race.

There is some encouraging news. Almost three quarters of countries have adopted at least one national-level adaptation planning instrument. Most developing countries are working on national adaptation plans. There are also a growing number of adaptation actions. Since 2006, multilateral climate funds have initiated around 400 adaptation projects in developing countries, with their size and scope growing.

However, there are huge caveats on the progress. Developing countries need funding for their adaptation efforts, yet finance remains low. The pace of adaptation financing is indeed rising, but it continues to be outpaced by rapidly increasing adaptation costs. Meanwhile, an extensive analysis of adaptation actions surveyed in scientific articles showed that the majority were in early stages of implementation. Only 3 per cent reported evidence of real reductions in climate risks posed to the communities where the projects were being implemented.

The report also looks at nature-based solutions, which are increasingly recognized as a way to soften the blow of climate change and bring additional benefits for nature and economies. An analysis of four major climate and development funds suggested that support for green initiatives with some element of nature-based solutions has risen over the last two decades, although not enough. Cumulative investment for climate change mitigation and adaptation projects under the four funds stood at US\$ 94 billion. However, only US\$ 12 billion of this funding was spent on nature-based solutions.

Reducing greenhouse gas emissions will reduce impacts and costs associated with climate change. Achieving the $2^{\circ} \mathrm{C}$ target of the Paris Agreement could limit losses

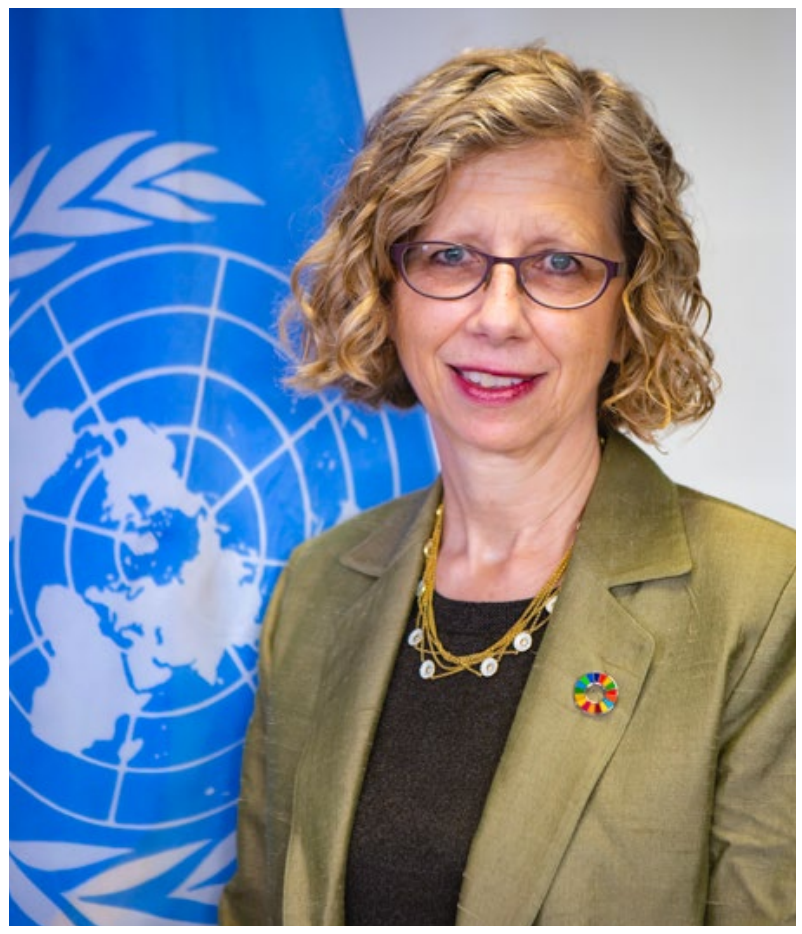

in annual growth to up to 1.6 per cent, compared to 2.2 per cent for $3^{\circ} \mathrm{C}$ trajectory. We must pursue all efforts outlined in UNEP's Emissions Gap Report 2020, which called for a green recovery post-pandemic and updated nationally determined contributions that include new netzero commitments.

But we must also plan to adapt and back it with financing and support to countries least responsible for climate change, but most at risk. This is as much an economic decision as any other. The Global Commission on Adaptation in 2019 estimated that a US\$ 1.8 trillion investment in adaptation measures would bring a return of US\$ 7.1 trillion in avoided costs and other benefits.

Yes, the fallout from the COVID-19 pandemic is hitting budgets and could harm adaptation efforts, but I echo the UN Secretary-General's call for a global commitment to put half of all global climate finance towards adaptation ahead of the next climate meeting. This will allow a huge step up in implementation - in everything from early warning systems to resilient water resources to nature-based solutions. The hard truth is that climate change is upon us. Its impacts will intensify, even if we limit global warming. We cannot afford to lose the race to adaptation.

Inger Andersen

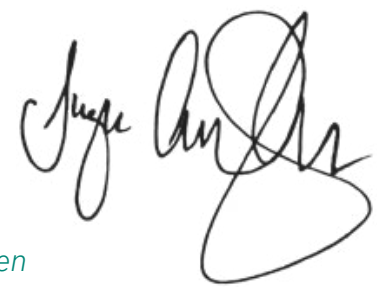

Executive Director

United Nations Environment Programme 


\section{Executive summary - Adaptation Gap Report 2020}

\author{
Overall framing of the UNEP Adaptation Gap \\ Report 2020
}

The year 2020 has been the year of COVID-19. The fallout of the pandemic is expected to significantly influence the ability of countries to plan for, finance and implement adaptation actions in response to current and future climate impacts, disproportionately affecting the most vulnerable countries and population groups. While it is too early to gauge the full extent to which COVID-19 will affect global adaptation processes, in the short term the acute need to manage the direct public health impacts of the virus and the subsequent economic fallout has seen adaptation fall down the political agenda at all levels of governance and resources earmarked for adaptation planning, finance and implementation have been reallocated to combat the pandemic. In the longer term, the socioeconomic consequences of the pandemic can be expected to have lasting implications for adaptation processes, as the economic downturn will put additional pressure on public finances and may change national and donor priorities regarding climate action. If implemented well, COVID-19 stimulus packages could lead to a more climate-resilient and low-emission recovery. However, analysis of the economic stimulus packages announced to date indicates that most of these are not taking advantage of this opportunity. The pandemic has already impacted the United Nations Framework Convention on Climate Change (UNFCCC) process, postponing COP 26 and delaying countries' revisions of their nationally determined contributions (NDCs) to raise the ambition for strong mitigation and adaptation action.

All the while, climate change impacts and extreme events persist, undeterred by the pandemic. The year 2020 has been one of the warmest years on record; over 50 million people globally have been recorded as directly affected by floods, droughts, or storms; and wildfires have raged with greater intensity in Australia, Brazil, Russia and the USA, among other countries. It is therefore more important than ever that countries make progress on adaptation. The fifth edition of the United Nations Environment Programme (UNEP) Adaptation Gap Report therefore provides an update on the current actions and emerging results of global adaptation planning, finance and implementation. All three elements are critical for tracking and assessing progress towards the global goal on adaptation. In addition to the latest literature, new analyses form the basis of the assessment. Considering the growing recognition of nature's contributions to humanity, this year's report focuses on nature-based solutions as key instruments for adaptation to the impacts of climate hazards.
To synthesize the key findings of the report, this executive summary is grouped in three parts: status and progress of global adaptation planning, finance and implementation; planning, finance and implementation of nature-based solutions for adaptation; and outlook on the global progress of adaptation.

\section{Status and progress of global adaptation planning,} finance and implementation

Climate adaptation is now widely embedded in policy and planning across the world, but levels of engagement and the quality of instruments are vastly different from country to country. Adaptation action is critical to enable both public and private actors to prepare for and respond to the impacts of climate change. The Paris Agreement underscores the importance of national-level adaptation planning processes by committing all countries to report on progress made. The analysis shows that most countries (72 per cent) have adopted at least one national-level adaptation planning instrument (for example, a plan, strategy, policy or law), and some countries (9 per cent) that do not currently have such an instrument in place are in the process of developing one (figure ES.1). Most developing countries have begun formulating a national adaptation plan (NAP), which is a key mechanism to strengthen the focus on adaptation. Many countries have also developed, or are in the process of developing, sectoral and subnational plans. Progress in adaptation planning is expected to continue, not least because rising climate awareness is driving the emergence of an increasing number of subnational initiatives.

Analysis of adaptation planning paints a mixed picture in terms of achieving stated objectives. At the present time, we cannot assess the adequacy and effectiveness of adaptation planning as there is no consensus around definitions for and approaches to assessing these aspects. We can, however, examine important dimensions that influence these aspects, namely comprehensiveness, inclusiveness, implementability, integration and monitoring and evaluation (figure ES.2). Around half of countries' planning documents address risks comprehensively, include relevant stakeholders (including women) and have dedicated planning processes in place. Performance against criteria for integration across sectors ('horizontal') and across governance levels ('vertical') is mixed, showing fairly high horizontal but rather low vertical integration. Significantly fewer countries address the other criteria, suggesting a need for greater attention. The lack of consensus on appropriate assessment methodologies for adequate and effective planning also inhibits analysis of whether the progress made in these dimensions since 2000 is moving countries towards their adaptation objectives. 
Figure ES.1 Status of adaptation planning worldwide

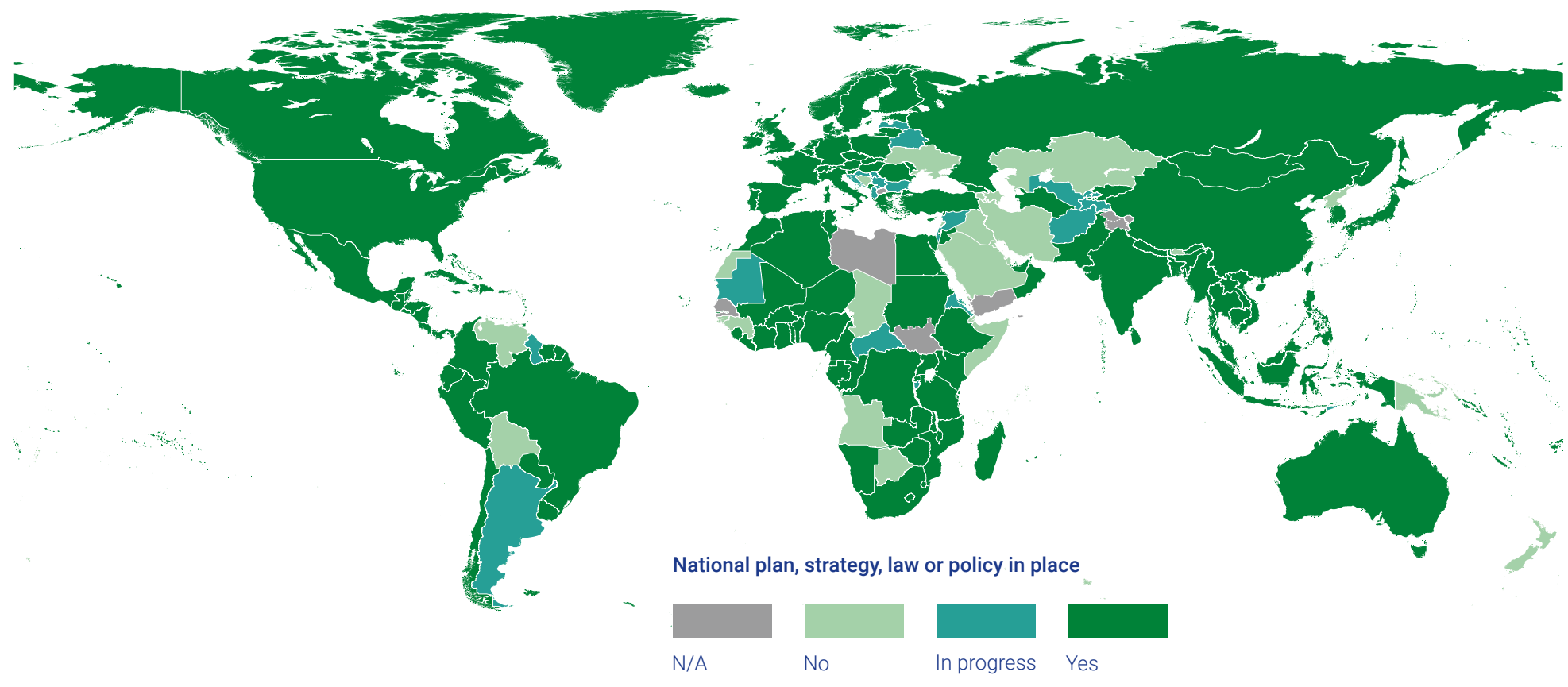

Figure ES.2 Assessing the adequacy and effectiveness of adaptation planning worldwide

Criteria for adequate and effective adaptation planning

1. Comprehensiveness

1.1 Options address assessed risks

2. Inclusiveness

2.1 Stakeholder engagement

2.2 Dedicated process in place

2.3 Gender

3. Implementability

3.1 Central administration in charge

3.2 Regulatory instruments

3.3 Incentive-based instruments

3.4 Direct investment/funding

\section{Integration}

4.1 Horizontal integration

4.2 Vertical integration

5. Monitoring and evaluation

5.1 M\&E system in place

5.2 Monitoring undertaken

5.3 Evaluation planned/undertaken

\section{Number of countries}

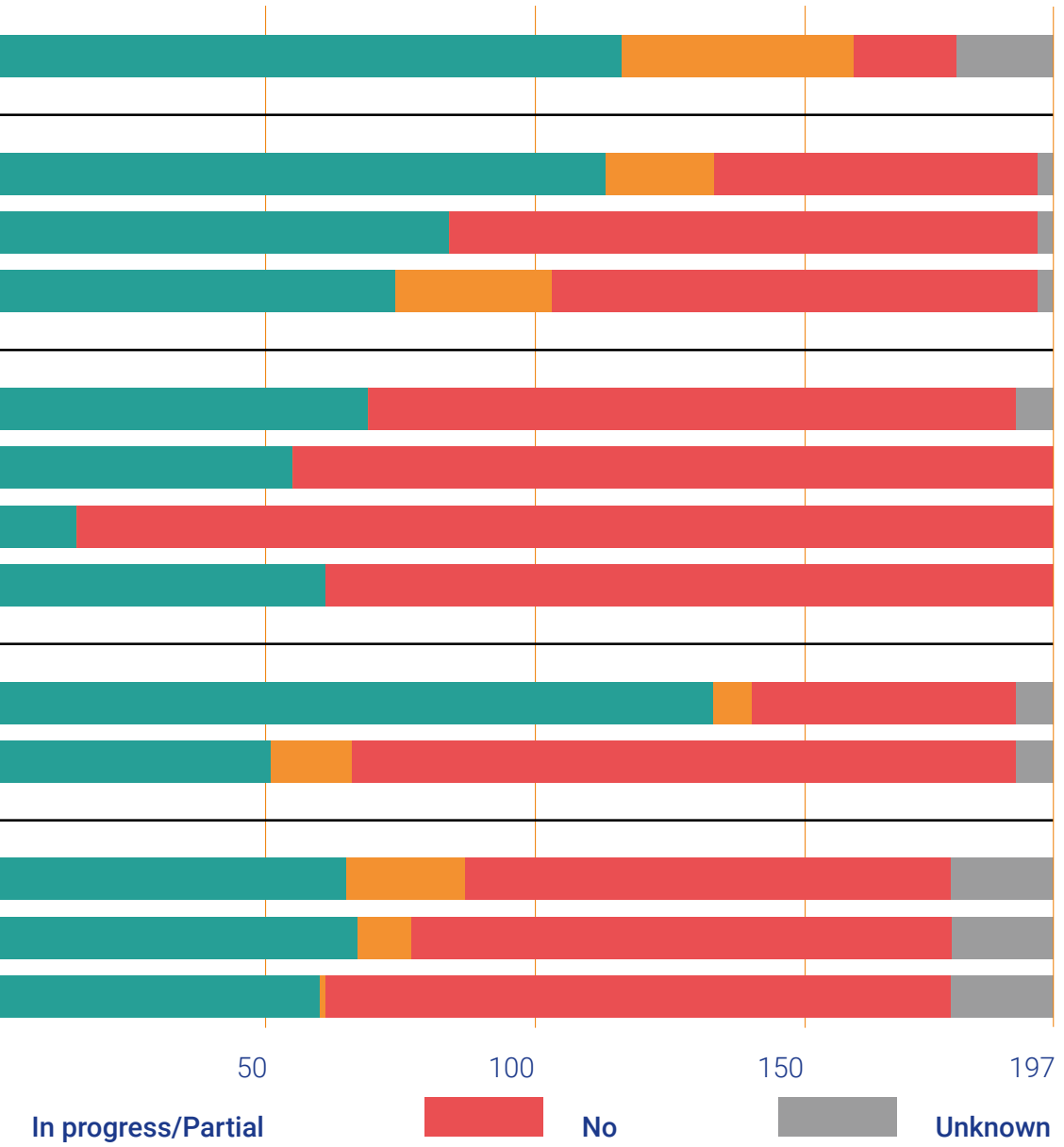


Additional adaptation finance is critical to enhance adaptation planning and implementation and limit climate damages, particularly in developing countries. While adaptation costs may be higher for developed countries in absolute terms, the burden is higher for developing countries relative to their gross domestic products, adding to their generally more constrained financial, technical and human capacities. Strong mitigation action would significantly reduce unavoidable damage costs, particularly in Africa and Asia, which will bear the brunt of future adaptation impacts. According to recent literature, a $2^{\circ} \mathrm{C}$ trajectory may be able to limit annual global growth depression to 1.0-1.6 per cent when compared with a $3^{\circ} \mathrm{C}$ trajectory with annual losses in the range of 1.5-2.2 per cent of global world product. At the same time, the benefits of investing in adaptation often outweigh the costs. The Global Commission on Adaptation estimated that a US\$1.8 trillion investment in the areas of early warning systems, climateresilient infrastructure, improved dryland agriculture, global mangrove protection and resilient water resources could generate US\$7.1 trillions of avoided costs and non-monetary social and environmental benefits.

Despite an increase in finance available for adaptation, the adaptation finance gap is not closing. International public adaptation finance is slowly rising, however there is insufficient data to identify such a trend in domestic public or private finance flows. At the same time, annual adaptation costs in developing countries alone are currently estimated to be in the range of US\$70 billion, with the expectation of reaching US\$140-300 billion in 2030 and US\$280-500 billion in 2050. As adaptation finance and adaptation costs are difficult to compare, all that can be deduced using the available evidence is that, given the pace of climate change and impacts, the adaptation finance gap is not narrowing as a result of current efforts. Providers of development finance are not integrating adaptation well enough across their activities. While multilateral support for adaptation as a share of overall multilateral development finance has risen significantly, bilateral support as a share of overall bilateral development finance has only increased slowly between 2013 and 2017. Moreover, the ongoing COVID-19 pandemic is expected to further aggravate the finance gap by constraining public finances at both national and international levels.
Significant scaling up and incentivizing for both public and private adaptation finance is required to narrow the gap. Adaptation finance modalities of bilateral and multilateral support are evolving, such that grants are increasingly accompanied by a broader range of instruments, actors and approaches. For instance, as the biggest dedicated multilateral climate fund, the Green Climate Fund has allocated 40 per cent of its total portfolio to adaptation and is increasingly using its catalytic power to crowd-in investments from private investors. Another important development is the increasing momentum towards ensuring a sustainable financial system. There is growing recognition that material physical risks and the risks introduced as we shift to a climate-resilient economy impact company returns, asset values and ultimately financial stability. Bringing in new tools such as sustainability investment criteria, climaterelated disclosure principles and mainstreaming of climaterelated risks into investment decisions can help to monitor finance flows that contribute to adaptation, in addition to the potential to stimulate an increase in investments in climate resilience and to direct finance away from investments that increase vulnerability.

Implementation of adaptation actions is growing worldwide but there is still very limited evidence of climate risk reduction. The Global Adaptation Mapping Initiative identified almost 1,700 articles detailing adaptation actions worldwide, a third of which were in early stages of implementation and only 3 per cent of which were in the stage of risk reduction. However, there is clear evidence of a rise in implementation (figure ES.3). Since 2006, close to 400 adaptation projects financed by multilateral funds serving the Paris Agreement (the Adaptation Fund, the Green Climate Fund and the Global Environment Facility) have been undertaken in developing countries, half of which began after 2015. While earlier projects rarely exceeded US\$10 million, since 2017, 21 new projects have had a value of more than US\$25 million, suggesting that adaptation actions are becoming more comprehensive and potentially more transformative. However, despite the positive signs, there is, as yet, very limited evidence of climate risk reduction, tempering any conclusion on adaptation progress as a whole.

Figure ES.3 Number of primary adaptation projects (excluding readiness activities) from UNFCCC climate funds per start year and grant size

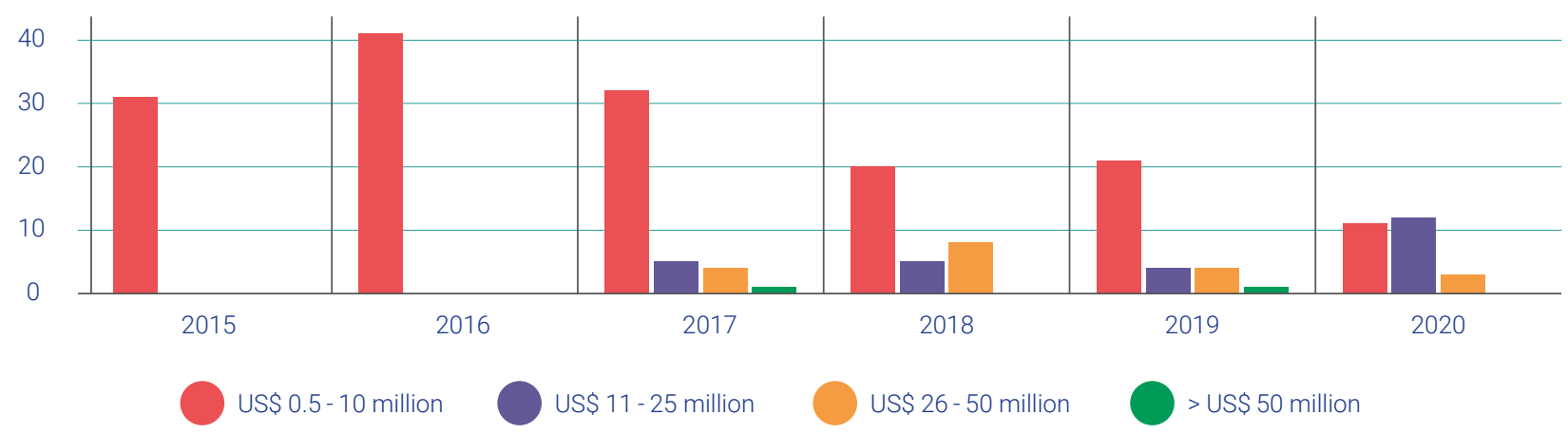


Most projects target vulnerable populations, and many explicitly mention gender-related outputs. Analysis of the adaptation projects that have started since 2015, supported by the three abovementioned multilateral funds, shows that more than half are being implemented in least developed countries (LDCs) and almost 15 per cent in small island developing States (SIDS). The majority focus on the most climate-sensitive sectors, i.e. agriculture and water, with drought, rainfall variability, flooding and coastal impacts among the most commonly addressed climate hazards. Engagement of the private sector remained low except for the tourism, agriculture and insurance industries. While national and local government actors are the primary recipients of support for adaptation actions, at least 25 per cent and possibly up to two-thirds of projects ultimately target the most vulnerable members of society. In addition, at least 20 per cent of projects explicitly mention gender-related outputs, and all new projects need to undertake a gender assessment. As a result, based on the latest figures, the Adaptation Fund, the Green Climate Fund and the Least Developed Countries Fund have together reached more than 20 million direct and indirect beneficiaries and trained more than 500,000 on climate resilience measures.

Further scaling up of the levels of implementation is needed to avoid falling behind with managing climate risks, particularly in developing countries. Close to 40 new adaptation projects using UNFCCC funds have been cleared to start and 80 are at an advanced stage of the approval process. However, adaptation projects often do not provide sufficient information on lasting outcomes, which raises concerns over effectiveness. Causal pathways that show how activities lead to results have often been found to lack clarity, highlighting the need to better elaborate how exactly adaptation is intended to occur. Therefore, despite progress made, continued high levels of global emissions imply that implementation at current rates may not be able to keep pace with increasing levels of risk. Together with other recent international reports, the 2018 Adaptation Gap Report showed that by enhancing adaptive capacity and resilience to climate impacts - for example, through capacity-building, empowerment, good governance and early warning systems - adaptation actions can markedly reduce vulnerability to climate hazards. At the same time, the report showed that most development indicators reflective of adaptive capacity are not catching up with developed countries and more people are exposed to climate hazards. Therefore, to avoid falling further behind and start catching up with developed countries, it is necessary to further increase implementation of adaptation actions.

Planning, finance and implementation of nature-based solutions for adaptation

There is increasing recognition, both nationally and internationally, that nature-based solutions ( $\mathrm{NbS}$ ) can make important contributions to climate change adaptation, but there are few tangible plans. NbS for adaptation can be lowcost options that are potentially effective in reducing climate risks, while simultaneously bringing important additional benefits for the economy, environment, livelihoods and other values to a wide range of stakeholders, including women, the poor and marginalized groups. However, NbS effectiveness may be limited by higher levels of climate change, so strong mitigation action is important to ensure the future contribution to adaptation of protecting managing and restoring nature. More than half of countries, including over 90 per cent of LDCs, refer to protecting nature as an important motivation for adaptation planning and have added elements of $\mathrm{NbS}$ to the adaptation components of their NDCs (figure ES.4). However, most of these describe only broad goals and less than a third include measurable targets, which mainly highlight the aim to restore floodplains and mangroves as methods to reduce the impacts of flooding, droughts and sea level rise. A similar pattern is reflected in the national communications of Annex I countries, most of which explore the climate vulnerability of ecosystems and biodiversity - some highlight NbS to reduce climate risks, but few provide explicit plans for deploying these approaches to address specific climate hazards, which are usually related to flood control and urban heat reduction.

NbS are often considered in fora not related to climate change planning and at levels other than national but require system-scale approaches to achieve the full potential of their benefits. At least 50 per cent of the National Biodiversity Strategies and Action Plans, which countries develop under the United Nations Convention on Biological Diversity, specifically emphasize the potential and importance of $\mathrm{NbS}$ in addressing the vulnerability of species and ecosystems to climate change, as well as other anthropogenic pressures. NbS are also being considered in sectoral planning processes, contributing to resilience building in sectors ranging from infrastructure and energy to water, agriculture and urban planning. However, planning for $\mathrm{NbS}$ requires system-scale approaches to secure the provision of ecosystem services that contribute to adaptation. In many cases, this necessitates planning and coordination across national or jurisdictional boundaries, creating both a challenge and an opportunity for environmental policy frameworks and transboundary negotiations.

Despite evidence of an increase in finance for $\mathrm{NbS}$ with adaptation benefits, funding levels remain low. Analysis of investments by four major climate and development funds (the Global Environment Facility, the Green Climate Fund, the Adaptation Fund and the International Climate Initiative) suggests that support for green and hybrid adaptation solutions has risen considerably over the past two decades, with cumulative investment in projects with $\mathrm{NbS}$ components now standing at US\$94 billion, of which 13 per cent is directed towards NbS. Funding for NbS, however, makes up only a tiny fraction of total adaptation and conservation finance, despite many commitments by governments, the private sector, philanthropy and finance institutions for scaling up ambition and investments in NbS (figure ES.5). Many questions therefore remain regarding the adequacy and scope of $\mathrm{NbS}$ finance, not least because it continues to be difficult to track investment flows, as NbS are not recorded as a distinct funding category or investment option. 
Figure ES.4 Nature-based solutions in adaptation components of nationally determined contributions in developing countries
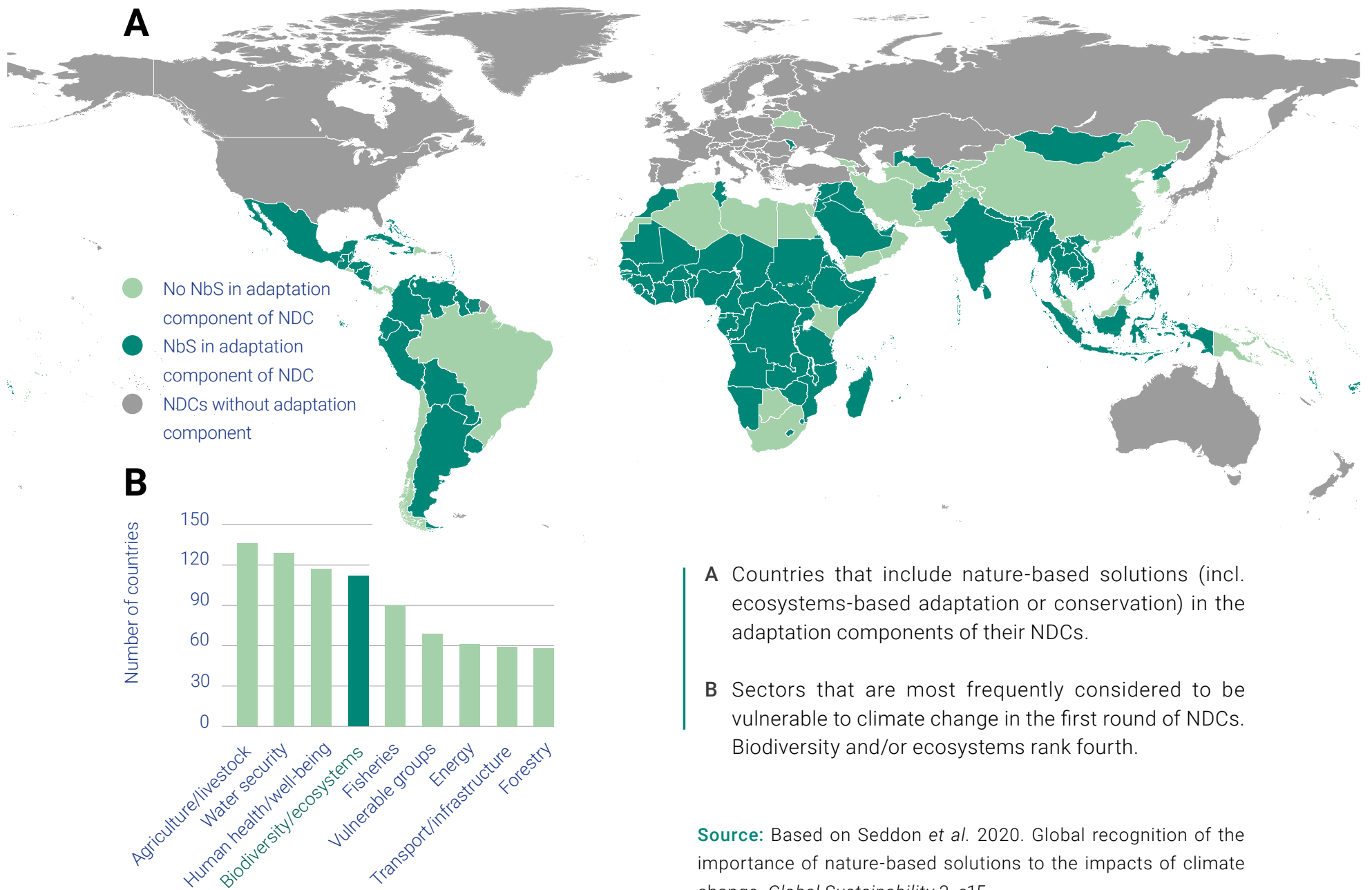

A Countries that include nature-based solutions (incl. ecosystems-based adaptation or conservation) in the adaptation components of their NDCs.

B Sectors that are most frequently considered to be vulnerable to climate change in the first round of NDCs. Biodiversity and/or ecosystems rank fourth.

Source: Based on Seddon et al. 2020. Global recognition of the importance of nature-based solutions to the impacts of climate change. Global Sustainability 3, e15.

Figure ES.5 Visualizing the relationship between nature-based solutions finance for adaptation, climate finance and conservation finance

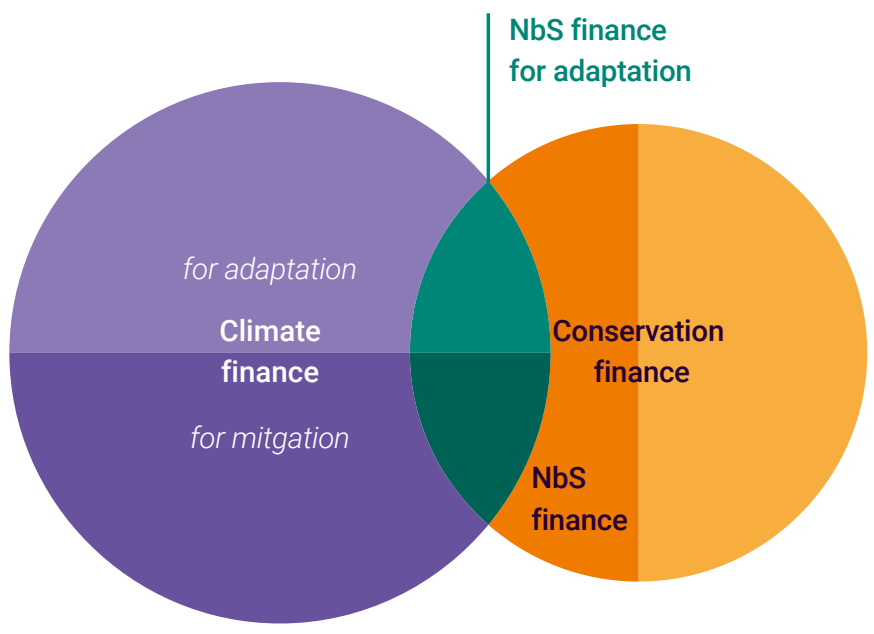


Figure ES.6 Sankey diagram connecting underlying hazards to their impacts on the ground (proximate hazards) and how different nature-based solutions are being used to address them

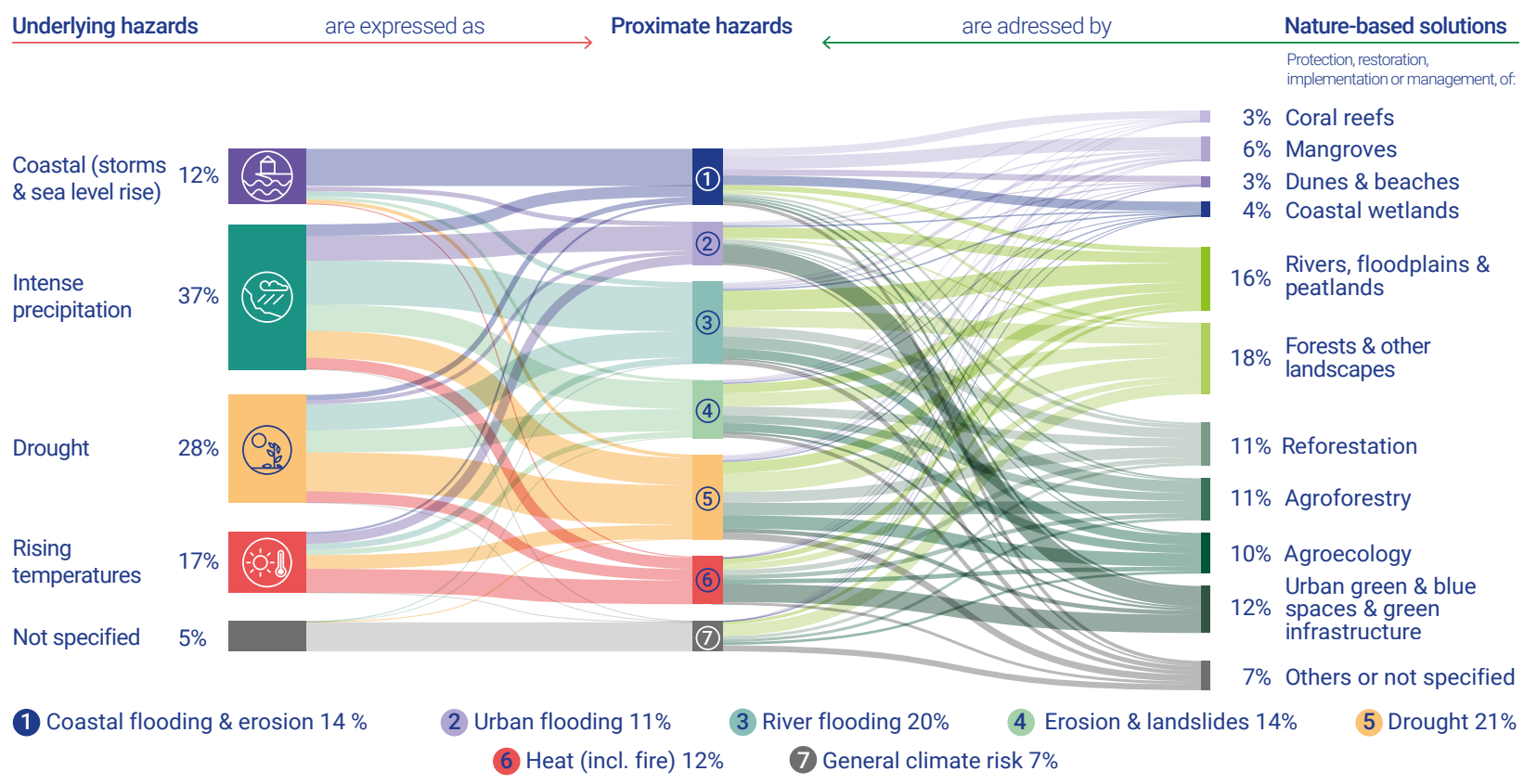

Note: The thickness of the ribbons is determined by the number of projects referring to each of the categories. Projects often mention multiple underlying and proximate hazards and can refer to several NbS to address them. (Example how to read the figure: temperature rise can lead to increased heat in urban areas that is effectively ameliorated with green and blue spaces as well as green infrastructure. Many other NbS are sometimes also used in the context of heat-related hazard). Percentage values presented in the figure are rounded to the nearest integer.

Mobilizing additional funding, diversifying the investment portfolio and creating innovative new finance mechanisms for $\mathrm{NbS}$ are important to provide considerable opportunities but remain a challenge. While examples of innovative finance mechanisms have emerged (for example, payments for ecosystem services, debt instruments, insurance products and performance-based payments), NbS continues to rely heavily on traditional government and philanthropic sources. The complexity of $\mathrm{NbS}$, for example, high opportunity and transaction costs, the large number of stakeholders involved, as well as the long period typically needed to achieve the benefits, means that only a fraction of NbS can be financed and maintained as purely commercial ventures. Despite significant benefit to cost ratios over the longer term and multiple cobenefits that are typically not accounted for, investments are often not feasible for the private sector alone. The NbS finance base for adaptation could therefore be amplified, strengthened and diversified by deploying innovative mechanisms that combine public and private sources of funding. There is also an urgent need, at a structural level, to create the conditions and incentives that are required to enable, encourage and facilitate improved funding and investment flows.

NbS are being used in a multitude of ways to manage climate risks by reducing exposure or vulnerability to climate hazards (figure ES.6). NbS for adaptation are mainly used to address coastal hazards, intense precipitation, rising temperatures and drought. Coastal flooding and erosion are mainly reduced through restoration or protection of coral reefs, seagrass meadows, coastal wetlands, mangrove forests and dunes and beach vegetation. Urban flooding is addressed through urban green and blue spaces, as well as upstream NbS. River flooding, as well as landslides and erosion, are mainly addressed by restoring or protecting floodplains and peatlands and by enhancing riparian vegetation. To smaller degrees, forest and landscape restoration or protection, reforestation, agroforestry and agroecological practices also contribute to managing surface runoff. Heat-related risks are frequently connected to urban environments and managed through green and blue spaces, as well as green infrastructure. Lastly, drought-related risks are most frequently addressed through integrated watershed and landscape management, as well as reforestation and climate-smart agricultural practices such as agroforestry and agroecology.

Implementation of NbS targeting coastal hazards, intense precipitation, drought and rising temperatures has been growing worldwide for the past two decades, but evidence of the level of risk reduction remains sparse. Prior to 2000 , only a handful of initiatives could be considered to be actively using NbS for climate risk management. Since then, levels of implementation have risen markedly, and tracked initiatives are in the range of 70 new projects per year, most of which focus on rural environments in developing countries and primarily target coastal flooding and erosion, freshwater flooding and rising incidence of drought, as well as urban heat and wildfires (figure ES.7). Urban NbS have 
Figure ES.7 Global map of nature-based solution initiatives for adaptation, showing the number of investments per country, the geographic distribution of cities reporting on nature-based solution activities (red dots), and the regional distribution of hazards being addressed by nature-based solution initiatives (pie charts)

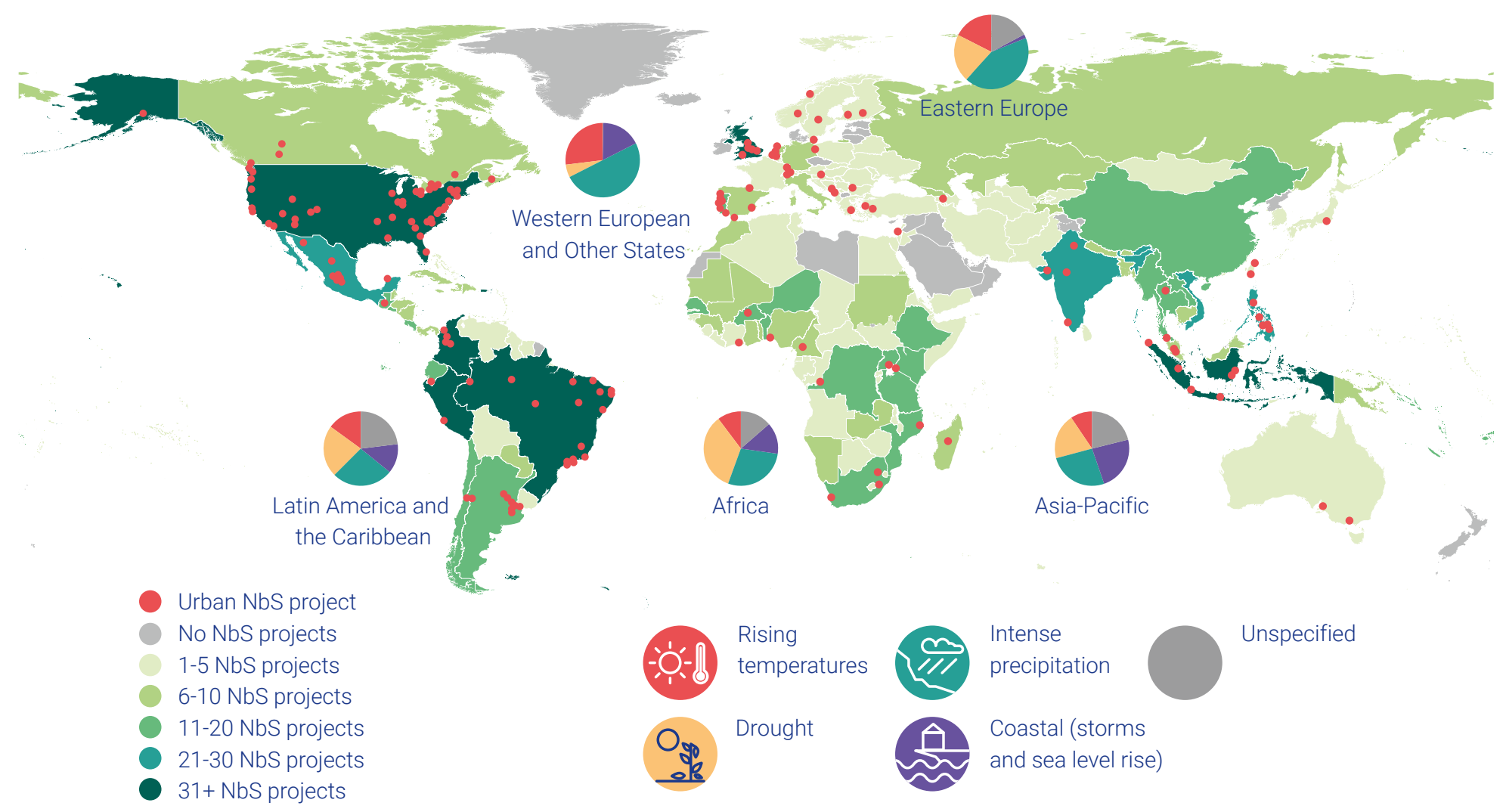

also seen a surge in implementation, the majority of which is taking place in developed countries, focusing on coastal and freshwater flooding and heat. Existing evidence suggests that successful implementation of NbS can deliver a multitude of social, environmental, economic and governance-related benefits in addition to reducing climate hazards, not least for indigenous peoples, local communities and women. To deliver their services - particularly ecosystem services - NbS require inclusive governance and institutions to manage public goods, frequently related to secure land tenure and access rights, as well as sufficiently long-term investments and planning stability. However, to date, evidence of risk reduction via NbS is scant because implementation at larger scales is still in its infancy.

\section{Outlook on the global progress of adaptation}

Overall, there is robust evidence that progress has been made on greater engagement in national-level adaptation worldwide over the course of the last decade but further ambition is needed. Climate adaptation is now fully part of climate policy action across the world with widespread adoption and continued development of national, subnational and sectoral adaptation planning instruments. However, the effectiveness and adequacy of planning, finance and implementation differ depending on national circumstances and climate risk profiles and will require greater effort. Early signs of deeper transformation towards more climate-resilient and sustainable financial systems and investments are emerging but require stronger, longterm commitments and action.

Despite encouraging trends, the scale of adaptation progress at the national level is insufficient and tracking progress remains a challenge. There is a real risk that adaptation costs will increase faster than adaptationoriented finance. There is inconclusive evidence to indicate whether national-level adaptation planning is being sufficiently mainstreamed into sectoral and subnational planning to address growing risks. Furthermore, monitoring and evaluation, which is widely recognized as being key to tracking and assessing progress in adaptation, is inadequate and in urgent need of further development and implementation. Lastly, national-level data only provide limited indications of current and future levels of risk reduction in connection with trends in adaptation planning, finance and implementation. These gaps urgently need to be narrowed as recent Intergovernmental Panel on Climate Change reports warn of increasing climate risk levels, even under emission scenarios curtailing end-ofcentury global warming to $1.5-2^{\circ} \mathrm{C}$ above pre-industrial temperatures (figure ES.8). 
A

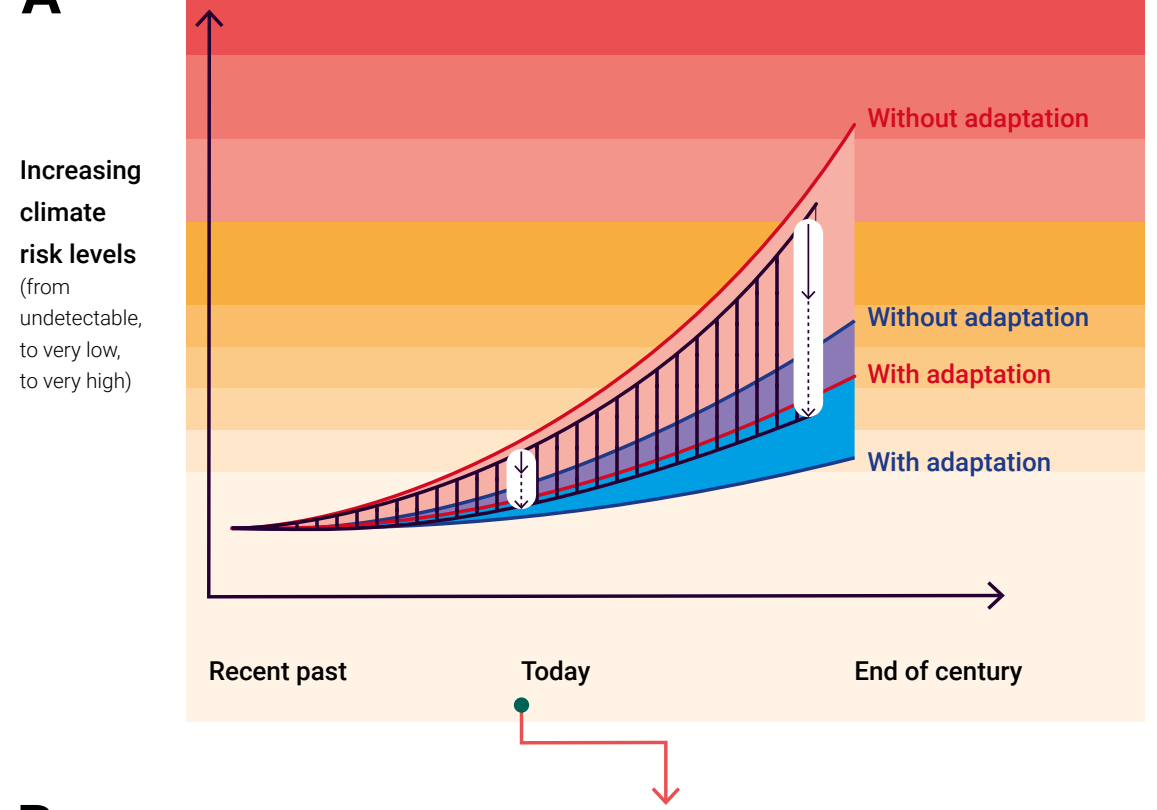

Risk scenarios under RCP2.6 (blue) and RCP8.5 (red), with and without adaptation, are inspired by the recent IPCC special reports (SRCCL; SROCC). The midway risk scenario (black) is purely hypothetical and is used for illustrative purposes.

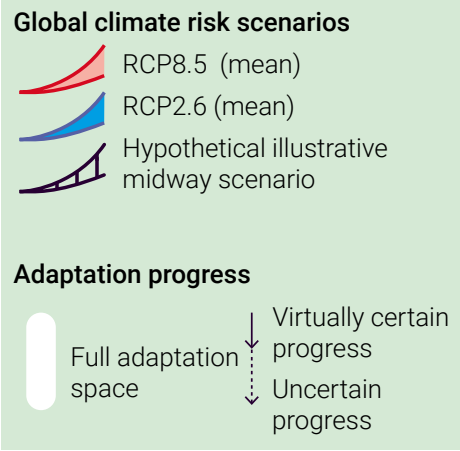

B

\section{Progress is being made, but there is a lack of robust evidence across regions, sectors and hazards, for which data are scattered.}

Progress is, nevertheless, estimated to not be occurring at the required scale (when assessed against present and future risk levels).

\section{Evidence of adaptation progress}

Identification of gaps

Elements that constrain the interpretation of findings
- National-level adaptation plans, strategies, frameworks or laws are in place in most countries (either they have been adopted or are currently being developed - the maturity of adaptation planning instruments varies across countries)

- Both adaptation finance and the number of adaptation projects in developing countries (supported by multilateral and bilateral funds) are increasing

- Some movement towards creating actionable policies that lead to principal adaptation (better inclusion of specific types of adaptation measure)

- Financing modalities are quickly evolving (for example, diversifying the range of instruments, approaches and funding sources) and there are early signs of movement towards more climate-proof and sustainable financial systems and investments

- Adaptation finance is increasing at a lower rate than adaptation costs (in a context of increasing and accelerating climate change) and therefore the adaptation finance gap appears to be widening

- Limited development of monitoring and evaluation ('M\&E') mechanisms

- Limited evidence to indicate that adaptation planning at the national level is stimulating adaptation planning at the subnational level

- Limited information available about future trends in national-level adaptation (its nature, scale and the degree to which plans, strategies, frameworks or laws will be implemented)

- The extent to which gender dimensions are prioritised in national adaptation plans and policies is still not clear

- Adaptation goals at the global and national level need further clarification to help set precise targets

- Poor availability of shared databases documenting planning/implementation efforts in high-income countries, as well as information on private finance and on the effectiveness of policies and actions to reduce present and future risk levels under different global warming scenarios

- Uncertainty surrounding the long-term effects of the COVID-19 pandemic on future trends in adaptation plannina. financina and implementation 



\section{Chapter 1}

Setting the scene

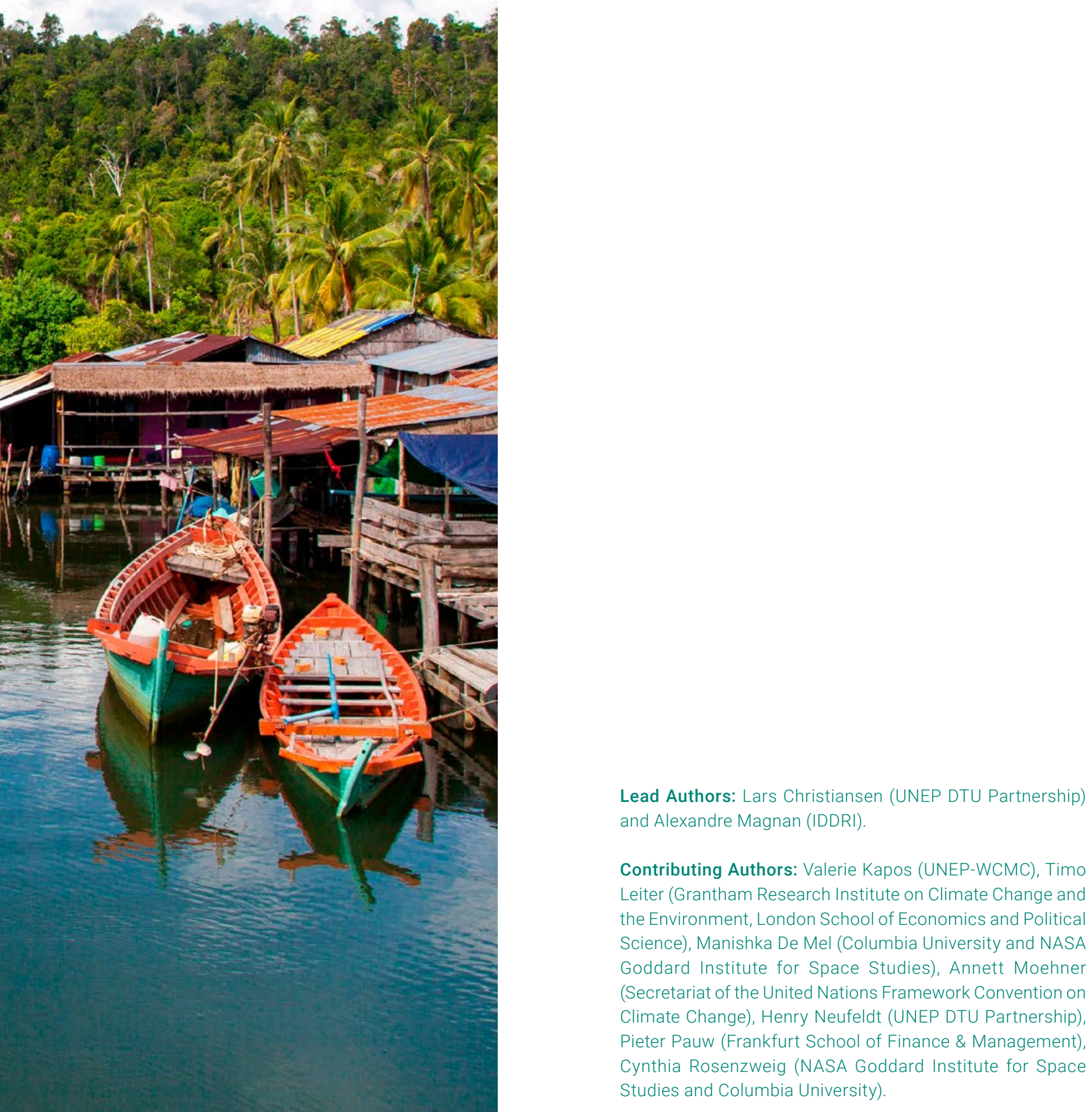

Photo: (c) Shutterstock 


\subsection{Context}

The COVID-19 pandemic has dominated 2020, bringing severe human health challenges as well as economic turmoil and unprecedented restrictions to daily life. As nations of the world continue to deal with the pandemic, another global emergency - climate change - is intensifying across the globe. 2020 has been one of the warmest year on record (World Meteorological Organization [WMO] 2020). Meanwhile, the International Federation of Red Cross and Red Crescent Societies (IFRC) estimates that by September 2020, 51.6 million people globally had been directly affected by floods, droughts or storms combined with the COVID-19 pandemic (Walton and van Aalst 2020).

This year also marks the fifth anniversary of the Paris Agreement, which was a major milestone in international climate efforts convened under the United Nations Framework Convention on Climate Change (UNFCCC). The Paris Agreement established, for the first time, a global goal on adaptation of "enhancing adaptive capacity, strengthening resilience and reducing vulnerability to climate change" (article 7.1). Reviewing the overall progress made towards this global goal on adaptation is one of four adaptation-related functions ${ }^{1}$ of the UNFCCC Global Stocktake, which will take place every five years starting in 2023, with data collection and input due to begin during 2021. Exact details regarding how to undertake the adaptation part of the Global Stocktake, and how the Global Stocktake will be able to fulfil its four adaptationrelated functions, are yet to be confirmed (Christiansen, Olhoff and Dale 2020).

Reflecting the need for a scientifically based and policyrelevant global perspective on adaptation, the United Nations Environment Programme (UNEP) has produced an Adaptation Gap Report (AGR) since 2014. This 2020 report is its fifth edition. From the outset, the report has sought to provide negotiators of the UNFCCC Member States, the broader UNFCCC constituency and the general public with scientifically based assessments of global adaptation gaps and to inform on the status and results of global adaptation efforts (see box 1.1). The objective of the AGR process as a whole is therefore closely aligned with that of the Global Stocktake, while remaining an independent assessment.

\subsection{The 2020 Adaptation Gap Report}

In the lead-up to the Global Stocktake in 2023, the AGR aims to address three important questions: What are we doing today to adapt? To what extent are we currently reducing climate risks? To what extent will our adaptation trajectory help us reduce future climate risks? An answer to these questions will need to be formed in parallel with methodological advances and the generation of new global data in order to address data restrictions and methodological issues outlined in chapter 2 of this report. Building on currently available information (including scientific literature, internationally funded project documents and countries' reports to the UNFCCC), this fifth edition of the AGR thus focuses on adaptation outputs, while laying the foundation for future AGRs to go further on observed and future outcomes in terms of risk reduction. Chapter 2 introduces the conceptual framework of the AGR in more detail.

Leading up to 2023, AGRs will have a three-part structure:

- Part I (chapters 3 to 5 in this year's report) provides a regular assessment of progress in three central elements of the adaptation process: planning, financing ${ }^{2}$ and implementation. The primary objective of this part is to assess progress on adaptation outputs in quantitative and qualitative ways. In the years to come, these chapters will also increasingly provide information on observed adaptation outcomes. This part will appear in each AGR to provide, over time, an indication of trends in the global adaptation process, with this year's report effectively constituting the baseline.

Part II (chapter 6 in this year's report) presents a deep dive into the same three elements of progress for a particular theme or sector and at both output and, where possible, outcome levels. The purpose of a deep dive section in the AGR is twofold: 1. It provides a more detailed picture of progress in the selected focus area and 2. It adds supplementary perspectives, nuance and detail to the overall progress assessment of the report. The theme or sector will be decided by UNEP from year to year in light of global developments, international priorities and the needs of the UNFCCC and related global agreements.

Part III (chapter 7 in this year's report) synthesizes findings from parts I and II into a status of global progress of adaptation and offers an outlook on future developments. It also outlines the challenges ahead and intended future work towards better global assessment of adaptation.

1 Article 7, paragraph 14 of the UNFCCC stipulates that the global stocktake shall, inter alia: a) Recognize adaptation efforts of developing country Parties; b) Enhance the implementation of adaptation action taking into account the adaptation communication referred to in Article 7, paragraph 10; c) Review the adequacy and effectiveness of adaptation and support provided for adaptation; and d) Review the overall progress made in achieving the global goal on adaptation referred to in Article 7, paragraph 1.

2 Under the UNFCCC, finance is one element of the so-called 'means of implementation' (finance, technology and capacity-building). In the context of this report, however, capacity-building and technology transfer are considered to be elements of 'implementation' more broadly. Furthermore, in the context of Article 2.1c of the Paris Agreement, this report also looks at how sustainable financial systems can contribute to adaptation and monitoring of investments in adaptation. 
Box 1.1. Overview of past Adaptation Gap Reports ${ }^{1}$

UNEP produced the first AGR for the twentieth session of the Conference of the Parties (COP 20) in Lima in 2014, in response to requests by UNFCCC Parties for an assessment on adaptation, complementary to the annual Emissions Gap Report. ${ }^{2}$ In particular, the aim was that the independent assessment of the 'adaptation gap' would help inform UNFCCC discussions on adaptation ahead of COP 21 in Paris in 2015. From the outset of the first AGR, it was clear that assessing the adaptation gap was going to be a very different and methodologically more challenging exercise than that of assessing the emissions gap.

The first report proposed a definition of the adaptation gap as "the difference between actually implemented adaptation and a societally set goal, determined largely by preferences related to tolerated climate change impacts, and reflecting resource limitations and competing priorities". It provided a preliminary framework for assessing adaptation gaps and proposed three dimensions: the funding gap, the technology gap and the knowledge gap.

The second AGR followed in 2016, providing an indepth assessment of the adaptation finance gap, looking at both estimates of the costs of adaptation and the availability of bilateral, multilateral and private sector financing.

The third AGR released in 2017 did not assess a specific gap, but focused on providing an assessment of the methodological issues involved in assessing global progress on adaptation.

In 2018, the fourth AGR introduced a focus topic alongside the assessment of adaptation progress in terms of enabling environments, adaptive capacity and finance, namely looking at the adaptation gap in the health sector.

1 All Adaptation Gap Reports can be downloaded here: https://www.unep.org/explore-topics/climate-change/what-wedo/climate-adaptation/world-adaptation-science-programme-5

2 The Emissions Gap Report 2020 can be downloaded here: https://www.unenvironment.org/emissions-gap-report-2020

The deep dive in the 2020 AGR is nature-based solutions for adaptation, given the growing connections and the potential for synergies between the climate and biodiversity agendas, and the urgent need for policy and action to secure and harness nature's benefits. This is reflected in the designation of 2020 as the Super Year for Nature (with much activity postponed to 2021 due to the pandemic), the fifth UN Environment Assembly's focus on Strengthening Actions for Nature to Achieve the Sustainable Development Goals, and the UN Decade on Ecosystem Restoration. To date, much discussion of nature-based solutions has focused on climate change mitigation, but they also play a crucial role in adaptation.

This year's report features a number of innovative elements that are directly relevant to the Global Stocktake:

- Evaluation criteria for adaptation planning. Given that there is currently no consensus around how to assess progress on adaptation planning, the AGR taking into account existing tools, assessments and provisions of the Paris Agreement - applies five criteria (comprehensiveness, inclusiveness, implementability, integration and monitoring and evaluation) to review for the first time whether adaptation planning in 196 countries is adequate (sufficient) and effective (successful) in meeting adaptation objectives.
Mechanisms for financial sustainability. As it is important to go beyond monitoring of climate finance under the UNFCCC, private finance and domestic public finance, this year's AGR explains how efforts to make the financial sector sustainable could help monitor adaptation and pro-actively support the shifting of capital towards climateresilient investments.

Status of implementation. A new addition to the AGR is a chapter on implementation that reflects the importance of understanding which actions are being taken, where, by whom and in what form. This is a prerequisite to assessing the results of adaptation. This chapter combines insights from a systematic review of the scientific literature on adaptation from the Global Adaptation Mapping Initiative (GAMI) with findings of an analysis of adaptation projects financed by UNFCCC climate funds.

- Analysis of nature-based solutions for adaptation. An in-depth analysis of multiple data sources describing nature-based solutions planning, finance and implementation efforts across the globe makes the AGR 2020 the most representative assessment of its kind. 


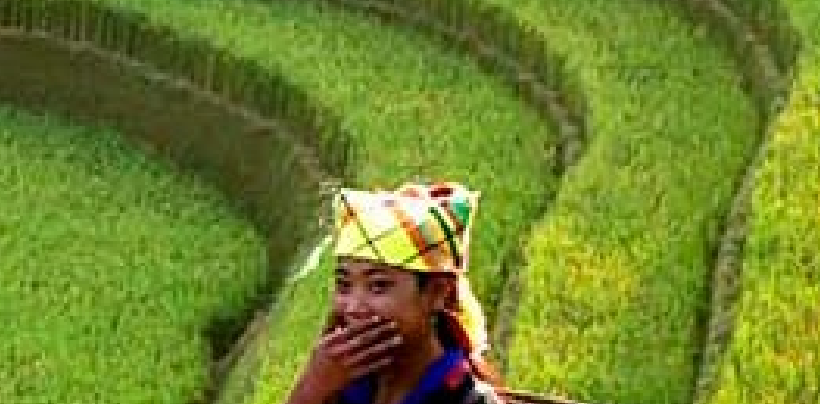

\section{Chapter 2}

Framing the Adaptation

Gap Report

Lead Authors: Alexandre Magnan (IDDRI), Lars Christiansen (UNEP DTU Partnership), Henry Neufeldt (UNEP DTU Partnership).

Contributing Authors: Valerie Kapos (UN Environment Programme World Conservation Monitoring Centre), Timo Leiter (Grantham Research Institute on Climate Change and the Environment, London School of Economics and Political Science), Manishka De Mel (Columbia University and NASA Goddard Institute for Space Studies), Annett Moehner (Secretariat of the United Nations Framework Convention on Climate Change), Cynthia Rosenzweig (NASA Goddard Institute for Space Studies and Columbia University).

Photo: () Sirisak Baokaew (Shutterstock) 


\subsection{Introduction}

The 2020 edition of the Adaptation Gap Report (AGR) is the first building block of a broader series of AGRs that aims to progressively advance knowledge on adaptation progress made globally. By providing a conceptual framing to contextualize the challenges related to the assessment of adaptation progress, including current and future adaptation results, it paves the way for the AGR series as a whole. It is primarily focused on the global and national scales, with source material drawn from data, reports and scientific literature, which will be updated and refined in subsequent editions of the AGR

This chapter highlights some of the basic elements of the longer-term approach in terms of assessing adaptation in the context of climate risks. First, climate risks are discussed in the context of the interlinkages between adaptation and mitigation, the current and future risk levels against which to assess adaptation progress, and the extent to which ambitious adaptation could reduce climate risks. Second, the process of assessing adaptation is discussed in the context of framing adaptation progress, barriers in tracking adaptation outcomes (i.e. results in terms of climate risk reduction see box 2.1), and the scope and methodology of the report. Understanding of these two aspects - climate risk trajectory and adaptation assessment - will continually evolve over the coming AGRs as new knowledge emerges from the literature and more consistent data and information are provided by countries, donors and implementing organizations.

\subsection{Framing the climate risks context}

\subsubsection{Climate risks in the context of adaptation and mitigation}

Climate risks are rising as climate change leads to increases in global temperatures, sea level rise and many extreme events, including heatwaves, droughts and floods (Intergovernmental Panel on Climate Change [IPCC] 2014; Oppenheimer et al. 2019; Hurlbert et al. 2019). Adaptation is a process by which levels of risk are reduced at any given temperature level (figure 2.1, panel A). With increasing climate change, the efforts and costs - required to avoid or limit the resulting impacts continue to grow, and there is residual risk, whereby some level of damages can no longer be avoided at all.

The IPCC Special Report on Global Warming of $1.5^{\circ} \mathrm{C}$ updated the five integrated 'reasons for concern'1 to encompass a wider range of both natural and social systems. These all show a significant rise in impacts between current temperatures and $1.5^{\circ} \mathrm{C}$ above pre-industrial levels, as well as between the $1.5^{\circ} \mathrm{C}$ and $2^{\circ} \mathrm{C}$ scenarios (IPCC 2018). Warm-water corals, for example, are already at high risk and will experience very high risks at $1.5^{\circ} \mathrm{C}$ (IPCC 2018). It is expected that 99 per cent of warm-water corals will be destroyed if global temperature levels rise by above $2^{\circ} \mathrm{C}$, with significant consequences for biodiversity, livelihoods and the natural protection that these ecosystems provide against coastal flooding and erosion (IPCC 2018; chapter 6).

If mitigation measures were implemented as planned in the nationally determined contributions (NDCs), future warming would be at least $3^{\circ} \mathrm{C}$ above pre-industrial levels (United Nations Environment Programme [UNEP] 2020). Strong mitigation is therefore the most effective option to avoid the severe impacts of climate change associated with the exponentially rising damages and costs expected after 2050 (IPCC 2014; IPCC 2018; Gattuso et al. 2018; UNEP 2020). According to Warren et al. (2018), the global economic damages of climate change will be lower under a trajectory that stays within $1.5^{\circ} \mathrm{C}$ at the end of the century as compared to one that leads to $2^{\circ} \mathrm{C}$ warming. Hsiang et al. (2017) estimate that the USA stands to lose 0.1-1.7 per cent of gross domestic product (GDP) by the end of the century for the $1.5^{\circ} \mathrm{C}$ scenario, compared with a median GDP loss of 4.5 per cent (uncertainty range of 2.5 per cent to 8.5 per cent) under a no-mitigation policy trajectory.

Similarly, De Cian et al. (2016) suggest that limiting global warming to $2^{\circ} \mathrm{C}$ approximately halves the economic damages to 1-1.6 per cent of global world product (GWP) compared to 2.4-2.7 per cent under the business-as-usual baseline. Adaptation can significantly reduce these damages, particularly under higher temperature changes, with GWP reductions limited to $1.5-2.1$ per cent for the baseline scenario. However, these projections differ dramatically between regions. Developing countries, particularly in Africa and Asia, are expected to suffer much higher losses, further accentuating their development disadvantages and higher vulnerabilities to climate change. Using a different set of integrated assessment models, Hof, Elzen and Vuuren (2010) reach similar conclusions regarding damages and their regional distribution.

\section{Box 2.1. Defining adaptation outputs and outcomes}

- Adaptation outputs refer to the sum of activities engaged on the ground and address the question: what are we doing today to adapt?

- Adaptation outcomes refer to the results of those activities in terms of reducing risk today (observed outcomes) and in the future (expected outcomes).

1 Risks to unique and threatened systems, risks associated with extreme weather events, risks associated with uneven distribution of impacts, risks associated with global aggregate impacts, and risks associated with large-scale singular events 


\subsubsection{Against which current and future risk levels should adaptation progress be assessed?}

Assessing progress made to reduce current and future risks implies consideration of a broader spectrum of risks than only under a $1.5-2^{\circ} \mathrm{C}$ warming. Although it is widely acknowledged that the nature and level of climate risks is highly context-specific, some global-scale assessments have emerged in recent decades to allow for cross-scale framing. These assessments could lay some foundations for the AGR series.

The IPCC Fifth Assessment Report (AR5; Oppenheimer et al. 2014; O'Neill et al. 2017) developed a climate risk framework (Box 2.2) and an assessment of eight key risks that are considered representative of the range of critical climate risks to global society, across all latitudes, levels of development and types of climate hazards. These risks refer to important dimensions for sustainable life, livelihoods and settlements: risk to lives, land-based food security, oceanbased food security, water security, urban systems, critical infrastructure and networks, terrestrial biodiversity and ocean biodiversity. Such a generic list of climate risks could be useful in framing future AGR reports.

The three recent IPCC Special Reports (on Global Warming of $1.5^{\circ} \mathrm{C}$, Climate Change and Land (SRCCL) and the Ocean and Cryosphere in a Changing Climate (SROCC)) further expanded risk characterizations for a range of ecosystems, sectors and human systems. Some of these assessments will be updated in the IPCC Sixth Assessment Report (AR6). Other sources (such as the WorldRiskReport ${ }^{2}$ and the Global Risk Report ${ }^{3}$ ) will also contribute to the knowledge base on future risk levels against which adaptation outcomes, and therefore progress or gaps, can be assessed in the context of the AGR series (Magnan and Chalastani 2019).

Furthermore, comparing risk levels under a range of global warming scenarios could help in defining some risk reduction targets - for example, around bridging the gap between impacts under low-end (such as Representative Concentration Pathway (RCP) 2.6) and high-end (such as RCP8.5) global warming scenarios. This could contribute to refining, even qualitatively, the global goal on adaptation and set the scene for better tracking of global adaptation progress. Risk comparison across global warming levels represents another important framing element for future reports in the AGR series

\subsubsection{To what extent could ambitious adaptation reduce risk?}

In addition to the assessment of risk levels, the other critical information needed to understand adaptation progress relates to the actual future benefits, in terms of risk reduction, to be expected from ambitious adaptation over this century (see figure 2.1). This, however, constitutes a significant knowledge gap and, to date, only emerging insights are available in the scientific literature (for example, Melvin et al. 2016; De Cian et al. 2016), as well as in the recent IPCC Special Reports on Climate Change and Land, and the Ocean and the Cryosphere (Hurlbert et al. 2019; Oppenheimer et al. 2019). This explains why the outcome dimension of adaptation progress cannot be fully considered in this edition of the AGR.

Improving the evaluation of adaptation outcomes in future AGRs relies on a better understanding of the potential effectiveness of a wide range of adaptation plans, policies and measures. Much work is required to define the degree to which these instruments individually and collectively fulfil specific goals relating to risk reduction now (observed outcomes) and in the future (expected outcomes). This calls for an assessment framework to be developed that will capture adaptation effectiveness as a whole, including multiple dimensions. These dimensions include, for example, potential outcomes of adaptation-labelled policies and measures; readiness in terms of implementation; lead time until full benefits are achieved; lifespan of their benefits; undesirable side effects; and barriers to implementation (Gattuso et al. 2018; Magnan et al. 2020). Overall, such a framework could help improve the assessment of adaptation outcomes and, by extension, the tracking of adaptation progress in a consistent way throughout subsequent AGRs.

\subsection{Understanding progress in adaptation}

Understanding adaptation progress means asking three intertwined overarching questions: what are we doing today to adapt? To what extent are we currently reducing climate risks? And will our adaptation trajectory help us reduce future climate risks? This 2020 AGR edition responds to the first question by discussing current adaptation outputs observed at the national and international levels, thereby paving the way for upcoming AGRs to effectively address the other two questions. Answering the first question, however, raises its own important methodological and data challenges, as highlighted in the next chapters on planning, financing and implementing.

\subsubsection{Framing adaptation progress}

'Adaptation progress' is understood here at two distinct levels of analysis and builds on the 2017 edition of the AGR (UNEP 2017). First, progress can be considered in the context of outputs from the adaptation process. The adaptation process is the sum of targeted activities engaged in to help achieve adaptation objectives, for example the global goal on adaptation or national-level objectives. The adaptation process necessarily covers a broad range of activities, including early awareness and assessment of specific climate risks at global 
Figure 2.1. Progress in adaptation under different climate risk scenarios

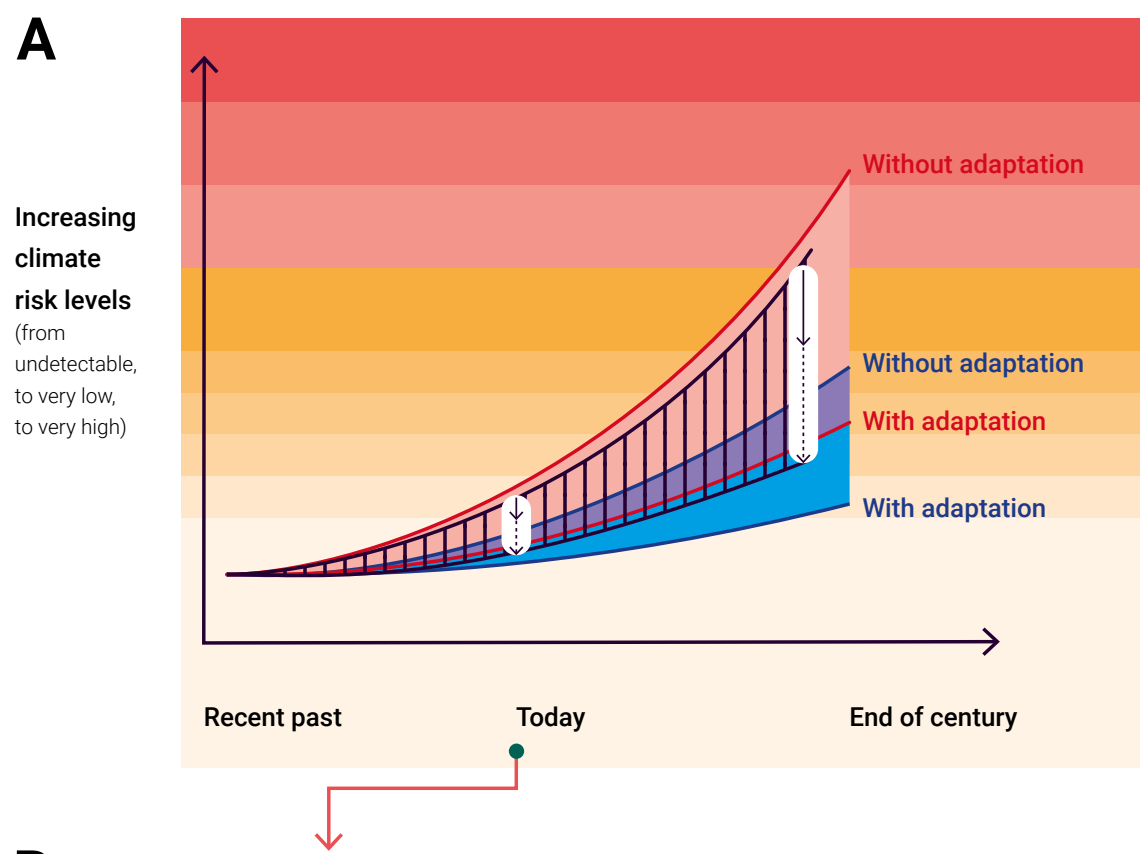

Risk scenarios under RCP2.6 (blue) and RCP8.5 (red), with and without adaptation, are inspired by the recent IPCC special reports (SRCCL; SROCC). The midway risk scenario (black) is purely hypothetical and is used for illustrative purposes.

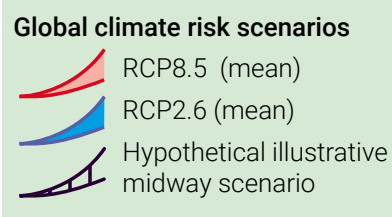

B

- Recognition of the policy importance of adaptation in order to galvanize action at the international and national levels

\section{Evidence of} adaptation progress

Identification of gaps

- Maturity in the way adaptation is either mainstreamed into existing policies or considered as an overarching policy area in its own right

- Actionable policies refer to the extent to which multi- and bilateral cooperation and national policies provide clear guidance on how to operationalize adaptation on the ground (i.e. beyond only providing strategic guidance)

- Early signs of further progress highlight emerging experience and knowledge, which indicates that more progress is to be expected in the near to long-term future

- Adaptation finance represents an important aspect of international cooperation towards adaptation and is a key prerequisite to its implementation

- Monitoring and evaluation is a key prerequisite for planning to remain adequate and effective over time

- Knock-on effects refer to how progress made at a given level (e.g. national) has a subsequent effect on progress at lower levels (e.g. local)

- Effectiveness in terms of climate risk reduction is key to understanding whether existing or planned policies and actions (outputs) lead to effective adaptation (outcomes)

- Gender and broader concerns around equity and justice

- Adaptation goals refer to the scenario that we want to achieve in the context of a changing climate, either at the global level or the national-level

- Availability of information on both outputs (what are we doing to adapt?) and outcomes (to what extent does this reduce climate risks?) is key to building confidence in whether we are achieving the progress desired or whether we are falling short (i.e. there is an adaptation gap)

- Uncertainty around the enabling conditions for adaptation describes the external, non-climate-related factors that can influence vulnerability and adaptive capacity, and can therefore make achieving adaptation goals easier or harder

Note: This figure is inspired by the 2014 AGR (UNEP 2014) and recent IPCC Special Reports (Oppenheimer et al. 2019; Hurlbert et al. 2019). In panel A, the background colouring illustrates the increase in climate risks for various warming scenarios (Representative Concentration Pathway (RCP)2.6 and RCP8.5) and adaptation scenarios (with/without). The blue and light red curved drawings represent risk scenarios under RCP2.6 and RCP8.5, respectively, while the central black drawing represents a hypothetical risk scenario under a speculative, midway warming scenario. This figure is purely illustrative and does not rely on any quantitative data. The white vertical boxes show, for today (left) and by the end of this century (right), the level of risk reduction to be expected from very limited adaptation efforts (top of white boxes) to high adaptation efforts (bottom of white boxes), i.e. the 'adaptation space'. The downward black arrows within these white boxes provide a theoretical interpretation of observed progress and uncertainty. While the solid arrows illustrate the progress that can be assessed and reported based on evidence - for example, in the AGRs -, the dotted arrows reflect knowledge gaps and therefore potential adaptation gaps. Together, the two arrows within the same box help us understand the balance between what we know has been achieved, and what we are uncertain about because of a lack of information, thus helping balance progress and potential gaps. Panel $\mathbf{B}$ describes the general framing used in this report to analyse progress and gaps, as well as to consider the contextual elements that constrain the interpretation of the findings (for example, related to the influence of the COVID-19 crisis on adaptation efforts globally). This framing has been used to structure the cross-chapter synthesis provided in chapter 7 (see figure 7.1). 


\section{Box 2.2. What is climate risk?}

Risk is the probability or likelihood of occurrence of hazardous events or trends multiplied by the impacts if these events or trends occur. Risk framing focuses on the potential for consequences where something of value is at stake and where the outcome is uncertain, recognizing the diversity of values. As is illustrated in figure 2.2 below, risks from climate change impacts arise from the interaction between hazard (triggered by an event or trend related to climate change), vulnerability (susceptibility to harm) and exposure (people, assets or ecosystems at risk). Hazards include processes that range from brief events, such as severe storms, to slow trends, such as multi-decade droughts or multi-century sea level rise. Vulnerability and exposure are both sensitive to a wide range of social and economic processes, with possible increases or decreases depending on development pathways (IPCC, 2014).

Figure 2.2. Schematic of the interaction among the physical climate system, exposure, and vulnerability producing risk

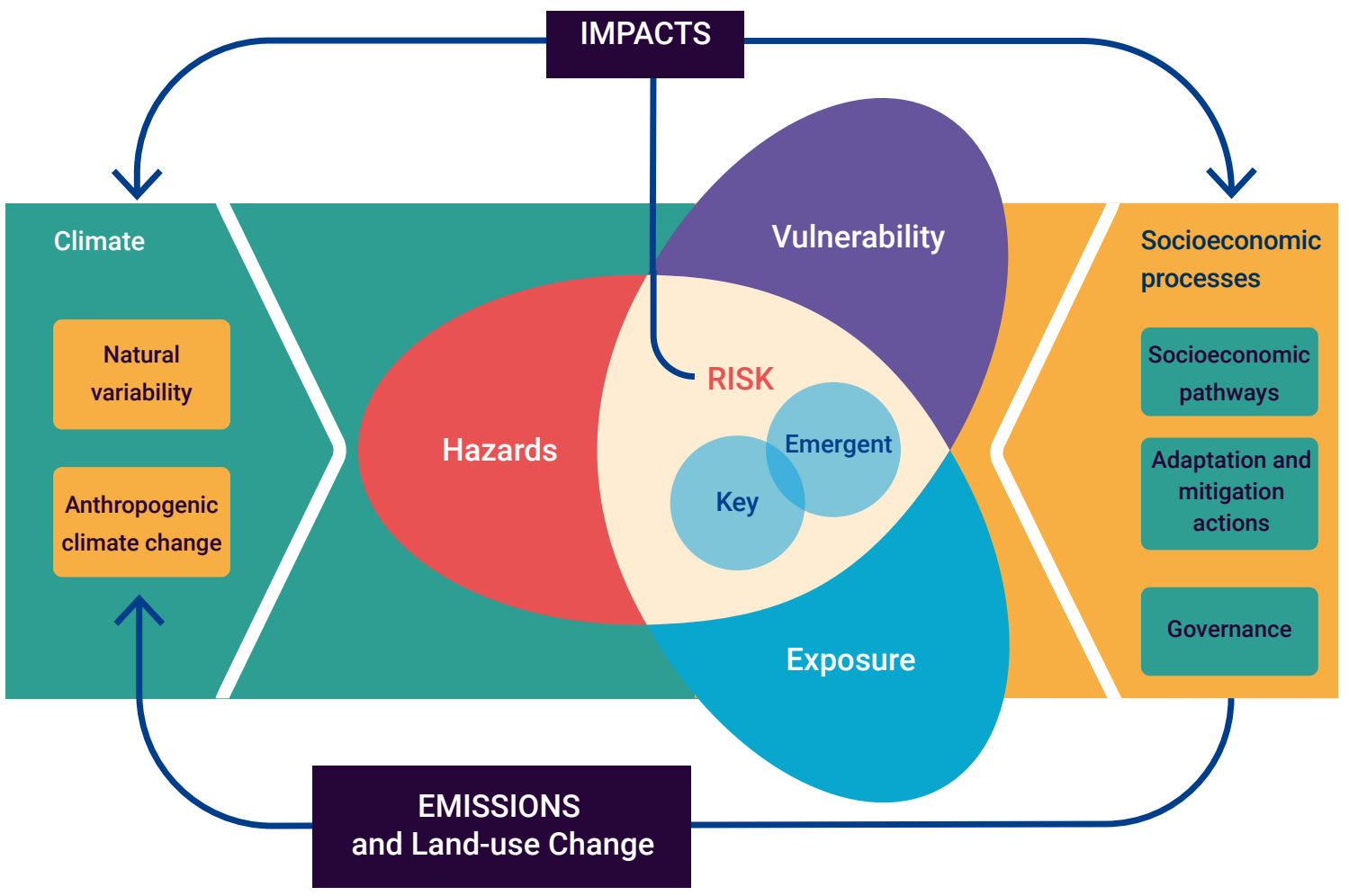

Source: Figure 19-1 from Oppenheimer et al. (2014)

to local scales, as well as planning, providing adequate means of implementation (finance, technology and capacity-building) and implementing concrete adaptation measures on the ground. The outputs of the adaptation process refer to the question: what are we doing today to adapt?

National-level adaptation or multi-/bilateral cooperation on adaptation can be assessed in quantitative terms (for example, number of plans, amount of financing committed, and type and scale of implementation activities) or qualitative terms (responding to questions such as: are plans covering all identified risks? Is finance mainly provided on concessional or market terms? Is implementation country-owned?).
Second, as outputs only provide part of the progress information, it is key to also understand the results of the adaptation process in order to answer the question: to what extent are we actually reducing climate risk levels today and in the future?

This is essentially the question raised by the global goal on adaptation and is intended to be answered by the Global Stocktake on adaptation, which will take place in 2023. Progress here would be in the form of outcomes and future impacts of the global adaptation process. ${ }^{4}$ Assessing progress on outcomes is generally more difficult to do than tracking outputs, for many reasons including the lack of

4 The terms 'results' and 'outcomes' are being used interchangeably in this report. 
scientific understanding of the effects of adaptation-related responses on risk levels, and the absence of a clear singular metric for adaptation. These issues mean that assessing outcomes will, by necessity, have to be rather qualitative.

While outputs are intended to lead to outcomes, in reality it is often difficult to attribute results (such as increased resilience to climate hazards) to individual actions. This is because the process involves multiple actors and a range of factors beyond the direct level of influence of any given initiative. A further complication associated with the 'missing link' between outputs and outcomes is that adaptation outputs, while intended to reduce exposure and/or vulnerability, can, if not properly anticipated, have few effects or may even lead to negative outcomes.

Figure 2.3 brings these dimensions together and includes the temporal dimension to show that adaptation outcomes can be further subdivided into observed and expected outcomes of adaptation. Observed adaptation outcomes refer to an ex-post assessment, i.e. the level of current climate risk reduction that has been achieved so far. Expected adaptation outcomes refer to an ex-ante assessment, i.e. the outcomes that are expected from planned or ongoing adaptation efforts in the future. To comprehensively assess adaptation progress in terms of future climate risks thus requires the combined appraisal of both observed and expected adaptation outcomes. This appraisal would need to take into account different levels of risk aversion or tolerance, i.e. the level (or range) of climate risks and associated impacts that a given society considers acceptable. Risk aversion is, however, highly context- and culture-specific and thus difficult to aggregate to a global level.

\subsubsection{Barriers in tracking adaptation outcomes}

There are three major constraints to assessing adaptation outcomes globally (see also panel B of figure 2.1).

First, contrary to mitigation where there is a specific target of limiting temperature increases to "well below" $+2^{\circ} \mathrm{C}$ and thus an associated target of critical carbon emission/ concentration (based on available warming scenarios), no single, straightforward and quantifiable metric (or even set of metrics) exists that could be used to convert the global goal on adaptation into a measurable target (and baseline) at the global level. Despite progress made on framing adaptation globally within the Cancun Adaptation Framework and the Paris Agreement, it thus remains difficult to quantify global progress on adaptation outcomes.

Second, no universal, agreed-upon assessment framework has emerged to date (UNEP 2017). Nevertheless, there has recently been progress in defining desirable criteria for an adaptation assessment framework at the global level (aggregable, transparent, longitudinal, feasible, coherent, sensitive to national context; UNEP 2017), as well as promising work promoting "concepts that are translatable and scalable across levels of government, and that can be systematically compared between governments" (Berrang-Ford et al. 2019). Despite this, progress towards adaptation goals cannot readily be compared across countries or other actors (private sector, subnational level, etc.).

Third, there is a data challenge as currently no central data repository documenting delivered adaptation outputs exists. While it is comparatively easy to track large-scale projects delivered by international donors (due to centrally available data sources), as well as national-level adaptation (due to these being well captured through reporting under the United Nations Framework Convention on Climate Change (UNFCCC) enhanced transparency framework5), subnational, non-state actor and local (often autonomous) adaptation efforts can go largely undocumented, despite being major factors in reducing climate risks locally. The AGR 2020 chapters dealing with planning, financing and implementing adaptation, as well as this year's topical chapter on nature-based solutions, all highlight such a gap in data availability, which future AGRs will explore ways to overcome (for example, by expanding the type and range of data considered).

\subsubsection{Scope and methodology of AGR 2020}

Recognizing the above barriers, the 2020 AGR analysis covers global outputs, with a focus on national adaptation actions across a broad range of sectors and multi- and bilateral cooperation, especially in terms of financing. Information is based on adaptation activities that have already begun or have been completed and focuses primarily on climate hazards and risks. The overall methodological approach is based on an assessment of the status and progress of adaptation planning, finance and implementation, and utilizes documentation from a wide range of reports, databases and scientific literature.

More specifically, the assessment in chapter 3 on planning is primarily based on data reported in national adaptation plans (NAPs), NDCs and national communications. Data are also drawn from, cross-checked with and complemented by the Grantham Research Institute's Climate Change Laws of the World database.

In chapter 4 on finance, analysis is primarily based on data related to public finance flows, including official development assistance (ODA) flows from the Organisation for Economic Co-operation and Development (OECD) Development Assistance Committee members and finance flows reported by countries in their UNFCCC Biennial Reports. 
Figure 2.3. Conceptual storyline of the AGR series on assessing global progress on adaptation

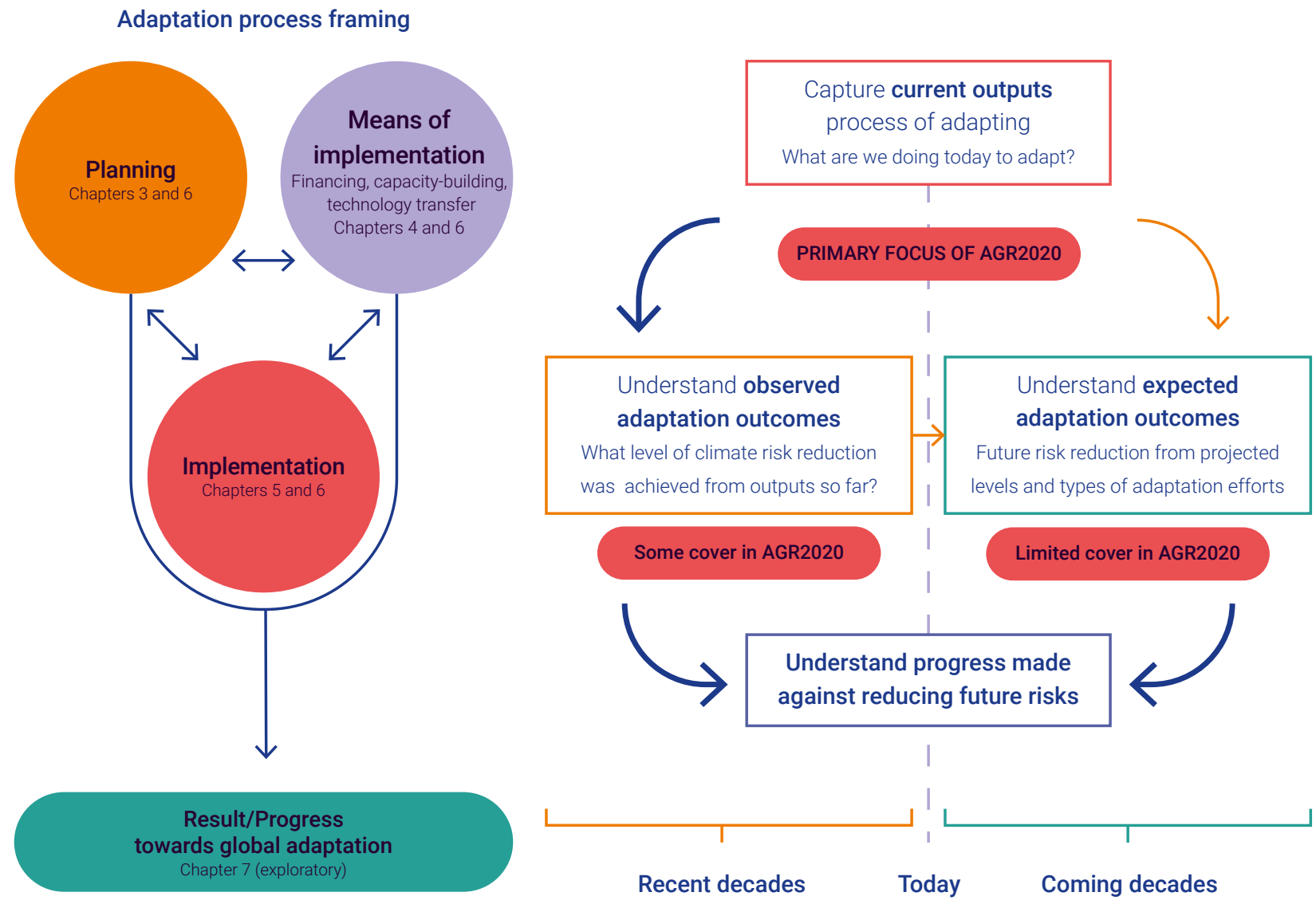

In chapter 5 on implementation, the two main sources of information are funded adaptation projects and scientific literature. The chapter draws on adaptation proposals from the major multilateral climate funds and on adaptation as documented in scientific literature.

The methodological approaches used in chapters 3-5 were then applied in the deep-dive chapter 6 on nature-based solutions for adaptation (NbS). Much of the information on NbS assessed is from NDCs under the Paris Agreement, NAPs, donor databases, as well as reports from major development organizations such as the World Bank and GIZ, with case examples coming from implementing organizations.

Limitations to the methods and data used in this report include a lack of rigorous standards of reporting by countries and incomplete information on domestic public sector finance and private sector investments in adaptation (see section 7.1.3 in chapter 7). A major challenge in assessing progress is that adaptation actions are often embedded within other programmes and projects with multiple objectives.

The categories presented in panel B of figure 2.1 are those that the AGR has identified as relevant to assessing the evidence presented in the planning, finance and implementation chapters of this report. These categories are used in chapter 7 to interpret the results and understand relevant aspects of adaptation progress presented in chapters 3-6. They have been foundational to figure 7.1 in chapter 7 .

The primary focus of this year's AGR is on establishing a baseline for assessing progress across planning, financing and implementation, i.e., on adaptation outputs (see figure 2.3). Beyond providing a snapshot of the current status of global adaptation efforts, the report seeks to serve as an inspiring foundation for advancing knowledge on global adaptation progress and for stimulating both the policy and scientific communities.

Thus, the AGR 2020 aims to clarify the needs in the context of the UNFCCC Global Stocktake process - which type(s) and level(s) of information are really needed to assess global adaptation progress? And what information is already available? Further conceptual and methodological developments are also required to understand and measure both past and present adaptation efforts (outputs) and the related observed and expected risk reduction (outcomes). The analysis in this 2020 edition thus builds on the 2017 AGR (UNEP 2017), which started to take stock of methodological progress over recent years to assess progress towards the global goal on adaptation. 

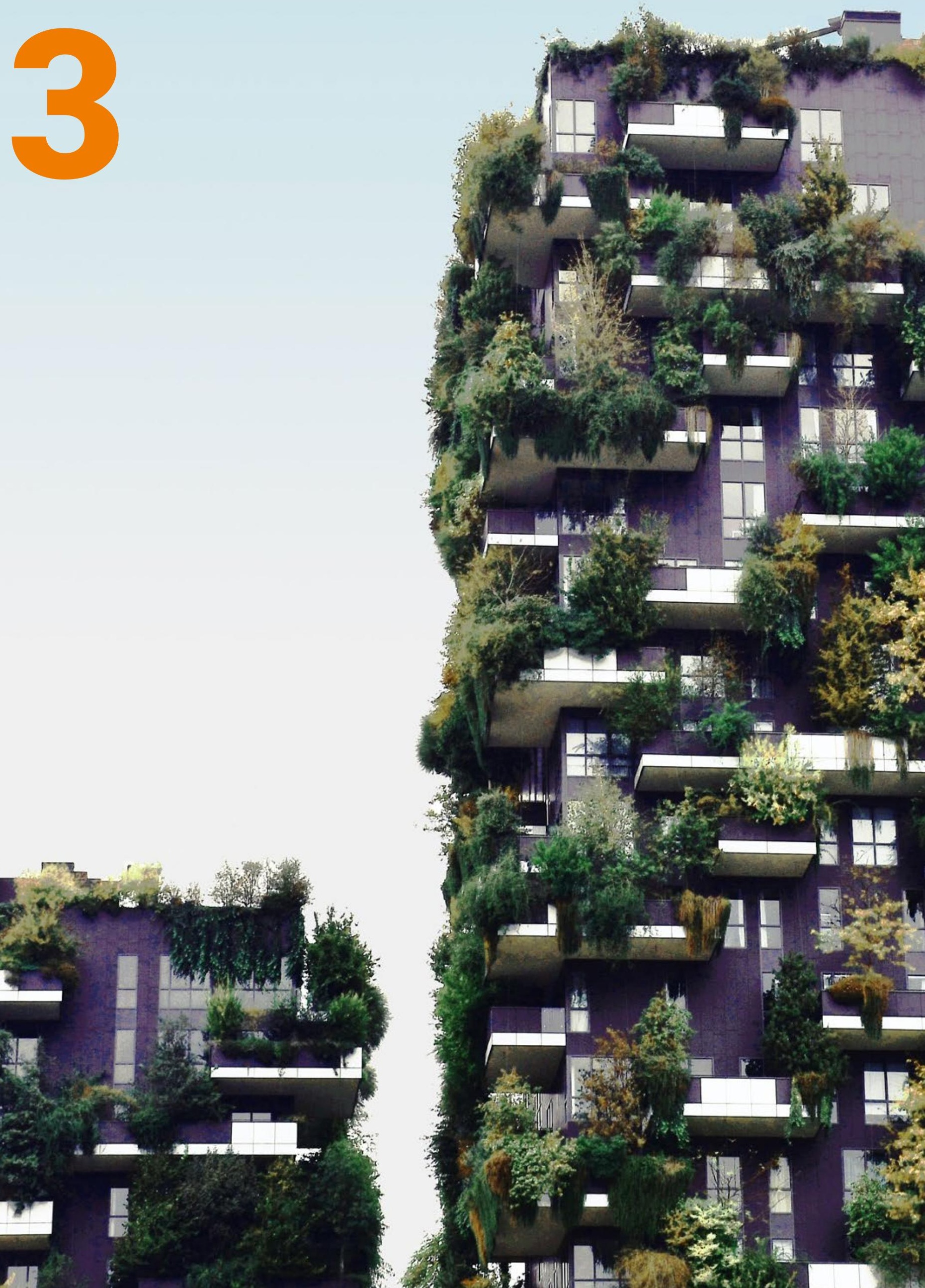


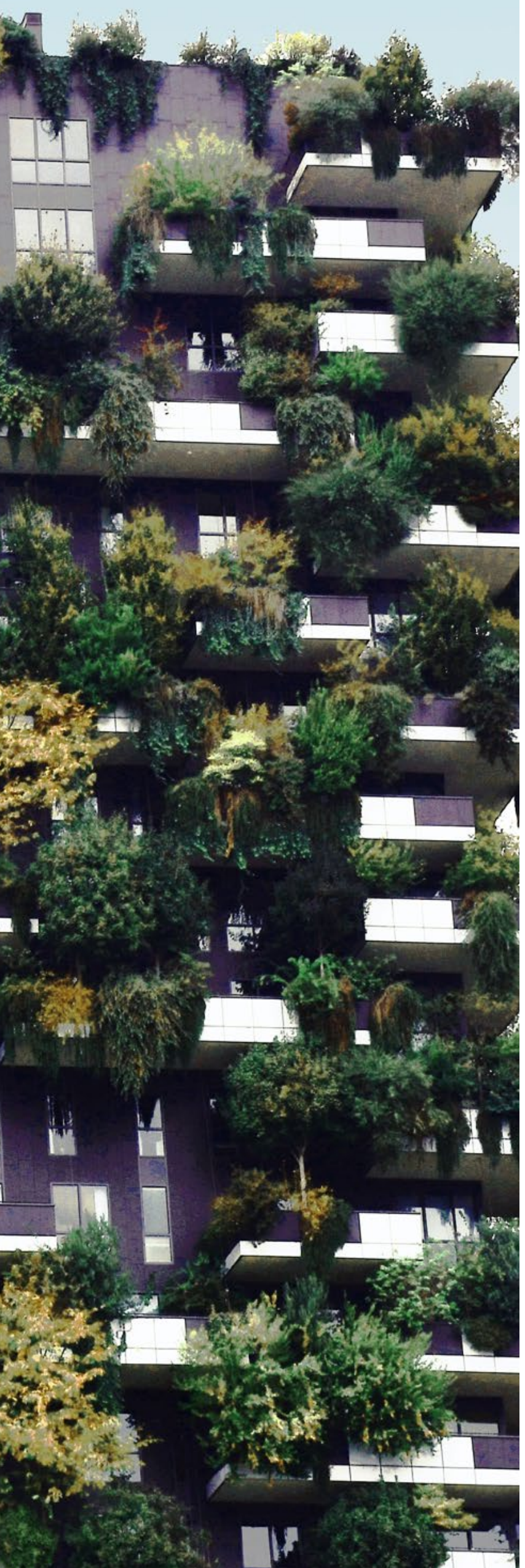

\section{Chapter 3}

Assessing global progress on adaptation planning

Lead Authors: Annett Moehner (Secretariat of the United Nations Framework Convention on Climate Change), Maryam Navi (Secretariat of the United Nations Framework Convention on Climate Change), Fatin Tawfig (Secretariat of the United Nations Framework Convention on Climate Change)

Photo: (c) Daryan Shamkhali (Unsplash) 


\section{Key messages}

- Adaptation planning is critical to enable both public and private actors to prepare for and respond to the impacts of climate change. By committing all countries to engage in adaptation planning processes, the Paris Agreement underscores the importance of national-level adaptation planning in particular.

- In terms of quantity, the last two decades have seen significant progress in adaptation planning: 72 per cent of countries have at least one national-level planning instrument in place that addresses adaptation, and 125 developing countries have begun the process of formulating and implementing national adaptation plans (NAPs). Countries have also increasingly established sectoral (58 per cent of countries) or subnational (21 per cent of countries) planning instruments.

- In terms of quality, it is difficult to assess the degree to which adaptation planning efforts are adequate or effective in achieving adaptation objectives. An assessment of variables relevant to adequacy and effectiveness paints a mixed picture. While around half of countries meet the criteria for comprehensive and inclusive adaptation planning, significantly less than half meet the criteria for implementability and monitoring and evaluation. The picture for the integration criterion is mixed, with about two-thirds having horizontal coordination mechanisms in place, compared with around one-quarter that have vertical coordination mechanisms.

- Looking ahead, as countries increasingly submit more consistent information under the Paris Agreement, more rigorous analyses can provide more nuanced insights into global progress on adaptation planning.

\subsection{Introduction}

Adaptation planning seeks to enable public and private adaptation to climate change through a wide range of strategies, plans, policies, laws, regulations and directives. While adaptation planning occurs on a local, site-specific to global scale, national-level planning is particularly vital due to the role national governments play in mandating, enabling, overseeing and allocating resources to adaptation activities in different sectors and at different governance levels (Mimura et al. 2014; Nachmany, Byrnes and Surminski 2019).

The 2015 Paris Agreement (United Nations Framework Convention on Climate Change [UNFCCC] 2016) commits all countries to engage in adaptation planning processes and the implementation of actions, including the development or enhancement of relevant plans (art. 7.9). The Agreement also stresses that adaptationaction should followa gender-responsive and participatory approach with a view to integrating adaptation into relevant socioeconomic and environmental policies and actions (art. 7.5). As part of the Global Stocktake, countries will review the adequacy and effectiveness of adaptation (art. 7.14 and art. 14).

This chapter seeks to assess how much progress has been made by 1961 Parties to the UNFCCC, of which 189 are also Parties to the Paris Agreement, in constructing such plans and strategies. It further endeavours to assess whether these plans and strategies are effective and adequate in leading to enhanced adaptive capacity, strengthened resilience and reduced vulnerability as envisaged by the global goal on adaptation (art. 7.1 of the Paris Agreement).

TheIntergovernmentalPanelonClimateChangeFifthAssessment Report (IPCC AR5) concluded that adaptation is transitioning from the awareness-raising phase to the construction of actual strategies and plans at the societal level (Mimura et al. 2014). As part of this transition, many countries have started assessing their adaptation planning, the design of which varies considerably, with differing combinations of qualitative analyses and qualitative and quantitative indicators (UNFCCC 2020a).

While there are currently no agreed-upon methods, indicators, metrics or frameworks designed for assessing progress towards the global goal on adaptation (United Nations Environment Programme [UNEP] 2017), existing frameworks provide insight into opportunities for aggregating and synthesizing countrylevel progress. In addition, proposals for methods of assessing adaptation as part of the Global Stocktake are beginning to emerge. Proposed criteria for assessment frameworks include the capacity to aggregate or synthesize country-level data, transparency, consideration of progress over time, avoiding undue burden on countries, inclusion of proxy indicators that are coherent with a collective understanding of meaningful adaptation, and sensitivity to national vulnerabilities, resources and contexts (UNEP 2017; UNFCCC 2020a).

1 Given that the focus of this chapter is on the analysis of the national level, the European Union, which is also a Party to the UNFCCC and the Paris Agreement, has been excluded from the analysis. 
Table 3.1. Overview of criteria used to assess adaptation planning, including the underlying rationale, and associated indicators

Rationale
1. Comprehensiveness
Identifying climate risks and hazards and assessing vulnerability to
existing and future climate hazards and impacts are both foundational
steps of the adaptation planning process. Countries can use this
information to prioritize sectors for adaptation action and develop
a comprehensive adaptation plan by identifying adaptation options
that align with these priorities and respond to the risks, hazards and
vulnerabilities they face.

\section{Inclusiveness}

For adaptation planning to adequately reflect existing and forthcoming risks and vulnerabilities and to effectively enhance ownership for eventual implementation, engagement of all relevant stakeholders, including local communities and the private sector, as well as gender considerations are paramount.

\section{Implementability}

Planning can be assumed to be effective if it leads to actual implementation by public and private actors. Therefore, planning can benefit from putting in place a central administration body officially in charge of adaptation policymaking, dedicated resources - particularly finance - and a variety of policy instruments, including incentives or regulations, to lead to the desired outcomes.
Indicators

- Identified adaptation options address assessed risks, impacts, hazards or vulnerabilities
- Dedicated stakeholder engagement process in place

- Consideration of gender

\section{Integration}

Integrating or mainstreaming adaptation planning and action horizontally (across sectors) and vertically (across levels of administration) is increasingly recognized as an important component of effective adaptation planning. Such efforts help ensure that adaptation planning is comprehensive, avoids duplication of efforts or maladaptation and enhances synergies.

\section{Monitoring and evaluation}

To allow for planning to remain adequate and effective, it needs to be monitored, reviewed, evaluated and revised periodically.

Presence of:

- A central administration body

- Direct investments

- Regulations

- Incentives
- Sectoral and subnational coordination mechanisms in place
- Monitoring and evaluation system in place

- Monitoring undertaken

- Evaluation planned/undertaken 


\subsection{Methodology}

Taking into consideration existing assessments of adaptation planning, as well as the provisions of the Paris Agreement, including the objectives of the Global Stocktake, this chapter assesses collective progress on adaptation planning, both quantitatively and qualitatively. It examines the overall number of national adaptation strategies, plans and laws, as well as the number of subnational and sectoral adaptation plans and strategies.
'No', 'Progress/partial' or 'Unknown'), which prevents any nuance or direct comparability between countries. Results are provided in percentage of countries and, given their particular vulnerability to climate change impacts and status under the UNFCCC and Paris Agreement, disaggregated for least developed countries (LDCs) and small island developing states (SIDS). To complement the indicator-based assessments, case studies are included in this chapter to illustrate how some countries are fulfilling the criteria in practice.

As there is currently no consensus on methods for assessing the extent to which adaptation planning is adequate (sufficient) and effective (successful) in achieving its targets and objectives, this chapter explores these dimensions indirectly by analysing key variables (criteria) that can reasonably be expected to contribute towards them: inclusiveness, implementability, integration and monitoring and evaluation (see table 3.1)

The criteria and associated indicators were chosen as they correspond to the commitments the Parties made under the Paris Agreement (art. 7, paras 5 and 9). They have also been included in relevant global guidance documents on adaptation planning ${ }^{2}$ or previous global or regional assessments of adaptation planning. ${ }^{3}$

The analysis considered 20 national adaptation plans (NAPs ${ }^{4}$ ) and 139 nationally determined contributions (NDCs) with adaptation components ${ }^{5}$ of developing countries and 42 Seventh National Communications ${ }^{6}$ of developed countries. If none of the abovementioned documents were available for a country, earlier National Communications were consulted. Data were also drawn from, cross-checked with and complemented by the Climate Change Laws of the World database, managed by the Grantham Research Institute on Climate Change and the Environment and the Sabin Center for Climate Change Law. ${ }^{7}$ Data limitations include the lack of rigorous standards regarding the accuracy and the comprehensiveness of reporting by countries. Furthermore, the criteria are output-based and do not facilitate the measurement of the actual outcomes or impacts of countries' adaptation planning.

Finally, in order to include as many countries as possible and account for the diverse quantity and quality of information, all indicators have simplistic scores ('Yes',

Box 3.1. Integrating gender considerations in Kiribati's adaptation planning

Countries have taken different approaches to integrating gender considerations into their adaptation planning, many of which rely on sex-disaggregated data. Kiribati's Joint Implementation Plan for Climate Change and Disaster Risk Management 2019-2028 is intended to serve as an implementation tool for climate change and disaster risk management-related policies. According to the plan, programmes, projects and activities to be developed should take into consideration the differences between and among women and men in terms of needs and capacities. Programmes should generate sex-disaggregated data to help ensure equitable access to financial resources and other benefits (for example, technologies and services, climate information and capacitybuilding on climate risk management) for women and men resulting from investments in adaptation. The plan also foresees the monitoring of the differentiated impacts of climate adaptation actions on women and men. In addition, gender balance in participation and influence in decision-making is sought.

Source: Kiribati, Secretariat of the Pacific Community 2019

2 For example, the 2012 Least Developed Countries Expert Group (LEG) technical guidelines for the NAP process (LEG 2012), the 2015 LEG progress, effectiveness and gaps monitoring and evaluation (PEG M\&E) tool (LEG 2015) and the 2016 guidance note on vertical integration in NAP processes (Dazé, Price-Kelly and Rass 2016).

3 For example, the 2018 European Commission assessment of the European Union Strategy on adaptation to climate change (European Commission 2018a) and the 2019 Grantham Research Institute on Climate Change and the Environment and Centre for Climate Change Economics and Policy global review of national laws and policies on climate change adaptation (Nachmany, Byrnes and Surminksi 2019).

4 NAPs can be consulted here: https://www4.unfccc.int/sites/NAPC/News/Pages/national_adaptation_plans.aspx.

5 NDCs can be consulted here: https://www4.unfccc.int/sites/ndcstaging/Pages/Home.aspx.

6 Seventh National Communications can be consulted here: https://unfccc.int/NC7.

7 The database is available here: https://climate-laws.org. 
Figure 3.1. Status of adaptation planning worldwide

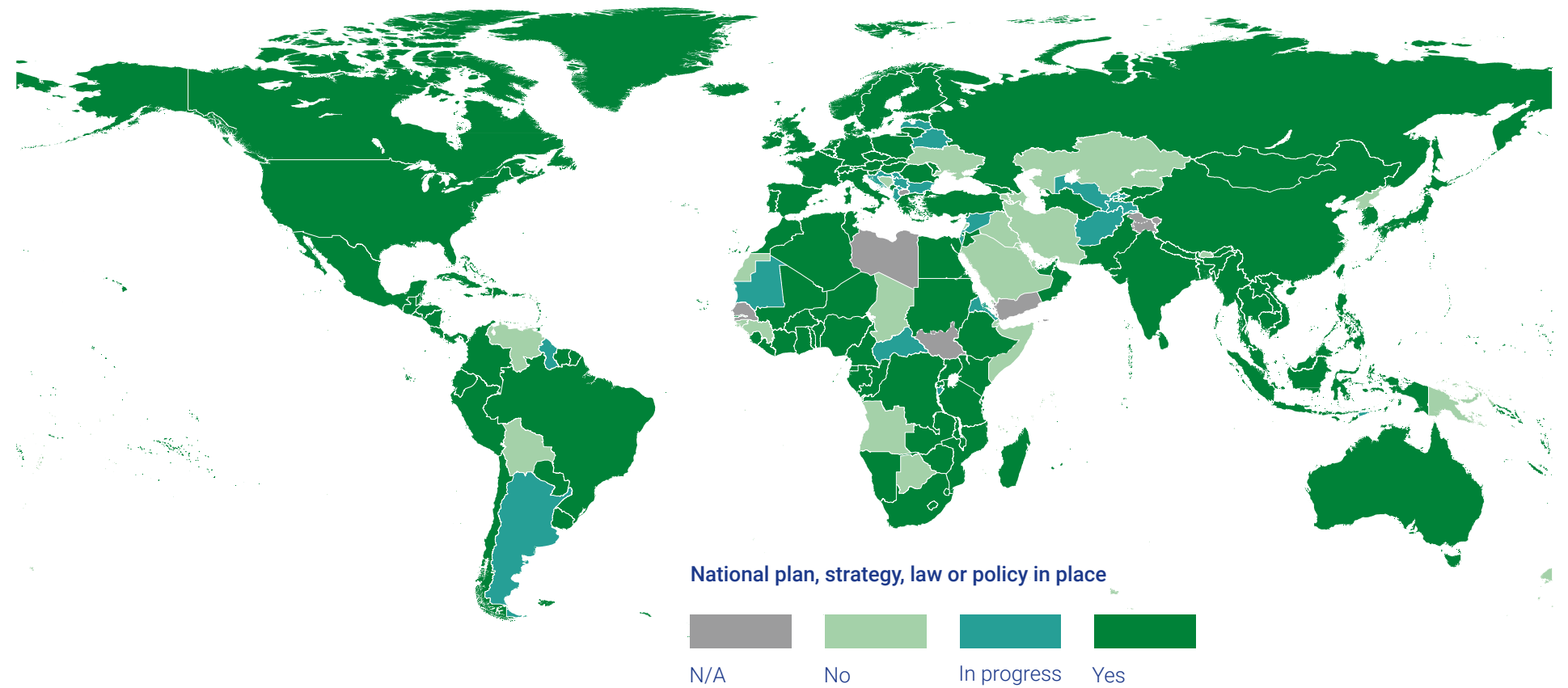

Figure 3.2. Progression of global adaptation planning since 2020

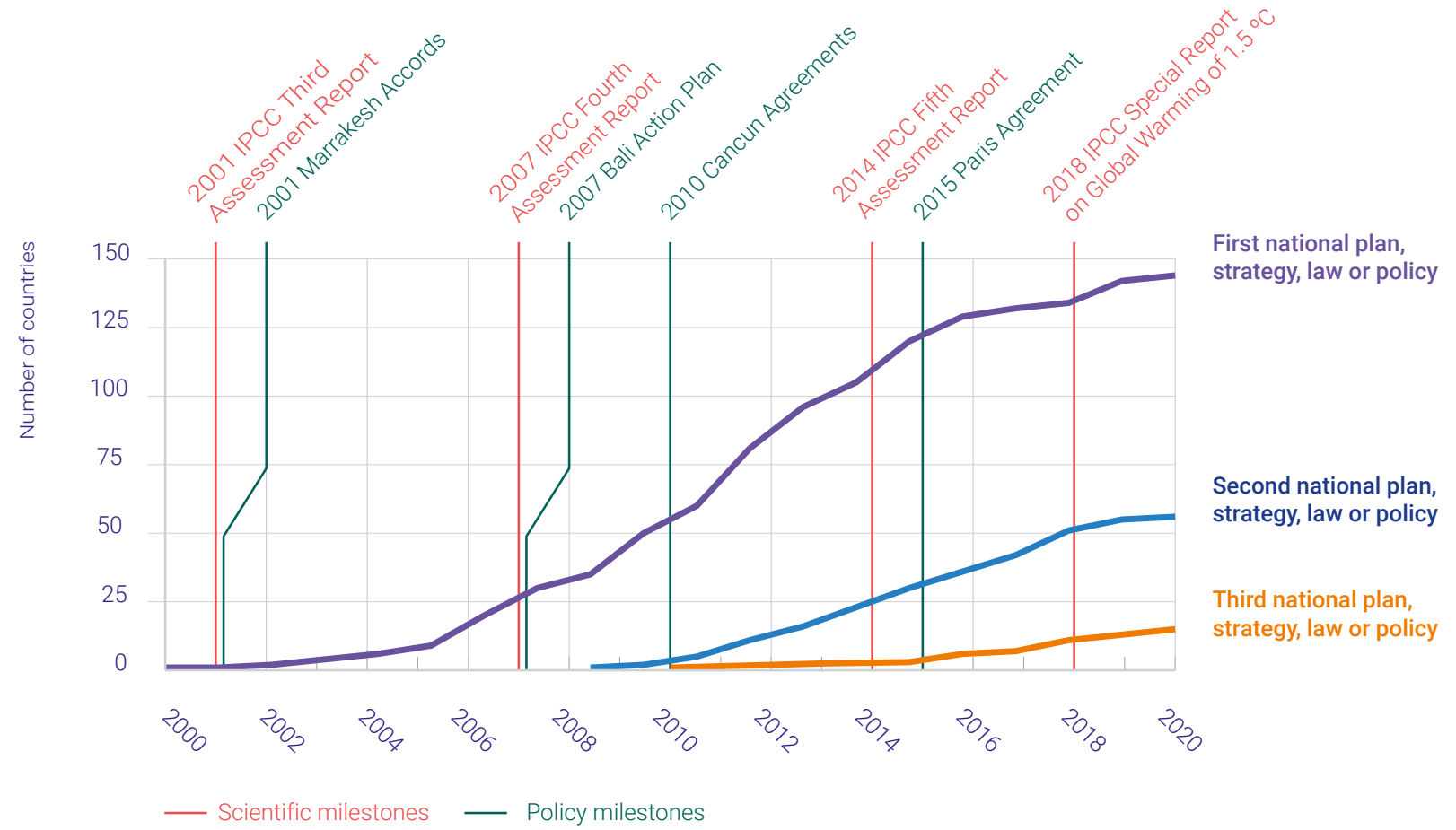


Figure 3.3. Assessing the adequacy and effectiveness of adaptation planning worldwide

Criteria for adequate and effective adaptation planning Number of countries

1. Comprehensiveness

1.1 Options address assessed risks

\section{Inclusiveness}

2.1 Stakeholder engagement

2.2 Dedicated process in place

2.3 Gender

3. Implementability

3.1 Central administration in charge

3.2 Regulatory instruments

3.3 Incentive-based instruments

3.4 Direct investment/funding

\begin{tabular}{l|l|l|l|} 
& & & \\
\hline 4. Integration & & & \\
\hline 4.1 Horizontal integration & & \\
\cline { 2 - 3 }
\end{tabular}

4.2 Vertical integration

5. Monitoring and evaluation

5.1 M\&E system in place

5.2 Monitoring undertaken

5.3 Evaluation planned/undertaken

\subsection{Progress on adaptation planning}

\subsubsection{Status of adaptation planning}

Most countries (72 per cent; 64 per cent of LDCs, 80 per cent of SIDS) address adaptation at the national level through a plan, strategy, policy or law, and several countries ( 9 per cent; 11 per cent of LDCs, 5 per cent of SIDS) that do not currently have such an instrument in place at the national level are in the process of developing one (see figure 3.1). ${ }^{8}$ These instruments vary in scope and primary focus, with some focusing explicitly on adaptation measures and plans and some outlining a general approach to climate change that includes adaptation. The NAP process is one key mechanism to increase the focus on adaptation, with 125 developing countries having initiated and launched the process to formulate and implement NAPs as at 20 November 2020, 20 of which have already been submitted (UNFCCC 2020b).

These figures represent significant progress in national adaptation planning over the past two decades, during which the number of adaptation instruments in place at the national level has significantly increased (see figure 3.2).

While a small number of countries introduced national-level disaster risk management instruments in the twentieth century that, to some extent, facilitated adaptation, national adaptation planning began in earnest in the early twenty-first century. Indeed, the first national-level adaptation instrument identified in this analysis was established in the year 2000. Of the 72 per cent of countries identified as having a national-level adaptation

8 For the purposes of this analysis, this includes national plans, strategies, policies or laws that were explicitly and primarily focused on adaptation, or more broadly, on climate change. Other plans, strategies, policies or laws that were not primarily focused on these areas but that are nonetheless relevant for adaptation - such as national development plans, national environmental policies and national disaster risk management strategies were therefore noted, but not included in this overall tally. National adaptation programmes of action were also considered separately from the overall tally due to their unique role as a tool for LDCs to identify and act on urgent priority adaptation activities, rather than an instrument to facilitate an overarching or holistic adaptation response. 
planning instrument in place, 5 per cent ( 6 per cent of LDCs, 13 per cent of SIDS) introduced their first instrument from 20002005, 30 per cent (32 per cent of LDCs, 31 per cent of SIDS) from 2006-2010, 49 per cent (39 per cent of LDCs, 41 per cent of SIDS) from 2011-2015, and 16 per cent (23 per cent of LDCs, 16 per cent of SIDS) from 2016-2020. Moreover, of these 72 per cent of countries, 29 per cent ( 29 per cent of LDCs, 38 per cent of SIDS) have developed at least one additional national-level instrument, which serves to replace, update, or complement the initial adaptation plan, policy, strategy or law.

In addition to national plans, 58 per cent of countries ( 57 per cent of LDCs, 55 per cent of SIDS) have one or more standalone sectoral plans in place that address climate change adaptation, while at least 6 per cent of countries (9 per cent of LDCs, 5 per cent of SIDS) are developing such plans. While these figures are limited to standalone plans, in many cases, countries have also embedded sectoral plans within overarching national-level plans. Furthermore, 21 per cent of countries (11 per cent of LDCs, 0 per cent of SIDS) mention that there are one or more subnational plans in place, and an additional 9 per cent of countries (4 per cent of LDCs, 5 per cent of SIDS) noted that such plans are in progress. These figures likely underestimate the true number of subnational plans, as in some cases the development of such plans is linked with membership of international initiatives (for example, the C40 Cities Climate Leadership Group) rather than being part of a national process.

\subsubsection{Adequacy and effectiveness of adaptation planning}

Though most countries already have a national-level policy or planning instrument dealing with adaptation in place, this alone does not necessarily translate into achieving adaptation targets and objectives. This section attempts a partial and indirect assessment of the degree of achievement by evaluating countries against five key criteria and 13 corresponding indicators that can be expected to contribute to the outcomes of adaptation in terms of adequacy and effectiveness (see figure 3.3).

\section{Comprehensiveness}

Available reporting indicates that about 59 per cent of countries (62 per cent of LDCs, 75 per cent of SIDS) identified a set of adaptation options within their identified priority sectors while 22 per cent (21 per cent of LDCs, 22 per cent of SIDS) have adaptation measures that partially matched their identified priority sectors. ${ }^{9}$ This might be due to lack of data, multi-causality, and the considerable degree of uncertainty associated with climate projections. A total of 15 per cent of countries (2 per cent of LDCs, 0 per cent of SIDS) either did not address adaptation options linked to key priorities within their assessments or did not address any at all in the documents reviewed. Information was unavailable for the remaining portion of countries, but this does not mean that this type of assessment was not carried out in those countries.

\section{Box 3.2. Direct investments as part of Denmark's adaptation planning}

Countries can facilitate the implementation of their adaptation plans by clearly identifying and/or allocating financial resources to support their plans. For example, Denmark's National Adaptation Strategy outlined several funding initiatives, including for technology development and demonstration; investments in wastewater; and for an innovation fund for the development and market preparation of new generic climate adaptation solutions for export. Furthermore, the 2018 budget allocated resources to support municipalities and property owners to develop coastal protection as part of climate adaptation action between 2018-2021. While the Danish Ministry of Environment and Food granted municipalities DKK 34.4 million in 2016 to undertake climate proofing, local adaptation projects dealing with watercourses in cities and by roads are most often financed directly by the water utility companies and municipalities.

Source: European Commission 2018b

\section{Inclusiveness}

More than half of the countries (58 per cent; 49 per cent of LDCs, 55 per cent of SIDS) have developed their adaptation plans through consultations with a broad range of stakeholders. The stakeholders involved included different levels of government, nongovernmental and sectoral organizations, research institutes and the private sector. Among these, 43 per cent of countries (36 per cent of LDCs, 59 per cent of SIDS) outlined the details of their stakeholder consultation process, by outlining the key stakeholders for each sector of interest and/or designating a body (most frequently the Department of the Environment) to continuously involve all relevant stakeholders in the process of assessing vulnerabilities, developing plans, and/or implementing adaptation measures and policies.

Additionally, several countries (52 per cent; 74 per cent of LDCs, 65 per cent of SIDS) highlighted the importance of integrating gender considerations into adaptation planning. It must be noted, however, that these figures may be nuanced by differing approaches to reflecting the extent of their inclusion of stakeholder participation and gender consideration in their adaptation planning (see box 3.1 for an example of one approach). 


\section{Implementability}

Only 35 per cent of countries (32 per cent of LDCs, 18 per cent of SIDS) report having put in place a central administrative body to oversee adaptation policymaking and implementation, with 61 per cent (62 per cent of LDCs, 82 per cent of SIDS) not having done so. Most countries have instead built institutional frameworks with different bodies holding primary responsibility for adaptation policymaking or implementation in different domains.

One-third of the countries (31 per cent; 36 per cent of LDCs, 35 per cent of SIDS) have set aside financial resources to support their identified adaptation options, including through direct funding or budget allocations (see box 3.2 for an example). While many developing countries have quantified the costs of their adaptation options and are investing significant domestic resources in adaptation, they lack sufficient resources to meet these costs and highlight the need to receive international support in the form of finance, technology transfer and capacity-building (UNFCCC 2019).

Finally, only one-quarter of the countries (28 per cent; 23 per cent of LDCs, 30 per cent of SIDS) currently make use of regulatory instruments such as standards and obligations, building codes, zoning and spatial planning and disclosure obligations, and even fewer (8 per cent; 4 per cent of LDCs, 5 per cent of SIDS) include incentives such as taxes or subsidies to encourage adaptation action. Employing these various policy instruments helps create an enabling environment for different actors to engage in adaptation planning and action.

\section{Integration}

According to the documents reviewed, 68 per cent of countries (72 per cent of LDCs, 65 per cent of SIDS) have horizontal coordination mechanisms in place (see box 3.3 for an example) and at least 4 per cent ( 0 per cent of LDCs, 5 per cent of SIDS) are in the process of establishing a horizontal coordination mechanism. Additionally, 26 per cent (23 per cent of LDCs, 10 per cent of SIDS) have vertical coordination mechanisms - such as a national committee, working group, or other body related to adaptation that includes representatives from different levels of governance - in place and at least 8 per cent ( 2 per cent of LDCs, 5 per cent of SIDS) are in the process of establishing vertical coordination mechanisms. Even among those with coordination mechanisms in place, several countries have noted that this area must be strengthened and highlight this as a priority going forward

\section{Monitoring and evaluation}

According to the documents reviewed, 33 per cent of countries (30 per cent of LDCs, 22.5 per cent of SIDS) have put in place dedicated monitoring and evaluation systems for adaptation (see box 3.4 for an example) and a further 11 per cent (13 per cent of LDCs, 10 per cent of SIDS) are in the process of developing them. A total of 34 per cent of countries (30 per cent of LDCs, 22.5 per cent of SIDS) are monitoring their adaptation efforts to varying degrees while 31 per cent of countries (28 per cent of LDCs, 25 per cent of SIDS) are planning to undertake or have already undertaken an evaluation of their adaptation plans, with a few having already revised their plans. Many countries highlight the lack of financial, human and technical resources and capacities that hinders the development and use of effective monitoring and evaluation systems.

\section{Conclusion and outlook}

Since 2000, countries have made significant progress in establishing adaptation plans at the national level, and some progress at the sectoral and subnational levels. Whether these plans are adequate and effective in moving countries towards their adaptation objectives remains to be seen. This uncertainty is partially due to this chapter's methodology, which aimed to provide a broad analysis of 196 countries, rather than an in-depth analysis of the few countries for which sufficient data are available. Accordingly, this chapter sheds some light on the current limitations of global assessments of adaptation progress, particularly in relation to the concepts of adequacy and effectiveness, for which there remains no consensus around an appropriate assessment methodology. As countries are preparing their adaptation communications and biannual transparency reports under the Paris Agreement following common guidance, more consistent data will allow for more nuanced analyses in the future and, in turn, more insights into global progress on adaptation planning

\section{Box 3.3. Horizontal integration in Saint Lucia's adaptation planning}

Saint Lucia's NAP is a good example of a systematic and detailed approach to horizontal integration. It highlights 40 cross-sectoral and 271 sectoral adaptation measures across eight key sectors: tourism, water, agriculture, fisheries, infrastructure and spatial planning, natural resource management, education and health. The NAP is complemented by sectoral adaptation strategies and action plans (SASAPS). The overarching NAP presents broad sectoral plans of action while the government works to secure funding to develop the more detailed SASAPS, which are intended to serve as the blueprints for sectoral adaptation. While the country is prioritizing these sectors at the outset, it will continue to identify other key sectors, as well as corresponding adaptation measures, through a cyclical, iterative NAP process.

Source: Saint Lucia, Department of Sustainable Development 2018 
Box 3.4. Monitoring, review and evaluation in Germany's adaptation planning

A well-designed monitoring and evaluation framework is informative and linked to planning processes. In this spirit, Germany established a national-level monitoring and evaluation process for the German Strategy for Adaptation to Climate Change (DAS) to assess whether the strategy's instruments and measures move the country towards achieving its goal of reducing "vulnerability and the maintenance and improvement of the adaptability of natural, societal and economic systems to the unavoidable impacts of global climate change." The monitoring and evaluation system consists of three parts:

1. A monitoring system comprising 102 indicators organized across the 15 action fields of the DAS. Notably, the system makes provisions for cases where data are unavailable or of insufficient quality, allowing case studies or proxy indicators to be used instead until the required data become available.
2. A national vulnerability assessment that is conducted every seven years to monitor changes in vulnerability over time. It has been developed in close collaboration with stakeholders and academia and is based on sectoral impact chains.

3. An evaluation report that is published every five years to inform the process of updating the Adaptation Action Plan. The evaluation is based on additional information about experiences and progress made, considering qualitative information and stakeholder feedback beyond the indicators themselves.

The combination of these three parts provides for a well-informed review of the Adaptation Action Plan every five years.

Sources: Umweltbundesamt 2015; 2020

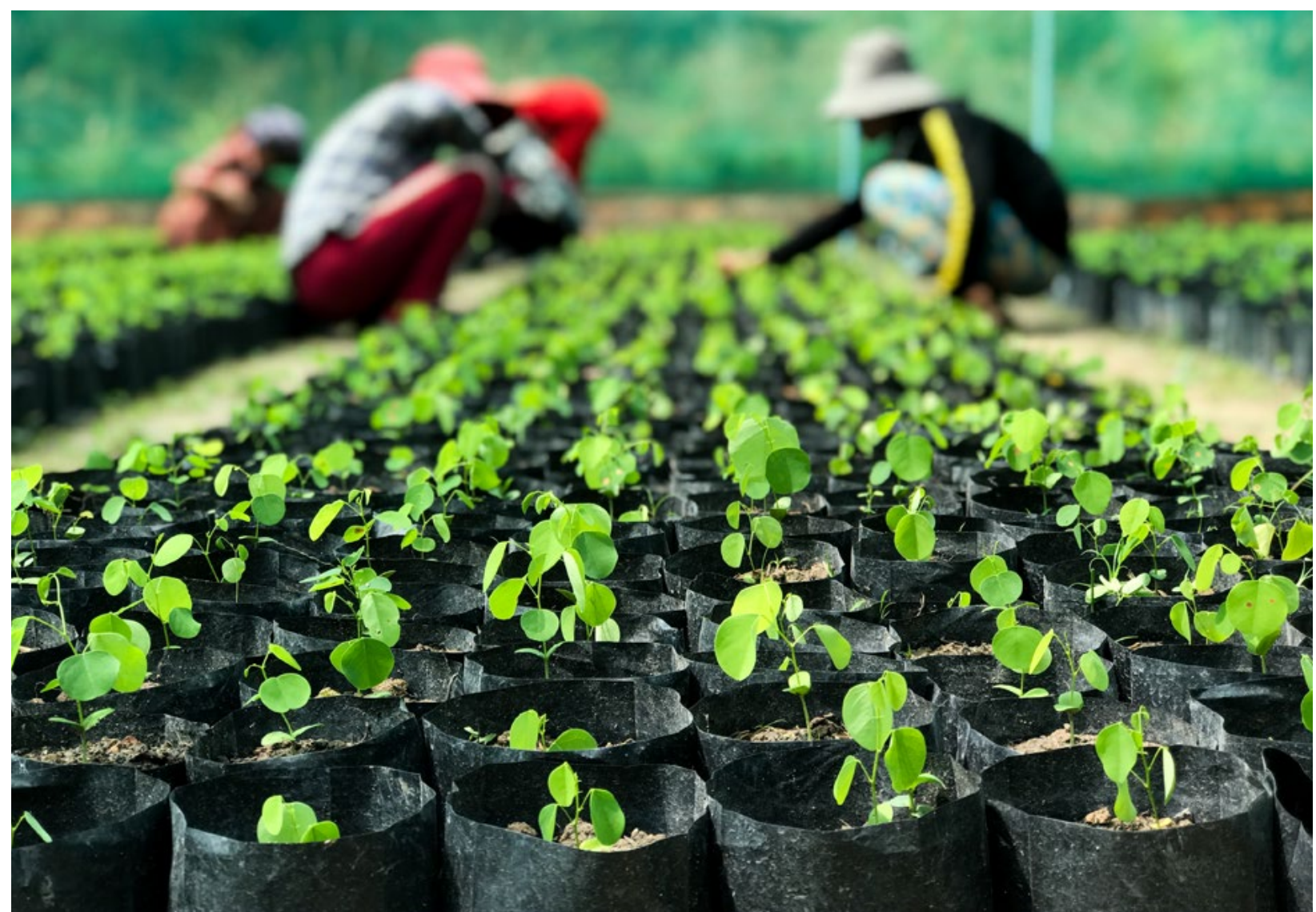




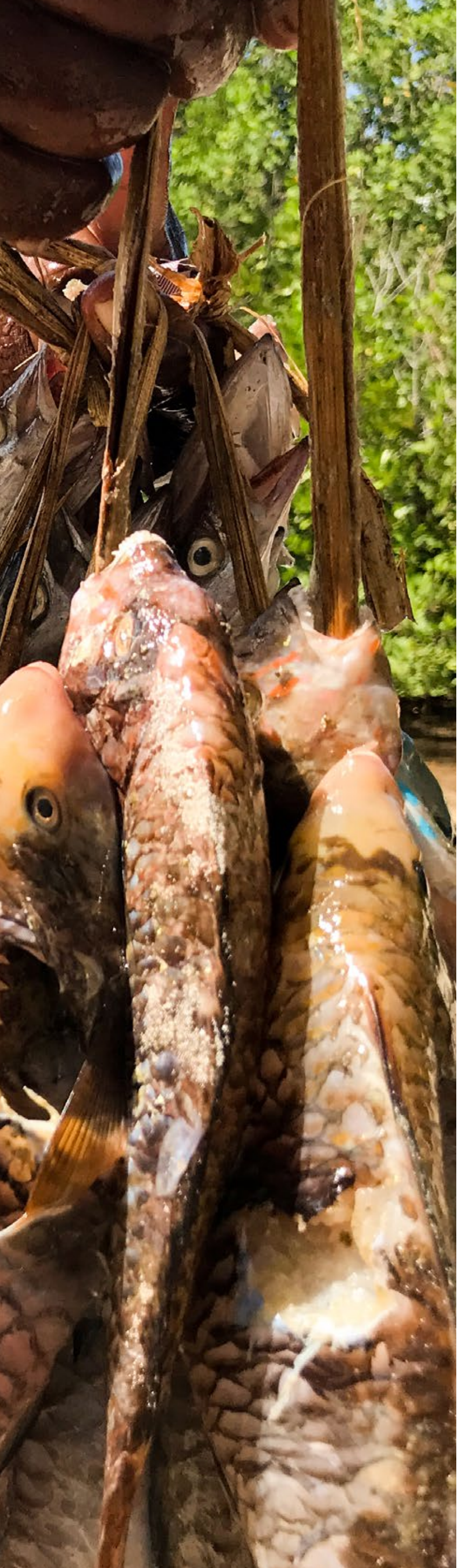

\section{Chapter 4}

Global progress on financing for adaptation

Lead Authors: Pieter Pauw (Frankfurt School of Finance \& Management), Romain Weikmans (Université Libre de Bruxelles), Charlene Watson (Overseas Development Institute), Henriette Jahns (Frankfurt School of Finance \& Management), Martin Prowse (Independent Evaluation Office of the Green Climate Fund), Adriana Quevedo (Overseas Development Institute), Jyotsna Puri (International Fund for Agricultural Development).

Photo: @ UNEP 


\section{Key messages}

- International public adaptation finance is slowly increasing. There is not enough data to identify such a trend in domestic public or private finance flows. There is insufficient evidence, however, that this increase over time is narrowing the distance to meet the increasing adaptation costs.

- A closer look at international public adaptation finance flows shows that multilateral support for adaptation increased significantly between 2013 and 2017 to 14.6 per cent of overall multilateral development finance. In contrast, over the same period, bilateral adaptation support as a share of overall bilateral development finance has only increased slowly, from 4.6 per cent to 6.1 per cent (see Organisation for Economic Co-operation and Development [OECD] 2019a).

- Efforts are being made to expand the instruments, actors and approaches through which adaptation finance is delivered. The role of public adaptation finance in catalysing private adaptation finance is increasingly being tested as it takes on the upfront risks of investments. New solutions and financial instruments such as insurance and results-based finance are being tested.

- New impetus for adaptation may be provided by the increasing momentum to ensure a sustainable financial system. This momentum is underpinned by growing recognition that both material physical risks and the risks introduced as we shift to a climate-resilient economy impact company returns, asset values and, ultimately, financial stability. New tools should be used to identify and factor in these risks in investment decision-making and financial stability monitoring.

\subsection{Financing of adaptation - introduction}

In the Copenhagen Accord in 2009, developed countries pledged to mobilize US\$100 billion annually by 2020 to support developing countries with mitigation and adaptation. In Paris in 2015, this goal was reiterated, and countries agreed to set a new collective quantified goal prior to 2025, using the US\$100 billion as a floor. Has the US\$100 billion goal been met? At this stage, that question seems impossible to answer. Developed countries are not required to report their climate finance data for 2020 to the United Nations Framework Convention on Climate Change (UNFCCC) before January 2022. In addition, there has been intense debate on what should count towards this US\$100 billion goal (Bodnar, Brown and Nakhooda 2015; Weikmans and Roberts 2019).

A critical part of the discussion on the US\$100 billion goal concerns the role of public and mobilized private finance in meeting the goal. Adaptation is often most needed in non-market sectors or is focused on public goods that benefit many stakeholders (United Nations Environment Programme [UNEP] 2018), which makes it challenging to mobilize private finance. Public finance can address this by strengthening the capacities of various stakeholders, covering incremental costs of adaptation, creating incentives for institutions and investors (for example, by addressing market imperfections), and by taking on risks that would otherwise disincentivize private flows of adaptation finance. Private finance for adaptation, however, also remains essential, given the nature, scale and related costs of adaptation.

The UNEP 2016 Adaptation Gap Report concluded that annual costs of adaptation in developing countries could range from US\$140 billion to US\$300 billion annually by 2030 and rise from US\$280 billion to US\$500 billion by 2050 . Adaptation costs are higher for high-income countries in absolute dollar value, but costs are higher relative to gross domestic product for low-income countries. ${ }^{1}$ High levels of global mitigation action would put the world in a relatively low-risk (RCP2.6) scenario and may reduce adaptation costs by 75 per cent compared with a high-risk scenario (RCP8.5) (Chapagain et al. 2020). It is also important to note that the benefits of investing in adaptation often outweigh the costs. For example, the Global Commission on Adaptation (2019) estimated that a US\$1.8 trillion investment in the areas of early warning systems, climate-resilient infrastructure, improved dryland agriculture, global mangrove protection, and resilient water resources could generate US\$7.1 trillion of benefits. These benefits mostly concern avoided costs, and include non-monetary social and environmental benefits. Significant scaling up and incentivizing for both public and private finance is required to cover adaptation costs and benefits.

1 Low-income countries and high-income countries according to the World Bank List of Economies 2019. 
Many different challenges complicate the estimation of both adaptation costs and adaptation finance (figure 4.1 and annex 1 [online] and annex 2 [online]). These challenges make it hard to quantify the gap between adaptation costs and adaptation finance (see also Pauw et al. 2020 for an assessment of adaptation costs and adaptation finance needs in nationally determined contributions [NDCs]). Nevertheless, available estimates of adaptation costs (for example, UNEP 2016; Chapagain et al. 2020) and adaptation finance (for example, OECD 2019a; Climate Funds Update [CFU] 2020) tend to show that a major adaptation finance gap remains in quantitative terms. Nonetheless, it is important to measure and monitor adaptation finance needs and progress in finance provision. It can foster better understanding of the alignment of adaptation investments with country priorities and it will help gauge the accountability of developed countries given their commitments under the UNFCCC to provide adaptation finance. Together, these can lead to increased ambition and effectiveness of support for adaptation.

In addition to climate finance under the UNFCCC, and to domestic public and private financing of adaptation within countries, this chapter also discusses how sustainable finance efforts can contribute to adaptation. Section 4.3 elaborates on this 'new consideration' on financing for adaptation.

\subsection{Financing adaptation - status and progress in adaptation finance flows}

This section considers the main channels of adaptation finance and how they have evolved over time. Our understanding of the status of adaptation finance flows is heavily constrained by data availability. For the reasons detailed in annex 2 [online], tracked adaptation finance represents only a partial estimate of current flows. Some international concessional public finance flows (predominantly official development assistance [ODA] flows from OECD Development Assistance Committee [OECD DAC] members) are well documented, as are several multilateral flows. However, much less data exist on domestic public sector finance and private sector investments in adaptation (UNEP 2018; UNFCCC Standing Committee on Finance [UNFCCC SCF] 2018; Weikmans and Roberts 2019; Pauw et al. 2016). Details on the specific data sources considered for the assessments in this chapter are included in the sections that follow.

Two other important considerations must be made when considering tracked adaptation finance. Firstly, the amount of funding for adaptation does not provide much information about efficient or effective use of these funds. To date, there are no universally agreed upon metrics to assess outcomes of adaptation finance or to measure the effectiveness of those funds, though many climate finance contributors continue to work on improving their results frameworks to this end. Secondly, there is no systematic tracking of public or private financial flows that could undermine adaptation objectives or lead to maladaptation. This recognizes that where climate risks are not factored into investment-decision-making, they could increase vulnerability to climate impacts of individuals, institutions and systems and therefore, should be concurrently assessed.

\subsubsection{Global climate-related finance}

According to Climate Policy Initiative's Global Landscape of Climate Finance 2019 (Climate Policy Initiative [CPI] 2019), total climate finance flows - including domestic and international, public and private flows - were estimated at US\$579 billion per year for 2017-2018. The overwhelming majority (US\$537 billion) of tracked finance went to mitigation, with US\$30 billion to adaptation and US\$12 billion to cross-cutting themes (ibid.). Water and wastewater management, land use and disaster risk management are the sectors that make up much of this tracked adaptation finance. Global finance flows for adaptation have increased by 35 per cent since 20152016. This constitutes 5 per cent of total tracked flows, a percentage that is similar to the 2015-2016 period. The majority of adaptation finance arises from public finance channels (ibid.). These global figures do not only concern flows to UNFCCC developing country Parties and care must be taken when comparing them with the US\$100 billion mobilization goal.

While there is a clear need to increase adaptation finance flows, it is also recognized that there are significant challenges in tracking adaptation finance. CPI reports that coverage of adaptation remains "very limited". This stems from definitional challenges, accounting issues, confidentiality restrictions, and a lack of universally accepted impact metrics (UNFCC 2018; UNEP 2016b; CPI 2019).

\subsubsection{Adaptation finance under the UNFCCC}

Under the UNFCCC, Annex II Parties ${ }^{2}$ are required to report on the climate finance that they provide to and mobilize in developing countries. They notably do so in the Biennial Reports that they submit to the UNFCCC secretariat. Annex II Parties use various methodologies to track adaptation finance (see annex 2 [online]) and in some cases, methodologies have changed over time, which, in turn, makes it very difficult to compare data over time (Weikmans and Roberts 2019). However, it is clear that the adaptation component of such self-reported finance under the UNFCCC is growing.

\section{Bilateral public flows}

Bilateral and regional flows reported to the UNFCCC by Annex II Parties are showing an increasing trend (see figure 4.2).

2 Under the UNFCCC, Annex I Parties include the industrialized countries that were members of the OECD in 1992, plus countries with economies in transition. Annex II Parties (considered here as developed countries) are those Annex I Parties obliged to provide support to non-Annex I (considered here as developing country) Parties. 
Figure 4.1. Challenges that complicate the estimation of both adaptation costs and adaptation finance, and why it is practically impossible to makes estimations match

\section{Estimated adaptation finance:}

Adaptation finance is used to implement adaptation actions and plans. It can come from different sources, incl. public and private sources, and international (e.g. development banks and funds) and domestic (government spending) sources. The lack of universally agreed modalities to account for international adaptation finance has given rise to multiple accounting practices.

The challenges listed below complicate the estimation of adaptation finance. These challenges are explained further in Annex 1 [online].
Improved accounting modalities could lead to

Could go in both directions

Improved accounting modalities could lead to lower finance estimates higher finance estimates

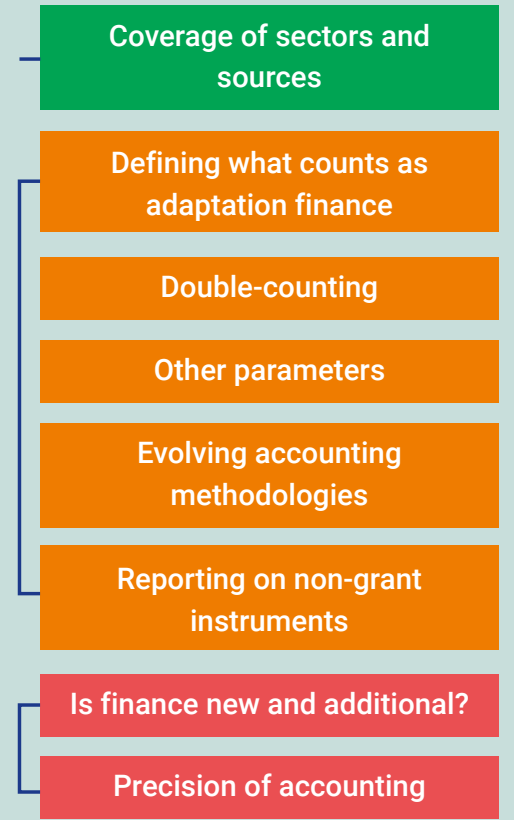

Precision of accounting
Estimated adaptation costs:

Global adaptation costs can be estimated through top-down or bottom-up studies. Top-down studies use models that relate total impacts with impact damages, often at the global level and on the basis of a sectoral breakdown of cost elements. Bottom-up studies calculate costs by adding up more detailed estimates of national or sectoral levels.

The challenges listed below complicate the estimation of adaptation costs. These challenges are explained further in Annex 2 [online].

\section{Consideration of soft and hard adaptation measures}

Co-benefits of adaptation

Could lead to lower costs than estimated

Learning, innovation and scaling up

Trade-off costs mitigation, adaptation and residual impacts

Omission of autonomous

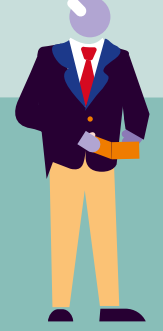

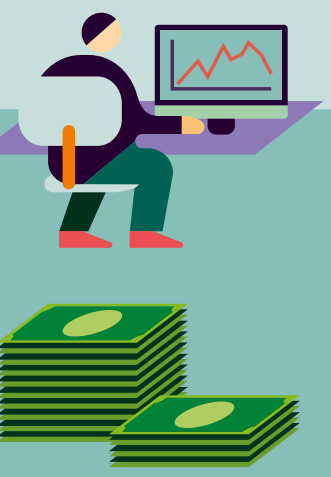

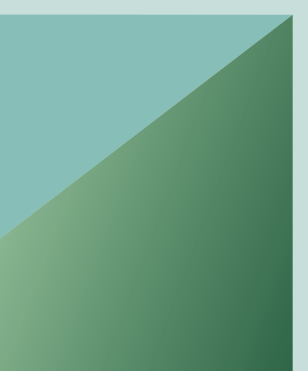
adaptation

Socio-economic development

Integrating positive impacts of climate change

Incomplete coverage of sectors and risks

Unforeseen indirect climate effects

Underestimated implementation
Could lead to higher costs than estimated
Could go in both directions

\section{costs}

Addressing current adaptation deficit

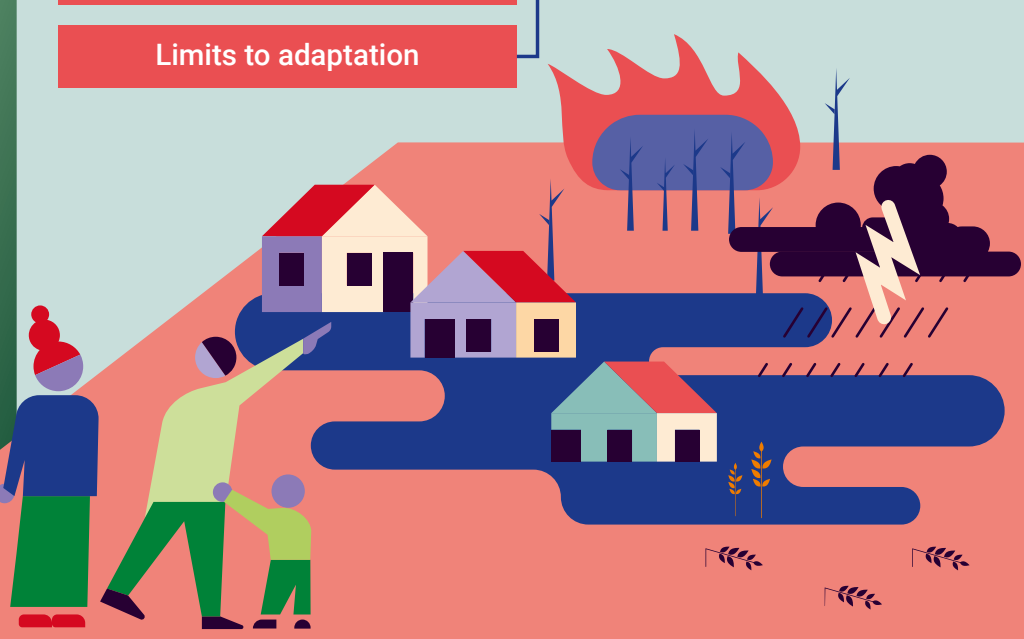


Figure 4.2. Adaptation-related bilateral flows to developing countries

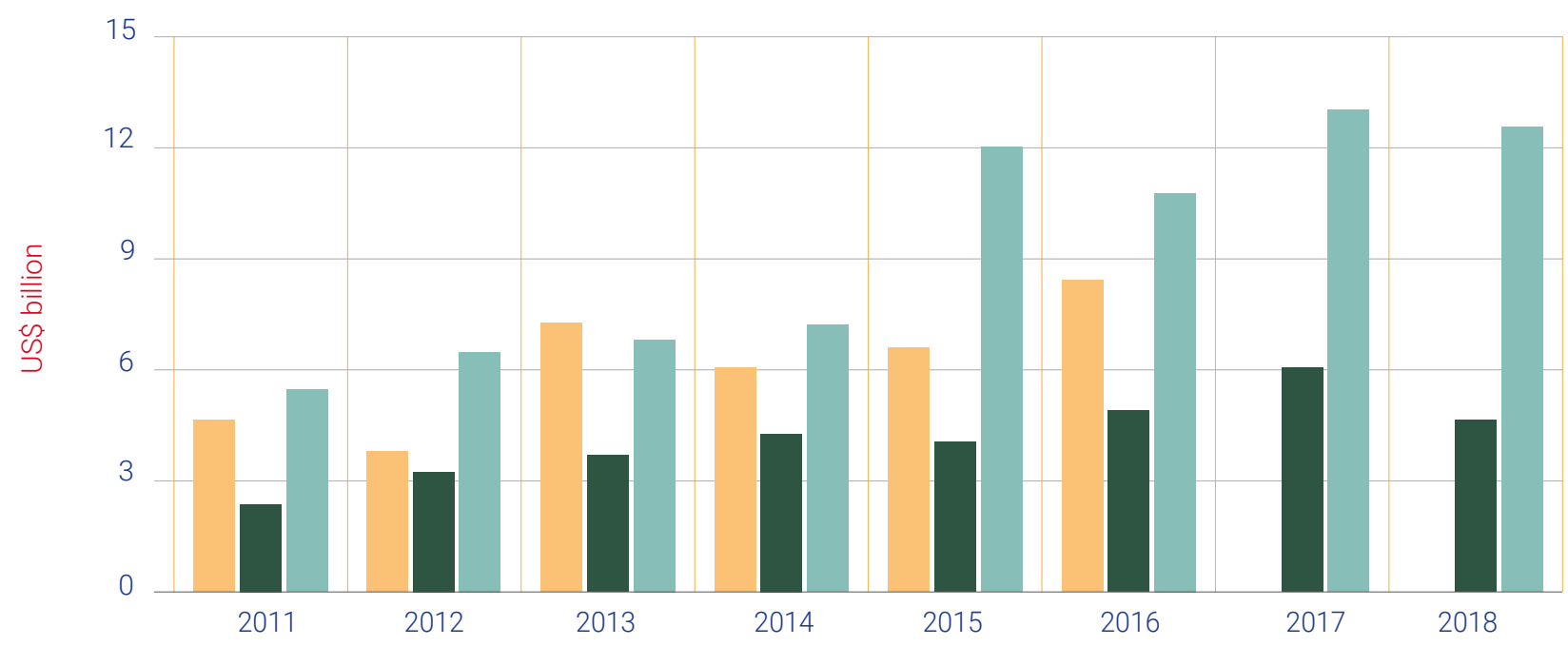

Adaptation-related ODA (Score: Significant) as reported to the OECD

Adaptation-related ODA (Score: Principal) as reported to the OECD

Adaptation finance as reported to the UNFCCC by Annex II Parties

Note: Data overlap and are not aggregable. Adaptation finance as reported to the UNFCCC includes bilateral, regional and other channels for adaptation and cross-cutting themes (commitments in current US\$). Data include both adaptation and cross-cutting finance (targeting adaptation and mitigation at the same time). Data for 2017 and 2018 are not yet available at the time of writing. Adaptation-related ODA data (commitments in 2018US\$) include an overlap between adaptation and mitigation. Data providers use different methods including definitions of adaptation finance, and have differing eligibility for funding (see annex 2 [online]).

Sources: Annex II Parties' Biennial Reports to the UNFCCC; information related to the United States is drawn from preliminary data provided to the UNFCCC SCF (2018); CFU 2020; OECD DAC 2020.

Data on bilateral provisions reported to the UNFCCC mainly rely on government tracking (through the OECD 'Rio markers' methodology) of ODA commitments that have adaptation objectives (see figure 4.2). This methodology was established to assess the degree to which the objectives of the Rio Conventions are mainstreamed into ODA, which also allows for cross-cutting analyses, for example, on the extent to which adaptation finance is gender-responsive (see box 4.1). The methodology is also increasingly being used as a basis for Annex II Parties' reporting on climate finance (Weikmans et al. 2017; OECD 2020a). To account for the fact that the Rio markers methodology was not originally designed to monitor financial pledges, most Annex II Parties 'scale down' the volume of finance associated with the Rio markers in their financial reporting to the UNFCCC. They do so by using 'coefficients' to differentiate between funding marked as targeting adaptation as a 'significant objective' - reflecting that these projects have other 'principal objectives' (such as biodiversity conservation or gender). These coefficients differ across Annex II Parties and range from zero to 100 per cent (OECD 2015; OECD 2019b; Oxfam 2020).
While bilateral adaptation-related ODA shows an upward trend in absolute terms, its share of overall ODA hardly increased, from 4.6 per cent in 2013 to 6.1 per cent in 2017. In 2018, 24 per cent of ODA with adaptation components were channelled to small island developing states (SIDS) and least developed countries (LDCs). In the same year, 78 per cent of ODA with adaptation components was delivered in the form of grants and 22 per cent in the form of concessional loans (OECD 2019a).

\section{Multilateral public flows}

It is relatively straightforward for Annex II Parties to report on contributions made to multilateral climate funds such as the Least Developed Countries Fund or the Adaptation Fund. However, despite some improvements in recent years, estimating the adaptation-specific share of core contributions made to multilateral institutions is much more complex, and sometimes impossible.

Figure 4.3 summarizes adaptation-related multilateral flows to developing countries. Upward trends are visible in absolute terms for multilateral banks, UNFCCC funds and adaptation finance as reported by Annex II Parties. ${ }^{3}$ Adaptation funding

3 Annex II Parties also report on core/general finance flows separately, that are committed to multilateral and bilateral institutions that Parties cannot identify as climate-specific, such as to MDBs. 
Figure 4.3 Adaptation-related multilateral flows to developing countries

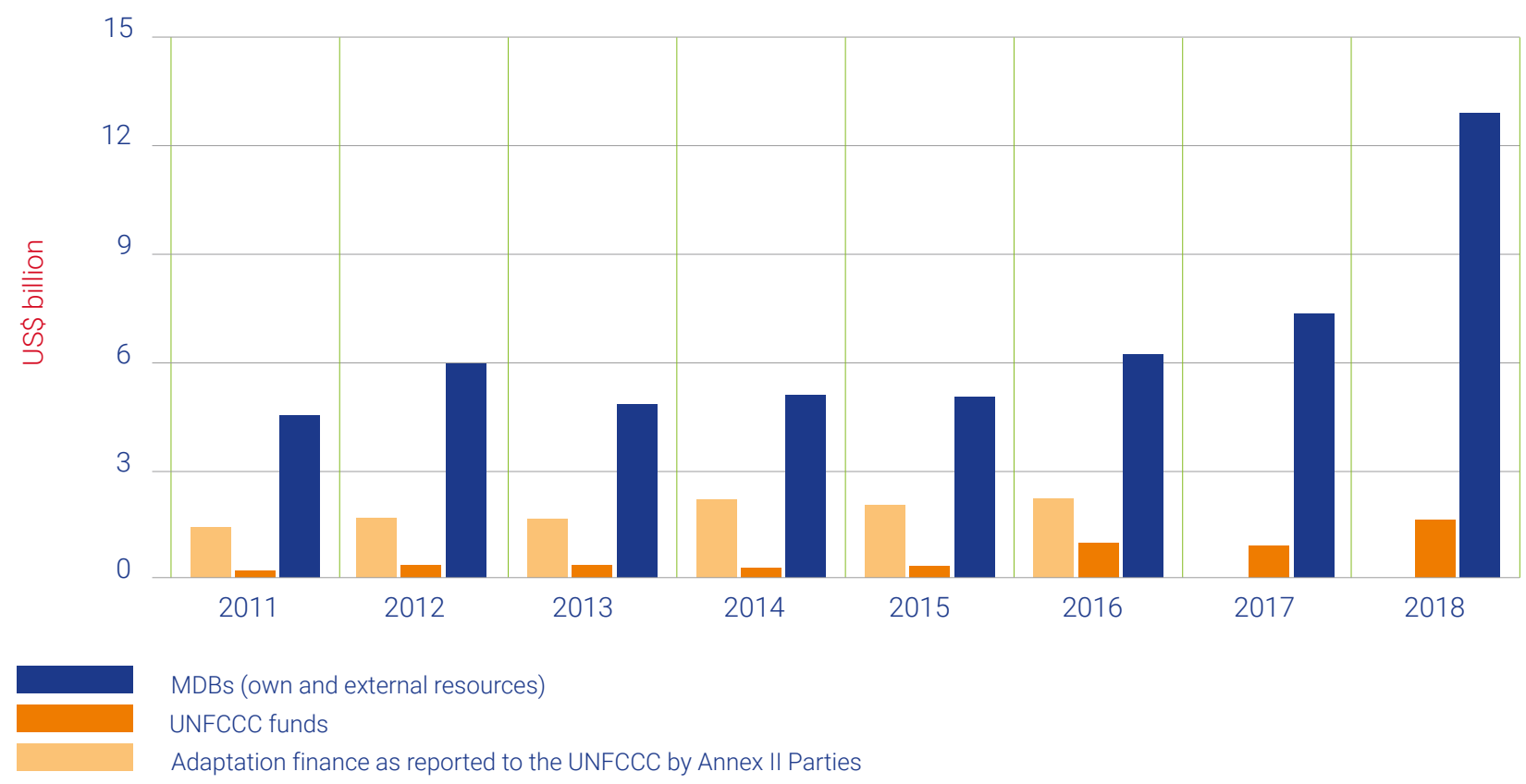

Note: All figures in current US\$. Data partly overlap and are not aggregable. Adaptation finance as reported to the UNFCCC includes multilateral channels for adaptation and cross-cutting themes, but excludes general core commitments including those to multilateral institutions that cannot be identified by Parties as climate-specific. Data for 2017 and 2018 is not yet available at the time of writing. Data include both adaptation and cross-cutting finance. Data providers use different methods including definitions of adaptation finance, and have differing eligibility for funding (see annex 2 [online]).

UNFCCC funds are the Adaptation Fund, the Global Environment Facility Trust Fund, the Green Climate Fund, the Least Developed Countries Fund and the Special Climate Change Fund. MDBs included in this data are the Asian Development Bank, the African Development Bank, the European Bank for Reconstruction and Development, the European Investment Bank, the Inter-American Development Bank Group and the World Bank Group.

Sources: Annex II Parties' Biennial Reports to the UNFCCC; information related to the United States is drawn from preliminary data provided to the UNFCCC SCF (2018); CFU 2020; MDBs (2013-2019).

channelled through the UNFCCC multilateral climate funds almost doubled between 2015-2016 and 2017-2018 to US\$1.25 billion per year (CFU 2020). Multilateral support for adaptation also increased significantly as a share of the overall multilateral development finance: from 8 per cent in 2013 to 14.6 per cent in 2017 (OECD 2019a).

Since 2012, data on multilateral public flows are supplied by a group of multilateral development banks (MDBs) that have developed their own tracking methodology (Multilateral Development Banks [MDB] 2019). Adaptation-related financial resources flowing through MDBs are on a strong upward trend and averaged US\$10.15 billion per year in 2017-2018. Support for adaptation as a share of overall MDB climate finance has risen from 20 per cent to 30 per cent between 2015 and 2018. In 2018, 20 per cent of adaptation-related MDB finance went to LDCs and SIDS. In the same year, 9 per cent of adaptationrelated MDB finance was delivered as grants and 72 per cent as concessional loans; 19 per cent were channelled through other financial instruments (such as non-concessional loans).

Alongside MDBs, a number of other development finance institutions (DFIs) are also relevant to adaptation action. The
International Development Finance Club (IDFC), a group of 23 regional and national DFIs, programmed US\$125 billion in climate finance in 2018, of which US\$15 billion was estimated to flow to adaptation (IDFC 2019). Financing volumes reported by these multilateral institutions cannot be directly compared with the adaptation-related multilateral flows reported by Annex II Parties as these institutions also receive contributions from non-Annex II Parties and do not only fund activities in developing countries.

\section{Private flows}

So far, few Annex II Parties have reported on private climate finance that they mobilize through their public interventions in their Biennial Reports. According to OECD (2020a), the majority of private finance mobilized by developed countries' public climate finance continues to benefit mitigation activities (95 per cent in 2016-2018 compared with 90 per cent in 2013-2014). However, OECD (2020a; 33) also notes that there is room for improvement in identifying adaptation-relevant activities within mobilized private finance datasets. While the MDBs track private finance mobilized by their interventions, they do not provide adaptation-specific data. Tracking of mobilized private adaptation finance is expected to remain challenging. 


\section{Box 4.1. Gender in adaptation finance}

The Biennial Reports submitted by Annex II Parties to the UNFCCC secretariat do not systematically include data on gender. However, 65 per cent of bilateral ODA from OECD DAC contributors marked as relevant to adaptation was also marked as supporting gender equality in the 2017-2018 period. Most of this adaptation-related finance has a significant objective for the gender marker, rather than a principal objective. Public finance that is gender-responsive is found to be more effective and efficient (World Bank 2012). For adaptation finance, this will entail projects and programmes taking into account the gender dynamics of, for example, food production. The Gender Action Plan of the UNFCCC approved at COP23 included the use of gender-responsive finance as a core tool for implementation (UNFCCC 2017). While a number of multilateral climate funds are increasingly considering gender considerations in their governance and implementation (Schalatek 2019), best practices on gender-budgeting have not yet been compiled or adopted and few funds are reporting gender-disaggregated results. Recent assessment of progress in implementing the gender mandates of multilateral climate funds highlight the need for more capacitybuilding support for implementing entities and strengthened guidance for monitoring and reporting (Adaptation Funding Board [AFB] 2019; CIF 2020).

\section{Domestic finance flows}

Domestic public finance data with climate relevance remains sparse, and it is not clear whether finance is increasing. The data that are currently available are largely based on case studies. For example, 2 per cent of the total annual budget was found to be climate-relevant in Ghana between 2014-2017, compared with 3 per cent in Antigua and Barbuda, 4 per cent in Bangladesh and Indonesia; 8 per cent in Kenya and Pakistan; and 31 per cent in Nepal. However, countries apply their own definitions and methods, and transparency around those is often low (Watson et al. 2020; UNDP 2019).

Nonetheless, there is growing recognition of the role that fiscal policy can play in building resilience to climate change. This includes taxes, price supports, revenue and expenditure measures, for example, that work to reduce, retain or transfer climate-related risks that build resilience to shocks (International Monetary Fund [IMF] 2019; World Bank 2019).

\subsection{New trends in the financing of adaptation}

\subsubsection{Adaptation finance modalities of bilateral and multilateral support are evolving}

Grant modalities are increasingly bolstered by a broader range of instruments, actors and approaches. While this trend is visible among many funds and funders, the Green Climate Fund (GCF)'s adaptation portfolio is used for illustrative purposes for two reasons. Firstly, the GCF is the world's largest dedicated multilateral climate fund. Secondly, its portfolio reflects recent project approaches: the GCF just completed its first funding period of 20162019 (its so-called 'Initial Resource Mobilisation' process) which allows for reflection and learning. By early 2020, the GCF had invested US\$2.228 billion in 93 adaptation projects and components in cross-cutting projects, representing 40 per cent of its total portfolio in nominal terms (and close to 50 per cent in grant equivalent terms). Increasingly, these investments have been made using non-grant instruments, predominantly senior loans (see box 4.2).

It is clear that multilateral institutions can play a strong role as catalytic agents, especially when they take a firstloss position that can help to crowd-in investments. Here we discuss a few examples.

The GCF acts as the anchor investor in Acumen's Resilient Agriculture Fund (ARAF, project FP078) which makes small investments (US\$1-3 million) in agriculture in East and West Africa. An initial technical assistance grant of US\$3 million from the GCF is accompanied by a US\$23 million junior equity stake. This investment has been matched by senior equity stakes from investors including a development bank, foreign direct investors, family offices and a philanthropic source. In turn, ARAF has invested in companies delivering: (i) solar irrigation bundled with bespoke meteorological and agronomic advice for smallholders; (ii) innovative contract farming schemes with strong forward linkages in processing; (iii) dairy farming through irrigation and a bundled range of goods and services. The GCF investment is for 12 years and the GCF expects to recover its investment following the return of capital and costs to senior equity holders.

Another approach combines improvements in hazard forecasting and early warning systems with refining how local communities, decision makers and actors prepare and plan for extreme events. An investment in the Philippines (GCF project SAP010) of US\$10 million combines an improved forecasting and warning system at the local level with the use of index-based triggers and standard operating procedures to support a shock-responsive social protection system. In contrast to traditional approaches, the use of forecast-based financing and action improves efficiency for those implementing interventions and reduces distress and indebtedness within beneficiary communities. 
Results-based financing 4 has also been used and the GCF has earmarked US\$500 million for this purpose. Although, to date, this has only been applied to United Nations 'reducing emissions from deforestation and forest degradation' (REDD+) projects, it is clear that this modality may be employed in many ways, especially for impact investing and yielding resilience-related benefits, as long as mechanisms for results verification are well established (see, for example, Puri et al. 2020).

In addition, it is important to bear in mind that funds that combine grant and non-grant instruments are able to stagger the finance to form more mutualistic public-private innovation 'ecosystems'. Overall, it is vital that private and public sector actors recognize resilience and wealth creation as a collective endeavour and sequence grant and nongrant instruments in a symbiotic fashion (see Mazzucato 2013). Therefore, evaluating mobilized private investments in adaptation based on their quantity alone would not be beneficial.

\section{Box 4.2. Evolution of financial instruments in the GCF adaptation portfolio}

By the end of 2017, the GCF had committed just under US\$1 billion to adaptation projects in grants yet only US\$54 million had been committed in senior loans. By March 2020 (after completion of the 'Initial Resource Mobilisation' period), a further US\$800 million in grants had been supplemented by US\$317 million in senior loans. As of August 2020, US\$3.73 billion in cofinance had been committed, mainly by national governments and MDBs. The co-financing ratio of the portfolio stood at 1.5. This ratio is much higher for non-grant instruments (at over 10) than for grants (0.7).

\subsubsection{Sustainable finance}

The creation of sustainable financial systems is increasingly recognized as a promising avenue for scaling up adaptation and monitoring of investments in adaptation. Sustainable finance can be defined in a narrow sense as taking "due account of environmental and social considerations in investment decision-making" (European Commission 2018). In a broader sense, sustainable financial 'systems' can be understood as "financing as well as related institutional and market arrangements that contribute to the achievement of strong, sustainable, balanced and inclusive growth, through supporting directly and indirectly the framework of the Sustainable Development Goals (SDGs)" (G20 Sustainable Finance Study Group 2018). A sustainable financial system is crucial to implement Article 2.1c of the Paris Agreement to make "finance flows consistent with a pathway towards low greenhouse gas emissions and climate-resilient development". It could support the scale-down of 'harmful' activities and reposition US\$ trillions to scale up finance that supports long-term low-carbon and climate-resilient development.

There is a growing understanding that both physical risks resulting from climate change and risks caused by transitioning to a low-carbon economy can have a negative impact on the stability of the financial system. This has led to a fast-evolving sustainable finance policy landscape. Alongside public sustainable finance policies and international initiatives supporting the establishment of a sustainable financial system, the private financial sector also takes part in initiatives towards alignment of the financial system with the Paris Agreement. This includes the 2019 'Collective Commitment to Climate Action' under the UNEP Finance Initiative's Principles for Responsible Banking and the 2019 Net-Zero Asset Owner Alliance of 33 institutional investors (representing nearly US\$5.1 trillion assets under management). Sustainable finance has the potential to significantly impact adaptation, both financially and in terms of engaging the private sector, in three different ways.

Firstly, sustainability taxonomies and standards establish criteria for "determining whether an economic activity qualifies as environmentally sustainable" (European Commission 2018). This can help identify and track finance flows - for example, those related to adaptation. Taxonomies can also serve as indicators, as they can be used to help determine targets or transition pathways for taxonomy-compliant shares of green activities across sectors. The European Union (EU) has recently established the 'EU taxonomy for sustainable activities', linked to six environmental objectives, including adaptation (EU 2020). Other approaches for defining sustainable or green investments are also in place in other regions, such as China (Climate Bonds Initiative [CBI] 2019).

Secondly, climate-related financial disclosure regulations across the financial system can increase transparency on the vulnerability of investments and assets to climate change impacts. Such disclosure was recommended by the Task Force on Climate-Related Financial Disclosure (TCFD) (2017) and support for it is growing (TCFD 2019). An implication of regulatory requirements for climaterelated disclosure could be that investments that are highly vulnerable to climate change impacts will become less attractive for investors, and the financial sector could take proactive measures to reward the financing of climateresilient activities with preferential financing conditions.

4 Results-based finance is defined as a programme where the principal [in this case, GCF] investor sets financial or other incentives for an agent [in this case, the accredited entity] to deliver predefined outputs or outcomes and rewards the achievement of these results upon verification (Musgrove 2011). 
Lastly, sustainable financial systems stimulate the mainstreaming of climate-related risk management beyond the financial system to real economy corporate clients. Improved climate risk management could therefore actively contribute to a more climate-resilient financial system and global economy. The Network for Greening the Financial System (NGFS) has recently concluded that it is "within the mandates of central banks and supervisors to ensure the financial system is resilient to these risks" (NGFS 2019).

Stringent climate disclosure and climate risk management requirements - based on solid taxonomies - across the financial sector can help to monitor finance flows that contribute to adaptation, and also have the potential to stimulate an increase in investments in climate resilience and direct finance away from investments that increase vulnerability. However, the scale and scope of the effects of sustainable finance regulation are not yet fully understood. Monitoring and impact assessment of sustainable finance measures are central to capitalizing on their potential. However, qualitative assessments and quantitative indicators are at an early stage of development, particularly those concerning adaptation. For example, there is initial comparative research on sustainability taxonomies across different geographies (OECD 2020b; International Platform on Sustainable Finance 2020). This research could be expanded to look into respective coverage of adaptation and disclosure requirements. Furthermore, ongoing research on climate risk integration into mainstreamed financial- sector risk management (NGFS 2020) could be expanded to look into the impacts on adaptation. Finally, the understanding of the link between sustainable finance and implementing Article 2.1c should be further researched to inform and support climate finance tracking. Future Adaptation Gap Reports should look into this in greater detail.

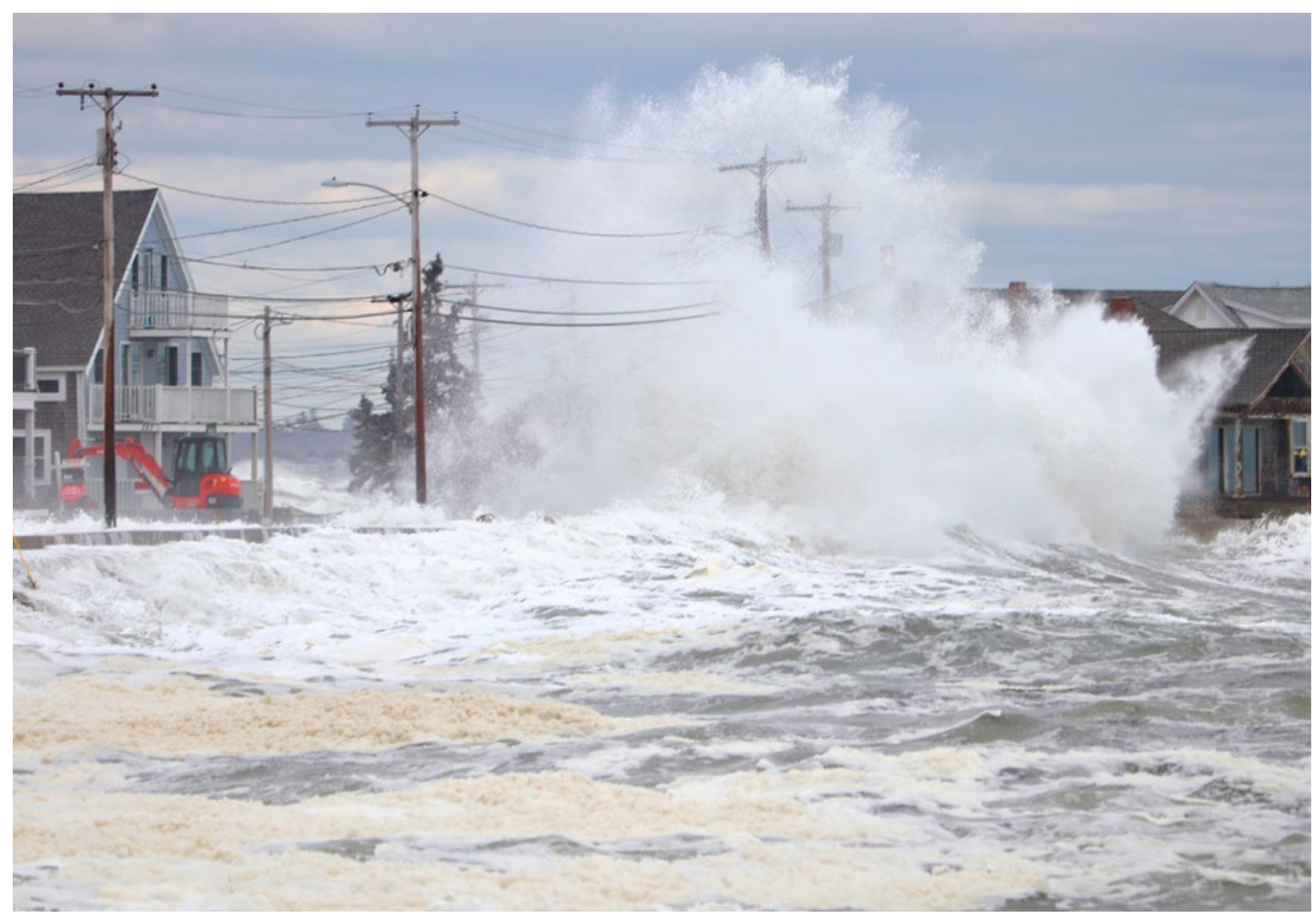




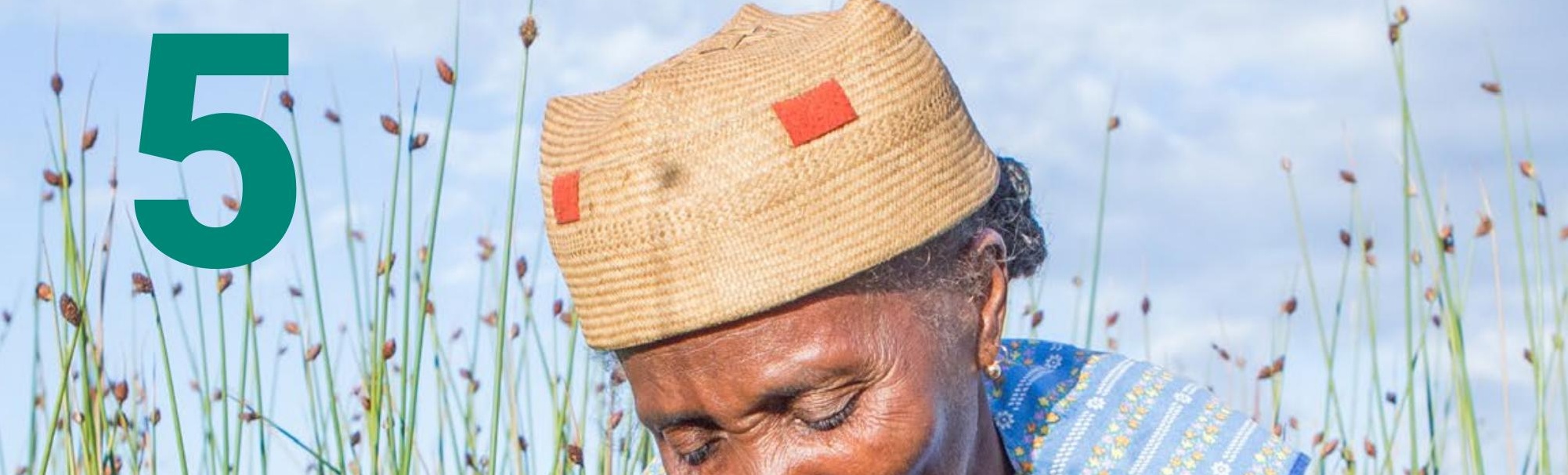

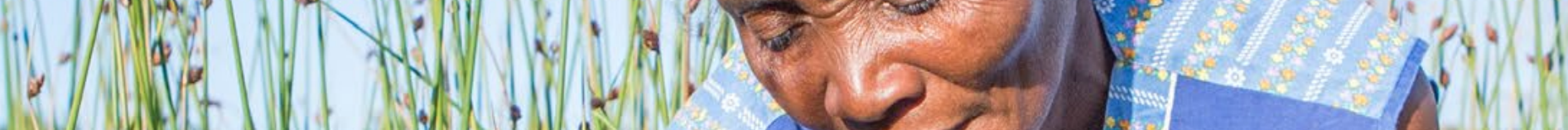

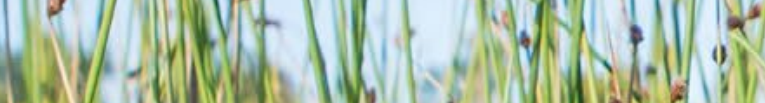

Natis

Griva wa n w

(2)

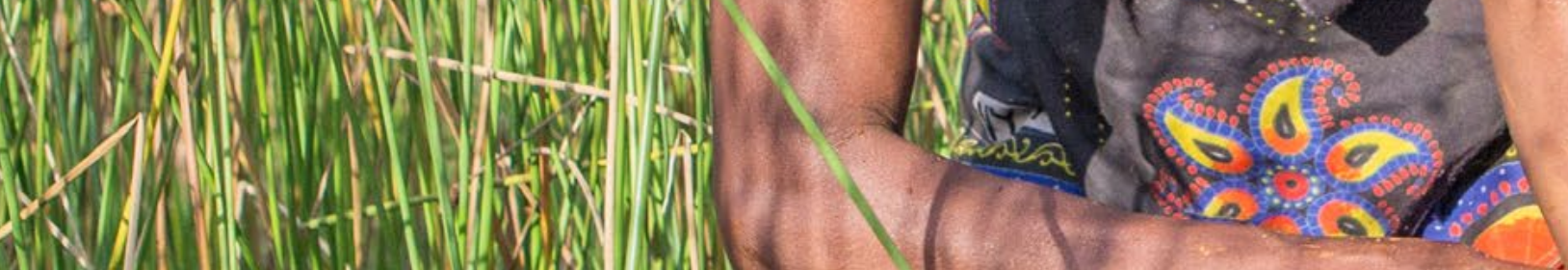

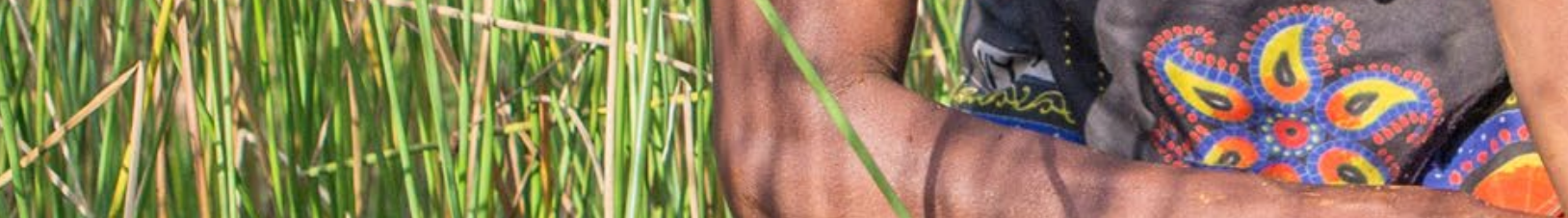
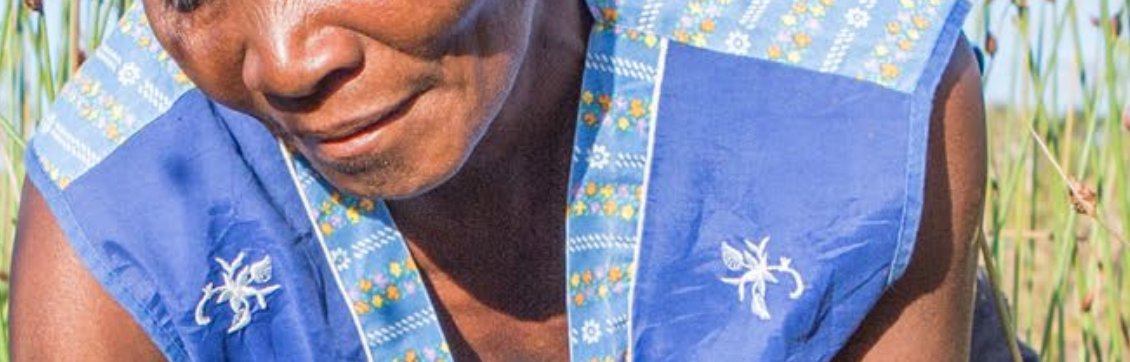

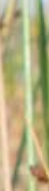

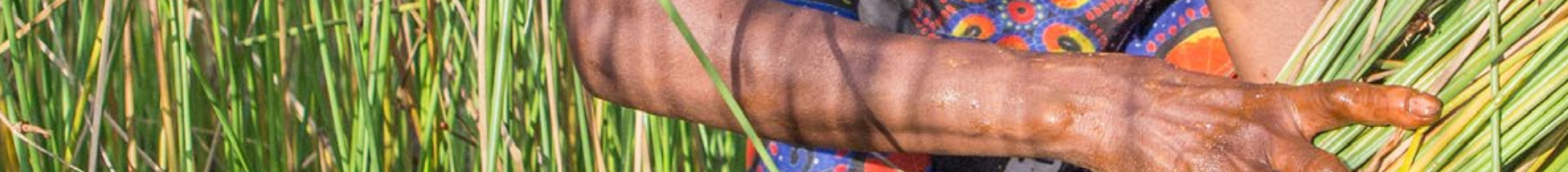
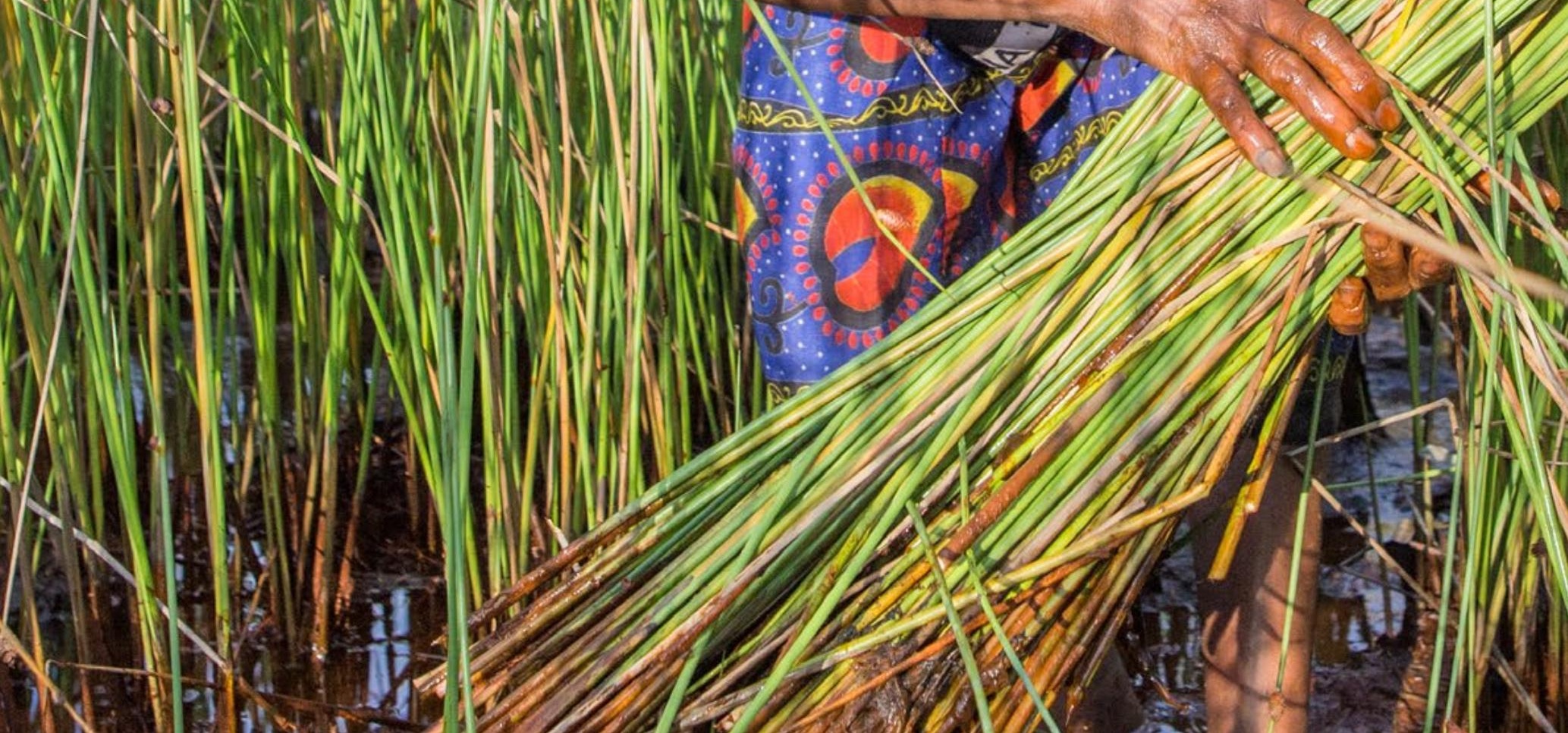



\section{Key messages}

- Since 2006, the United Nations Framework Convention on Climate Change (UNFCCC) climate funds have financed close to 400 projects with the primary aim of adaptation. A trend towards larger projects (from more than US\$10 million to over US\$100 million) is apparent since 2017, which might signal a shift in programming from smaller pilots to larger scale implementation.

- The most frequently addressed sectors by projects under UNFCCC climate funds align with two of the three sectoral priorities for adaptation mentioned in the first round of nationally determined contributions (NDCs), namely agriculture and water. Health as the third priority is seldom the primary subject of adaptation projects in developing countries. However, evidence from scientific articles shows that extreme heat is the fourth most-targeted climate hazard globally.

- The top three climate hazards addressed by adaptation projects under UNFCCC climate funds and by actions documented in the literature are drought, rainfall variability and flooding.

- The actors most commonly targeted are national and local governments, individuals and households, farmers and pastoralists, local communities and technical government agencies. Engagement of the private sector has remained low except for tourism, agriculture and the insurance industry.

- UNFCCC climate funds primarily monitor portfolio indicators at the output level. As at May 2019, the Adaptation Fund had reached over 6 million direct beneficiaries and trained close to 100,000 people on climate resilience measures, while the Least Developed Countries Fund (LDCF) projects that were active as at 30 June 2020 had reached more than 13.6 million direct beneficiaries and trained 414,000 people.

- Evidence of adaptation outcomes, such as reduced vulnerability, however, is still rare to find even within evaluations of UNFCCC climate fund projects. To understand whether adaptation actions make a difference, more attention is needed to assess the effects of adaptation, safeguard against maladaptation and share lessons learned.

\subsection{Introduction}

The preceding two chapters examined progress in adaptation planning and finance. This chapter looks at implementation of adaptation by addressing the question: are adaptation actions taking place? It provides one of the first global accounts of implemented adaptation actions, including which hazards they address, who is adapting, how they align with the adaptation priorities in NDCs, whether they target the most vulnerable and whether gender and naturebased solutions are considered. Findings of this analysis are therefore directly relevant for the Global Stocktake and can serve as a baseline for future Adaptation Gap Reports.

\subsection{Scope and data sources}

While information on climate risks and adaptation planning processes is generally available (for example, for national planning see chapter 3), information on adaptation actions is scattered across funding and implementing entities and information on results is scarce and not easily comparable or aggregable. Therefore, this implementation chapter of the Adaptation Gap Report focuses on adaptation actions and their results. This is an important complement to the assessment of planning and finance in chapters 3 and 4 , neither of which examine whether on-the-ground action actually follows from plans, nor the impacts that financial investments have had. For resources administered by UNFCCC climate funds, this chapter provides the first combined account of the actions that the finance translates into on the ground.

As outlined in the 2017 Adaptation Gap Report (United Nations Environment Programme [UNEP] 2017), global assessments of adaptation require a coherent data source with global coverage. While chapter 3 on national adaptation planning is based on submissions by countries to the UNFCCC, few countries have so far reported on actions other than creating enabling environments and even fewer have reported results of adaptation actions (Lesnikowski et al. 2015). For this year's report, two original data sources have been employed, namely project proposals funded by UNFCCC climate funds and 
observed adaptation actions documented in scientific articles. As these data sources have only limited overlap, combining them enables greater insight into the extent of adaptation than what would otherwise be possible. For example, actions funded by UNFCCC climate funds only cover developing countries, while responses documented in scientific articles are in principle open to any type and form of adaptation anywhere.

Nevertheless, even when taken together, both sources cover only part of the large variety of actions and actors that contribute to adaptation worldwide. Autonomous and community-based actions, adaptation by the private sector as well as the many activities with co-benefits for adaptation are not accounted for. However, finding reliable data with global coverage has been identified as a bottleneck to assessments of adaptation progress (Ford et al. 2015). The two data sources chosen for this chapter have two decisive advantages: they have undergone some form of quality review and are accessible online, making them feasible for a deskbased analysis of global adaptation progress with immediate relevance to the UNFCCC community.

One of the difficulties of assessing adaptation progress is defining what counts as adaptation (Ford and BerrangFord 2016). In line with the intention to understand explicit adaptation actions under the UNFCCC, this chapter takes a conservative approach whereby actions need to directly aim towards climate risk reduction, meaning they need to have adaptation as their explicit objective. This approach includes mainstreaming, capacity-building and technology transfer as long as they are targeted at addressing climate risks, while excluding efforts that only indirectly support adaptation. The purpose of this chapter is not to identify the maximum number of activities that could somehow be linked to adaptation, but to form the basis for determining whether those that explicitly aim at adaptation actually support it. ${ }^{1}$

The chapter also excludes readiness and other preparatory actions such as vulnerability assessments or national planning that are setting the foundation for later implementation of actions. This is not to discount the importance of such preparatory efforts, but rather to enable a better understanding of whether adaptation ultimately takes place. Furthermore, under the framework of the 2020 Adaptation Gap Report (see section 1.2), progress in national planning is addressed in chapter 3 and financial flows including readiness funds in chapter 4 . Finally, since this chapter is mainly concerned with actual implementation rather than possible future actions, its focus is on implementation that is ongoing or has already been completed. The cut-off date for scientific articles was December $2019^{2}$ and for adaptation projects 30 November 2020. The project pipeline of UNFCCC climate funds was considered separately to enable an outlook on near-term adaptation actions.

Adaptation actions can be funded by a variety of sources. For those funded by international climate funds, this first edition of the implementation chapter of the Adaptation Gap Report focuses on the climate funds under UNFCCC, i.e. those that officially serve the Paris Agreement, namely the Adaptation Fund, ${ }^{3}$ the Green Climate Fund $(\mathrm{GCF})^{4}$ and the Global Environment Facility (GEF), which manages the Least Developed Countries Fund (LDCF) and the Special Climate Change Fund (SCCF). ${ }^{5}$ Together, these funds account for a significant, albeit partial, share of international adaptation finance (approximately 50 per cent of adaptation finance reported by Annex II countries in 2016, but a far lower percentage if all multinational sources are considered; see figure 4.3 in chapter 4). It was not feasible for this year's report to undertake an analysis of projects from other international funding sources such as multilateral development banks, partly because details of their portfolios relevant to adaptation are not commonly available online. However, future reports will intend to expand the analysis to cover further funding bodies.

To account for adaptation responses in all countries and irrespective of funding source, the second data source for this chapter is scientific articles that describe implemented adaptation actions. Since 2016, literature on adaptation has been growing at a rate of over 10,000 articles per year (Callaghan, Minx and Fosters 2020). However, most articles are conceptual rather than empirical, discussing concepts or undertaking vulnerability assessments rather than documenting actual adaptation. The Global Adaptation Mapping Initiative (GAMI) has been created to systematically screen and review the scientific literature (articles published in scientific journals between January 2013 and December 2019) to find evidence of human adaptation that has already occurred (details of the methodology are described in Berrang-Ford et al. forthcoming). It enables a comparison between trends documented in the literature and trends under UNFCCC climate funds. Together, both sources provide a unique account of observed adaptation actions

1 Independent reviews of the practice of applying the Organisation for Economic Co-operation and Development (OECD) Rio markers found that up to two-thirds of projects labelled as 'adaptation' did not have any relation to adaptation (Weikmans et al. 2017).

2 This date has been determined by the Global Adaptation Mapping Initiative (Berrang-Ford et al. forthcoming).

3 The Adaptation Fund was established in 2001 under the Kyoto Protocol and operationalized in 2007. Since 1 January 2019, the Adaptation Fund has also served the Paris Agreement.

4 The Green Climate Fund was set up in 2010 and became operational in 2015.

5 The LDCF and the SCCF were established in 2001. The LDCF is exclusively focused on adaptation in least developed countries (LDCs), while the SCCF is open to all developing countries and primarily supports adaptation. In addition to these two funds, the GEF Trust Fund previously supported adaptation through the Strategic Priority on Adaptation (SPA), which ran from 2004 to 2010 . The GEF now finances primary adaptation projects solely through the LDCF and the SCCF. However, numerous projects under the GEF Trust Fund have adaptation co-benefits that are not accounted for in this chapter. 


\subsection{Implemented adaptation actions}

In collaboration with the secretariats of the Adaptation Fund, the GCF and the GEF, the number of projects that primarily aim at adaptation have been identified alongside the number of proposals in the pipeline. Excluding readiness projects, close to 400 explicit adaptation projects were counted, 51 per cent of which have started since 2015 (see table 5.1). In addition, the Global Adaptation Mapping Initiative identified almost 1,700 articles that document the implementation of adaptation actions (Berrang-Ford et al. forthcoming). The articles provide evidence of some degree of adaptation in almost every country while indicating regional concentrations in South-East Asia; Eastern, Southern and parts of West Africa; Europe; and North and Central America. The majority of adaptation actions documented in scientific articles published between 2013 and 2019 are in the early or expanding stages of implementation, with less than 15 per cent under widespread implementation (see figure 5.1).

Adaptation projects implemented under UNFCCC climate funds vary widely in content and budget. The total number of projects, while providing a rough indication of the extent of adaptation actions globally, conceals these differences and must therefore be interpreted with care. One way towards a more meaningful interpretation is to differentiate projects by funding size. Figure 5.2 shows the number of projects that have started per year since 2015 according to four categories of grant size: US\$0.510 million, US\$11-25 million, US\$26-50 million, and more than US\$50 million (based on total grant amount provided by the fund, excluding co-financing and nongrant based forms of funding such as loans). Before 2015 , the largest grant provided for individual projects by UNFCCC climate funds was less than US\$15 million and grant sizes rarely exceeded US\$10 million. Few projects had a successor or a follow-up phase. Since 2017, a trend towards larger projects is apparent, which might signal a shift in programming from smaller pilots to larger scale projects that address climate risks more widely. This trend has been facilitated by the GCF, which accounts for 82 per cent of all projects with grant sizes above US\$10 million since 2015.

Accounting for different funding sizes explains that despite a decrease in the total number of new projects since 2018, the overall funding volume per year has in fact increased (see chapter 4). To understand what these figures mean on the ground, adaptation projects that have started since 2015 were analysed regarding the sectors covered, the hazards responded to, and the actors adapting (see figures 5.3-5.5). The analysis is based on the short project descriptions on the funds' websites (see box 5.1). If that information was inconclusive, the detailed project documents were consulted.

Of the 203 projects that have started since 2015, 53 per cent are located in least developed countries (LDCs) and
Box 5.1. Adaptation projects funded by UNFCCC climate funds

- Adaptation Fund (www.adaptation-fund.org): an interactive map of projects, a list of projects by sector and a list of all projects are provided. Project documents are available online.

- Green Climate Fund (www. greenclimate.fund): a list of all projects can be filtered for adaptation. Project documents, gender assessments and annual performance reports are available online.

- Global Environment Facility (www.thegef.org): a list of all projects is available for download and can be filtered by topic area or fund (for example, LDCF or SCCF). Short project descriptions with a timeline are presented for most projects. Project documents are available online.

14 per cent in small island developing states (SIDS). The sectors most commonly addressed were agriculture (including food security) and water, which correspond to the top two priorities mentioned in the first round of NDCs that were mainly submitted in 2015 and 2016 (see figure 5.3). Agriculture and water are closely interlinked and projects often considered them together. Hence, their flipped order compared to NDC adaptation priorities does not indicate a significant divergence. Ecosystems and forestry rank in joint fourth position. A noticeable difference concerns health, which was the third most commonly mentioned adaptation priority in the first round of NDCs, but none of the 203 projects since 2015 were dedicated primarily to adaptation in the health sector. However, the analysis of observed adaptation in scientific articles found that health concerns related to extreme heat were the fourth most-targeted hazard, indicating that health aspects are underrepresented in the sample of projects from developing countries (see figure 5.4).

To determine the climate hazards that adaptation projects responded to, up to three of the most prominently mentioned hazards in each project description were extracted. If a broad range of hazards was mentioned without a specific focus, the label 'multitude of hazards' was applied. Drought and inland flooding were most often mentioned, followed by rainfall variability. This order is almost identical to the top three hazards addressed by responses documented in the literature (see figure 5.4). Hence, most adaptation actions deal either with too much or too little water, extreme events, and sea-level rise alongside associated salinization of soils or water resources. Extreme heat ranked as the fourth most 
Table 5.1. Number of Adaptation Fund, GCF and GEF explicit adaptation projects under implementation, completed or in the pipeline as at 30 November 2020

\begin{tabular}{|c|c|c|c|c|}
\hline & \multicolumn{2}{|c|}{ Implementation } & \multirow{2}{*}{$\begin{array}{l}\text { Pipeline } \\
\left.\text { (approved }{ }^{1}\right)\end{array}$} & \multirow{2}{*}{$\begin{array}{l}\text { Pipeline } \\
\text { (proposals) }\end{array}$} \\
\hline & $\begin{array}{l}\text { Implementation } \\
\text { started during } \\
2006-2020\end{array}$ & $\begin{array}{l}\text { Percentage started } \\
\text { since } 2015\end{array}$ & & \\
\hline Adaptation Fund & 86 & $65 \%(56)$ & $4^{2}$ & $9^{3}$ \\
\hline GCF & 54 & $100 \%(54)$ & 11 & 294 \\
\hline GEF-LDCF & 161 & $42 \%(67)$ & $18^{5}$ & $38^{6}$ \\
\hline GEF-SCCF & 74 & $35 \%(26)$ & 3 & 4 \\
\hline $\begin{array}{l}\text { GEF Trust Fund (SPA } \\
\text { 2004-2010) }\end{array}$ & 22 & $0 \%$ & N/A & $\mathrm{N} / \mathrm{A}$ \\
\hline Total & 397 & $51 \%(203)$ & 36 & 80 \\
\hline
\end{tabular}

1 Referring to projects that have been approved but whose implementation has not yet started.

2 Proposals stated on the Adaptation Fund website under Project waitlist.

3 Proposals stated on the Adaptation Fund website under Active pipeline projects as 'Proposal not approved'.

4 Number of funding proposals (not concepts) in the entire pipeline.

5 For LDCF and SCCF, the numbers provided are for proposals that have been CEO endorsed but are not yet under implementation.

6 For LDCF and SCCF, the data provided is for Council-approved and CEO-approved concepts that are not yet CEO endorsed or under implementation.

Figure 5.1. Stage of implementation of adaptation actions documented in scientific articles

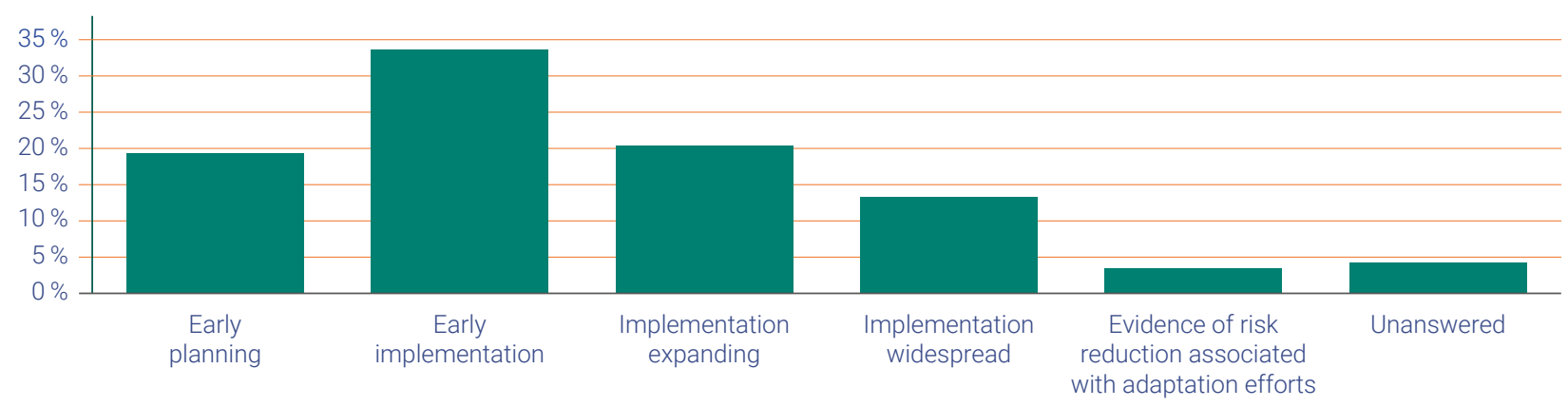

Note: This figure is based on data from the Global Adaptation Mapping Initiative (Berrang-Ford et al. forthcoming) which identified close to 1,700 scientific articles published between 2013 and 2019 that document adaptation actions. It shows the percentage of articles per stage of implementation. It is worth noting that just 3.5 per cent of articles referred to some degree of achieved risk reduction.

Figure 5.2. Number of primary adaptation projects per year and size of grant (excluding co-financing)

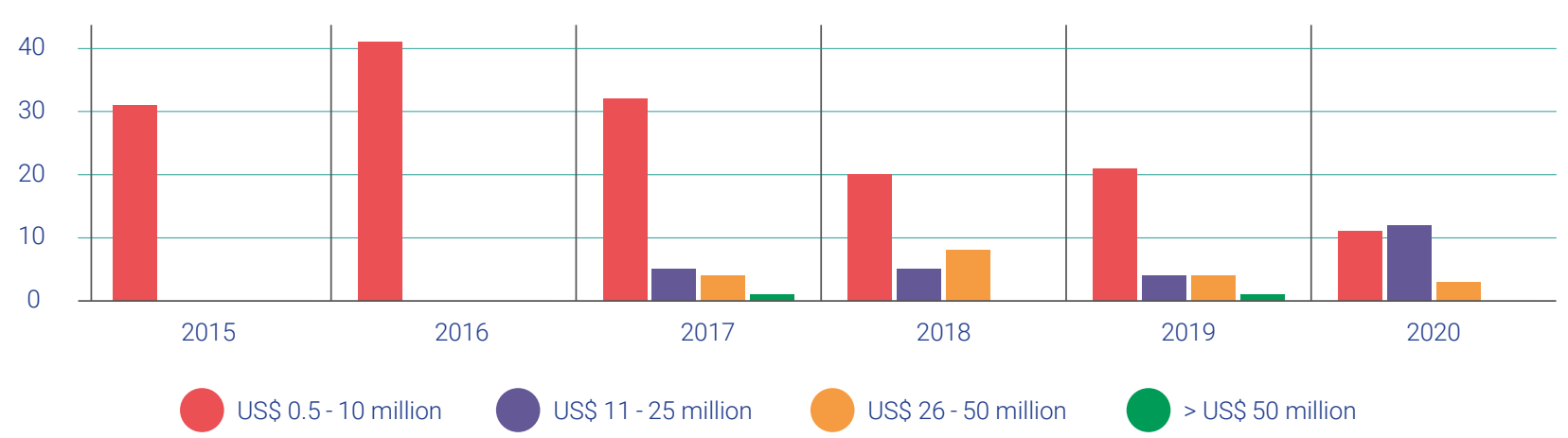


Figure 5.3. Panel A: Primary sectors of UNFCCC climate fund adaptation projects since 2015

Panel B: Sectors identified as adaptation priorities in the first round of NDCs

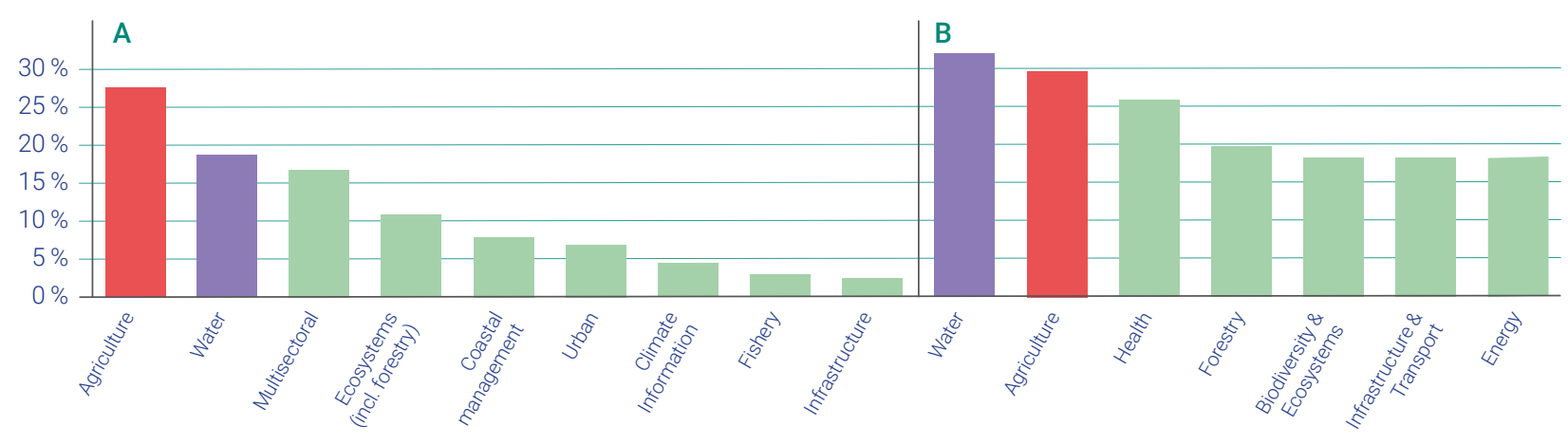

Note: Agriculture and water were marked in the same colour in both panels to highlight the alignment of the top two sectors between UNFCCC adaptation projects and NDCs. Panel $\mathbf{A}$ is based on the primary sector of each of the 203 projects (the designation of sectors used by UNFCCC funds is not harmonized, therefore, a reassignment was necessary to obtain comparability). The bars in Panel A add up to 100 per cent because each project was assigned to just one primary sector (1.5 per cent were left unassigned due to missing project documents). Panel B shows the five most frequently mentioned priority adaptation sectors in the first round of NDCs (GIZ 2020). The bars in Panel B do not add up to 100 per cent because each NDC mentions multiple adaptation priorities.

Figure 5.4. Panel A: Hazards addressed by UNFCCC climate fund projects

Panel B: Hazards addressed by observed adaptation responses documented in scientific articles from 2013-2019

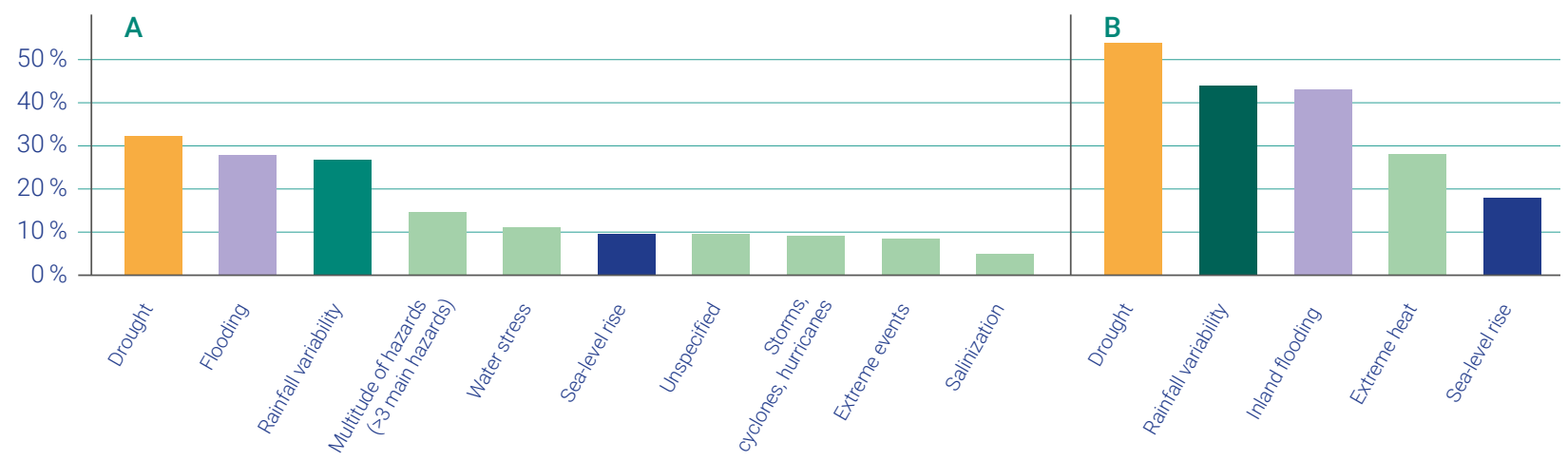

Note: Identical hazards in Panels A and B have been highlighted in the same colour to ease comparison. The hazards most frequently addressed by the 203 adaptation projects that have started since 2015 under UNFCCC climate funds (Panel A) and by adaptation actions documented in scientific articles (Panel B) are shown (Berrang-Ford et al. forthcoming). The Global Adaptation Mapping Initiative used the label 'Extreme precipitation and inland flooding', whereas 'Flooding' in Panel A includes both inland and coastal flooding.

Figure 5.5. Panel A: Actors targeted by adaptation projects under UNFCCC climate funds since 2015

Panel B: Actors addressed by observed adaptation as documented in scientific articles

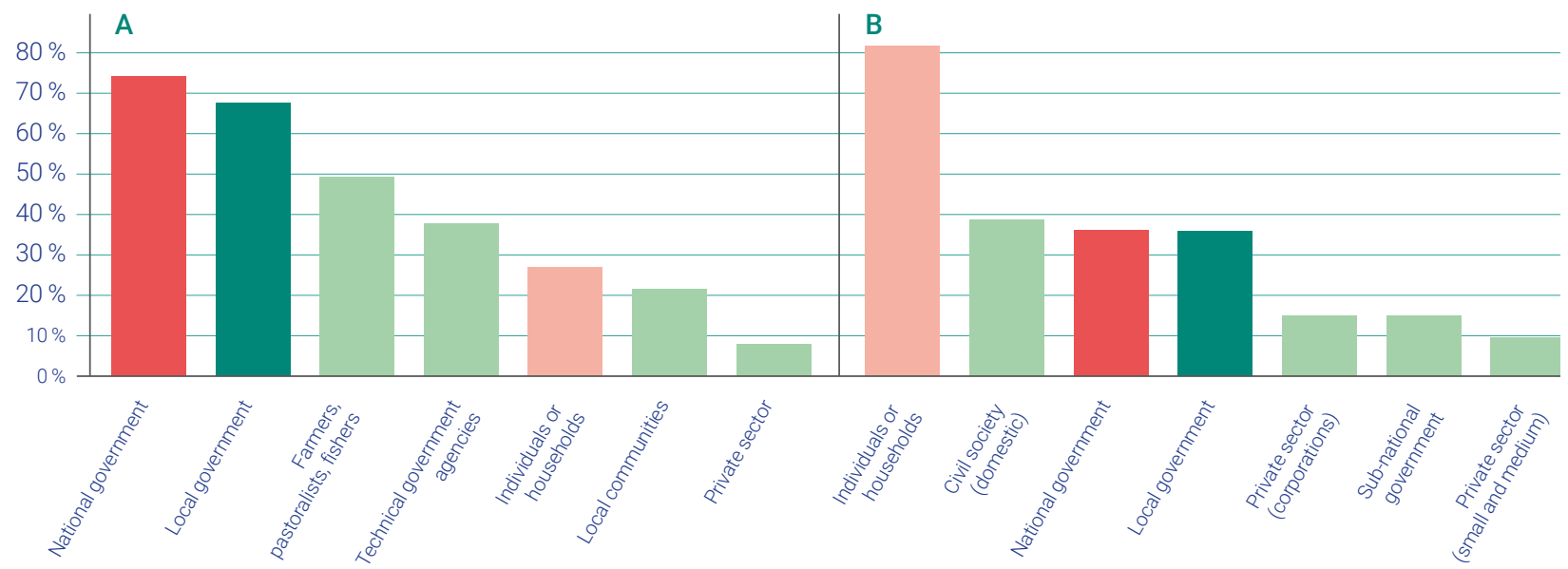

Note: Identical types of actors in Panels A and $\mathbf{B}$ have been highlighted in the same colour to ease comparison. The Global Adaptation Mapping Initiative (Berrang-Ford et al. forthcoming) that provided the data for Panel B divided the private sector into small and medium-sized enterprises and larger ones (corporations). In Panel A, the label 'Private sector' includes any business involvement, irrespective of its size. 
commonly addressed hazard by actions documented in the literature, while very few of the projects in developing countries addressed its impacts on human health. ${ }^{6}$

Adaptation projects under UNFCCC climate funds have primarily targeted national and local governments, farmers, local communities, technical government agencies (such as agricultural services or meteorological offices) and individuals and households (see figure 5.5). Projects often address different target groups through different components or activities. As the vast majority of adaptation actions reported in scientific articles took place at the local level, they therefore had far less involvement of national governments than local governments. Private sector engagement was equally low among both data sources except for the tourism sector in Europe and Australasia (Berrang-Ford et al. forthcoming). Farming associations and the insurance industry were among the most common private sector actors involved in developing countries. Additional findings from the analysis of project descriptions are:

- At least 22 per cent and possibly up to two-thirds of projects that have started since 2015 target the most vulnerable. ${ }^{7}$

- Six per cent of projects are primarily aimed at gender and adaptation and an additional 15 per cent explicitly mention gender aspects in their short descriptions. 8 The Adaptation Fund, the GCF and the GEF require a gender assessment for every project and some GCF projects also have an associated gender action plan available on each project's webspace (see box 5.1).

Twelve per cent of projects either focus primarily on advancing climate information and services or have a component addressing it. At least another 20 per cent include it as one of their outputs.

Twelve per cent of projects fall into ecosystembased adaptation or conservation and another 15 per cent partially focus on it (see section 6.5 for details).

The most common linkages to related topics were to natural resource management (mainly countering degradation through restoration, afforestation and rehabilitation), land and soil management and disaster risk reduction.

\subsection{Adaptation results}

As outlined in chapter 2, results of adaptation can be separated into outputs (what has been done) and outcomes (what effects these outputs have had). For example, training farmers about better adapted farming techniques may lead to new knowledge that, if properly applied, may have a positive effect on yields and eventually on farmers' livelihoods and well-being. The outputs (such as number of trainings and people trained) are typically directly measurable, while their effects occur later, are influenced by multiple factors, and may require more complex methods or concepts (for example, what constitutes resilience or wellbeing) to be measured. Accordingly, most of the portfolio indicators used by international climate funds remain at the level of outputs (Leiter et al. 2019). For example, as at May 2019, the Adaptation Fund had reached over 6 million direct beneficiaries and trained close to 100,000 people on climate resilience measures (Adaptation Fund 2019). Projects under the LDCF that were active as at 30 June 2020 had reached more than 13.6 million direct beneficiaries and trained 414,000 people (Global Environment Facility [GEF] 2020). As at 31 December 2019, GCF-funded activities under implementation were reported to have reached a total of 10 million direct and indirect beneficiaries (GCF 2020).

Output indicators are useful to illustrate immediate products and services created by a project and their reach. However, they neither capture whether outputs are being utilized (for example, whether participants apply the knowledge gained at a training) nor their effects (for example, whether beneficiaries' vulnerability has been reduced). One challenge in measuring adaptation outcomes is that they depend on the context and can differ among people living in the same location due to differential levels of vulnerability (Thomas et al. 2018). In the worst case, maladaptive actions could leave those most vulnerable worse off than before (Schipper 2020). Accordingly, adaptation outcomes are contextand people-specific and cannot easily be expressed in a few global indicators (Leiter and Pringle 2018). Although UNFCCC climate funds do employ some sector-specific portfolio indicators at the outcome level - for example increased income or hectares of natural habitat restored these indicators are usually only relevant to a small part of the portfolio (Leiter et al. 2019). Therefore, information on outcome-level results of adaptation projects remains limited to date.

Out of almost 1,700 scientific articles identified by the Global Adaptation Mapping Initiative, less than 3.5 per cent were classified as being at the stage of risk reduction (see figure 5.1). While risk reduction was often

6 For an overview of adaptation and human health, see the 2018 Adaptation Gap Report (UNEP 2018).

7 This was determined based on information about the vulnerability of the beneficiaries as mentioned in the projects' online descriptions or project documents. A more precise determination would require a closer analysis of the project contexts and would depend on the definition of who counts as 'most vulnerable'.

8 Not mentioning gender aspects in the short descriptions does not mean that the projects do not consider gender. A more detailed exploration would require an analysis of the project's gender assessments. 
alluded to, evidence of it remained the exception rather than the norm. Assessments of risk or vulnerability reduction at the end of a project lifetime are similarly rare, despite having shown to be useful complements to traditional project monitoring systems. Their applicability, however, depends on the type of project and the available resources (Leiter 2018).

Given the limited information on the results of implementation, more attention needs to be paid to understanding the effects of adaptation actions, ensuring systematic risk reductions and avoiding maladaptation. One positive trend is that annual reports by the UNFCCC climate funds to the Conference of the Parties (COP) increasingly provide information on outputs rather than just on financial allocations and spending. New approaches to assessing results, for example via high-frequency mobile phone surveys of subjective resilience, offer the potential to directly monitor effects on beneficiaries in a resource-efficient way (Jones 2019; von Engelhardt and Jones 2018).

\subsection{Outlook}

As of 30 November 2020, 36 approved adaptation projects under UNFCCC climate funds were ready to start and 80 funding proposals were in advanced stages awaiting approval (see table 5.1). Around twice as many concept notes had been submitted to the funds' secretariats for review. However, the lack of information on lasting outcomes of adaptation projects raises concerns over their effectiveness. A review by the GCF's Independent Evaluation Unit (2018) found that "more than two-thirds of the GCFapproved funding proposals did not clearly define causal pathways that show how activities lead to climate change impact" (p.2). Climate funds and project developers alike need to focus more attention on how exactly adaptation is intended to occur amidst social realities and multiple drivers of vulnerability. Theories of change offer a way to map the intended change process and gain a common understanding about the mechanisms of change (Oberlack et al. 2019). However, they need to be developed in a socially inclusive way and informed by local experiences in order not to miss causes of risk that could reduce effectiveness, particularly among the most vulnerable groups (Forsyth 2018). Greater attention to scrutinizing proposed theories of change and their assumptions also provides the basis to better monitor what matters during implementation and to adjust actions as needed. Rather than performing an accountability function, well-designed monitoring systems and evaluations need to be seen as an opportunity for learning and lesson-sharing.

Another concern for the outlook on implementation progress is that continued high amounts of global greenhouse gas emissions imply rising levels of climate risk (Intergovernmental Panel on Climate Change [IPCC] 2018; UNEP 2020). The adaptation gap is therefore inextricably linked to the emissions gap. As stated in the foreword to the first edition of the Adaptation Gap Report, "ambitious and immediate mitigation action is the best insurance against an insurmountable future adaptation gap" (UNEP 2014; see also 2.2). Although progress made in implemented adaptation as documented in this chapter is positive, it may not be able to keep pace with increasing levels of risk, despite the trend towards larger projects. In fact, 2020 saw for the first time more projects approved with funding sizes between US\$11 million and US\$50 million than those up to US\$10 million which had, with rare exceptions, been the maximum project value under UNFCCC climate funds until 2017 (see figure 5.2). While funding volume is no indication of the quality of a proposal, the possibility to design projects larger than US\$10 million offers the potential to more comprehensively address climate risks and underlying causes of vulnerability and to upscale tested applications. Finally, future adaptation projects also need to consider the occurrence of compound risks from climate hazards, economic recession and a global health crisis which could exceed levels of resilience that might have otherwise been sufficient to withstand individual shocks (Phillips et al. 2020). Future editions of the Adaptation Gap Report will continue to look at levels of implementation and achieved results in order to understand adaptation progress and identify areas for improvement. 


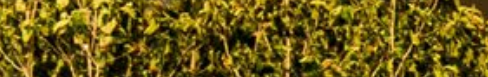

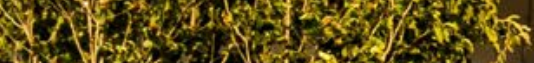

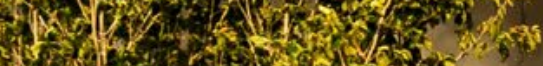

N(S)

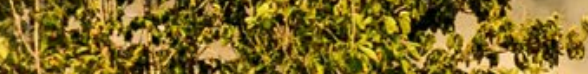

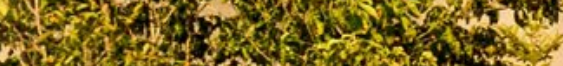
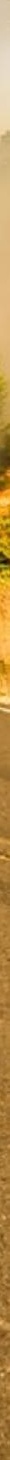


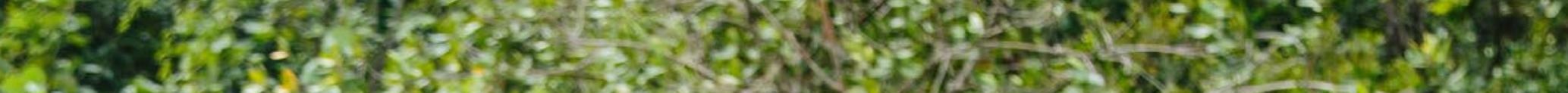

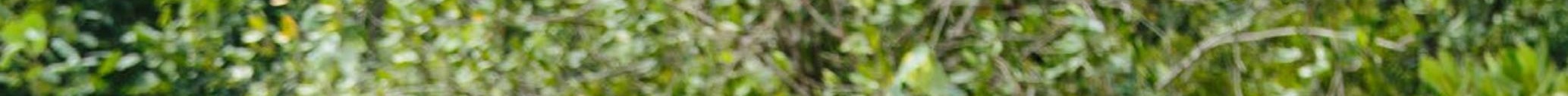

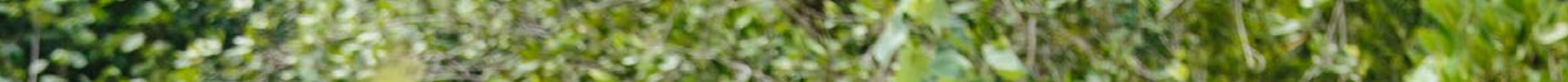

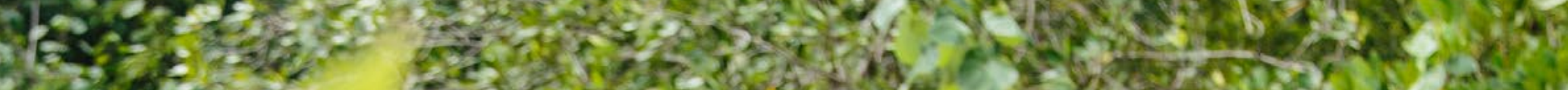
tos

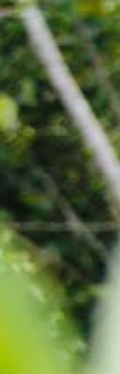

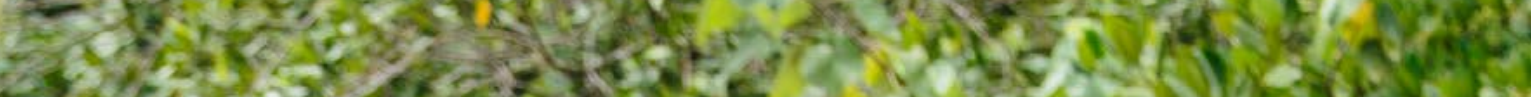
218640 -

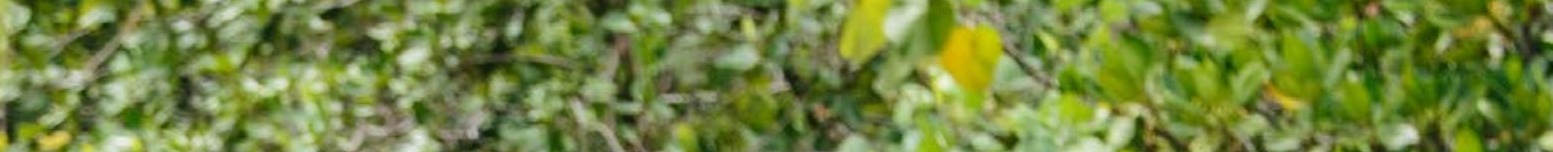

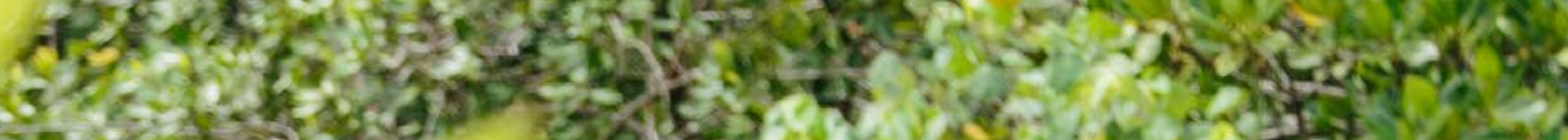

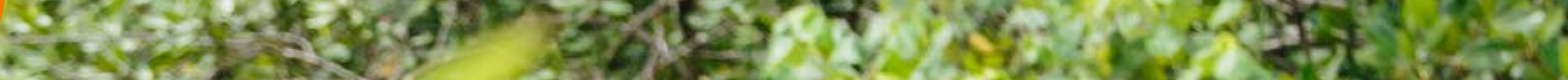

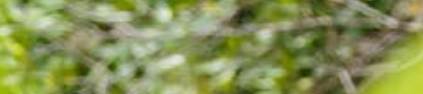

19. 98

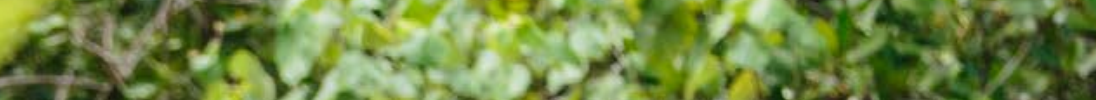
sy

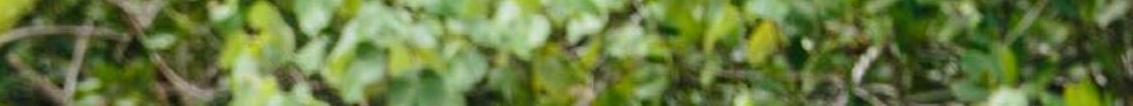
3 C.

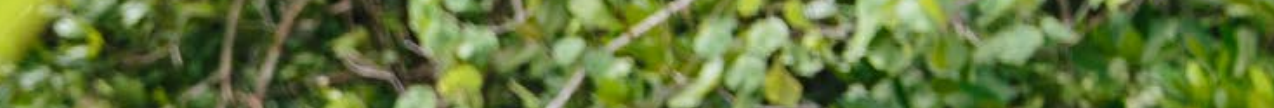

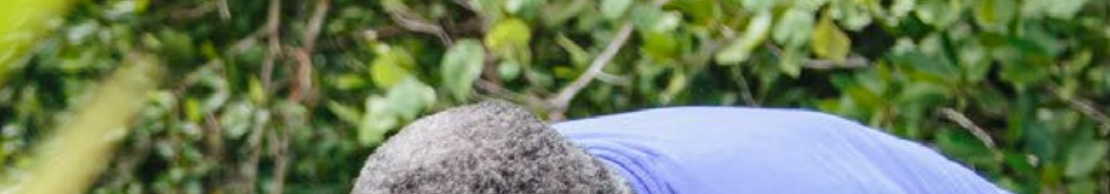

$x^{2} x^{2}$

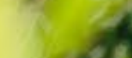

(2) 201. 400305

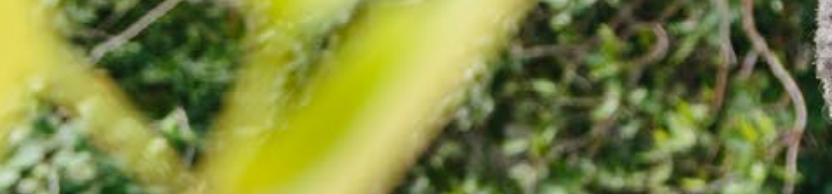
ares?

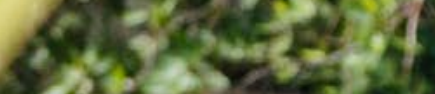
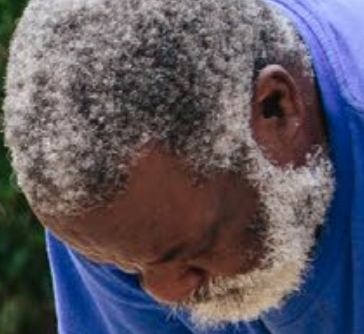

2

(1)

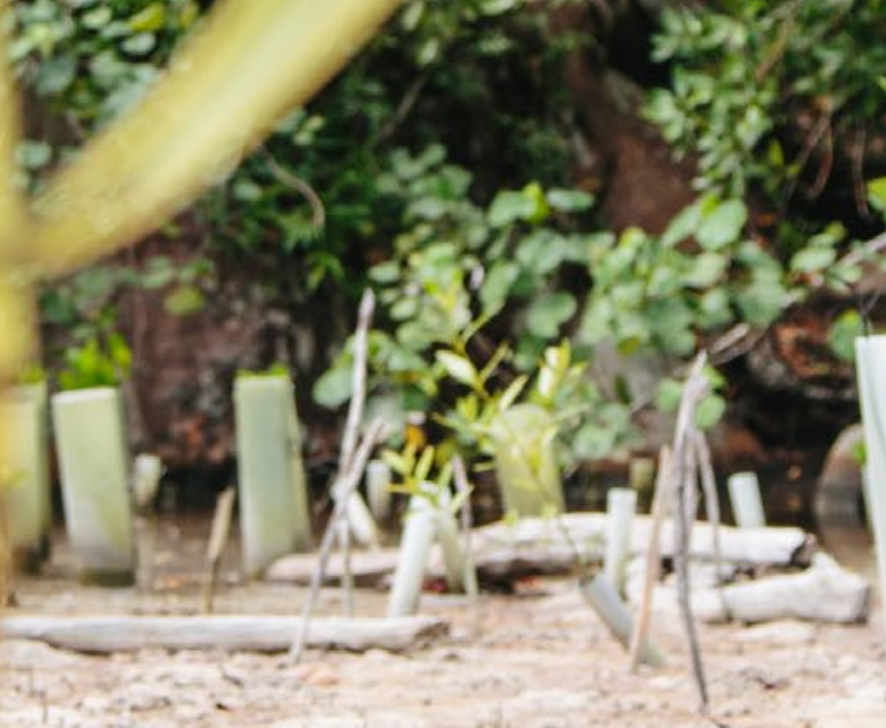

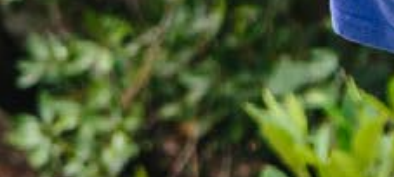

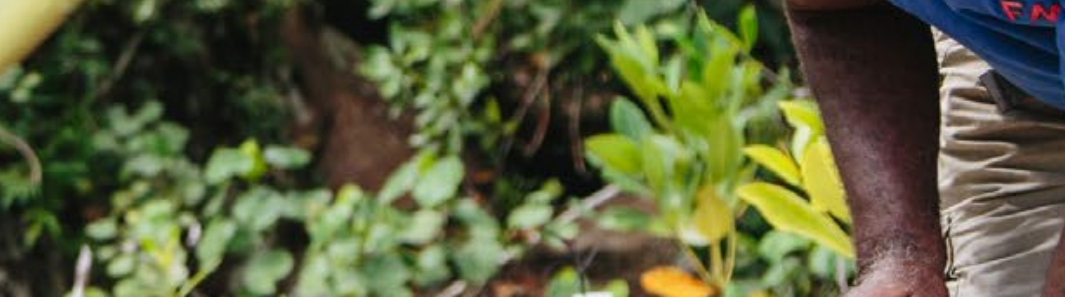

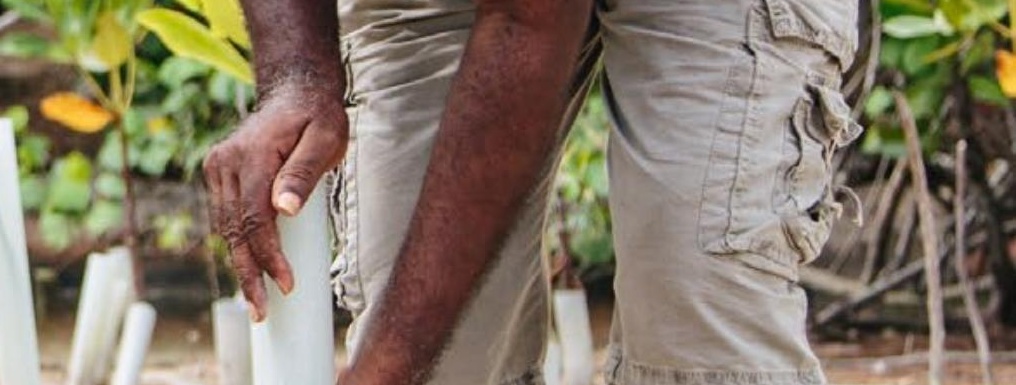

a.
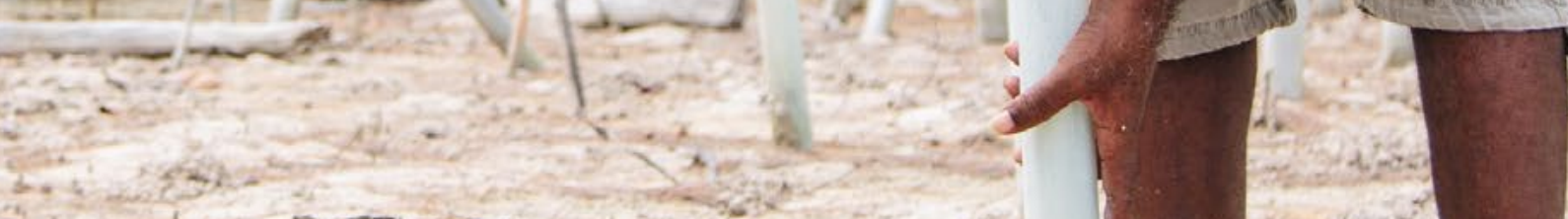


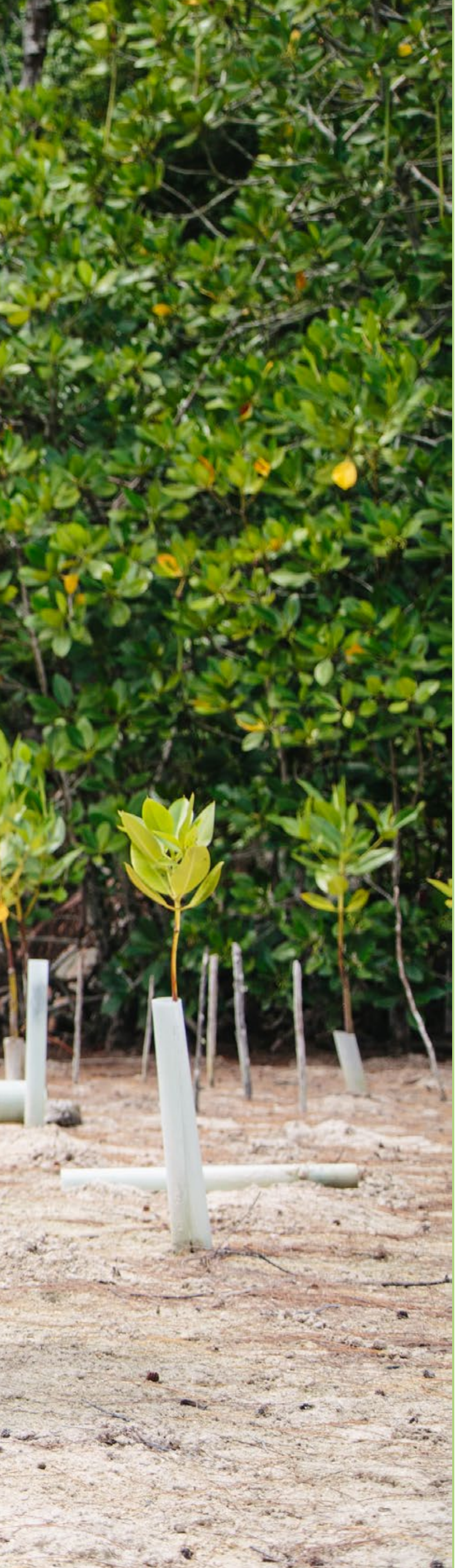

\section{Chapter 6}

Nature-based solutions for

adaptation

Lead authors: Valerie Kapos (UN Environment Programme World Conservation Monitoring Centre (UNEP-WCMC)), Manishka De Mel (Columbia University and NASA Goddard Institute for Space Studies), Cynthia Rosenzweig (National Aeronautics and Space Administration, Goddard Institute for Space Studies (NASA GISS)), Mathilde Kolenda (UNEP DTU Partnership), Lucy Emerton (Environment Management Group), Henry Neufeldt (UNEP DTU Partnership).

Contributing authors: Elisabeth Bernhardt (UNEP), Thomas William Dale (UNEP DTU Partnership), Adam Freed (Bloomberg Associates), Julie Greenwalt (Go Green for Climate/Co-chair GEO for Cities), Shaun Martin (World Wildlife Fund), Karen Podvin (International Union for Conservation of Nature), Ali Raza Rizvi (International Union for Conservation of Nature), Anika Terton (International Institute for Sustainable Development), Tint Thaung (The Nature Conservancy), Suyeon Yang (UNEP), Alberto Yanosky (Guyra Paraguay).

Photo: ( ) UNEP 


\section{Key messages}

- National and international policy and actions are increasingly recognizing that nature-based solutions (NbS) play a vital role in climate change adaptation.

- NbS for adaptation are often low-cost options that bring environmental, economic and social benefits to a wide range of stakeholders, including women and poor and marginalized groups.

- The substantial impacts of high-end climate change on biodiversity can limit the effectiveness of NbS and increase societal vulnerability thus reducing adaptation choices.

- A majority of countries' nationally determined contributions (NDCs) and national adaptation plans (NAPS) acknowledge the vulnerability of ecosystems to climate change, as well as their ability to effectively reduce climate impacts. However, the potential of $\mathrm{NbS}$ for reducing specific climate risks is rarely explicitly recognized and few goals and targets for implementation of NbS for adaptation are evident in adaptation planning.

- Only a small proportion of climate finance is targeted towards NbS for adaptation. The NbS finance base for adaptation could be amplified, strengthened and diversified by deploying innovative mechanisms that combine public and private sources of funding.

- There has been a marked increase in implementation of NbS for adaptation over the past two decades, but it is unclear whether this trend will continue. Implementation of NbS is taking place in all regions of the world, addressing all key climate hazards through a wide range of approaches, but it is still too early to assess the effects of these interventions systematically.

- The potential of NbS for adaptation can best be fully realized by limiting the risks of dangerous levels of warming and by scaling up ambition and action on protecting, conserving and restoring nature.

\subsection{Introduction}

There is growing recognition that the global crises of climate change and biodiversity loss are strongly interlinked, with climate change representing a major driver of biodiversity loss, while nature has a fundamental role in both mitigating climate change and enabling us to adapt to it (Intergovernmental Science-Policy Platform on Biodiversity and Ecosystem Services [IPBES] 2019). The growing connections and potential for synergies between climate and biodiversity agendas, and the urgent need for policy and action to secure and harness nature's benefits, are reflected in the growing recognition of nature's contribution to humanity. For example, the fifth United Nations Environment Assembly focuses on "Strengthening Actions for Nature to Achieve the Sustainable Development Goals", and the UN Decade on Ecosystem Restoration will begin in 2021. Most recently, the COVID-19 pandemic and the associated economic crisis have further highlighted the vital importance of our relationship with nature - given the links that have been made between the emergence of the virus and the ongoing destruction of ecosystems and exploitation of wild species (IPBES 2020) - while also delaying urgent action related to the protection and restoration of nature.
Addressing the role of nature in adaptation to climate change is therefore both timely and vital (Global Commission on Adaptation [GCA] 2019). To date, much of the discussion surrounding nature-based solutions (NbS) has focused on their ability to mitigate climate change. However, their role in adaptation is also of central importance (box 6.1), since the effectiveness of most adaptation action, whether using engineered measures or other approaches, is fundamentally dependent on the continued or enhanced provision of ecosystem services (Kapos et al. 2019).

Focusing on the national level, this chapter explores progress in uptake and implementation of NbS for adaptation. It first introduces NbS for adaptation and the basis for increasing interest in them, before exploring the impacts of climate change on ecosystems and the role that ecosystems and their services, as well as their management, can play in reducing climate risks and impacts for both people and ecosystems. Following this, the chapter reviews progress in integrating NbS for adaptation into planning and policy at the national level, explores the financing landscape for NbS for adaptation, and describes progress and lessons learned in their implementation. Finally, the chapter highlights barriers to, and enablers for, further scaling-up of NbS for adaptation and provides suggestions for key next steps to advance the contribution of $\mathrm{NbS}$ to adaptation globally. 


\section{Box 6.1. Defining NbS for adaptation}

Nature-based solutions (NbS), a term that has been increasingly used in recent years, is most commonly defined as:

\section{Actions to protect, sustainably manage and restore natural and modified ecosystems that address societal challenges effectively and adaptively, simultaneously providing human well-being and biodiversity benefits $/$}

(International Union for Conservation of Nature [IUCN] 2020)
Climate adaptation is just one of the societal challenges that NbS can be used to address. Others include climate change mitigation, disaster risk reduction, food and water security, human health and socioeconomic development, as well as environmental degradation and biodiversity loss. Many of the activities and approaches that are encompassed by the umbrella term $\mathrm{NbS}$ are also associated with other widely used terms specific to particular sectors and disciplines (Ozment et al. 2019). Such terms include green infrastructure, natural infrastructure, ecological engineering, ecosystem-based mitigation, ecosystembased adaptation (EbA) and ecosystem-based disaster risk reduction (Eco-DRR).

The latter two terms have particularly strong linkages with $\mathrm{NbS}$ that are employed to achieve adaptation benefits - i.e. 'NbS for adaptation' - due to their relevance to reducing vulnerability to climate-related hazards. The relationship between these three terms is illustrated in figure 6.1.

Figure 6.1. Relationship between the terms Eco-DRR, EbA and NbS

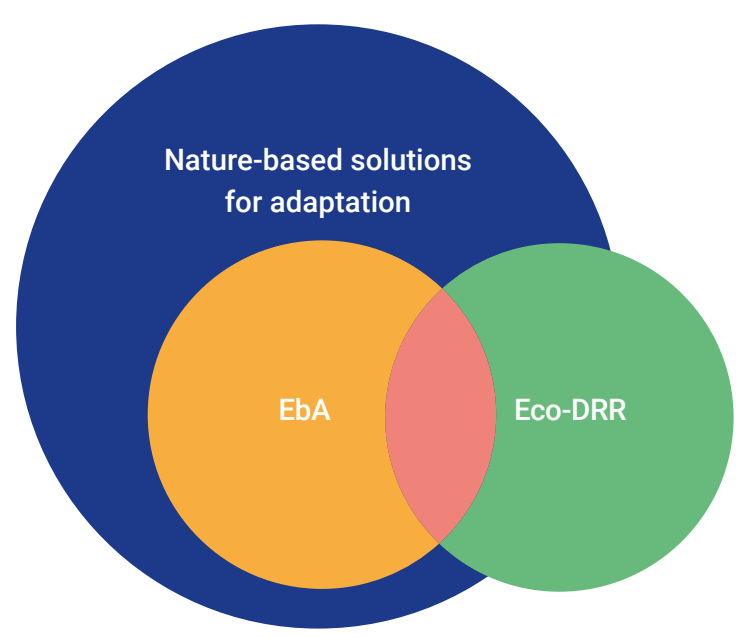

Ecosystem-based adaptation (EbA)

Ecosystem-based
disaster risk
reduction (Eco-DRR)

"The use of biodiversity and ecosystem services as part of an overall adaptation strategy to help people to adapt to the adverse effects of climate change" (Secretariat of the Convention on Biological Diversity [CBD] 2009).

\footnotetext{
"The sustainable management, conservation and restoration of ecosystems to reduce disaster risk, with the aim to achieve sustainable and resilient development" (Estrella and Saalismaa 2013).
}

Note: Eco-DRR is depicted as being only partially within the term NbS for adaptation as Eco-DRR can also refer to activities and approaches that address non-climatic disaster risk, such as tsunamis and earthquakes. As EbA refers to ecosystem-based approaches to climate change adaptation, it is situated entirely within the scope of $\mathrm{NbS}$ for adaptation. 


\subsubsection{Introducing $\mathrm{NbS}$ for adaptation}

NbS for adaptation restore, build on and enhance ecosystem services in order to manage climate change risks and impacts, help people (including women and marginal groups) adapt to climate change, and enhance the climate resilience of communities, assets and society. They can be utilized to address a wide range of climate hazards across a wide variety of contexts (table 6.1). They are commonly applied to address four main types of climate-related hazard: i) coastal hazards (including sea level rise, storm surge and coastal erosion); ii) intense precipitation (including floods, soil erosion, and landslides caused by intense precipitation) iii) drought; and iv) rising temperatures (heat stress, urban heat islands and wildfires) (Kapos et al. 2019). NbS for adaptation may be implemented on their own or in combination with engineered approaches for reducing climate risk. Often, their design, implementation and management may draw on local and traditional, as well as expert, knowledge.

NbS for adaptation can cost less than hard engineered approaches for addressing climate hazards (Reguero et al. 2020; Narayan et al. 2016) and generate substantial economic benefits (see, for example, Menéndez et al. 2020). When well-designed and implemented, they have the potential to generate larger returns (in a broad economic, rather than financial, sense) because of the multiple societal benefits they deliver in addition to reducing climate risk (table 6.1; Rizvi 2014; Seddon et al. 2020a and 2020b). Additional benefits can include environmental benefits (such as carbon sequestration and storage and biodiversity conservation) and socioeconomic benefits such as the provision of food, marketable products, jobs and livelihoods, improved health, and support for cultural and religious values. Most of these benefits can be especially important for women and for poor and marginalized people (Reid et al. 2019).

Despite the benefits associated with NbS for adaptation, their successful implementation presents a number of challenges. For example, as adaptation tends to be highly context-specific, there can be some uncertainty around how effective individual $\mathrm{NbS}$ will be for addressing hazards of varying severity or in different locations. In tandem with this, it can take a significant amount of time for interventions to reach the stage where they deliver the full level of risk reduction benefits and co-benefits that were initially anticipated; this is particularly the case for interventions that involve restoring badly degraded ecosystems. Furthermore, as some NbS types depend on effective land management across large areas, their successful implementation can require the extensive and sustained engagement of a wide range of stakeholders. Finally, since ecosystems and their services are themselves climate-sensitive, NbS for adaptation must account for, and manage, climate risks to help ensure their long-term viability.

\subsubsection{International policy context}

Policy drivers for using nature-based solutions to address climate change and other challenges are growing in various arenas of environmental governance and from global to jurisdictional levels.

The Paris Agreement of the United Nations Framework Convention on Climate Change (UNFCCC) recognizes the importance of ecosystems for mitigation and adaptation, calling on Parties to "note the importance of ensuring the integrity of all ecosystems, including oceans, and the protection of biodiversity [...]", and includes NbS for mitigation in the text referring to REDD +1 in article 5.2. In addition, "joint mitigation and adaptation approaches for the integral and sustainable management of forests" are also mentioned in this article, along with the importance of non-carbon benefits associated with managing forests to preserve and enhance carbon stocks. Article 7.1 meanwhile encourages Parties to build the resilience of socioeconomic and ecological systems, including through economic diversification and sustainable management of natural resources.

NbS were a major focus of the United Nations SecretaryGeneral's Climate Action Summit in 2019, where participants launched the Nature-Based Solutions for Climate Manifesto. In the same year, paragraph 15 of the overarching decision stemming from UNFCCC COP 25 "[u]nderlines the essential contribution of nature to addressing climate change and its impacts and the need to address biodiversity loss and climate change in an integrated manner" (United Nations Framework Convention on Climate Change [UNFCCC] 2020).

Meanwhile, the Convention on Biological Diversity (CBD) has continued to highlight the importance of the relationship between biodiversity and progress on climate change mitigation and adaptation. It has emphasized the value of ecosystem-based adaptation (EbA; see box 6.1) and endorsed the Voluntary Guidelines for the Design and Effective Implementation of Ecosystem-Based Approaches to Climate Change Adaptation and Disaster Risk Reduction in 2018. Governments, intergovernmental and nongovernmental organizations worldwide have embraced EbA, leading to a proliferation of such projects.

The conservation, sustainable management and restoration of ecosystems that NbS for adaptation entail can also help to meet a wide range of other international objectives. These include: the Sustainable Development Goals (SDGs), in particular SDGs 13 (climate action), 15 (life on land), 6 (clean water) and 14 (life below water); the Sendai Framework for Disaster Risk Reduction, which explicitly recognizes the importance of NbS; the Bonn Challenge on forest and landscape restoration; the New York Declaration on Forests; and the United Nations Convention to Combat Desertification (UNCCD) agenda on land degradation neutrality.

1 REDD+: Reducing emissions from deforestation and forest degradation and the role of conservation, sustainable management of forests and enhancement of forest carbon stocks in developing countries 
Table 6.1. NbS for adaptation: examples of applications to reduce impacts related to major climate hazards

\begin{tabular}{|c|c|c|}
\hline Hazard & NbS for adaptation & Potential additional benefits \\
\hline $\begin{array}{l}\text { Coastal hazards } \\
\text { - Sea level rise } \\
\text { - Storm surge } \\
\text { - Coastal erosion }\end{array}$ & $\begin{array}{l}\text { Mangrove protection and restoration to } \\
\text { anchor sediments and dissipate wave } \\
\text { energy } \\
\text { - Management and restoration of coastal } \\
\text { marshes and/or dunes to dissipate wave } \\
\text { energy and/or complement engineered } \\
\text { protection } \\
\text { - Coral reef management and restoration } \\
\text { to attenuate wave energy }\end{array}$ & $\begin{array}{l}\text { - Improved fish stocks } \\
\text { - Biodiversity conservation } \\
\text { - Carbon sequestration and storage } \\
\text { - Sediment accretion } \\
\text { - Tourism and recreation and associated } \\
\text { employment }\end{array}$ \\
\hline $\begin{array}{l}\text { e precipitation } \\
\text { erosion } \\
\text { dslide }\end{array}$ & $\begin{array}{l}\text { - Management and restoration of } \\
\text { watershed vegetation to enhance } \\
\text { infiltration, reduce run-off and peak } \\
\text { flows, and stabilize slopes } \\
\text { - Agroforestry to enhance canopy } \\
\text { interception of rainfall and rainwater } \\
\text { infiltration and reduce soil exposure, } \\
\text { thereby reducing run-off and erosion } \\
\text { - Urban watercourse restoration, and } \\
\text { 're-naturing' to reduce assets at risk and } \\
\text { secure riverbanks } \\
\text { - Maintenance and restoration of urban } \\
\text { greenspaces to improve rainwater } \\
\text { infiltration and reduce run-off } \\
\text { - Management and restoration of } \\
\text { wetlands to store floodwater or slow its } \\
\text { release and filter sediments }\end{array}$ & $\begin{array}{l}\text { - Increased availability of wild-sourced food } \\
\text { and other products } \\
\text { - Pollination services } \\
\text { - Carbon sequestration and storage } \\
\text { - Improved soil fertility } \\
\text { - Biodiversity conservation } \\
\text { - Improved water quality } \\
\text { - Improved physical and mental health } \\
\text { among urban populations }\end{array}$ \\
\hline & $\begin{array}{l}\text { - Management and restoration of } \\
\text { watershed vegetation to enhance } \\
\text { infiltration, recharge groundwater stores } \\
\text { and maintain surface water flows } \\
\text { - Establishment of 'Green Belts' to } \\
\text { increase water availability, improve soil } \\
\text { quality, provide shade and windbreaks }\end{array}$ & $\begin{array}{l}\text { - Increased availability of wild-sourced food } \\
\text { and other products } \\
\text { - Pollination services } \\
\text { - Carbon sequestration and storage } \\
\text { - Improved soil fertility } \\
\text { - Biodiversity conservation }\end{array}$ \\
\hline $\begin{array}{l}\text { Rising temperatures } \\
\text { - Heat stress } \\
\text { - Urban heat islands } \\
\text { - Wildfire }\end{array}$ & $\begin{array}{l}\text { - Agroforestry to enhance canopy cover } \\
\text { and provide shade } \\
\text { - Rehabilitation and restoration of } \\
\text { rangelands to repair ecological } \\
\text { processes and enhance fire resistance } \\
\text { - Creation of urban green spaces to } \\
\text { increase vegetative canopies, which } \\
\text { provide shade and evaporative cooling }\end{array}$ & $\begin{array}{l}\text { - } \text { Carbon sequestration and storage } \\
\text { - Improved soil fertility } \\
\text { - Biodiversity conservation } \\
\text { - Improved physical and mental health } \\
\text { among urban populations }\end{array}$ \\
\hline
\end{tabular}


NbS for adaptation feature highly on the agendas of international financing institutions and donors. For example, the Global Environment Facility (GEF), the Adaptation Fund (AF) and the Green Climate Fund (GCF) have all supported numerous projects that use ecosystems to advance adaptation objectives, and bilateral donors, such as Germany's International Climate Initiative (IKI), are also prioritizing NbS for adaptation (see sections 6.4 and 6.5). Furthermore, there is also increasing interest among multilateral development banks and the private sector in using NbS to increase the climate resilience of their investments in, for example, infrastructure (Inter-American Development Bank [IDB] 2019). This is an important development as financial institution and private sector investment will be key to scaling up implementation of NbS for adaptation.

\section{Box 6.2. Ecosystem services}

'Ecosystem services' are the ecological characteristics, functions or processes that directly or indirectly contribute to human well-being: that is, the range of benefits that people derive from functioning ecosystems (Costanza et al. 1997; Millennium Ecosystem Assessment 2005; Costanza et al. 2017). These services can be broadly categorized as provisioning, regulating, cultural or supporting.

Provisioning services result in material benefits that people obtain from ecosystems, such as food, fuel, fibre, fresh water and genetic resources. Regulating services from ecosystem processes include air quality maintenance, climate regulation, erosion control and water purification. Non-material benefits that people obtain from ecosystems through spiritual enrichment, cognitive development, reflection, recreation and aesthetic experiences comprise cultural services. Lastly, supporting services are those that are essential for the generation of all other ecosystem services, such as primary production, production of oxygen and soil formation (Millennium Ecosystem Assessment 2005).

\subsection{Biodiversity and climate risks}

All three aspects of biodiversity - diversity within species, between species and of ecosystems - are impacted by climate change. Effective adaptation considers these aspects of ecological vulnerability and how this can in turn affect social vulnerability, including of youth, women, indigenous peoples and local communities. By specifically aiming to address broad societal goals such as human well-being, $\mathrm{NbS}$ go beyond some more narrowly defined approaches to adaptation (Seddon et al. 2020a).

\subsubsection{Implications of climate change for biodiversity}

Ecosystems can be broadly categorized into terrestrial, freshwater, coastal and marine. An ecosystem is a dynamic complex of plant, animal and micro-organism communities and their non-living environment interacting as a functional unit (Secretariat of the Convention on Biological Diversity 2010). Along with the services they provide (box 6.2), ecosystems play a key role in building the resilience of social systems.

Climate risks to ecosystems and their services are affected by multiple factors, including magnitude and rate of warming, geographic location, levels of ecosystem degradation, levels of ecosystem development and vulnerability, connectivity and fragmentation of ecosystems, local ecosystem tipping points, and selection and implementation of adaptation and mitigation options (Intergovernmental Panel on Climate Change [IPCC] 2018). Risks to species, ecosystems and ecosystem services can be addressed by adopting and accelerating mitigation and climate-informed natural resource management and conservation. Climate change can also alter ecosystems and their services, and may undermine the performance of $\mathrm{NbS}$ that rely on them (Calliari et al. 2019). Table 6.2 highlights some of the ways in which ecosystems and $\mathrm{NbS}$ interact with high- and low-risk climate scenarios.

Evidence of past climatic change indicates that ecosystems were strongly impacted by rates of climate change that were significantly lower than those currently projected under high warming scenarios (for example, Representative Concentration Pathway (RCP) 8.5). As such, under midand high-end climate scenarios (see table 6.2), many species are not expected to migrate at rates fast enough to follow suitable climatic conditions (Settele et al. 2014). An ecosystem's inherent sensitivity to the impacts of climate change and its capacity to adapt vary across ecosystems, meaning that some ecosystems are more vulnerable than others. However, these traits can be strongly influenced by the management approaches adopted. For example, ecosystem sensitivity to climate change can be reduced, and its capacity to adapt increased, by addressing non-climatic pressures on ecosystem function (such as invasive species, habitat loss and fragmentation) and by increasing genetic, species and functional richness through active management or through allowing degraded areas to regenerate naturally (Seddon et al. 2020a).

Applying NbS to address slow-onset events is often overlooked, with limited or no research available on specific $\mathrm{NbS}$ to tackle these issues. These include risks and impacts of events such as increasing temperatures, loss of biodiversity, desertification, land and forest degradation, glacial retreat and related impacts, sea level rise, ocean acidification and salinization (UNFCCC 2018). However, many $\mathrm{NbS}$ utilized to address more extreme events can also be harnessed to build resilience against these slowonset events. For example, protection, management and restoration of mangroves, sand dunes and coastal marshes 
Table 6.2. Examples of potential impacts under low- and high-end climate scenarios

Low-end climate scenarios

- Risks to natural and human systems are expected to be lower at $1.5^{\circ} \mathrm{C}$ than at $2^{\circ} \mathrm{C}$ of global warming (high confidence), as lower rates of change help maintain the ability of natural and human systems to adapt.

- Terrestrial and wetland ecosystems and the services they provide will suffer less if warming is limited to $1.5^{\circ} \mathrm{C}$ rather than to $2^{\circ} \mathrm{C}$, with the percentage of terrestrial land area projected to be affected by ecosystem transformations standing at 13 per cent at $2^{\circ} \mathrm{C}$ and approximately 4 per cent at $1.5^{\circ} \mathrm{C}$.

- Large-scale changes are observed in ocean ecosystems with critical thresholds expected to be reached at $1.5^{\circ} \mathrm{C}$

Warming towards $1.5^{\circ} \mathrm{C}$ will see increases in water temperatures that are expected to drive some species (such as plankton and fish) to migrate to higher latitudes and cause novel ecosystems to assemble. Species that are less able to relocate (e.g. corals) are projected to experience high rates of mortality and loss.

- Risks to ecosystems in oceans include declining ocean productivity, shifts of species to higher latitudes, ecosystem damage (such as to coral reefs and mangroves), loss of productivity in fisheries, and changes to ocean chemistry (for example, acidification).
High-end climate scenarios

- High-end scenarios project an increased risk of global extinctions - the fraction of species at risk of climaterelated extinction is 5 per cent at $2^{\circ} \mathrm{C}$ warming, rising to 16 per cent at $4.3^{\circ} \mathrm{C}$ warming.

Although the adaptive capacity of ecosystems and species is substantial, many will neither be able to cope with increased extreme events and variability, nor adapt to the projected high rates and magnitudes of climate change. This will ultimately result in their loss, along with the services they provide to people.

Species with long generation times show limited adaptive capacity at high rates of climate change, due to the inherent adaptive capacities of many species being exceeded.

Under high magnitudes of climate change, species with restricted populations (for example, in isolated habitats or on mountain tops) are expected to undergo adverse effects, reducing their abundance, resilience and viability.

Terrestrial and freshwater ecosystems are at risk of abrupt and irreversible regional-scale change in their composition, structure and function under large magnitudes and high rates of climate change.

Sources: Settele et al. (2014); IPCC (2018); IPBES (2019)

can build resilience as sea levels rise, while simultaneously protecting against extreme events such as coastal storms and surges (Kapos et al. 2019).

Many ecosystems that play a critical role in nature-based approaches to adaptation are themselves highly vulnerable to climate change. Mountain ecosystems, for example, play a critical role as 'water towers' reducing drought risk for surrounding communities. However, mountain ecosystems are among the most vulnerable to the negative impacts of climate change due to their low adaptive capacity (Immerzeel et al. 2020).

Climate change is having impacts on most ecological processes, with species across terrestrial, freshwater and marine ecosystems exhibiting changes in genetics, physiology, morphology and phenology. Shifting species distribution is another significant impact, which in turn has knock-on effects on food webs, resulting in new interactions between species (Scheffers et al. 2016). Risks to people from these changes include reduced and/ or unpredictable fishery and crop yields, loss of genetic diversity in wild crop varieties, and increasing impacts of pests and diseases.
The exposure, sensitivity and adaptive capacity of ecosystems both directly and indirectly affects their ability to act as a sink for carbon dioxide emissions and to reduce socioeconomic vulnerability to climate change (Seddon et al. 2020a). Although many natural systems are usually well adapted to natural disturbance regimes and can recover from major hazards (such as grasslands' ability to recover after fires), others are more sensitive (for example, forest dieback due to drought and heat stress) (Allen et al. 2010; Seddon et al. 2020a). Non-climatic stressors such as land-use change can induce additional disturbances that prevent adequate recovery. Furthermore, even in the absence of additional non-climatic stressors, increases in the frequency and intensity of climate hazards can compromise the adaptive capacity of ecosystems, potentially leading to a transition that results in a new community of species or the formation of a new ecosystem altogether (Seddon et al. 2020a).

Across marine, terrestrial and freshwater ecosystems, shifts in species distribution, changes in phenology, altered population dynamics, and changes in the composition of species assemblage or the structure and function of 


\section{Box 6.3. Addressing coastal hazards in the Mesoamerican Reef region}

The Mesoamerican reef is home to the world's second longest barrier reef. Stretching across more than 1,000 kilometres of coastline in Mexico, Belize, Guatemala and Honduras, it is also the largest transboundary reef system in the world. This hotspot for biodiversity is home to endangered marine turtles, more than 60 types of corals and over 500 fish species. Coastal and marine resources in the region provide essential ecosystem services and boost national economies by sustaining key economic sectors including fisheries and tourism and supporting the livelihoods of more than 2 million people.

While the Mesoamerican reef helps protect coastal communities against adverse effects of climate change, the ecosystems and species of this region are vulnerable to climate change impacts. For example, erosion and inundation of coastal areas due to storms and sea level rise, coral bleaching through increased ocean temperatures, and changes in ocean parameters such as $\mathrm{pH}$, leading to ocean acidification, are key climate change impacts affecting the region.

Climate-Smarting Marine Protected Areas and Coastal Management in the Mesoamerican Reef Region (the 'Smart Coasts' project), funded by the German Government's International Climate Initiative (IKI), was initiated to strengthen capacities in coastal communities and government institutions. It is implemented by the World Wildlife Fund for Nature (WWF), Stanford University and Columbia University in partnership with government agencies, coastal-marine resource co- managers, local communities and civil society groups from all four countries.

This project integrates climate change scenarios and adaptation options into a participatory decision-making process that can inform marine protected areas as well as coastal zone management and development policies. The project will enhance knowledge and capacities at local and national levels, contribute to national adaptation policies and action plans and make best practices available in relevant national and international forums. It takes an inclusive approach to implementation: women and men are offered equal opportunity to participate in its activities, including but not limited to meetings and workshops, analysis of local vulnerability and provision of recommendations to reduce vulnerability.

The analyses built on previous work in the region, applying science-based tools including ecological risk assessments and cost-benefit analyses that integrated climate change and social development scenarios, ecosystem services modelling and green versus grey infrastructure. Climate-risk information - which included sea level rise, sea surface temperatures, surface air temperature, extreme heat, and precipitation - was developed in consultation with stakeholders and incorporated into ecosystem service models on coastal protection, sedimentation, fisheries and tourism. Based on this information, stakeholders identified and prioritized $\mathrm{NbS}$ through a participatory decision-making process (see figure 6.2). In addition to informing relevant policy and management frameworks, adaptation measures will be implemented in selected coastal areas of Mexico, Belize, Guatemala and Honduras.

Figure 6.2. Inclusive framework used for NbS decision-making process in the Smart Coast project

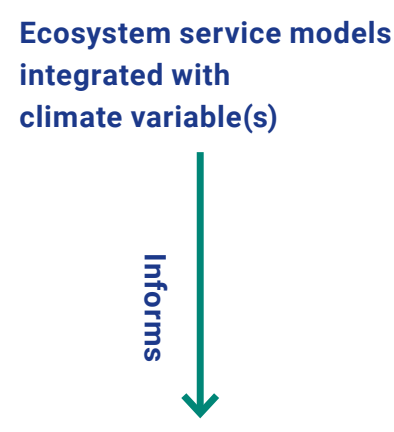

\section{Nature-based solutions}
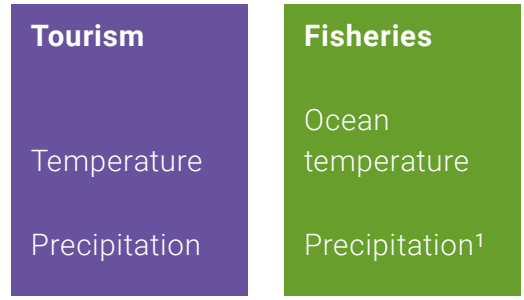

- Sustainable agriculture

- Fire management

- Sustainable palm oil

1 Precipitation is integrated into coastal risk reduction and fisheries models through its indirect effects on sediment export which can influence coral health

Sources: World Wildlife Fund for Nature (WWF) (undated); Reynolds (2019); Arkema et al. (2015) 
ecosystems, are already evident and accelerating (IPBES 2019). Changes are being seen across the organism, population, species and community levels. At the scale of organisms (such as individual plants and animals), genetic, physiological and morphological changes have been identified, while at the population level, changes in phenology, abundance and population dynamics have been observed. Changes in species distribution have ranged from shifts in fisheries to changes in pollinator ranges and abundance. In communities, interspecific relationships are changing due to redistribution of species where existing interactions are distributed and new interactions forming. These can lead to trophic disruptions and phenological mismatches. Changes in productivity have also been observed in communities in both terrestrial and aquatic systems (Scheffers et al. 2016). Finally, studies show that species are undergoing changes in their genetics, indicating evolutionary adaptation to human-induced climate change. For example, studies on pink salmon indicate an increased frequency of a genetic marker for late-migration timing (Kovach, Gharrett and Tallmon 2012).

\subsubsection{Effectiveness of nature-based solutions}

$\mathrm{NbS}$ for adaptation tend to be highly context-specific, adding to uncertainties about their effectiveness under changing climate conditions. In some cases, NbS may therefore be less effective for adaptation under future climate scenarios, in particular those involving highmagnitude climate hazards (Kapos et al. 2019).

Since ecosystems are already in the process of transitioning, reduced ecological resilience can lower the potential of $\mathrm{NbS}$ to support adaptive capacity in the long run (Scheffers et al. 2016; Lavorel et al. 2015). Severely altered ecosystems (such as mass coral mortality from bleaching) are unlikely to be able to adapt quickly enough (Graham et al. 2015). A study on the effectiveness of mangroves indicates that it is highly likely ( $>90$ per cent probability) that mangroves are unable to initiate sustained accretion when relative sea level rise rates exceed $6.1 \mathrm{~mm} \mathrm{yr}-1$. This threshold is likely to be surpassed on tropical coastlines within 30 years under high emissions scenarios (Saintilan et al. 2020), potentially limiting their ability to safeguard coastlines against rising sea levels.

Altered ecosystems could, in some cases, provide similar or novel adaptation services (Lavorel et al. 2015; Lavorel et al. 2019). Adaptation services are identified as ecosystem properties that facilitate societal climate adaptation by supporting current ecosystem service bundles, supplying novel services and moderating or enabling ecological transformation. Floodplain ecosystems are one example of a system that is likely to persist with an altered vegetation structure (probably with reduced extent) due to attributes such as high diversity of tree species, drought-resistant life-cycle stages, and high connectivity for recolonization via riparian vegetation.

\subsection{Planning}

Similar to the analysis in chapter 3 , this section summarizes available information on the degree to which countries' planning for adaptation incorporates NbS for adaptation, drawing primarily on nationally determined contributions (NDCs) under the Paris Agreement and national adaptation plans (NAPs) for which relevant analyses are available (no comprehensive analysis on the role of nature in the adaptation components of national communications is currently available). This section also explores progress both at sectoral and subnational scales, and on broader transboundary scales that in many cases are essential to secure ecosystem services and their contribution to resilience.

Analyses of NDCs show that between just under half (Pauw et al. 2016) and two-thirds (Seddon et al. 2020b) of countries' original NDC submissions acknowledged in their adaptation components that ecosystems and biodiversity are vulnerable to climate change (figure 6.3, Panel B). Lowand lower middle-income countries account for just over half of such submissions (Seddon et al. 2020b). Most NDCs assessed (106 out of 168) list ecosystem protection as an important motivation for adaptation planning, and include ecosystems in their overall statements of adaptation needs and approaches.

According to Seddon et al. (2020b), over 60 per cent of countries (104 nations) included aspects of $\mathrm{NbS}$ (EbA or conservation action) in the adaptation component of their NDCs (figure 6.3, Panel A). This is especially frequent among poorer nations; over 90 per cent of NDCs from least developed countries (LDCs), but only 26 per cent from highincome countries, include plans corresponding to $\mathrm{NbS}$ in the adaptation components of their NDCs. However only 30 of the NDCs that address NbS in the context of adaptation include relevant measurable targets that are distinct from broader adaptation goals (www.nbspolicyplatform.org).

Annex I countries' seventh National Communications to the UNFCCC show a similar pattern. In nearly all of these, the adaptation sections explicitly explore climate-changerelated risks to ecosystems and biodiversity. Some highlight the general utility of ecosystem-based approaches for reducing climate-related risks in general, but few reflect on any explicit plans for deploying these approaches in relation to specific climate risks - and if they do, any such plans are usually in reference to flood control or reducing urban heat island effects.

As required in preparation for UNFCCC COP 26, countries are in the process of revising their NDCs with a view to enhancing ambition and the probability of achieving the goals of the Paris Agreement. Of the few 2020 submissions (11 as at 1 Sept 2020), only Andorra, Chile, Moldova and Singapore include explicit reference to $\mathrm{NbS}$ in the context of adaptation - the first appearances of this terminology in NDCs - and aim to increase and mainstream their use 
Figure 6.3. Nature-based solutions in adaptation components of nationally determined contributions in developing countries

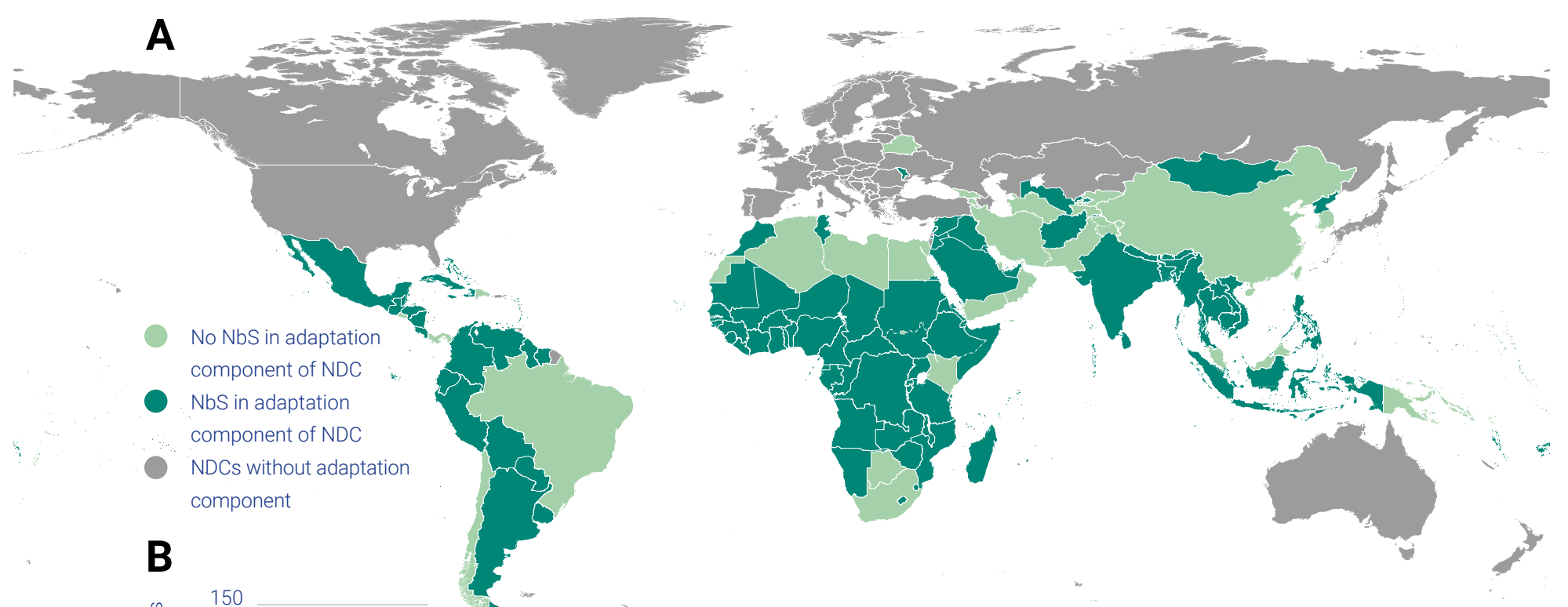

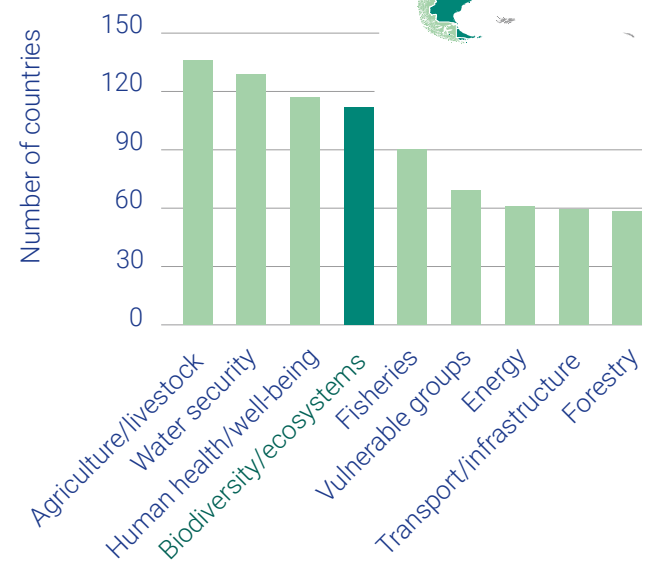

across sectors. They highlight, in particular, drought and flooding as hazards for which NbS are helpful approaches. For example, Singapore explicitly aims to 'naturalize' many of its waterways as a means of reducing flood risk and to conserve and restore mangroves to reduce the impacts of sea level rise.

Another major vehicle for adaptation planning under the UNFCCC is the national adaptation plan (NAP) process. This can be an important enabler for planning and implementing NbS through providing a framework and, potentially, financial resources for implementation at scale. The UNFCCC Technical Guidelines (Least Developed Countries Expert Group of the United Nations Framework Convention on Climate Change 2012) emphasize that the NAP process is to be inclusive of vulnerable groups, communities and ecosystems, promote the integration of gender perspectives and encourage countries to recognize the need to protect and build ecosystem resilience. All of the elements of the NAP process include key entry points for applying an ecosystem perspective (box 6.4), including through vulnerability assessments and explicit consideration of ecosystem-based approaches to adaptation.
A review undertaken for the NAP Global Network showed that all 19 of the NAPs submitted to the UNFCCC by March 2020 included some consideration of ecosystems and their vulnerability to climate change, and that most had identified ecosystem services at risk from climate change (Terton and Greenwalt 2020). The majority of NAPs referred explicitly to EbA and all included measures corresponding to EbA. The measures proposed mostly addressed forests, freshwater and coastal ecosystems, which were also those most commonly identified as vulnerable. However, it was often not made explicit how the individual measures described were expected to address climate-related hazards and risks and deliver measurable adaptation outcomes, or who the beneficiaries would be. Several countries had made efforts to link their NAPs to sectoral plans, including national biodiversity strategies.

Planning for NbS that contribute to adaptation is often needed and/or takes place in contexts where the focus is not climate change per se and at scales other than national. National biodiversity strategies and action plans (NBSAPs), which countries develop under the CBD, are one important example. The CBD has emphasized the potential and importance of 
Box 6.4. Entry points for NbS for adaptation in the NAP process

In principle, all four elements of the NAP process as laid out in the NAP Technical Guidelines (Least Developed Countries Expert Group of the United Nations Framework
Convention on Climate Change 2012) should incorporate $\mathrm{NbS}$ for adaptation, but specific attention to particular areas makes appropriate emphasis on the contribution of NbS more likely (UNEP 2019; Food and Agriculture Organization of the United Nations [FAO] and United Nations Development Programme [UNDP] 2020).

Figure 6.4. Entry points for NbS for adaptation in the NAP process

A2: Stocktaking: Identifying available information on climate change impacts, vulnerability and adaptation...

- Including ecosystems, ecosystem services and ecosystem dependencies in information compilation

- Engage experts on ecosystems and climate and relevant institutions

A4: Comprehensively and iteratively assessing development needs and climate vulnerabilities

- Identifying existing policy objectives on conservation, management \& restoration of ecosystems

- Examine potential for synergies with other multilateral environment agreements
B2: Assessing climate vulnerabilities and identifying adaptation options at sector, subnational, national and other appropriate levels

- Include assessments of ecosystem vulnerabilities

- Include ecosystem and ecosystem service dependencies in other vulnerability assessments

B3: Reviewing and appraising adaptation options

- Assess costs and benefits of adaptation options in ecosystems, as well as economic and social terms

- Examine potential for synergies with other multilateral environment agreements

B5: Integrating climate change adaptation into national and subnational development and sectoral planning - Involve environmental institutions as stakeholders

- Examine potential for synergies with other multilateral environment agreements
D1: Monitoring the NAP process

- Include monitoring of the status and vulnerability of ecosystems in the NAP monitoring and evaluation framework

- Include progress and impacts of implementing NbS for adaptation in the NAP monitoring and evaluation framework

D2: Review the NAP process to assess progress, effectiveness and gaps

- Draw on and expand existing ecosystem monitoring as needed to inform this process

Source: Least Developed Countries Expert Group of the United Nations Framework Convention on Climate Change (2012)

Element A

Laying the ground work and addressing gaps

20

Element B Preparatory element
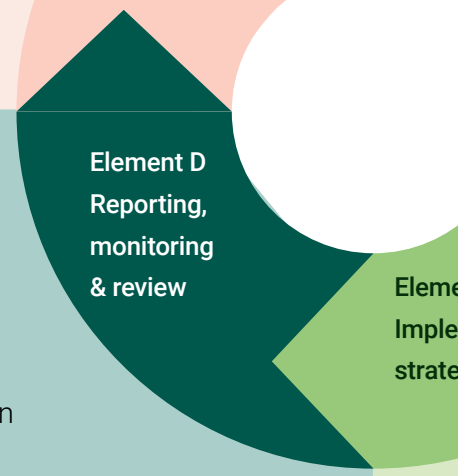

Element C Implementation trategies

\section{es}

C1: Prioritising climate change adaptation in national planning - Include the 'potential to complement national goals on protecting and enhancing ecosystem structures' among the criteria for prioritising implementation

- Examine potential for synergies with other multilateral environment agreements

C2: Develop a (long-term) national adaptation implementation strategy

- Including an ecosystem-based approach in the implementation strategy and in implementation itself

C3: Promoting coordination and synergy at the regional level and with other multilateral environmental agreements

- Involve sectors directly involved with and/ or dependent on ecosystems, including in a transboundary context 
EbA. Many countries have assessed climate vulnerability of species and ecosystems to inform their NBSAPs, and some have planned action to reduce that vulnerability, including reducing other anthropogenic pressures, as specified in the CBD's Aichi Biodiversity Target 10.2 While at least half of countries' NBSAPs include actions on ecosystem restoration, few explicitly address the restoration of ecosystem services or restoration for adaptation or to strengthen climate resilience (United Nations Development Programme [UNDP] 2016). The emerging post-2020 framework for the CBD, along with the UN Decade on Ecosystem Restoration, is likely to provide further opportunity for increasing coherence between planning for adaptation using NbS and action under the CBD, especially on ecosystem restoration.

NbS have also begun to be considered in sectoral planning processes, as they have the potential to contribute to resilience in sectors ranging from infrastructure (IDB 2019) and energy to water, agriculture and cities, and in some cases are being included substantively in sectoral plans (see box 6.5 for examples).

National plans are not the sole determinant of adaptation action at subnational and local scales: subnational plans and strategies may also incorporate NbS. This is especially notable in relation to local adaptation plans for cities. Of the 210 cities across the world that disclosed their adaptation actions to the Carbon Disclosure Project (CDP) in 2016, 101 reported planting trees and creating green spaces as actions taken to adapt to climate change, especially for reducing heat island effects and flood risk (Carbon Disclosure Project [CDP] 2016). Local adaptation planning is also relevant beyond the urban environment; for example, a GEF-funded project in Djibouti led to the development of district-level adaptation plans, which included NbS in the form of watershed and mangrove rehabilitation, for two regions of the country home to nearly 80,000 people in total.

Effective NbS for adaptation require system-scale approaches. For many locations, this will involve planning and coordination across national or jurisdictional boundaries, for example in managing hydrological catchments to address water supply and flood control (box 6.6). The need for NbS design to incorporate risk identification and risk management beyond the intervention site is highlighted in IUCN's Global Standard for NbS (IUCN 2020).

Successful adaptation from the national through to local scales requires coherence, integration and consistency between local decisions and actions and national-level strategies (Dazé, Price-Kelly and Rass 2016). If the use of NbS for adaptation is to be scaled up along with the associated potential socioeconomic and environmental co-benefits, $\mathrm{NbS}$ will need to be incorporated in more concrete terms into relevant planning processes that cross scales and sectors.
The NAP process can play a significant role in this. Area-based planning frameworks such as integrated water management or integrated coastal zone management, given their emphasis on landscape-scale ecosystem management and a holistic systems perspective, can also help facilitate vertical, as well as horizontal/cross-sectoral harmonization of adaptation action and support planning for NbS in adaptation.

There is also scope to incorporate into mitigation planning the role of ecosystems in providing NbS for adaptation. For example, the Paris Agreement emphasizes the importance of incentivizing, as appropriate, non-carbon benefits associated with REDD+ action and joint adaptation-mitigation action (UNFCCC 2016). However, despite some examples in spatial planning for REDD+ (Epple et al. 2016), there is as yet limited understanding and experience of planning for mitigation cobenefits from adaptation action or for enhanced benefits for adaptation from mitigation action. Critically, NbS planning needs to account for climate risks to ecosystems and include measures to address them in order to avoid investment in solutions that may be ineffective or short-lived.

\section{Box 6.5. Examples of sectoral adaptation plans that include NbS for adaptation}

Uruguay's NAP focuses specifically on the agriculture sector, with ecosystems and natural resources highlighted as one of the four major pillars around which it is organized. EbA plays a central role, with an emphasis on action at the landscape scale to achieve conservation, sustainable management and restoration of ecosystems to provide ecosystem services. Valuation of these services is seen as central to designing policies that account for their contribution to resilient production systems.

In its 2020 NDC submission, Chile both emphasizes the importance of $\mathrm{NbS}$ for adaptation and anticipates adaptation plans for 11 priority sectors. Its 2016 National Communication highlights the potential importance of EbA for the water, infrastructure and agriculture sectors.

Saint Lucia's Sectoral Adaptation Strategy and Action Plan for the Water Sector specifically prioritizes EbA solutions (including maintenance of vegetative buffers and protection of wetland ecosystems) as a strategic objective in strengthening preparedness for climate variability and extremes.

2 "By 2015, the multiple anthropogenic pressures on coral reefs, and other vulnerable ecosystems impacted by climate change or ocean acidification are minimized, so as to maintain their integrity and functioning." 


\section{Box 6.6. Transboundary planning/ implementation}

The commissions that oversee management of some transboundary hydrological systems provide a useful medium for adaptation planning. The Mekong River Commission has highlighted the potential importance of EbA in the countries of the Lower Mekong Basin (Mekong River Commission [MRC] 2014), while the Lake Victoria Basin Commission has developed a Climate Change Adaptation Strategy and Action Plan for the basin that emphasizes the importance of reducing the vulnerability of ecosystems and their services.

The private sector may also play a role in transboundary planning and implementation of $\mathrm{NbS}$ for adaptation. Facilitated by existing legal frameworks for protecting watershed forests and for compensating landowners who preserve forests that are important for water, Itaipú Binacional (a hydroelectric company that supplies 91 per cent of Paraguay's and 15 per cent of Brazil's electricity) worked with authorities and communities on both sides of the border to restore forest in the transboundary watershed supplying the dam. This resulted in reduced erosion and sedimentation and secured an improved water supply.

\subsection{Financing NbS for adaptation}

While NbS for adaptation have gained traction worldwide, securing the investments required to operationalize and sustain them continues to pose a major challenge. These funding needs are immense, far exceeding the current investment in NbS. As described in chapter 4 of this report, needs range from US\$140 billion to US\$300 billion annually by 2030 , rising to between US\$280 billion and US\$500 billion by 2050 (UNEP 2018). Long a concern of the conservation community (IUCN 2018; Thiele et al. 2020), the topic of NbS finance ${ }^{3}$ is now entering high-level global climate agendas.

Politically, there are urgent calls to raise the ambition for financing for NbS. For example, NbS was one of nine action areas at the 2019 Climate Action Summit, where the initiatives under discussion included increasing commitments from governments, private sectors, philanthropy, multilateral development banks and financial institutions to advance innovative, green climate finance and technical assistance, in order to scale up NbS investment in climate action (UN Climate Action Summit 2019). Furthermore, the next UNFCCC Forum of the Standing Committee on Finance will focus on financing NbS. These calls also includes considerations of how existing finance flows could be better oriented or redeployed towards NbS. The UN Decade on Ecosystem Restoration Strategy for example notes that fossil fuel subsidies total in excess of 1 trillion dollars a year and that a large proportion of these subsidies should be diverted to ecosystem restoration in order to manage climate change and degradation globally (UNEP 2020).

$\mathrm{NbS}$ are frequently a far cheaper and more cost-effective option than employing artificial technologies or taking remedial measures after natural functions have been lost. For example, every dollar invested in coastal ecosystem conservation in the United States is estimated to reduce the burden on US taxpayers by US\$4 in terms of avoided costs, losses and damages from storm-surge effects and other natural hazards (Multihazard Mitigation Council [MMC] 2005). In southern Vietnam, the restoration of 12,000 ha of mangroves has saved an estimated US\$7.3 million/year in dyke maintenance, a figure that is more than six and a half times the costs of planting (Powell et al. 2011). On the west coast of Sri Lanka, long-term climate adaptation benefits and costs saved were found to be more than twice as high as the costs of conserving coastal and estuarine ecosystems (De Mel and Weerathunge 2011).

To respond to the growing recognition of its value and costeffectiveness, NbS finance requires strengthening. Major gaps remain - not just in the availability of funds, but also in information and understanding about NbS financing needs, opportunities and solutions. The following sections address four key questions that are fundamental to advancing the NbS finance agenda: What is/are the scope, source and trends in global finance and investment flows to NbS? Are current funding levels sufficient? What can we learn from recent financing innovations? And what do we need to do to address NbS finance gaps?

\subsubsection{Tracking NbS funding status and gaps}

Gauging the current status of NbS funding, or tracking trends over time, is challenging. While this reflects the difficulties faced in estimating adaptation financing and costs more generally (figure 4.1), the specific characteristics and complexities of NbS pose a number of unique challenges. One is the rather nebulous nature of $\mathrm{NbS}$ financing, which in general nestles somewhere between 'climate finance' and 'conservation finance' (figure 6.5). In some cases - often in cities - NbS financing is instead part of general capital planning. New York City's watershed protection (US\$1.5 billion over 10 years) and green stormwater infrastructure plan ( US\$2 billion) are large-scale NbS programmes (City of New York

3 As this chapter is concerned specifically with nature-based solutions to climate adaptation, the use of the term 'NbS finance' should be taken to refer specifically to climate adaptation. 
Figure 6.5. Visualizing the relationship between $\mathrm{NbS}$ finance for adaptation, climate finance and conservation finance

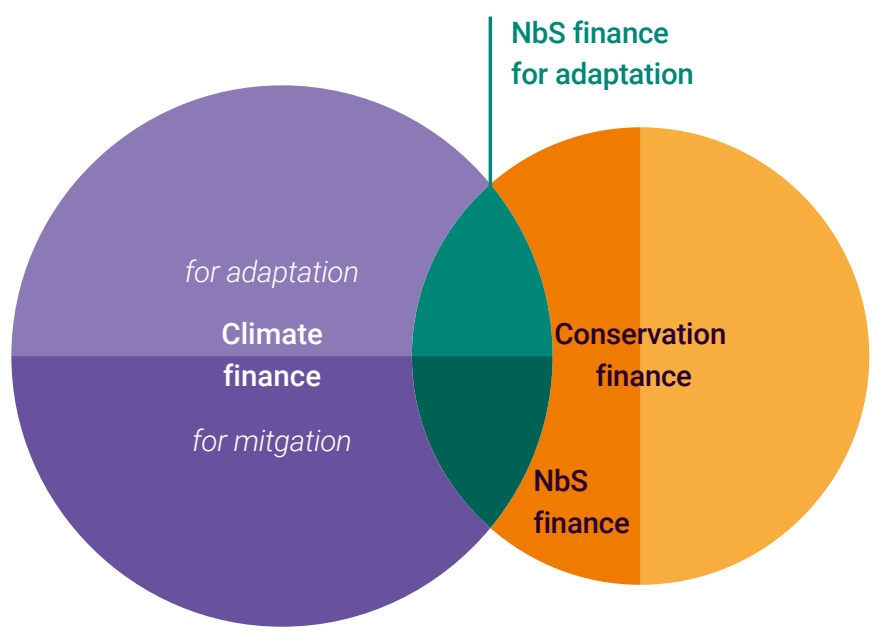

Note: This figure illustrates that NbS finance for adaptation is situated in the overlap between climate and conservation finance. For simplicity, it does not include other overlapping and intersecting funding categories, including infrastructure finance, disaster risk reduction finance, grey-green, hybrid, EbA amongst others. Relative sizes of the funding categories presented in this figure is not to scale.

\section{Box 6.7. A snapshot of private capital and implications for $\mathrm{NbS}$}

\section{Conservation investing}

Globally, just over US\$8 billion of private capital was committed to conservation investing between 2004 and 2015, averaging just under US\$1 billion a year (Hamrick 2016). Much of this investment appears to be oriented towards, or motivated by, climate-related goals.

\section{Climate bonds}

By the end of 2019, certified climate bonds were worth US\$100 billion, representing some 13 per cent of the green bonds market (Climate Bonds Initiative [CBI] 2020). In 2018, the issue was US\$23.3 billion (CBI 2019) - around twice as high as total Organisation for Economic Co-operation and Development (OECD) Development Assistance Committee (DAC) bilateral assistance to climate in the same year.

\section{Impact investing}

Total US-domiciled assets under management using sustainable, responsible and impact-investing strategies grew from US\$8.7 trillion at the start of 2016 to US\$12.0 trillion at the start of 2018, an increase of 38 per cent. This represents 26 per cent - or one in four dollars - of the US\$46.6 trillion in total US assets under professional management (The Forum for Sustainable and Responsible Investment [US SIF] 2018).

\section{Natural capital}

A recent survey of private asset owners and managers found that the single biggest factor driving them to natural capital, cited by almost half of investors, was 'resilience against climate change' (Cooper and Trémolet 2019). 
2019; The Nature Conservancy [TNC] 2020). Medellin's Green Corridors programme and Madrid's El Bosque Metropolitano on urban forestation to combat heat are other examples (C40 Cities Climate Leadership Group and Nordic Sustainability 2019; Cool Coalition 2020).

Most funding statistics do not distinguish $\mathrm{NbS}$ as a distinct category or specifically record $\mathrm{NbS}$ investments and spending. Even when there are disaggregated data, the many different (and often overlapping) terms and categories used to refer to environmentally oriented adaptation approaches often lead to confusion. The question arises as to whether ' $\mathrm{NbS}$ funding' is synonymous with, for example, funding for 'blue solutions', 'green solutions', 'green infrastructure', 'building with nature' or 'ecosystem-based adaptation'? Indicators specific to finance are largely absent in publications on $\mathrm{NbS}$ (Raymond et al. 2017), a gap that has been argued to serve as a constraint to mainstreaming (Somarakis et al. 2019).

The fact that $\mathrm{NbS}$ are almost always blended or integrated with other approaches and solutions - or are often not even conceived or presented as climate adaptation activities in the first place - increases the confusion and leads to possible underreporting. Particularly in the private sector, investments in natural capital are often a subset of larger categories, such as environmental, social and governance (ESG) financing, sustainable finance, green finance or impact investments (Cooper and Trémolet 2019) - if they recognize (and report on) 'naturebased' investments at all (box 6.7). The data that does exist, however, suggests that $\mathrm{NbS}$ continue to account for only a small share of total climate adaptation funding.

Worldwide, only around 24 per cent or US\$7 billion of public funding to climate adaptation in 2017/18 was destined for agriculture, forestry, land use, and natural resource management (Buchner et al. 2019). Of this, only a small portion is destined for NbS. Less than 1 per cent of global climate finance goes to coastal protection, infrastructure and disaster risk management, including NbS (Seddon et al. 2020a).

In 2018, the World Bank Group allocated over US\$7 billion for adaptation, of which US\$750 million or 11 per cent fell into the category of 'environment and natural resources', with projects ranging from landscape restoration and resilience to strengthening entrepreneurship in productive forest landscapes (World Bank, undated).
Between 2010 and 2018, a total of US\$111 billion in bilateral aid from the Organization for Economic Cooperation and Development's (OECD) Development Assistance Committee (DAC) countries was tagged as having climate adaptation as a significant objective, of which just over a quarter was for projects where adaptation was the principal objective. Of this, US\$9.6 billion and US\$20.3 billion respectively (31\% and $18 \%$ of total) was also categorized as environmental and forestry spending - giving an idea of the broad resource envelope available for NbS. While the funding to environment and forestry-oriented climate adaptation projects has been steadily increasing in absolute terms over the last decade (more than 30\%, from US\$2.2 billion to US\$2.8 billion, for funding with climate adaptation as a principal or significant objective), its share in overall climate adaptation funding has however progressively decreased (from $27.7 \%$ to $17.1 \%$ ) (OECD, 2020b) 4 .

An analysis of $\mathrm{NbS}$ for adaptation financing through four major international funding facilities - the Global Environment Facility (GEF), the Green Climate Fund (GCF), the Adaptation Fund (AF) and the International Climate Fund (IKI) - shows a total investment of US\$18.8 billion directly in support of climate change mitigation and adaptation over the last 30 years (table 6.3), supplemented by over US\$75 billion in co-financing. Projects with a focus on, or containing elements related to, NbS for adaptation account for only 13 per cent of this figure. Only a fraction of these investments are for on-the-ground implementation, while a large proportion of funding is for 'soft' activities such as policy formulation, institutional strengthening, technical capacity-building and awareness-raising (see section 6.5 for further analysis).

\subsubsection{Understanding $\mathrm{NbS}$ financing needs}

Limited access to finance is a key barrier to scaling up NbS implementation (Cooper and Matthews 2020). There is growing consensus about the need to identify new and additional financial mechanisms for NbS (Kapos et al. 2019; Seddon et al. 2020a). This extends beyond merely generating more funding and it is generally accepted that environmental and climate finance have multiple dimensions and requirements. It is also necessary, for example, to operate effective systems to plan, mobilize and administer financial resources, as well as to set in place the conditions and incentives that will enable, encourage and even demand long-term investments (Deutsche Gesellschaft für Internationale Zusammenarbeit [GIZ] 2019; Lazić and Emerton 2020). Most 'finance solutions'

4 Calculated from data sourced at https://stats.oecd.org/Index.aspx?DataSetCode=RIOMARKERS: 'Aid activities targeting Global Environmental Objectives'. All values expressed in constant 2017 US\$, and refer to total flows of bilateral allocable aid to developing countries. Obtained from dataset on bilateral commitment data on aid in support of environment sustainability and aid to biodiversity, climate change mitigation, climate change adaptation and desertification from the Development Assistance Committee (DAC) Creditor Reporting System (CRS) database. Total 'Climate Adaptation' refers to total, all sectors. 'Forestry' refers to sector 312: III,1,b Forestry, Total, marked with climate change adaptation as principal or significant objective. 'Environment' refers to sector 410: IV.1. General Environmental Protection, Total, marked with climate change adaptation as principal or significant objective. In their reporting to the DAC CRS, donors are requested to indicate for each activity whether or not it targets environment and the Rio Conventions (biodiversity, climate change mitigation, climate change adaptation and desertification). A scoring system of three values is used, in which aid activities are "marked" as targeting environment as the "principal objective" or a "significant objective", or as not targeting the objective. 
therefore look to combine mechanisms and strategies that generate, manage and deploy financial resources and align incentives to achieve nature conservation outcomes (Meyers et al. 2020).

It is also important to recognize that NbS often have particularly complex and wide-ranging financing needs. They typically incur a relatively high burden of opportunity costs (for example, foregone land and resource use options) and transactions costs (for example, participation in planning, management and enforcement). Another challenge (not insurmountable or different to 'grey' infrastructure) is the need for ongoing operating funds for maintenance. This does not necessarily mean that NbS are a more expensive option than 'grey' alternatives. Ample evidence suggests that they are often far cheaper and more cost-effective (see, for example, Reguero et al. 2020). It does however translate into an additional layer of funding needs, which are often indirect, are usually incurred by local populations (who may not always be the primary recipients of their adaptation benefits) and frequently demand imaginative and carefully thought-through approaches that take special account of i) the diversity of NbS cost-bearers and their differential financing needs, and ii) the strong equity principles that must be factored into funding, benefit-sharing and cost recovery.

Another important characteristic is that NbS are almost always justified and selected at least partially due to their ability to generate a broad range of public benefits and co-benefits, that include, but are not limited to, their primary adaptation objective. Often only a fraction of $\mathrm{NbS}$ (and usually a much smaller proportion than is the case with other adaptation approaches) can be financed, and maintained as purely commercial ventures or with full cost recovery. Many $\mathrm{NbS}$ also revolve around the management or improvement of public or communally held assets (including land). In most countries, regulatory and institutional frameworks only allow for very limited private investments in such assets, and place strict controls over the ownership of any benefits or revenues that are generated. This can act as a barrier to private finance. Modifying these frameworks and controls can enable private investment and the scaling-up of NbS benefits.

\subsubsection{Financing mechanisms for $\mathrm{NbS}$}

The diversity and heterogeneity of NbS financing needs requires a similarly wide-ranging portfolio of financing mechanisms that can be tailored to different situations, sectors and stakeholders. Yet, while a large volume of literature now exists on financing mechanisms for conservation and adaptation more generally (see, for example, Climate Finance Advisors 2019; Lo, Wu and Lin 2016; Meyers et al. 2020; Tonkonogy, Mazza and Micale 2018), there is as yet little guidance that looks specifically at NbS (see, for example, Droste et al. 2017; Somarakis et al. 2019; TNC 2018). This literature suggests that there is a wide range of financing mechanisms with potential application to $\mathrm{NbS}$, some of which are already widely used and others that are still emerging (table 6.4).
Despite the wide array of financing mechanisms that have the potential to be used to fund $\mathrm{NbS}$, there remains a heavy reliance on government and philanthropic sources (including international development assistance as well as domestic funding) - traditionally the foundation of both conservation and adaptation finance. Many of the more innovative mechanisms have been applied and tested (and often funded) as part of externally driven 'projects', and remain as pilot schemes. Issues of scalability, long-term sustainability and mainstreaming remain a major concern.

One barrier to deploying a broader (and more innovative) range of financing mechanisms in support of $\mathrm{NbS}$ is undoubtedly a lack of information. Articulating the multiple benefits of $\mathrm{NbS}$ in financial terms is challenging for many reasons, including limited or restricted data, limited research regarding quantified benefits, and a lack of coordinated knowledge transfer (Somarakis et al. 2019). There is a need to be able to provide convincing evidence to potential investors and project developers that NbS can be effective, sustainable and - if relevant - generate an adequate return in adaptation and/ or commercial terms. Despite a growing evidence base on the benefits and cost-effectiveness of NbS investments, this information is still not widely known, or is not communicated in a form that is accessible and convincing to investors and decision makers. Similarly, there is an urgent need to share information about the successes and lessons learned from piloting innovative $\mathrm{NbS}$ financing mechanisms, if they are to be taken up and replicated more broadly.

Another significant barrier to diversifying, scaling up and mainstreaming NbS financing mechanisms is unsupportive policy, legal and institutional conditions. This touches on a wide range of factors, ranging from improving fiscal and economic incentive structures and dismantling barriers, through developing new markets and pricing systems, to clarifying land and resource tenure regimes. This is a particular concern in relation to mobilizing private investment flows.

A recent World Bank Group (2020) report on Mobilizing Private Finance for Nature stresses that "governments and regulators, supported by financial institutions and multilateral development banks, hold the key to mobilizing private finance at the scale needed to transform the way we build, produce, and consume in order to protect nature while fostering sustainable poverty reduction." It highlights that the public sector needs to create a supportive enabling environment with efficient and effective incentives, standards and regulations, and to provide data and finance.

Blended or hybrid solutions and clustering projects have been suggested as ways of potentially making NbS more attractive to investors and helping increase investment (Cooper and Matthews 2020). Environmental fiscal reforms that include NbS (table 6.4) can be explored as a component of postpandemic recovery. Providing catalytical capital is another way in which government and multilateral development banks can mobilize private investment (World Bank Group 2020). 


\section{Box 6.8. Financing NbS: Itaipú Dam in Paraguay and Brazil}

Constructed in 1984, Itaipú Dam is one of the world's largest hydroelectric dams and produces 90 per cent of Paraguay's electricity and 16 per cent of Brazil's. Itaipú Binacional was set up as a company mandated by both countries to administer the plant's construction and operation. The company's mission is to generate quality electrical energy via socially and environmentally responsible practices that foster sustainable economic, tourist and technological development in Brazil and Paraguay.

It was recognized early on that sediment blockage and unreliable flows during periods of dry weather would pose significant challenges to the dam's efficient functioning and performance. Itaipú Binacional therefore pioneered a series of watershed restoration programmes, one such example being the Cultivating Good Water initiative situated on the Brazilian side. This 15-year programme involves a series of sub- programmes and initiatives aimed at improving water quality and flows in the Paraná watershed. It achieves a broad range of social and environmental goals, including food security, poverty alleviation, health and sanitation, climate change mitigation and adaptation, and biodiversity support.

The initiative is led by Itaipú Binacional, with implementation support from hundreds of organizations including governments, city administrators, NGOs, farmers, schools, community associations, businesses and others. A range of stakeholders fund this initiative, blending several financing types from three groups that provide roughly equal support (one-third): i) Itaipú Binacional, ii) municipalities and iii) communities and farmers. This cross-community approach has helped sustain the programme in the long term, creating buy-in from all the necessary stakeholders.

Sources: Rycerz et al. (2020); Itaipú Binacional (2020)

Table 6.3. Funding distribution of NbS projects or projects including NbS components of several funding institutions ${ }^{1}$

\begin{tabular}{l|c|c|c|c|c}
\hline \multirow{2}{*}{ Funding source } & GEF & GCF & AF & IKI & Total \\
\cline { 2 - 5 } & $(1991-2020)$ & $(2015-2020)$ & $(2010-2020)$ & $(2008-2020)$ & \\
\hline $\begin{array}{l}\text { Climate funding with } \\
\begin{array}{l}\text { co-financing (US\$ } \\
\text { billion) }\end{array}\end{array}$ & 66.77 & 23.1 & 0.742 & 3.556 & 94.17 \\
\hline $\begin{array}{l}\text { NbS funding (US\$ } \\
\text { billion) }\end{array}$ & 8.61 & 2.02 & 0.504 & 0.92 & 12.05 \\
\hline $\begin{array}{l}\text { NbS funding (\% of } \\
\text { total) }\end{array}$ & $13 \%$ & $9 \%$ & $68 \%$ & $26 \%$ & $13 \%$ \\
\hline
\end{tabular}

1 This analysis includes NbS relevant for adaptation, even if they are primarily focusing on carbon or biodiversity or are hybrid projects. There are many projects that focus on NbS for adaptation and also include other project components. 
Table 6.4. Selected NbS financing types and examples

\begin{tabular}{|c|c|c|c|}
\hline $\begin{array}{l}\text { Financing } \\
\text { category }\end{array}$ & $\begin{array}{l}\text { Financing } \\
\text { types }\end{array}$ & Examples of financing types & Case examples \\
\hline \multirow{3}{*}{$\begin{array}{l}\text { Public funding } \\
\text { (domestic) }\end{array}$} & $\begin{array}{l}\text { Institutional } \\
\text { budgets }\end{array}$ & $\begin{array}{l}\text { Routine budget allocations to the } \\
\text { public agencies and authorities } \\
\text { responsible for implementing } \\
\text { NbS or managing land, resources } \\
\text { and services upon which they } \\
\text { depend (for example Ministry of } \\
\text { Environment, national parks). }\end{array}$ & $\begin{array}{l}\text { Raingardens in Rotterdam installed in } 2016 \text { as } \\
\text { part of the city's climate adaptation strategy } \\
\text { to enable water retention and increase flood } \\
\text { protection (Frantzeskaki 2019). }\end{array}$ \\
\hline & $\begin{array}{l}\text { Direct public } \\
\text { investment }\end{array}$ & $\begin{array}{l}\text { Publicly funded NbS measures and } \\
\text { projects, typically at the domestic/ } \\
\text { national scale. }\end{array}$ & $\begin{array}{l}\text { Watershed forest restoration to support } \\
\text { functioning of the Itaipú Dam in Paraguay/ } \\
\text { Brazil by the public (municipalities) and } \\
\text { private (dam authority) sectors (Inter- } \\
\text { American Development Bank [IDB] 2020). }\end{array}$ \\
\hline & $\begin{array}{l}\text { Environmental } \\
\text { fiscal reforms } \\
\text { (EFRs) }\end{array}$ & $\begin{array}{l}\text { Governments could include EFRs as } \\
\text { part of crisis recovery plans. These } \\
\text { could be used to realign incentives } \\
\text { with sustainable practices (World } \\
\text { Bank Group 2020). }\end{array}$ & $\begin{array}{l}\text { Reforming agricultural subsidies and land } \\
\text { ownership complemented with investment } \\
\text { in social, development and job-creation } \\
\text { programmes (World Bank Group 2020) } \\
\text { with potential to include NbS. }\end{array}$ \\
\hline
\end{tabular}

Other types: Fiscal revenues and earmarking, ecological-fiscal transfers, subsidies or preferential finance

\begin{tabular}{|c|c|c|c|}
\hline \multirow{3}{*}{$\begin{array}{l}\text { International } \\
\text { development } \\
\text { transfers }\end{array}$} & $\begin{array}{l}\text { Grants } \\
\text { (public) }\end{array}$ & $\begin{array}{l}\text { Grants for NbS activities from } \\
\text { international development agencies } \\
\text { such as: the Department for } \\
\text { International Development (DFID)/ } \\
\text { UK Aid, the United States Agency } \\
\text { for International Development } \\
\text { (USAID) and the German Federal } \\
\text { Ministry for the Environment, } \\
\text { Nature Conservation and Nuclear } \\
\text { Safety. }\end{array}$ & $\begin{array}{l}\text { The International Climate Initiative (IKI) has } \\
\text { funded many global initiatives, including } \\
\text { NbS, for example the Ecosystem Based } \\
\text { Adaptation in Mountain Ecosystems project } \\
\text { in Nepal, Peru and Uganda (International } \\
\text { Climate Initiative 2020a). }\end{array}$ \\
\hline & $\begin{array}{l}\text { Global } \\
\text { financing } \\
\text { facilities } \\
\text { (public) }\end{array}$ & $\begin{array}{l}\text { Large international funding facilities } \\
\text { such the Global Environmental } \\
\text { Facility, the Green Climate Fund } \\
\text { and the Adaptation Fund, include } \\
\text { funding for NbS-related projects. }\end{array}$ & $\begin{array}{l}\text { The Adaptation Fund has committed US\$720 } \\
\text { million since 2010, including } 100 \text { concrete } \\
\text { adaptation projects, of which some are NbS } \\
\text { for example Enhancing Climate Resilience of } \\
\text { Rural Communities Living in Protected Areas } \\
\text { of Cambodia (Adaptation Fund, undated a). }\end{array}$ \\
\hline & Microfinance & $\begin{array}{l}\text { Microfinance uses intermediated, } \\
\text { concessionary finance to enable } \\
\text { inclusive microfinance solutions } \\
\text { that allow communities vulnerable } \\
\text { to climate change to adapt and build } \\
\text { resilience (OneWorld Sustainable } \\
\text { Investments and Oxford Policy } \\
\text { Management 2018). }\end{array}$ & $\begin{array}{l}\text { The Microfinance for EbA project provides } \\
\text { vulnerable populations in the Andean region } \\
\text { of Colombia and Peru with microfinance } \\
\text { services, allowing investment in activities } \\
\text { related to ecosystem sustainability to } \\
\text { improve their income and resilience (Climate } \\
\text { Technology Centre and Network [CTCN], } \\
\text { undated). }\end{array}$ \\
\hline
\end{tabular}

Other types: Loans, debt-for-nature swaps 


\begin{tabular}{|c|c|c|c|}
\hline $\begin{array}{l}\text { Financing } \\
\text { category }\end{array}$ & $\begin{array}{l}\text { Financing } \\
\text { types }\end{array}$ & Examples of financing types & Case examples \\
\hline \multirow[b]{2}{*}{$\begin{array}{l}\text { Grants, donations } \\
\text { and philanthropy }\end{array}$} & Direct grants & $\begin{array}{l}\text { External grants for NbS are available } \\
\text { from a variety of sources, including } \\
\text { public sector bodies and charitable } \\
\text { or philanthropic organizations. }\end{array}$ & $\begin{array}{l}\text { Rockefeller Foundation was a funding } \\
\text { partner for Rebuild by Design, along with US } \\
\text { government institutions. It included the Living } \\
\text { Breakwaters project to reduce risk, revive } \\
\text { ecologies and benefit residents in Staten } \\
\text { Island (New York State [NYS], undated). }\end{array}$ \\
\hline & $\begin{array}{l}\text { Corporate } \\
\text { sponsorship } \\
\text { and advertising }\end{array}$ & $\begin{array}{l}\text { These initiatives include initiatives } \\
\text { set up by corporate entities to } \\
\text { directly sponsor NbS activities. }\end{array}$ & $\begin{array}{l}\text { The HSBC Water Programme funded } \\
\text { the restoration of traditional cascading } \\
\text { freshwater tanks (reservoirs) in Sri Lanka, to } \\
\text { collect and utilize rainwater for agriculture } \\
\text { and to build community resilience (IUCN } \\
2015 \text { ). }\end{array}$ \\
\hline
\end{tabular}

Other types: Private donations and contributions, crowdfunding

\begin{tabular}{|c|c|c|c|}
\hline \multirow[t]{2}{*}{$\begin{array}{l}\text { Market-based } \\
\text { instruments }\end{array}$} & $\begin{array}{l}\text { Payments for } \\
\text { ecosystem } \\
\text { services (PES) }\end{array}$ & $\begin{array}{l}\text { PES occur when a beneficiary } \\
\text { or user of an ecosystem service } \\
\text { makes a direct or indirect payment } \\
\text { to the provider of that service } \\
\text { (UNDP, undated). }\end{array}$ & $\begin{array}{l}\text { The watershed PES scheme in Colombia } \\
\text { implemented in the Nima River region, } \\
\text { where large-scale private water users and } \\
\text { state agencies have paid private upstream } \\
\text { landowners to implement ecosystem } \\
\text { conservation measures (Rodríguez-de- } \\
\text { Francisco and Budds 2015). }\end{array}$ \\
\hline & \multicolumn{3}{|c|}{$\begin{array}{l}\text { Other types: Development of nature-based markets and products, user fees and service charges, } \\
\text { biodiversity offsets }\end{array}$} \\
\hline \multirow[t]{2}{*}{$\begin{array}{l}\text { Private } \\
\text { investments } \\
\text { and financial } \\
\text { instruments }\end{array}$} & $\begin{array}{l}\text { Debt } \\
\text { instruments } \\
\text { (e.g. bonds) }\end{array}$ & $\begin{array}{l}\text { These are the transfer of capital } \\
\text { from one entity to the borrowing } \\
\text { party who is then under an } \\
\text { obligation to pay the debt back at } \\
\text { a later date, usually with interest } \\
\text { (Meyers et al. 2020). }\end{array}$ & $\begin{array}{l}\text { Milwaukee Metropolitan Sewerage District } \\
\text { General Obligation Sewerage System Bonds } \\
\text { propose US\$80 million of funding with } \\
\text { Certified Climate Bonds and includes green } \\
\text { infrastructure (Kestrel Verifiers 2020). }\end{array}$ \\
\hline & \multicolumn{3}{|c|}{$\begin{array}{l}\text { Other types: Capital markets, investment funds, direct investments (venture capital, angel } \\
\text { investors, peer-to-peer, etc.) }\end{array}$} \\
\hline \multirow{2}{*}{ Risk management } & $\begin{array}{l}\text { Insurance } \\
\text { products }\end{array}$ & $\begin{array}{l}\text { Insurance products are financial } \\
\text { mechanisms that are used to } \\
\text { manage risks for governments, } \\
\text { companies, households and } \\
\text { individuals (Meyers et al. 2020). }\end{array}$ & $\begin{array}{l}\text { Restoration Insurance Service Company, a } \\
\text { planned pilot in the Philippines, will engage } \\
\text { in mangrove conservation and restoration to } \\
\text { provide flood reduction benefits. Insurance } \\
\text { companies will pay an annual fee for these } \\
\text { services (Conway and Mazza 2019). }\end{array}$ \\
\hline & $\begin{array}{l}\text { Pay for } \\
\text { success }\end{array}$ & $\begin{array}{l}\text { Pay for success is a mechanism by } \\
\text { which the government repays the } \\
\text { cost of service delivery if agreed- } \\
\text { on outcomes are achieved (Urban } \\
\text { Institute, undated). }\end{array}$ & $\begin{array}{l}\text { The Forest Resilience Bond includes forest } \\
\text { restoration and also a component whereby some } \\
\text { of the beneficiaries will sign 'pay-for-success' } \\
\text { cash flow contracts, which require payments } \\
\text { based on measured improvement in certain } \\
\text { benefits (Blue Forest Conservation, undated). }\end{array}$ \\
\hline
\end{tabular}




\subsubsection{Addressing the finance gaps and improving the sustainability of $\mathrm{NbS}$ efforts}

Several gaps have emerged in relation to NbS finance, which need to be addressed if the ambition to step up NbS action and reduce the NbS finance gap is to be met. These are:

Difficulty of gauging the current status and trends of $\mathrm{NbS}$ financing. The nature of $\mathrm{NbS}$ financing means that financing statistics do not distinguish $\mathrm{NbS}$ as a distinct category. It remains hard to know the status of $\mathrm{NbS}$ financing or to track changes over time. There is also a need for outcome metrics to inform tracking of adaptation finance effectiveness.

- Challenges related to NbS integration. NbS are almost always blended or integrated with other approaches and solutions and sometimes not presented as climate adaptation activities in the first place (for example, environmental, social and governance financing). This means that it is often difficult to mobilize or allocate funding for $\mathrm{NbS}$; in such cases, blending of financing mechanisms could help overcome this challenge.

Need for comprehensive assessment of NbS costs and funding needs. A comprehensive assessment of $\mathrm{NbS}$ costs and funding needs remains a major gap. Not knowing how much, or what type of, finance is required, or by whom, makes identifying ways of generating sufficient funds challenging.

- Identification of indirect and locally incurred costs. In particular, the opportunity costs of NbS translate into an additional layer of funding needs, which are often indirect and are usually incurred by local populations. Not only does this result in underfunding, but it can also give rise to significant inequalities.

Inequities in access to financing. Limited access to commercial financing mechanisms and global climate finance for subnational actors, including local communities, despite this being the scale at which many $\mathrm{NbS}$ are most effective. In particular, youth, women and indigenous peoples are often marginalized or excluded altogether from NbS funding. As above, this has implications for both funding security and equity.

Primary concern with public interest benefits. Investments in $\mathrm{NbS}$ are often largely justified by their ability to generate public interest, non-market benefits. Only a limited range of NbS interventions and benefits lend themselves to commercial or return-generating investments, can be captured by the market or are capable of full cost recovery. This makes a strong case for combined public-private partnerships.
In order to address NbS financing needs and move NbS financing forward, all of these issues must be addressed. This requires the following steps:

Improve information and reporting. There is a need to routinely generate quantitative information on NbS costs, funding flows and gaps. These basic data can be used to identify what the financing needs are, who the costbearers are, and which opportunities exist to strengthen NbS financing solutions, and to track changes over time. Aligning financial flows to NbS with impact metrics enables full accounting, so that the incremental costs of establishing $\mathrm{NbS}$ can be compared with the benefits provided. For example, avoided recovery costs from repeated storm surges can far exceed one-time mangrove restoration costs.

Understand costs and cost-bearers. This important prerequisite for financing remains a complex task. Typically, both the costs and cost-bearers of $\mathrm{NbS}$ are diverse, spanning direct expenditures, indirect or opportunity costs, transactions costs, and broader institutional, policy, regulatory and even capacity and training requirements. It is important to ensure that, when NbS actions and funding needs are estimated, these indirect costs are also included, alongside the more obvious direct physical expenditures. There is a particular need to ensure that local opportunity costs are adequately recognized and compensated.

Diversify and expand the funding base. Traditional sources such as public budgets and international assistance remain critical, but they are unlikely to be able to meet future needs for NbS finance. There is also a need to deploy innovative mechanisms that draw on and blend different sources, and are tailored to creating broader enabling financial conditions for public and private investments in NbS (table 6.4). It is vital that these funding sources are accessible to marginalized groups, including indigenous communities and women. In many cases, this requires tailoring funding to local-level needs, capacities and scales and prioritizing particular recipients - for example, through mechanisms such as microcredit, savings and loans, business start-ups and small grants.

Harness the growing sources of funding and innovations. There is an increasing interest in, and acceptance of, naturebased and 'green' approaches among investors, the general public and public funding agencies. NbS can be explicitly included as eligible activities in innovation and technology funds, and in global adaptation financing facilities. There is a strong case for using public finance as leverage or using blended finance to stimulate greater private investment flows to NbS from growing sources of funding (table 6.4), which can be used alone or in combination.

Improve equity. There is a need to promote equity and effectiveness in the way in which funding is generated, allocated and spent. This means ensuring that financing mechanisms reach the full range of $\mathrm{NbS}$ cost-bearers and 
implementors, including youth, women, indigenous peoples and local communities. The role of these key groups as innovators and implementers of NbS should be fully considered when designing and implementing financing mechanisms.

Create enabling conditions for NbS financing and investment. It is not enough only to identify NbS costs, funding needs and potential financing mechanisms. It is also necessary to ensure that potential investors, donors and cost-bearers are enabled and encouraged to finance $\mathrm{NbS}$. A wide range of factors constrain or act as barriers to NbS finance - or can act in its favour - including structural and regulatory frameworks, planning systems, market opportunities, fiscal and investment incentives, information and awareness.

Identify a convincing business case and bankable NbS projects. Defining a clear business case and bankable projects is essential to securing financing for $\mathrm{NbS}$ and needs to be clearly tailored to the target audience. Just as the needs for funding and financial support for $\mathrm{NbS}$ are diverse and wide-ranging, so are the interests and needs of the actors and stakeholders upon which they depend.

\subsection{Implementation of $\mathrm{NbS}$}

Acknowledging the recent traction that NbS have gained worldwide to effectively adapt to current and, to some degree, future climate risks, there is a need to better comprehend the extent to which they are being used in different regions and contexts and to what ends. This section provides an overview of the current level of $\mathrm{NbS}$ implementation worldwide in relation to coastal hazards (mainly sea level rise and storm surge), intense precipitation, drought, and rising temperatures.

Publicly available project-related information from global financing facilities, such as the GEF, ${ }^{5} \mathrm{GCF}, 6$ the $A F^{7}$ and $\mathrm{IKI}, 8$ has been collected and assessed to understand levels of NbS implementation and types of solutions used to address the climate hazards in low- and middle-income countries. Similar information has also been extracted from the Natural Hazards - Nature-based Solutions platform ${ }^{9}(\mathrm{NH}-\mathrm{NbS})$, which was hosted by the World Bank and covered a broader range of geographies and countries, as well as additional funding sources. For NbS projects in Europe, information was retrieved from the ClimateADAPT database. ${ }^{10}$ Information accessible via the CDP11 was analysed to identify NbS-related adaptation actions in urban areas and cities.

As the latter three databases rely on self-reporting, they do not provide a full picture of ongoing activities. Unlike the GEF, GCF, AF and IKI, they do not allow the level of $\mathrm{NbS}$ implementation to be assessed in relation to the implementation of other climate-related initiatives. While the focus of the data collected is on adaptation, initiatives pursuing other objectives that have clear adaptation cobenefits are also included in the analysis. Harmonizing the information across these seven data sources, the analysis is based on a total of 942 projects across all world regions that have NbS for adaptation either as the main focus (green) or as one element among others (hybrid).

Despite this probably being the most comprehensive assessment of $\mathrm{NbS}$ implementation to date, it is not possible to provide a full overview of $\mathrm{NbS}$ implementation, either because many initiatives are not recorded or because documented information about them is not readily accessible. For example, owing to a lack of available information, high-income regions outside Europe are not well covered in this analysis, apart from initiatives being implemented at the city level. Furthermore, initiatives presented on a number of project-based platforms, such as Oppla,12 Naturvation,13 Panorama ${ }^{14}$ and the Urban Climate Change Research Network, ${ }^{15}$ were not included in the analysis because the necessary data could not be retrieved. Despite providing a formidable repository of the peer-reviewed literature on the topic, the Nature-based Solutions Initiative ${ }^{16}$ was not included due to resource constraints. Therefore, while providing a good overview of the scale, regional distribution and types of NbS implementation to address climate hazards, the results presented in this chapter possibly reflect only a fraction of the full picture. The analysis thus complements assessments, building primarily on case studies and illustrative findings with regard to synergies and trade-offs, costs

5 https://www.thegef.org/projects

6 https://www.greenclimate.fund/projects

7 https://www.adaptation-fund.org/projects-programmes/

8 https://www.international-climate-initiative.com/en/projects

9 The NH-NbS platform information was downloaded from https://naturebasedsolutions.org, but as of January 2021 a modified website is accessible at https://documents.worldbank.org/en/publication/documents-reports/documentlist?qterm=P162684.

10 https://climate-adapt.eea.europa.eu/

11 https://www.cdp.net/en/data

12 https://oppla.eu/case-study-finder?combine=

13 https://naturvation.eu/atlas

$14 \mathrm{https} / / /$ panorama.solutions/en/portal/ecosystem-based-adaptation?page=2

15 https://uccrn.ei.columbia.edu/case-study-docking-station

16 https://www.naturebasedsolutionsinitiative.org/ 
Figure 6.6. Evolution of NbS initiatives over time, based on the total number of projects reported in the data sources

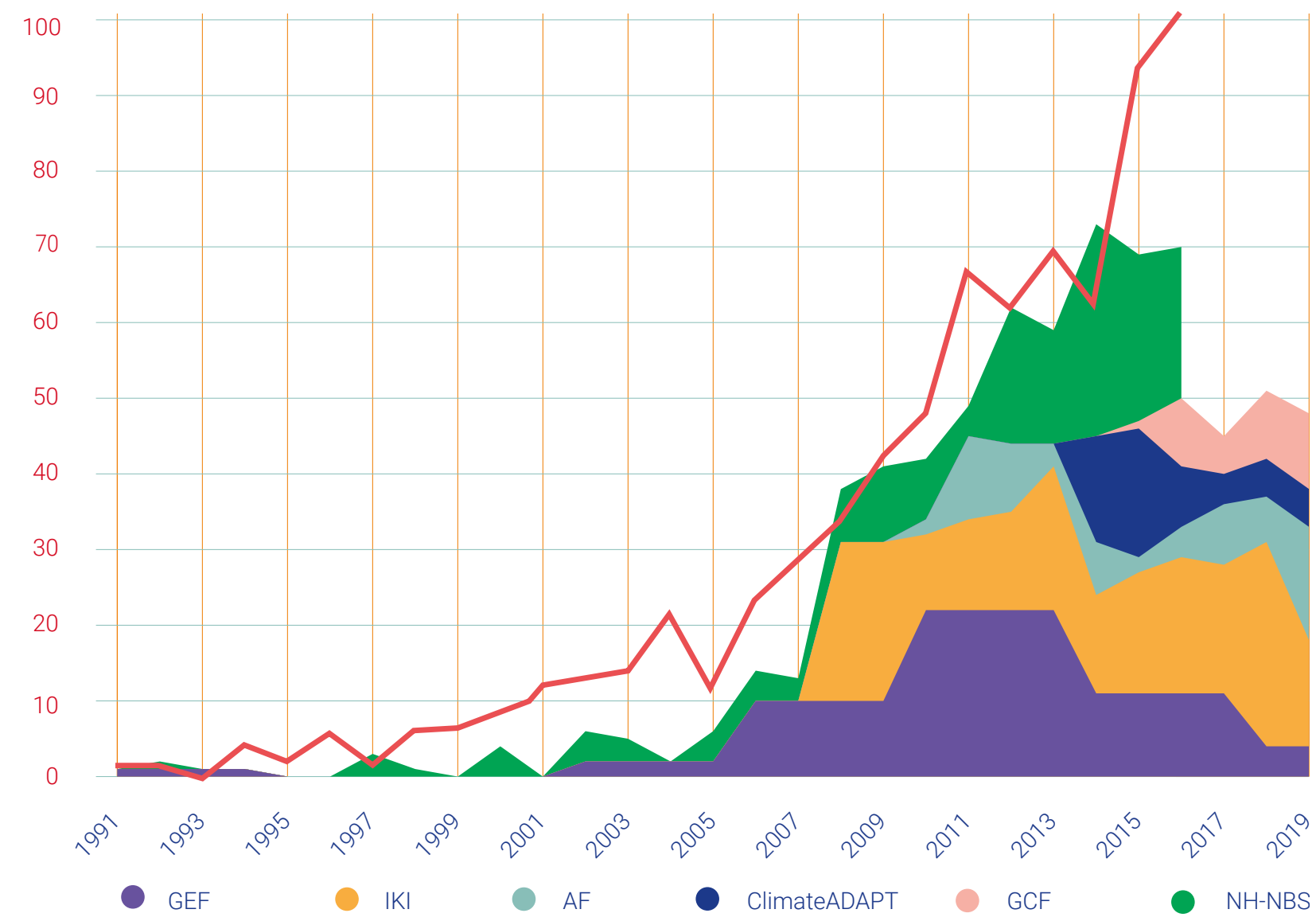

- Urban NbS mapped by the Naturvation project

Note: NbS projects presented include both green and hybrid initiatives. Years refer to the start date of the initiatives. ${ }^{1} \mathrm{NH}$-NBS data collection was discontinued after 2016. The red line depicts the evolution of NbS activities in European cities tracked within the Naturvation project. Sources: Authors' analysis; Almassy et al. (2018)

1 Data provided by the GEF does not include specific start dates for the initiatives it supports. Instead, it provides information about which funding cycle initiatives were included in. As such, GEF data presented in this figure represent a yearly average of the total number of NbS projects supported during each funding cycle.

and benefits, and challenges related to scaling-up (for example, Cohen-Shacham et al. 2016; Kapos et al. 2019; Organisation for Economic Co-operation and Development [OECD] 2020a; Seddon et al. 2020; Donatti et al. 2020; Chausson et al. 2020).

\subsubsection{Evolution of NbS implementation}

The fact that NbS for adaptation is a relatively recent concept is reflected in the limited number of projects that implicitly or explicitly build on it (figure 6.6). Prior to the early 2000s, NbS were only considered in the context of mitigation - if at all and are therefore not represented here. Between 2005 and 2015, there was an exponential increase in activities when integrating across the entire data set. However, from then on, the rate of increase seems to have plateaued at around 70 new initiatives per year, despite the emergence of new funding sources, foremost among them GCF. This mainly results from the fact that GEF-funded NbS initiatives peaked in the fifth funding cycle, both in the absolute number of projects and as a proportion of total climate-related investment, which dropped from 20 per cent in GEF-5 to 13 per cent in GEF$6 .{ }^{17}$ It is not yet possible to fully assess the trajectory after 2016, pending updates to data from the NH-NbS platform, which has been discontinued (B. Jongman, personal communication, 29.11.2020; World Bank 2017).

Data on NbS initiatives in urban areas from CDP are not presented in figure 6.6 because the database does not

17 Since its establishment on the eve of the Rio Earth Summit in 1992, the GEF has had eight four-year funding cycles. These are: Pilot phase, 1991-1994; GEF-1, 1994-1998; GEF-2, 1998-2002; GEF-3, 2002-2006; GEF-4, 2006-2010; GEF-5, 2010-2014; GEF-6, 2014-2018; and GEF-7, 2018-2022. 
Box 6.9 Using nature-based solutions to address coastal climate hazards, including storms, coastal erosion and flooding

As climate change intensifies, coastal areas are anticipated to be increasingly impacted by rising sea levels and increased frequency of extreme weather events. For coastal communities and ecosystems, these changes in climate conditions could result in increased exposure to storm surges and coastal flooding, increased rates of coastal erosion, and increased risk of groundwater salinization. While there are a number of interventions available to address coastal climate hazards (such as hard infrastructure), in recent decades the relative merits of implementing $\mathrm{NbS}$ have been increasingly recognized.

Increasing recognition of the benefits of $\mathrm{NbS}$ is facilitated through projects such as 'EbA: Strengthening the Evidence and Informing Policy', which was implemented by the IUCN and its partners - the International Institute for Environment and Development (IIED) and the UN Environment Programme World Conservation Monitoring Centre (UNEP-WCMC) (International Union for Conservation of Nature [IUCN], undated a). The project aimed to demonstrate to policymakers from developing countries why and when EbA represents an effective option for addressing climate hazards - discussing the conditions under which it works, and the benefits, costs and limitations of natural systems in relation to other available options - and to promote the integration of EbA principles into policy and planning processes. Over its lifespan, the project worked with the governments of 12 developing countries to develop clear country-specific policy recommendations and explore opportunities for, and barriers against, uptake. ${ }^{1}$

Another project raising awareness of $\mathrm{NbS}$, this time among both government and community actors, is the Neotropical Mangrove Conservation Alliance - a collaborative project between BirdLife partners that aims to conserve, restore and manage mangrove forests sustainably throughout the American tropics. The project facilitates knowledge-sharing and capacity-building among local stakeholders, while also raising awareness of the importance of mangroves and the need for on-the-ground conservation. In Samoa, where 74 per cent of people and infrastructure are situated in low-lying coastal areas, the project is working with the Matafaa indigenous village community to protect their coastal mangroves and help them to sustainably exploit the natural resources they provide (such as herbal medicine, fuel, fibre and fish). It is expected that protecting these coastal mangroves will reduce the vulnerability of the island's agricultural land to flooding and erosion caused by extreme weather events.

Exemplifying NbS for addressing coastal climate hazards in a developed country context, the UK Environment Agency - in collaboration with the Royal Society for the Protection of Birds (RSPB), engineers and the local community - created a new coastal wetland at Medmerry, a lowlying area on the south coast of England. This intertidal habitat acts as a buffer to sea level rise and storm surges. While the local community did not implement the project, they were engaged in the design process in order to ensure that the wetland enhanced recreational opportunities and contributed to the area's sense of place. Completed in 2013, the new wetland reduces flood risk for 348 homes. Aside from the scheme's biodiversity benefits, it has directly resulted in several major economic benefits, namely through significantly reducing ongoing maintenance costs of the area's flood defences, increasing tourism to the area and providing a natural fish nursery that is helping sustain the area's local fishing fleet (Royal Society for the Protection of Birds, undated).

Even as governments and other actors are increasingly addressing coastal climate hazards through applying nature-based approaches, it is often found that interventions are designed to address the impacts of coastal hazards on a single sector or stakeholder group, without properly consulting other stakeholders. As such, many NbS interventions can be seen to be lacking a truly common goal that benefits all of the area's stakeholders. Moving away from closed and/or silo-oriented design and implementation processes towards more comprehensive approaches will be the first step towards achieving truly effective and sustainable NbS. In particular, design and implementation processes for $\mathrm{NbS}$ need to find a greater role for local people and ensure that they are able to receive a share of the benefits provided by the intervention.

1 The 12 countries were: Bangladesh, China, Nepal, Burkina Faso, Kenya, Senegal, South Africa, Uganda, Chile, Costa Rica, El Salvador and Peru. 
Table 6.5. Number of NbS initiatives in relation to the total adaptation or climate-related portfolio, average funding including direct and co-finance, and ratio between green and hybrid interventions

\begin{tabular}{l|l|l|l|l}
\hline Data source & $\begin{array}{l}\text { Climate change } \\
\text { portfolio }(\mathrm{n})\end{array}$ & $\begin{array}{l}\text { NbS initiatives of } \\
\text { climate change } \\
\text { portfolio }(\mathrm{n})\end{array}$ & $\begin{array}{l}\text { Funding volume } \\
\text { (US\$ million) }\end{array}$ & $\begin{array}{l}\text { Green initiatives/ } \\
\text { hybrid initiatives } \\
(\% / \%)\end{array}$ \\
\hline $\mathbf{G E F}^{1}$ & 1,724 & 192 & $5.8+39.0$ & $46 / 54$ \\
\hline $\mathbf{G C F}^{1}$ & 139 & 37 & $27.3+27.4$ & $19 / 81$ \\
\hline $\mathbf{A F}^{2}$ & 107 & 70 & 7.2 & $13 / 87$ \\
\hline $\mathbf{I K I}^{1}$ & 766 & 207 & 4.4 & $55 / 45$ \\
\hline $\mathbf{C l i m a t e A D A P T}^{2,3}$ & 160 & 53 & - & $42 / 58$ \\
\hline $\mathbf{C D P}^{2}$ & 730 & 202 & - & $59 / 41$ \\
\hline $\mathbf{N H - N B S}{ }^{2}$ & - & 181 & - & $54 / 46$ \\
\hline
\end{tabular}

1 The climate change portfolio includes mitigation and other objectives besides adaptation.

2 The climate change portfolio includes only adaptation.

3 Only case studies and adaptation options were analysed.

Source: Authors' analysis

provide information about the start dates of initiatives, making it impossible to assess the timeline. However, data from NbS initiatives in European cities collected in the context of the Naturvation project (Almassy et al. 2018) also show a strong upward trajectory after 2000, although it is not possible to say whether the trend will continue unabated after 2016. Reassessment of the available data within the next three to five years will therefore be important if we are to establish a better sense of longer-term trends across the whole spectrum of $\mathrm{NbS}$ activities.

\subsubsection{Investments in NbS for adaptation}

In this section, investment in NbS for adaptation is discussed from three perspectives based on the information assessed: first, in the context of the contribution of NbS for adaptation compared with the overall portfolio of adaptation or, where not clearly distinguishable, climate-related initiatives; second, in relation to the project-level funding volume of NbS interventions; and third, as a ratio of green versus hybrid NbS interventions.

In relation to the total number of climate-related initiatives, the proportion of NbS projects across the four climate and development funds ranges from 11 per cent (GEF) to 65 per cent (AF), with GCF and IKI both standing at 27 per cent (table 6.5). These figures are comparable to the levels of funding described in section 6.4, except for GCF with only 9 per cent of financial investment (table 6.3). The discrepancy is mainly explained by higher levels of co-finance directed towards other targets, primarily mitigation, and suggests that NbS currently does not receive private sector support on a par with other climate-related interventions.
Adaptation employing NbS makes up some 33 per cent of all adaptation actions for ClimateADAPT, but for reasons that are unclear, the number of new interventions shows a fairly linear decline from 48 per cent in 2014 to 15 per cent in 2019. The proportion of cities reporting $\mathrm{NbS}$ in the CDP database is very consistent at around 28 per cent, despite the number of cities reporting adaptation actions having risen by over 50 per cent between 2017 and 2019 . This indicates that one in three cities uses NbS to address climate hazards. However, most cities implementing NbS also report a number of engineering or grey infrastructure solutions which, taken together, reduce the actual level of NbS implementation to circa 10 per cent of the overall adaptation portfolio. Nonetheless, the implementation of $\mathrm{NbS}$ is showing clear signs of growth, increasing from just 7 per cent in 2017 to nearly 12 per cent in 2019. Overall, considering the annual variations of implementation across the programmes, available time frames are still too short to determine clear trends in NbS implementation.

Based on the available information, the average funding volume for NbS-relevant projects varies considerably across funding sources, showing significant differences between funds with and without co-financing (table 6.5). With the exception of GCF, direct funding is typically between US\$4 and US\$7 million. Average co-funding levels are almost 1:7 for the GEF and 1:1 for GCF; in the absence of further information, however, it is unclear how to interpret the figures. The ClimateADAPT, CDP and $\mathrm{NH}-\mathrm{NbS}$ databases are not analysed in this context as they either provide no information, or incoherent 
Box 6.10. Using nature-based solutions to address intense precipitation, including flooding, erosion and landslides

Flooding, erosion and landslides induced by heavy rains pose risks to, among other things, human life, crops, livestock and infrastructure. In certain areas, climate change is projected to lead to increased precipitation, which will inevitably heighten the risk of these hazards occurring. The risks of flooding, erosion and landslides, however, has also been aggravated by human-driven processes that lead to long-term degradation of ecosystems and landscapes, such as the expansion of urban and agricultural areas and the exploitation of natural resources (for example, deforestation and mineral extraction). NbS are increasingly being recognized for their ability to reduce the risks of precipitation-induced hazards, as well as their potential to contribute to related societal challenges. In particular, ecosystem-based adaptation (EbA) - a subcomponent of $\mathrm{NbS}$ - is recognized for its ability to harnesses biodiversity and other ecosystem services at a scale that reduces the vulnerability of communities and ecosystems to climate change across a variety of landscapes.

For example, the Scaling Up Mountain EcosystemBased Adaptation project has implemented EbA measures across mountain ecosystems in Nepal, Uganda and Peru (International Union for Conservation of Nature [IUCN], undated b). In all cases, the project has implemented best-suited EbA measures, selected through participatory processes and evidencebased policy advocacy at the local and national levels. In Nepal, this led to the implementation of natural infrastructure such as bamboo check dams, and the planting of grass and tree species that help restore agricultural lands damaged by landslides and flooding. In Uganda, the project implemented EbA measures such as agroforestry and the re-vegetation of riverbanks alongside hard structural measures such as roadside drainage bunds and run-off retention drains, in order to reduce the risk of flooding, landslides and erosion occurring on Mt. Elgon's degraded landscape. Meanwhile in Peru, wetland conservation and communal native grassland management implemented by the project now contribute to, among other things, reduced erosion rates.

In Europe, the Lower Danube Green Corridor provides an ambitious example of EbA being implemented to reduce climate risks in a floodplain landscape (European Environment Agency, European Climate Adaptation Platform [ClimateADAPT], undated). The initiative aims to restore the Danube's floodplains across Bulgaria, Romania, Ukraine and Moldova, to reduce the risk of flooding and to enhance the landscape's ability to provide other ecosystem services (such as fishing, eco-tourism and grazing land). Over the last century, the river's capacity to provide these ecosystem services has been severely reduced due to human-driven processes that have reduced the river's floodplains, increased riverbed erosion and led to an 80 per cent loss of the river's wetlands. To combat this, the initiative aims to protect 1 million ha of land surrounding the river, restore 224,000 ha of natural floodplains and promote sustainable use and development within the river catchment. The first target has already been exceeded, with 1.4 million ha of wetland areas under some form of formal protection, while to date 60,000 ha of wetland has been restored.

The Building Climate Resilience through Rehabilitated Watersheds, Forests and Adaptive Livelihoods project being implemented in Comoros is aiming to increase the climate resilience of 15 villages across Comoros' three islands (UNEP, undated b). In these locations, increasingly erratic and decreasing rainfall are threatening the country's already tenuous water security (presently, less than 13 per cent of the population has access to good quality water supplies). Meanwhile, widespread deforestation has led to significant decreases in the water storage capacity of soil on the islands, leading to flooding and soil erosion. To combat these hazards, the project is promoting an integrated watershed management approach that includes implementing a number of EbA practices such as reforestation and restoring and sustainably managing 7,500 ha of watersheds, alongside small structural measures such as building rainwaterharvesting devices, constructing anti-erosion structures on farmland and developing sustainable livelihoods. To date, the project has reforested 170 ha of land and provided training on climate-resilient land management practices to the owners/leaseholders of 214 ha of land (UNEP, undated c).

Despite the growing number of EbA initiatives, ensuring that they are sustainable in the long-term, or that there is an incentive to upscale them in the future, remains a key challenge for implementers. To overcome this challenge, $\mathrm{NbS}$ - and in particular EbA - require that immediate responses be complemented by long-term strategies to ensure that they are able to enhance socioecological resilience in the longer term. Part of this long-term approach should be to integrate $\mathrm{NbS}$ and $\mathrm{EbA}$ into national and subnational policies and strategies and to mainstream these approaches into sectoral planning. 
information, in relation to funding levels. Despite this, it is apparent that the reported initiatives range from very small investments (such as greening a roof) to very large investments (such as thousands of hectares of floodplain restoration).

For the entire data set, the ratio between green initiatives (i.e. initiatives in which $\mathrm{NbS}$ are implemented on their own) and hybrid initiatives (i.e. initiatives in which $\mathrm{NbS}$ are combined with engineered solutions) is around 1:1. However, there are large differences across the platforms. For example, green initiatives constitute between 13 and 59 per cent of NbS-related initiatives, depending on the platform analysed (table 6.5). The relatively low proportions of green initiatives for the AF and GCF probably reflect their greater focus on traditional rural development in comparison with the GEF and IKI, which dedicate more attention to environmental protection and biodiversity while simultaneously pursuing development outcomes.

Irrespective of the ratio between green and hybrid NbS across the four funds, given their development focus, all projects allocate considerable resources towards other activities, namely capacity-building and training, awareness-raising, development of institutional and regulatory frameworks for scaling up pilots, innovative business and livelihood opportunities, and monitoring frameworks, such as climate information or early warning systems. While an in-depth assessment of the within-project distribution of funds was only possible for $A F$, the descriptions of envisaged benefits for the GEF, GCF and IKI portfolios suggest that they dedicate similar levels of project funds to developmentrelated activities.

Average funding for green initiatives directly related to NbS ranges from 61 to 67 per cent of total budgets, while it is merely 12 to 20 per cent for hybrid projects. This indicates that AF projects addressing climate hazards, whether employing NbS, infrastructure-based/engineered solutions, or a combination of the two, typically integrate development components in order to raise system resilience in the context of sustainable development and livelihood enhancement. In addition, while the NbS components of projects in more rural settings typically constitute between 19 and 27 per cent of available budgets, this is only 7 to 14 per cent for projects focusing on urban climate risks, potentially reflecting the greater need for engineered or grey infrastructure solutions in urban contexts.

However, OECD (2020a) suggests that regulatory frameworks might also be hampering stronger investment in $\mathrm{NbS}$. Qualitative comparisons with the ClimateADAPT database suggest that most European NbS projects lack this strong connection to development, instead focusing more on the technical, financial and sometimes legal aspects of $\mathrm{NbS}$ implementation.18 In view of the close correlation between positive development outcomes and climate resilience, the tendency of the four funds under consideration to allocate similar levels of funding to development-related activities is justified since improving livelihoods, capacity-building and governance are as necessary as technology transfer and implementation (UNEP 2018).

\subsubsection{Regional distribution and focus of $\mathrm{NbS}$ for adaptation}

Adaptation with $\mathrm{NbS}$ is recorded for all continents except Antarctica. While a few countries stand out with more than 30 initiatives (Brazil, Colombia, Indonesia, Peru, UK and USA), and 40 countries worldwide have no recorded initiatives, by far the largest group of countries (91 of 207) has between one and five projects (figure 6.7). Whereas 39 countries still record six to 10 projects, the number of projects per country then declines dramatically, to the extent that only five countries have $21-30$ projects. The distribution across regions is rather balanced with Africa, Asia-Pacific, Latin America and the Caribbean, and Western Europe and Other States all covering between 21 per cent and 25 per cent of initiatives. Only Eastern Europe is underrepresented with 4 per cent, while 3 per cent of projects were designed for multiple regions. Taking a closer look, it is also apparent that several countries in Central Asia and the Middle East have low levels of $\mathrm{NbS}$ implementation, warranting more focus on these regions in the future.

With the exception of projects described on the ClimateADAPT and $\mathrm{NH}-\mathrm{NbS}$ databases, developed countries are primarily represented via urban $\mathrm{NbS}$ initiatives documented on the CDP platform, on which more than half the entries are located in Western Europe, North America and other high-income countries (figure 6.7). In addition, one in four cities reporting NbS are from Latin America and the Caribbean, whereas cities in Africa, Asia-Pacific and Eastern Europe are strongly underrepresented. This suggests that urban $\mathrm{NbS}$ are in need of stronger recognition in most developing regions. Language barriers, access to information and/ or cultural and political reasons may also limit cities in these regions from disclosing information on CDP.

Globally, across the entire data set, intense precipitation is the climate hazard most frequently addressed (31 per cent), followed by drought (23 per cent). Coastal hazards, primarily sea level rise and storm surge, are covered in 16 per cent of cases, and rising temperatures is represented in 14 per cent of cases (figure 6.7). While 16 per cent of the data set does not mention specific climate hazards, in many cases more than one hazard is addressed. At the regional level, the picture is somewhat different: 
Figure 6.7. Global map of NbS initiatives for adaptation, showing the number of initiatives per country, the geographic distribution of cities reporting on NbS activities, and the regional distribution of hazards being addressed by NbS initiative

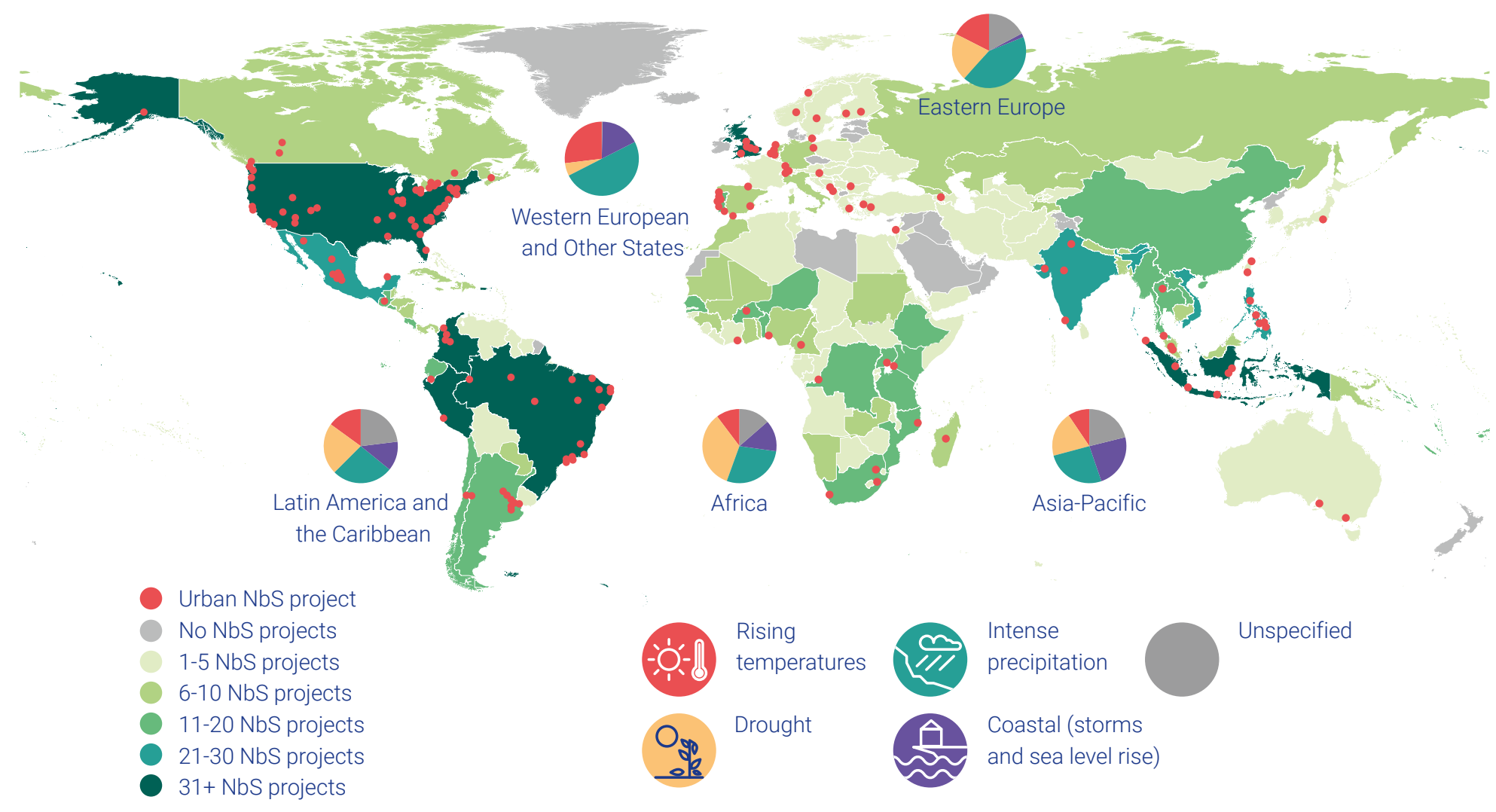

Note: Red dots represent the geographic location of cities reporting NbS activities via the CDP. Pie charts show the regional distribution of the hazards being addressed by NbS initiatives

Source: Authors' analysis based on data sourced from the GEF, GCF, AF, IKI, ClimateADAPT, CDP and NH-NbS databases

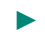

Coastal hazards: With 23 per cent of initiatives addressing coastal hazards in the Asia-Pacific region, coastal hazards are second only to intense precipitation. This is due in part to the region's large number of small island states and great exposure to tropical storms. At the other extreme, coastal hazards are mentioned in only 2 per cent of Eastern European cases, while for all other regions they are relevant in 13-17 per cent of initiatives.

- Intense precipitation: Western Europe and Other States and Eastern Europe stand out, with 50 per cent and 43 per cent of projects respectively addressing this hazard, compared with between 26 per cent and 28 per cent in all other regions. This might be explained by increasingly restricted waterways in Europe and other developed countries leading to more flooding downstream.

- Drought: For Africa, this is the most important hazard addressed, at 34 per cent, which is reflective of the region's greater exposure to drought risk in comparison with most other regions. While it is only reported in 6 per cent of initiatives in Western Europe and Other States, in all other regions drought represents 20-22 per cent of hazards addressed.

Rising temperatures: Perhaps surprisingly, for Western Europe and Other States rising temperatures represent the second most common hazard (at 27 per cent) and can largely be attributed to urban heat. Despite being exposed to typically higher temperatures, rising temperatures are only mentioned for 9-10 per cent of initiatives in the Asia-Pacific and Africa regions and in 15 per cent and 17 per cent of projects in Latin America and the Caribbean and Eastern Europe respectively, suggesting that there is a certain level of preexisting adaptation to current levels of heat in more tropical regions. 
Table 6.6. Geographical distribution of NbS initiatives

\begin{tabular}{l|l|l|l|l|l|l|l}
\hline & Africa & $\begin{array}{l}\text { Asia- } \\
\text { Pacific }\end{array}$ & $\begin{array}{l}\text { Eastern } \\
\text { Europe }\end{array}$ & $\begin{array}{l}\text { Latin } \\
\text { America } \\
\text { and the } \\
\text { Caribbean }\end{array}$ & $\begin{array}{l}\text { Western } \\
\text { Europe } \\
\text { and Other } \\
\text { States }\end{array}$ & $\begin{array}{l}\text { Multiple } \\
\text { regions }\end{array}$ & World \\
\hline Rural & $73 \%$ & $51 \%$ & $64 \%$ & $51 \%$ & $27 \%$ & $93 \%$ & $52 \%$ \\
\hline $\begin{array}{l}\text { Coastal } \\
\text { Urban } \\
\text { (incl. coastal) }\end{array}$ & $16 \%$ & $28 \%$ & $3 \%$ & $19 \%$ & $18 \%$ & $0 \%$ & $19 \%$ \\
\hline
\end{tabular}

Source: Authors' analysis based on data sourced from the GEF, GCF, AF, IKI, ClimateADAPT, CDP and NH-NbS databases

It will be important to track the regional distribution and hazard focus of future NbS projects to start understanding whether increasing climate change results in diverging trends.

Analysis of the available data indicates that over half of all $\mathrm{NbS}$ initiatives are carried out in rural geographies, while just under 20 per cent and 30 per cent of initiatives are located in coastal and urban environments, respectively. Four per cent of initiatives are located in coastal cities (table 6.6). In Africa and, to a lesser extent, in Eastern Europe, rural initiatives are significantly more prevalent, whereas in Western Europe and Other States the implementation of $\mathrm{NbS}$ within urban environments is much more prevalent than in rural areas.

\subsubsection{Using NbS to manage climate hazards}

This section describes the relationship between the distribution of primary climate hazards, presented above, and their expression in different contexts, referred to here as 'proximate climate hazards' for clarity. It also examines the NbS utilized to address them by reducing either vulnerability or exposure and thereby managing risk (figure 6.8). Descriptions of the relationships between the different primary and proximate climate hazards are followed by a summary of the connections between proximate climate hazards and the $\mathrm{NbS}$ used to manage them:

Coastal hazards, mainly sea level rise and storm surge, are relevant for 16 per cent of NbS projects. These are primarily concerned with addressing coastal flooding and erosion, but can also have implications on urban and river flooding when in the vicinity of the coast.

- Intense precipitation is addressed by nearly a third of all initiatives. These initiatives are primarily connected to river flooding, but urban flooding and erosion and landslides are also important. While the links between intense precipitation and these proximate hazards are immediately apparent, the fairly strong relationship between intense precipitation and drought illustrated in figure 6.8 is explained by the fact that floods and droughts often occur in the same rural landscapes due to increasing climate variability. They therefore need to be managed together.

Drought is addressed by 23 per cent of initiatives, which focus primarily on droughts affecting agricultural and livestock production and constraining water availability. River flooding and erosion and landslides are also important for the same reason described under intense precipitation. While erosion is more commonly related to intense precipitation events, wind can also be a major driver of soil erosion in dry landscapes.

Rising temperatures are the primary climate hazard in 14 per cent of cases analysed and shows strong links to temperature-related proximate hazards, including heat and fires. There is also an important connection to drought, which often occurs together with extended periods of extreme heat, and this can explain the minor connections to flood- and erosion-related hazards.

Although the relevance of specific NbS to addressing proximate climate hazards is complicated by the seemingly countless possibilities, there are a few clear trends:

Coastal flooding and erosion make up 11 per cent of all analysed climate hazards and relate primarily to coastal $\mathrm{NbS}$, namely restoration or protection of coral reefs, seagrass meadows, coastal wetlands (such as salt marshes), mangrove forests, and dunes and beach vegetation, all of which reduce wave and wind energy, thereby limiting their impacts. 
Box 6.10. Using nature-based solutions to address drought and rising temperatures, including heat, fires and desertification

In many parts of the world, climate change will lead to warmer, drier conditions, increased frequency of drought and longer fire seasons. These conditions will directly result in increased frequency of wildfires and accelerated rates of desertification (Center for Climate and Energy Solutions 2020). With increases in the frequency and magnitude of these impacts already being observed in certain regions, $\mathrm{NbS}$ are increasingly being recognized as an effective approach to addressing these climate risks.

For example, to combat the increasing risk of forest fires in Gambia, the national government (with support from UNEP) has developed a project to restore degraded forests and farmland, establish ecologically sustainable businesses to stimulate investments in environmental services, and integrate adaptation measures into sectoral policies that encourage/support the maintenance of healthy ecosystems that enhance resilience to climate impacts (UNEP, undated a).

Meanwhile in Paraguay, UNEP and the national government are working to reduce the vulnerability to drought events of the food systems of seven communities in the dry forests of the Chaco region by implementing cost-effective, on-theground EbA measures determined via community consultation (Adaptation Fund, undated b).

Finally, in Kazakhstan, UNDP and the Kazakh Government have expanded protected areas in the Altai-Sayan region by 328,000 ha and created a 'green corridor' to link up previously separated protected areas within the region. In parallel, to reduce the region's increasing vulnerability to wildfires, as part of the project a regional fire management system was established and training in wildfire management was provided to local firefighters (International Climate Initiative 2020b).

In these three case studies, the ecosystems involved are forested plains that are subject to periodic droughts and wildfires. In each case, these hazards threaten the sustainability of the ecosystem in question and degrade its capacity to deliver valuable ecosystem services. In response, all three interventions have adopted a landscapeapproach to adaptation that involves maintaining viable natural habitats, restoring degraded land, expanding conservation areas and implementing sustainable production practices tailored to the ecosystem in question. In all of these projects, this has resulted in the rehabilitation of degraded forest, wildlife and agricultural areas.

While the primary objective has been to restore degraded landscapes and make them resilient to climate change, in each case securing and maximizing tangible societal benefits has also been an overarching goal. This is reflected in the fact that all three projects use metrics based on societal units - such as number of communities, businesses, families, people or women who benefit from the project's outputs to quantify certain objectives and measure some parts of their success. Meanwhile, to ensure that success is achieved equitably, all three projects have taken measures during their planning and implementation phases to ensure that the project is gender sensitive.

A common challenge facing the successful implementation of these projects has been a lack of institutional capacity within communities and government actors to effectively implement and manage NbS. As such, all three projects incorporated capacity-building elements targeting relevant stakeholders to enable them to understand concepts, manage risks and implement best practices associated with $\mathrm{NbS}$.

Finally, these projects demonstrate the importance of holistic approaches to nature-based adaptation. For example, while each project clearly leverages the restoration or protection of landscapes as a means of enhancing the resilience of the ecosystem and its local populous to drought and wildfires, each project also utilizes other means to ensure further effectiveness and sustainability. For instance, in Kazakhstan the training of firefighters and installation of a fire management system in the Altai-Sayan region means that when wildfires inevitably occur, the extent of the damage sustained should be significantly reduced. Meanwhile, in Gambia the co-development of policies for the agriculture, environment and energy sectors with relevant government institutions could prove crucial in protecting gains made by the restoration of ecosystems and preventing a return to a businessas-usual scenario in which ecosystem degradation continues. 
Figure 6.8. Sankey diagram connecting underlying hazards to their impacts on the ground (proximate hazards) and how different $\mathrm{NbS}$ are being used to address them

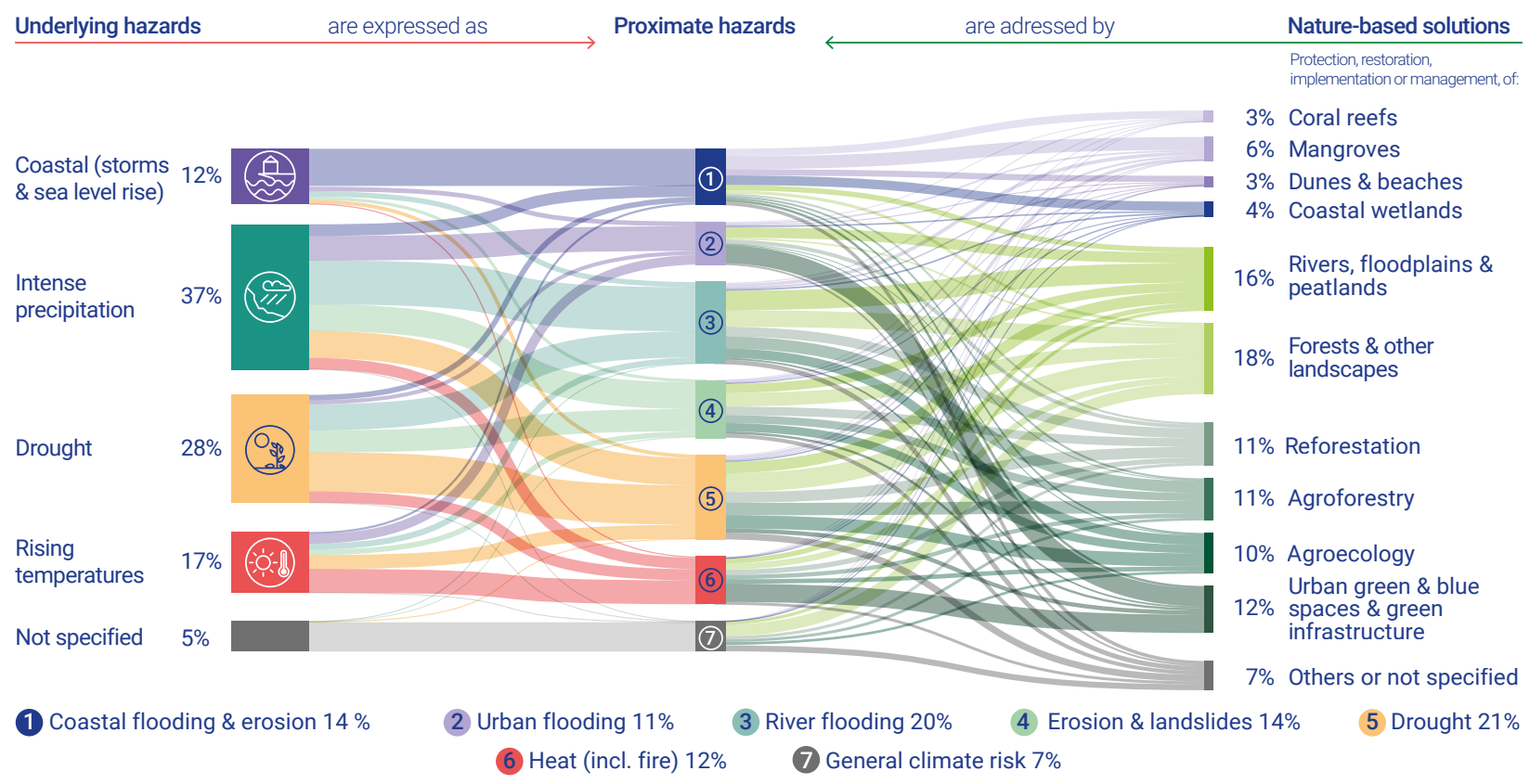

Note: The thickness of the ribbons is determined by the number of projects referring to each of the categories. Projects often mention multiple underlying and proximate hazards and can refer to several NbS to address them. (Example how to read the figure: temperature rise can lead to increased heat in urban areas that is effectively ameliorated with green and blue spaces as well as green infrastructure. Many other NbS are sometimes also used in the context of heat-related hazards). Percentage values presented in the figure are rounded to the nearest integer.

Source: Authors' analysis based on data sourced from the AF, GCF, ClimateADAPT, CDP, IKI and NH-NbS databases

- Urban flooding constitutes 11 per cent of examined cases and is addressed primarily via the implementation of urban green spaces, including urban watersheds, to enhance water infiltration and retention. Upstream nature-based watershed management also contributes to reducing peak run-off and thus flood risk.

- River flooding accounts for 21 per cent of reported hazards and is mainly mitigated by restoring or protecting floodplains and peatlands and by enhancing riparian vegetation to act as a buffer to fluctuations in water flux. To smaller degrees, forest and landscape restoration or protection, reforestation, agroforestry, and agroecological practices also contribute to managing surface run-off.

- Landslides and erosion represent 13 per cent of analysed cases. Similar to river flooding, watershed management options are primarily utilized to manage the resulting risks. Forest and landscape restoration and protection, reforestation, agroforestry and agroecology also play significant, though minor, roles.

- Droughts constitute 23 per cent of proximate hazards, which are most frequently addressed via integrated watershed and landscape management to enhance available water resources. Reforestation and more climate-smart agricultural practices (for example, agroforestry, agroecology) are also important measures to lower drought-related income losses through diversification and better water management.

Rising temperatures play a role in 16 per cent of examined projects. The majority of temperaturerelated risks relate to urban cases, which are mitigated through green spaces, trees, and green and blue infrastructure, all of which have cooling effects. Where heat and droughts occur together, a similar range of NbS are utilized to manage the hazards.

A general climate risk was attributed to 5 per cent of cases because no explicit climate hazard could be identified. This was often the case in earlier projects and those focusing on other goals (such as carbon sequestration or biodiversity) while providing important resilience co-benefits, primarily through forest and landscape restoration or protection.

While drawing upon a greater evidence base in terms of the number and scope of NbS activities analysed, the results of this assessment largely confirm the findings of recent literature describing how NbS approaches are being used to address climate hazards (for example, Kapos et al. 2019; Chausson et al. 2020; Seddon et al. 2020, Almassey et al. 2018). However, whereas a large meta-analysis of empirical studies suggests that NbS lead to clear positive outcomes 
Box 6.12. Using nature-based solutions to address urban climate risks, including to sea level rise, flooding and heat

As cities confront a range of increasing climate change hazards, from floods to heat to sea level rise, they must address how these affect businesses, infrastructure, delivery of services, biodiversity, the natural environments and residents. As recognition grows around how NbS can provide increased resilience alongside health and well-being co-benefits, NbS approaches are increasing in popularity in cities of all sizes, across developed and developing countries.

In Lao People's Democratic Republic (PDR), climate change is increasing the frequency and intensity of extreme rainfall, resulting in more frequent and more severe flooding in vulnerable and rapidly growing cities along the Mekong River. Flood management in the country has traditionally used a hard infrastructure approach; however, building on and scaling up previous successful interventions in wetland rehabilitation, UNEP and the national government (with GCF funding) have initiated a new project for integrated climate-resilient flood management utilizing NbS. Interventions include increasing green spaces and permeable surfaces within cities to reduce run-off and rehabilitating and protecting urban streams and wetlands. The results are expected to greatly reduce the economic burden of flooding, which is estimated to cost each household approximately US\$1,000 after each heavy rainfall event (Lao People's Democratic Republic and United Nations Environment Programme 2019).

Singapore, a much denser and more populous city than those found in Lao PDR, is also dealing with flood risk. The city is also concerned about accelerated coastal erosion and the increasing vulnerability of ecosystems to climate change. To better understand these hazards, the Government has undertaken an extensive assessment of the vulnerability of ecosystems and plant species from i) forests and wetlands that are vulnerable due to fragmentation compounded by changes in rainfall patterns, ii) mangroves that are at risk from sea level rise and iii) corals that are threatened by higher temperatures. As a result of this assessment, Singapore's response targets the restoration of forests and mangroves through both planting and minimization of other pressures, diversification of roadside tree species, and long-term planning approaches to address coastal vulnerability to flood and erosion. This comprehensive and interdisciplinary approach has consequently improved climate resilience for the population as well as ecosystems and biodiversity.

New York City has also focused on trees and urban forests with its MillionTreesNYC project for heat and flood reduction benefits. The project is notable for its public-private partnership approach that brings together city departments, academia, research institutes, community organizations, homeowners and local businesses to plant 1 million trees. In addition to the adaptation benefits, the project also prioritizes $\mathrm{CO}_{2}$ sequestration and air quality cobenefits. The project has a strong emphasis on cost-benefit analysis, emphasizing the economic benefits associated with the capacity of trees to reduce storm water and air pollutants estimated to equate to a return of US\$5.60 in benefits for every dollar spent (Quinn 2018). The goal of 1 million trees was reached in 2015, expanding the city's urban forest by 20 per cent (NYC Parks 2015)

Lao PDR, Singapore and New York are just a few examples of the many cities and countries pursuing urban $\mathrm{NbS}$ to build resilience and provide co-benefits for growing and changing populations. Each case highlights some effective strategies for expanding and enhancing NbS actions, whether by building on previous knowledge, experiences and projects or mobilizing interdisciplinary and multistakeholder partnerships. There are also several commonalities across the cases. One common challenge is that full results, especially in terms of building resilience and/or reducing risks, may not yet be apparent - either because the project has just started or because the results reflect the implementation of the $\mathrm{NbS}$ approach and not necessarily when it is 'tested'. The cases in Singapore and New York also hint at some of the limitations of $\mathrm{NbS}$ in urban environments where ecosystem fragmentation or remaining physical space for interventions is limited. Nevertheless, all three cases demonstrate the potential for NbS to improve resilience, especially to floodingrelated risks, for people while improving urban ecosystems and biodiversity. 
in relation to food production, landscape restoration, flood management, and erosion control (Chausson et al. 2020), whether the activities described here achieve their goals cannot be assessed using the approach applied. Determining this would require a far more in-depth assessment, which is presently not feasible given the small number of cases that are at the point at which they could be analysed through an ex-post impact assessment. Furthermore, even for $\mathrm{NbS}$ projects that have been fully implemented, there is presently no information available about these initiatives that would allow their outcomes to be assessed. This information gap represents a major barrier that urgently needs addressing in order to allow for independent and transparent analyses of the outcomes of NbS projects and a more systematic reflection on the pros and cons of future $\mathrm{NbS}$ investments.

\subsubsection{Benefits and co-benefits of NbS}

In contrast to engineered solutions to mitigate climate hazards, NbS can provide a wide range of additional direct and indirect benefits, which are frequently not sufficiently taken into account when making investment decisions (OECD 2020a). Besides the benefits mentioned in table 6.1, the analysis of available data sources shows several other benefits of $\mathrm{NbS}$ that are relevant for future decision-making (table 6.7). Some of the benefits listed in table 6.7 arise in the context of projects focusing primarily on rural development in a changing climate and are therefore much less relevant for projects that are situated in high-income regions or employed to manage urban climate risks. That is because NbS are often better positioned than their engineering-based counterparts to building adaptive capacity while also managing climate risks due to their important contributions to enhancing environmental governance, building capacity, raising awareness, developing innovative business models and offering alternative income streams to improve livelihoods.

$\mathrm{NbS}$ are also often favoured as solutions when it comes to simultaneously addressing several environmental challenges because of their capacity to provide multiple ecosystem benefits, such as enhancing or maintaining important ecosystem services, biodiversity, carbon storage and landscape restoration. For example, NbS were implemented in only 8 per cent of GEF projects focusing exclusively on climate change (GEF-1 to GEF-7), whereas they were selected in between 50 per cent and 70 per cent of projects that combined climate change with land degradation, biodiversity or transboundary water management. This suggests that NbS-related projects are being viewed as integrated solutions to a range of development challenges, rather than merely as a direct substitute to engineering solutions.

Several of the projects assessed explicitly mention gender equity as an important goal and some even focus on using NbS to improve women's livelihoods by enhancing incomes, health, or local governance and institutional capacity. Other initiatives highlight improvements in indigenous or local community rights and land tenure arrangements in the context of developing $\mathrm{NbS}$ to manage land sustainably, with clear benefits in terms of climate resilience. In addition, $\mathrm{NbS}$ are frequently mentioned as means of enhancing transboundary collaboration and conflict resolution where landscape-level interventions are being pursued. Furthermore, many interventions specifically envision developing blueprints and frameworks for scaling up pilot projects to larger scales as well as mainstreaming NbS into national planning processes.

While there is sufficient evidence supporting the effectiveness of NbS under current climatic conditions, $\mathrm{NbS}$ are subject to the impacts of climate change and may lose some or all of their capacity to reduce or manage climate risks in the future. For example, warm-water corals are already threatened by the impacts of climate change and are unlikely to survive a $2^{\circ} \mathrm{C}$ increase in global temperatures above pre-industrial levels (IPCC 2018). It is therefore important to consider ecological thresholds when devising new NbS initiatives to ensure that, despite unavoidable climate change, they can continue to provide their environmental and other benefits.

\subsubsection{Challenges and recommendations for scaling up NbS implementation}

$\mathrm{NbS}$ are increasingly being discussed as effective and cost-efficient solutions to climate-related risks (Costanza et al. 2008; Kapos et al. 2019; OECD 2020a). Chausson et al. (2020) evaluated a large number of cases from the peer-reviewed literature, concluding that 59 per cent of the cases analysed had positive effects on the climate hazard addressed, with improvements in soil erosion, freshwater flooding and reversal of degradation, but only limited information was available on coastal hazards, wildfire, and slope stability. Similarly, Seddon et al. (2020) report on multiple cases in which NbS contributed to reducing exposure to climate hazards in relation to soil erosion, inland and urban flooding, coastal hazards and sea level rise, urban heat waves and heat island effects, and to reducing the impacts of drought. They also describe cases of positive effects on vulnerability reduction via enhancing and diversifying ecosystem services and through governance reform, empowerment and improved access to natural resources established in the context of NbS interventions.

However, for most NbS initiatives analyzed in this context, it is too early to assess their effects on reducing climate risks, as work is often still ongoing. Further, where NbS projects have been fully implemented, there is surprisingly little information available on the effectiveness and efficiency of the intervention. Only AF provides easily accessible final project evaluations, but none of these discuss the longer-term results. Improving the availability of ex-post evaluations of $\mathrm{NbS}$ interventions and initiatives is therefore of utmost importance in order to shed more light on their effectiveness, efficiency and environmental, socioeconomic, and financial sustainability, all of which are critical to their long-term success and scalability. 
Table 6.7. Examples of environmental, social, economic, policy-related and other benefits related to interventions with NbS

\begin{tabular}{|c|c|c|}
\hline Scale & Environmental & Social \\
\hline $\begin{array}{l}\text { - Local } \\
\text { - Subnational } \\
\text { - National } \\
\text { - Regional } \\
\text { - Global }\end{array}$ & $\begin{array}{l}\text { - Improved water quality and } \\
\text { - } \text { Bvailability } \\
\text { - Carbon storage } \\
\text { - Reversal of degradation } \\
\text { - Lower air and noise pollution } \\
\text { - Protected area development } \\
\text { (e.g. park zonation) } \\
\text { - Nature corridors }\end{array}$ & $\begin{array}{l}\text { - Human capacity and training } \\
\text { - Greater opportunities for } \\
\text { women } \\
\text { - Awareness-raising and } \\
\text { knowledge-sharing } \\
\text { - Grass-roots mobilization } \\
\text { - Building adaptive capacity at } \\
\text { local levels }\end{array}$ \\
\hline Economic & Policy-related & Risk management / Other \\
\hline $\begin{array}{l}\text { - Income, livelihoods, and food } \\
\text { security } \\
\text { - Increased crop, livestock and } \\
\text { forestry productivity } \\
\text { - Creation of new jobs (e.g. } \\
\text { tourism, aquaculture, non- } \\
\text { timber forest products) } \\
\text { - Water security } \\
\text { - Health (e.g. water, sanitation } \\
\text { and hygiene) } \\
\text { - Energy security } \\
\text { - Regional development } \\
\text { - Market access } \\
\text { - Value and supply chain } \\
\text { development } \\
\text { - Innovative business models } \\
\text { - Enterprise development } \\
\text { - Public-private partnerships } \\
\text { - Microfinance and loans } \\
\text { - Benefit-sharing mechanisms } \\
\text { (e.g. PES, REDD+) } \\
\text { - Water councils, water funds }\end{array}$ & $\begin{array}{l}\text { - Improved indigenous and } \\
\text { community rights and land } \\
\text { tenure arrangements } \\
\text { - Local governance and } \\
\text { institutional capacity } \\
\text { - Urban planning } \\
\text { - Dialogue platforms } \\
\text { - Policy frameworks, including } \\
\text { national strategies to } \\
\text { mainstream and scale up NbS } \\
\text { - Strategies for biosphere } \\
\text { preservation and wildlife } \\
\text { habitats } \\
\text { - Subnational and national } \\
\text { governance structures } \\
\text { for watershed and forest } \\
\text { management } \\
\text { - Transboundary collaborations } \\
\text { - Peace processes }\end{array}$ & $\begin{array}{l}\text { - Infrastructure against coastal } \\
\text { erosion } \\
\text { - Flood control } \\
\text { - Soil protection against } \\
\text { landslides and erosion control } \\
\text { - Disaster risk reduction } \\
\text { - Development of early warning } \\
\text { and climate information } \\
\text { systems } \\
\text { - Adaptation M\&E } \\
\text { - Measurement, reporting and } \\
\text { verification of greenhouse } \\
\text { gas emissions } \\
\text { - Centres of excellence } \\
\text { - Insurance (e.g. against crop } \\
\text { loss or flooding) and other risk } \\
\text { transfer mechanisms }\end{array}$ \\
\hline
\end{tabular}


Despite the absence of more systematic assessments of project outcomes, there is encouraging evidence that, across the entire spectrum of information available, implementation of $\mathrm{NbS}$ for adaptation has been growing strongly since the early 2000s. However, there are also indications that this expansion may be slowing. It will therefore be important to continue monitoring both the rate of $\mathrm{NbS}$ implementation and the proportion of funding allocated to NbS across accessible donor and implementer platforms to assess whether the implementation of $\mathrm{NbS}$ for adaptation is indeed being scaled up.

This assessment suggests that the ratio between green and hybrid solutions is fairly balanced across the entire data set. However, whether green, hybrid or grey solutions are preferred often depends on local contexts. For example, in urban settings interventions are more commonly a mix of nature-based and engineered or infrastructure solutions. While this partially reflects context-specific constraints, giving greater prominence to $\mathrm{NbS}$ is often also limited by the existing policy, regulatory and financial frameworks which, for a number of reasons, tend to favour traditional planning and engineering solutions (OECD 2020a). In particular, $\mathrm{NbS}$ often require considerable time to reach their potential benefits but will then appreciate over time. On the other hand, while grey infrastructure may provide services immediately after implementation, it will depreciate thereafter and thus often requires more costly maintenance. Improving regulatory frameworks to ensure that benefits and costs are accounted for to address short- and long-term needs may enhance decision-making in favour of $\mathrm{NbS}$.

Moreover, in comparison with conventional engineered solutions, NbS provide a wide range of co-benefits, including securing a broad range of ecosystem services on which the livelihoods of local communities depend, generating diversified income revenues, and improving food security, water availability and health (Losada et al. 2018; Kapos et al. 2019; Seddon et al. 2019; Buckley et al. 2019, Chausson et al. 2020). However, due to challenges in evaluating and valuing these benefits, they are often not sufficiently taken into account in decision-making processes. Fully accounting for additional benefits of NbS, which can outweigh their direct climate-risk reduction and environmental benefits (for example, Buckley et al. 2019), would likely enhance acceptance and levels of implementation.

\subsection{Scaling up and moving forward}

This chapter has highlighted several key gaps that need to be filled in order to scale up the use of NbS for adaptation, as called for in a number of high-profile contexts (for example, GCA 2019), and to realize their many potential socioeconomic and environmental benefits. Progress in application and scaling-up of $\mathrm{NbS}$ is likely to depend on:

\begin{abstract}
Expansion and consolidation of currently limited and scattered evidence on the effectiveness and cost-effectiveness of NbS for adaptation that takes account of the full range of benefits they provide (including avoided costs).
\end{abstract}

Improved and long-term monitoring and evaluation of ongoing and completed initiatives to further expand the evidence base and link impacts to financial flows.

Effective communication of that evidence base in forms appropriate for, and accessible to, investors and decision makers.

Effective tracking of investment of finance and effort in NbS implementation to help identify gaps.

More concrete incorporation of NbS into planning for adaptation across scales and sectors, through the NAP process and beyond, including recognition of, and explicit planning for, the links and cobenefits between $\mathrm{NbS}$ for mitigation and $\mathrm{NbS}$ for adaptation.

Diversification and innovation in financing for $\mathrm{NbS}$, blending different sources and ensuring that aspects of the enabling environment such as structural and regulatory frameworks and fiscal incentives are conducive to investment in $\mathrm{NbS}$

Critically, NbS planning and implementation need to account for climate risks to ecosystems and include measures to address them in order to avoid investment in solutions that may be ineffective or short-lived.

The potential of NbS for adaptation can best be fully realized by limiting the risks of dangerous levels of global warming and by scaling up ambition and action on protecting, conserving and restoring nature. 
As $=$ Nowert

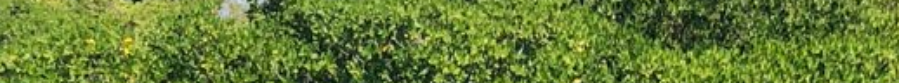

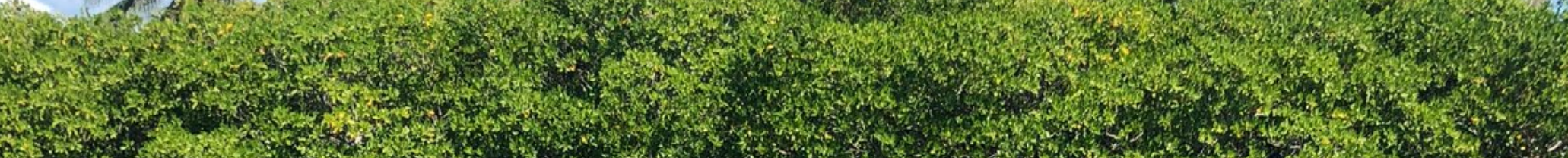
H.1.7. 1.6.

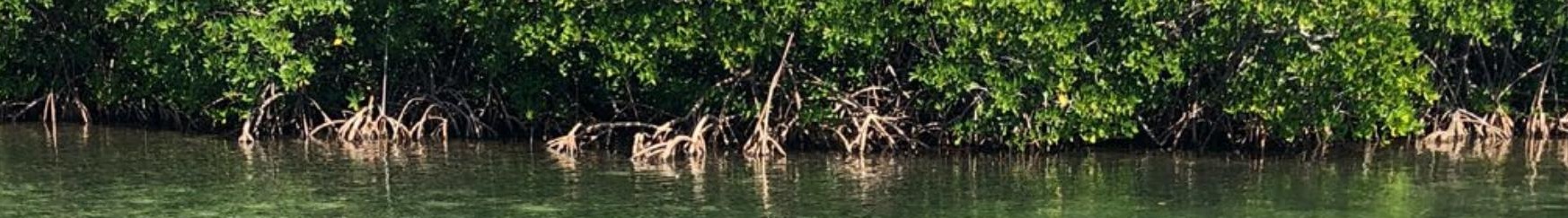
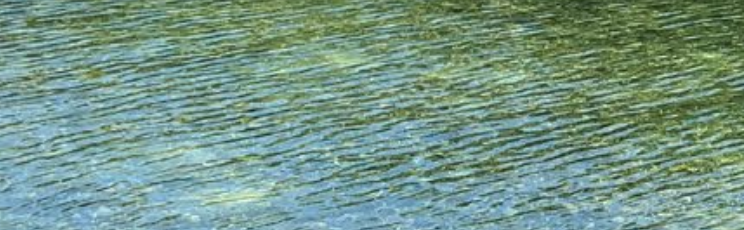

trate

The

(2)

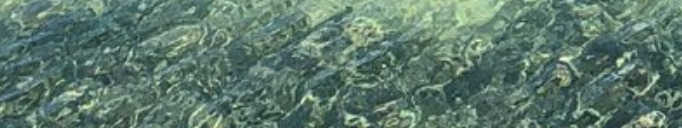

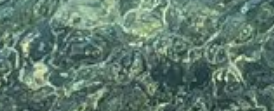

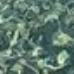

(5)

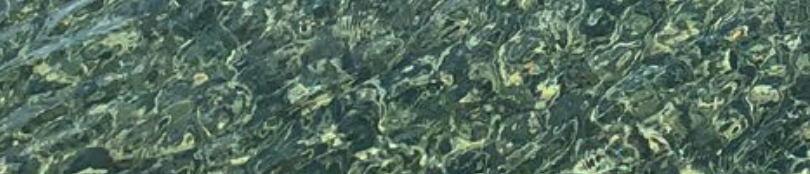

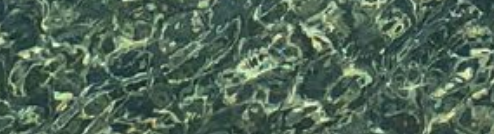

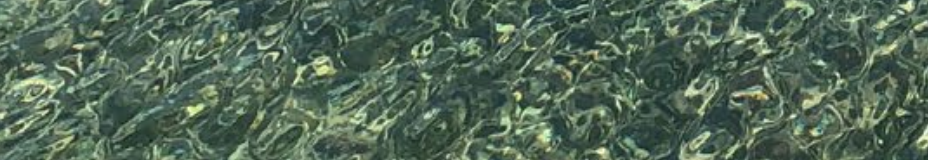

1.5.

and

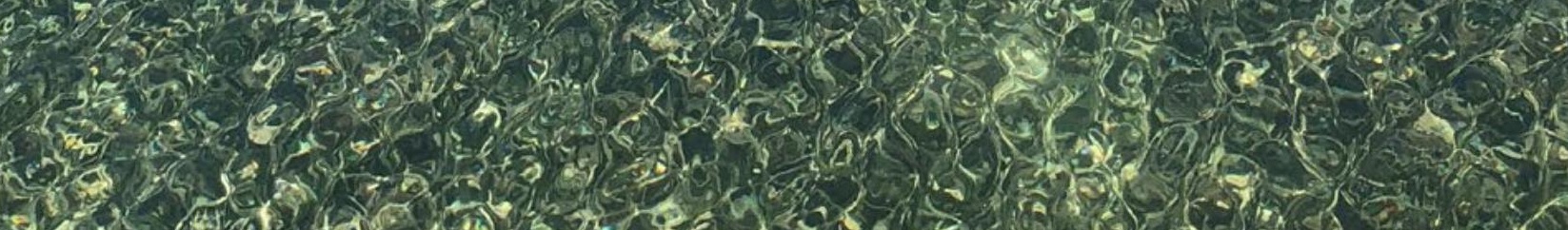

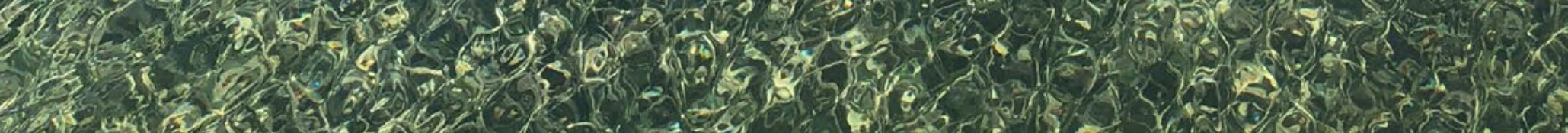

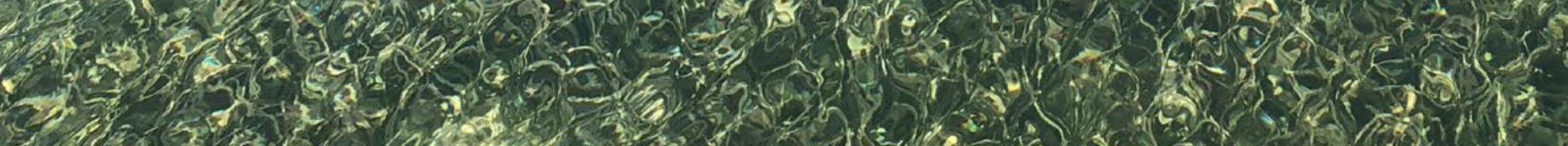

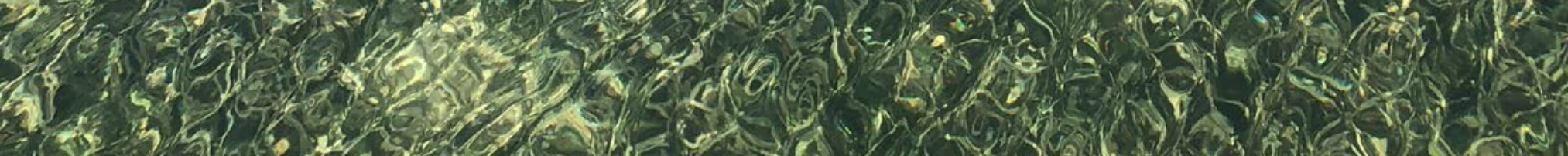

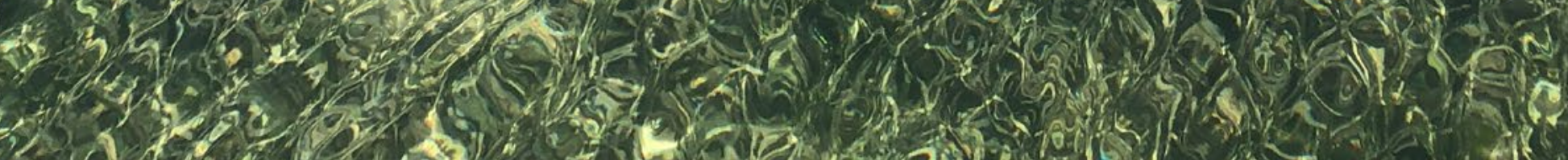
(25) 


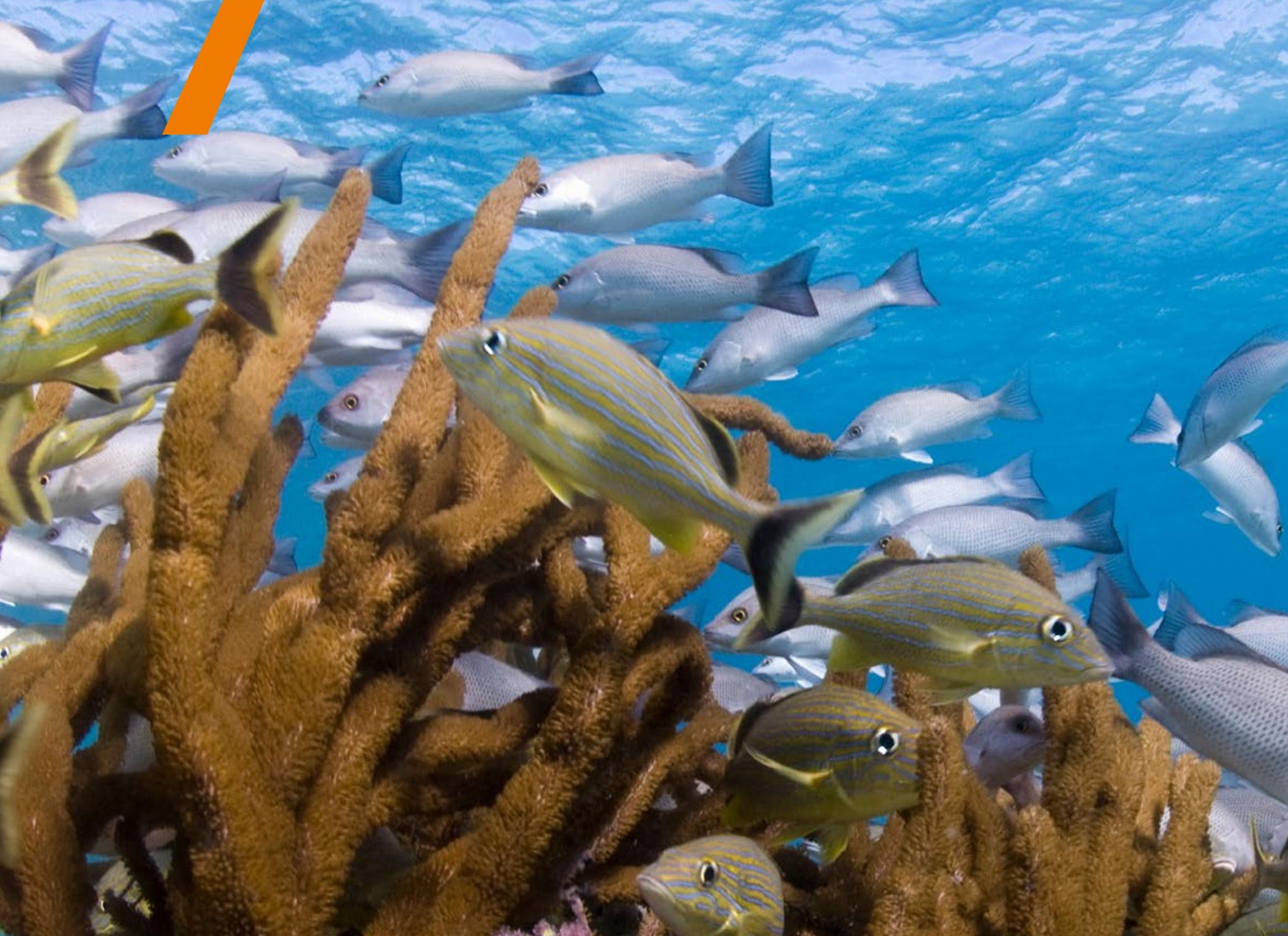

18 )
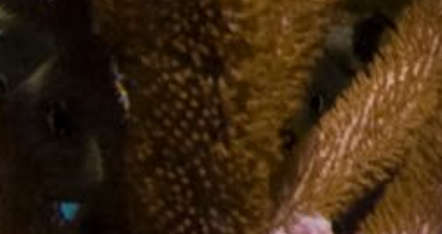

$5+3 \times \sin ^{2}$

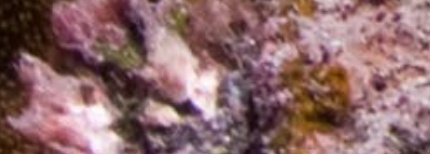

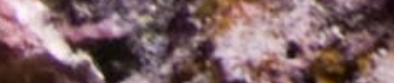

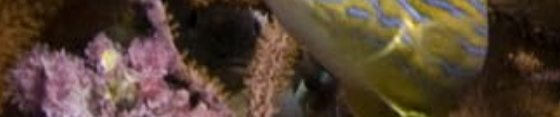

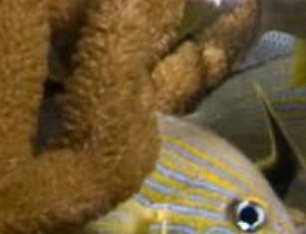

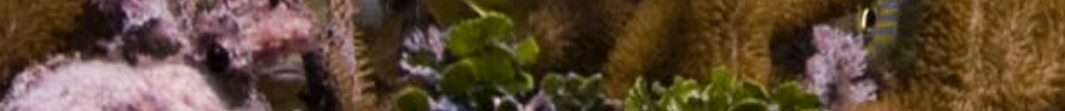
fovily

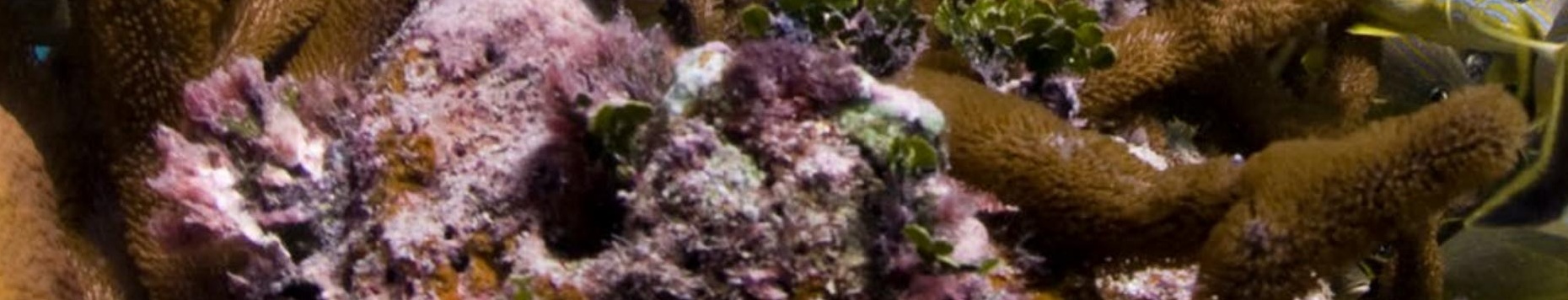

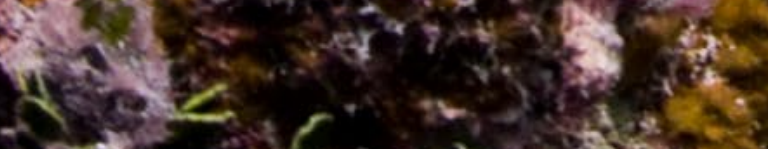

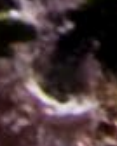

$\operatorname{lin} 30$

से

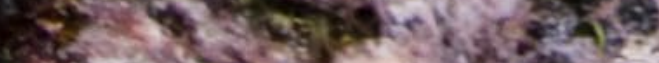

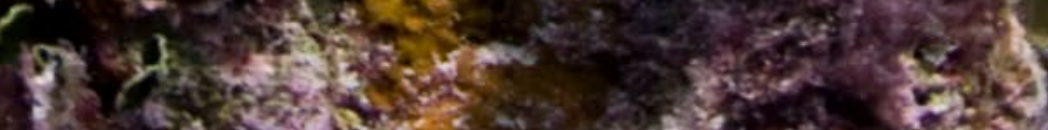

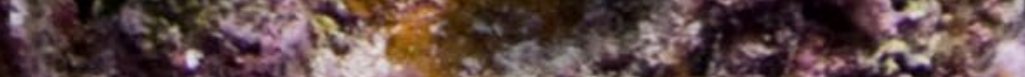
195.

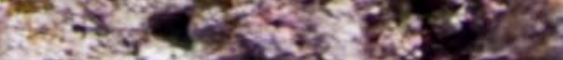

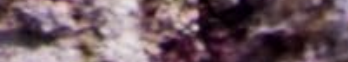

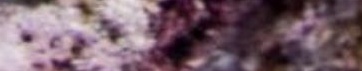

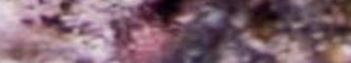




\section{Chapter 7}

Global progress on adaptation and outlook

Lead Authors: Lead authors: Alexandre K. Magnan (IDDRI), Thomas William Dale (UNEP DTU Partnership).

Contributing Authors: Henry Neufeldt (UNEP DTU Partnership), Lars Christiansen (UNEP DTU Partnership), Valerie Kapos (UNEP-WCMC), Timo Leiter (Grantham Research Institute on Climate Change and the Environment, London School of Economics and Political Science), Annett Moehner (Secretariat of the United Nations Framework Convention on Climate Change), Manishka De Mel (Columbia University and NASA Goddard Institute for Space Studies), Cynthia Rosenzweig (NASA Goddard Institute for Space Studies and Columbia University).

Photo: () Antonio Busiello / World Wildlife Fund for Nature 
This chapter builds on the framework laid out in chapter 2 to synthesize the overarching findings of chapters 3-6 and provide a more comprehensive and multifaceted understanding of adaptation progress at the global level. It does this by focusing on the progress being made across the planning, finance and implementation dimensions of adaptation at the national level and in terms of multilateral and bilateral cooperation (chapters $3-5$ ), as well as considering the lessons learned from the deployment of nature-based solutions (chapter 6). The chapter discusses the overarching conclusions that this Adaptation Gap Report (AGR) can draw regarding global progress on adaptation and emerging perspectives to improve global tracking of adaptation actions and results through the lens of the categories introduced in chapter 2, for example, evidence of adaptation progress; identification of gaps; and elements that constrain the interpretation of findings. The chapter concludes with a short summary of the key messages and an outlook.

\subsection{Cross-chapter synthesis}

The findings of the 2020 edition of the AGR allow some overarching conclusions to be made about global progress on climate change adaptation, as well as gaps and uncertainties that persist in this process. These overall conclusions are illustrated in figure 7.1. While panel $A$ is identical to panel A of figure 2.1 in chapter 2, panel B supplements this with headline-level information that is both drawn from the substantive chapters 3-6 and related to the three above-mentioned categories (progress, gaps, and constraints on the interpretation of findings).

\subsubsection{Progress}

There is robust evidence that progress has been made in enhancing national-level adaptation worldwide over the last decade, as illustrated by the solid downward grey arrows in figure 7.1. This conclusion is supported by various types of findings, as described below.

Recognition of the importance of adaptation policy to galvanize action at the international and national levels: Data show that climate adaptation is now fully part of climate policy action across the world, concurrently with greenhouse gas mitigation efforts (United Nations Environment Programme [UNEP] 2020). The adoption of national-level adaptation planning instruments (for example, plans, strategies, frameworks and laws) has been found to be widespread, with eight out of 10 countries having at least one instrument either already implemented or in development and over 60 per cent of countries including $\mathrm{NbS}$ in the adaptation component of their nationally determined contributions (NDCs) (see box 7.1 for a snapshot of the main findings for $\mathrm{NbS}$ ).

Maturity in the way adaptation is considered in policies and strategies: Often dependent on national circumstances and risk profiles, approaches to adaptation at the national level demonstrate varying degrees of maturity, with some countries presently building on previous adaptation plans while others are engaging in this area for the first time. Moreover, policy instruments can be adaptation-centred or incorporate the adaptation component into a broader perspective. The latter is particularly relevant for initiatives related to NbS, which are typically embedded in broader development interventions, providing a wide range of additional benefits besides addressing exposure or vulnerability to climate hazards. Various degrees of maturity are also apparent when analysing cross-sectoral approaches to adaptation, as well as within the development of more sector-specific adaptation policy instruments.

Actionable policies providing guidance on how to operationalize adaptation: The increasing recognition of topical approaches to adaptation - such as NbS and other cross-sectoral themes (for example, health; UNEP 2018) - within policy documents indicates that there is some movement towards more actionable policies. This is also the case for the increasing levels of adaptation finance reported by multilateral and bilateral aid agencies, with, for example, hundreds of projects in developing countries being supported by multilateral climate funds since the mid-2010s, although overall levels of support are still considered to be too low. Financing modalities are also considered to be evolving quickly, with a broader range of instruments, approaches and funding sources emerging to meet adaptation needs for different sectors, regions and actors.

Note for figure 7.1: This figure is based on the framework figure provided in chapter 2 (figure 2.1). In panel A, the colour of the background illustrates the increase in climate risks under various warming scenarios (RCP2.6 and RCP8.5) and adaptation scenarios (with/without) (Oppenheimer et al. 2019; Hurlbert et al. 2019). The blue and light red curves represent risk scenarios under RCP2.6 and RCP8.5, respectively, while the central black drawing represents a hypothetical risk scenario under a speculative, midway warming scenario. This figure is purely illustrative and does not rely on any quantitative data. The white vertical boxes show, for today (left) and by the end of this century (right), the level of risk reduction to be expected from very limited adaptation efforts (top of white boxes) to high adaptation efforts (bottom of white boxes), i.e. the 'adaptation space'. The downward black arrows within these white boxes provide a theoretical interpretation of observed progress and uncertainty. While the solid arrows illustrate the progress than can be assessed and reported based on evidence - for example, in the AGRs-, the dotted arrows reflect knowledge gaps and therefore potential adaptation gaps. Together, the two arrows within the same box help us understand the balance between what we know has been achieved, and what we are uncertain about because of a lack of information, thus helping balance progress and potential gaps. Panel B applies the general framework used in this report (progress, gaps, contextual elements that constrain the interpretation of the results) to the findings of the main chapters (3-6). 
Figure 7.1. Progress in adaptation at the national level against different climate risk scenarios, as discussed in this report

A

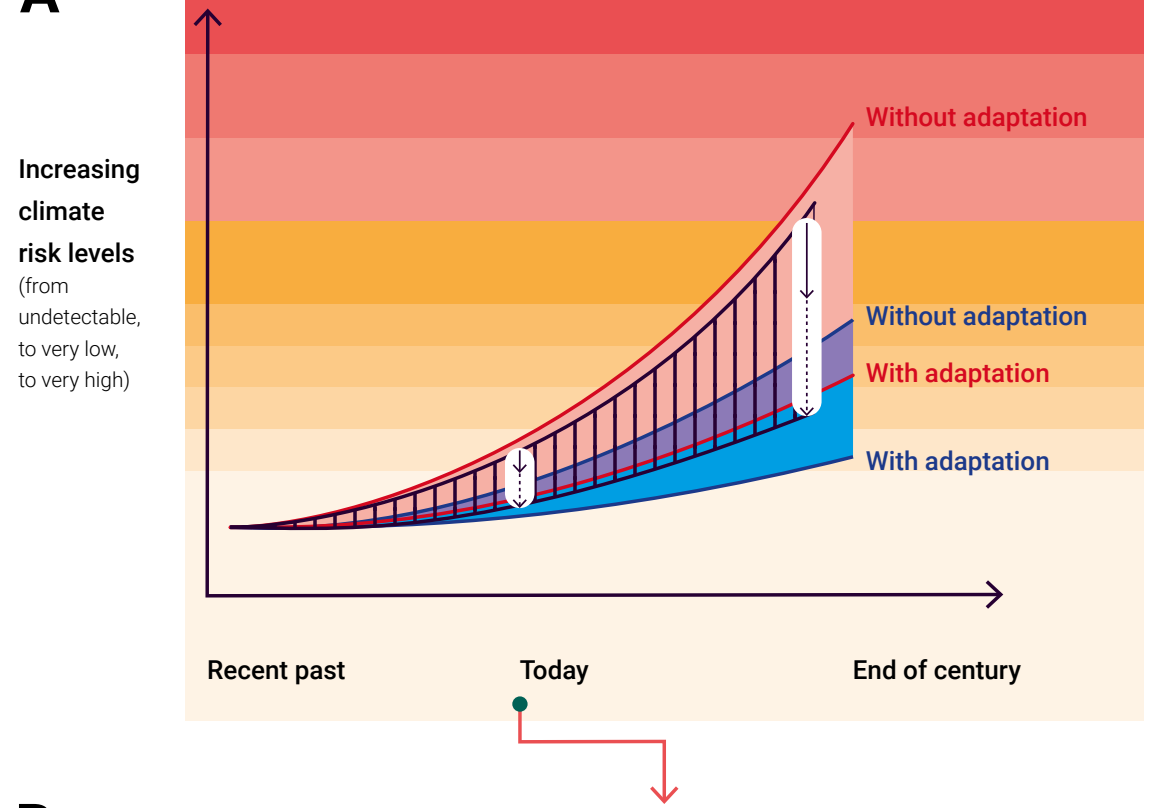

Risk scenarios under RCP2.6 (blue) and RCP8.5 (red), with and without adaptation, are inspired by the recent IPCC special reports (SRCCL; SROCC). The midway risk scenario (black) is purely hypothetical and is used for illustrative purposes.

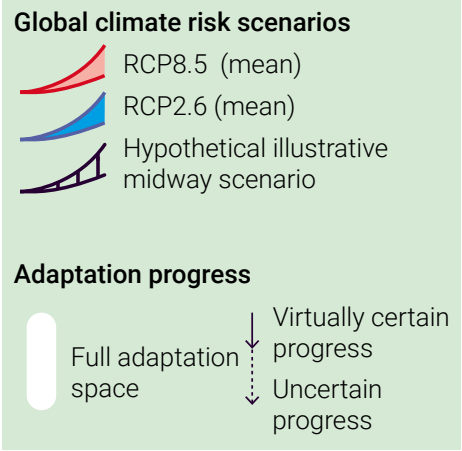

B

\section{Progress is being made, but there is a lack of robust evidence across regions, sectors and hazards, for which data are scattered.}

Progress is, nevertheless, estimated to not be occurring at the required scale (when assessed against present and future risk levels).

\section{Evidence of adaptation progress}

Identification of gaps

Elements that constrain the interpretation of findings
- National-level adaptation plans, strategies, frameworks or laws are in place in most countries (either they have been adopted or are currently being developed - the maturity of adaptation planning instruments varies across countries)

- Both adaptation finance and the number of adaptation projects in developing countries (supported by multilateral and bilateral funds) are increasing

- Some movement towards creating actionable policies that lead to principal adaptation (better inclusion of specific types of adaptation measure)

- Financing modalities are quickly evolving (for example, diversifying the range of instruments, approaches and funding sources) and there are early signs of movement towards more climate-proof and sustainable financial systems and investments

- Adaptation finance is increasing at a lower rate than adaptation costs (in a context of increasing and accelerating climate change) and therefore the adaptation finance gap appears to be widening

- Limited development of monitoring and evaluation ('M\&E') mechanisms

- Limited evidence to indicate that adaptation planning at the national level is stimulating adaptation planning at the subnational level

- Limited information available about future trends in national-level adaptation (its nature, scale and the degree to which plans, strategies, frameworks or laws will be implemented)

- The extent to which gender dimensions are prioritised in national adaptation plans and policies is still not clear

- Adaptation goals at the global and national level need further clarification to help set precise targets

- Poor availability of shared databases documenting planning/implementation efforts in high-income countries, as well as information on private finance and on the effectiveness of policies and actions to reduce present and future risk levels under different global warming scenarios

- Uncertainty surrounding the long-term effects of the COVID-19 pandemic on future trends in adaptation plannina. financina and implementation 
Early signs suggesting more progress in the near-tolong-term future: Evidence of more climate-resilient and sustainable financial systems and investments is emerging in the form of measures addressing the climate risks posed to certain cornerstones of the financial system (for example, industries, corporations, enterprises and consumers) that would lead to longer-term and transformational reductions in climate vulnerability. Continuing developments within financial systems and investments will be important to progressively minimize and counteract cascading risks throughout societies. There is also growing recognition of the effectiveness and cost efficiency of $\mathrm{NbS}$ at reducing climate risks next to providing critical ecosystem services, biodiversity, and opportunities for additional income and livelihoods.

\subsubsection{Gaps}

Despite encouraging trends, adaptation progress made to date at the national level does not appear to be on the required scale, as illustrated by the dotted downward grey arrows in figure 7.1. This section examines five aspects that support this conclusion.

Adaptation finance: In a context of accelerating climate change, there is some indication that adaptation costs are increasing at a higher rate than adaptation-oriented financial flows. This suggests that the adaptation finance gap seems to be widening, despite the increasing levels of funding to support adaptation planning and implementation.

Monitoring and evaluation: It is widely recognized that monitoring and evaluation (M\&E) is key to adequate and effective adaptation planning and implementation, as it enables actors to adjust objectives, strategies and resources over time. However, this report finds that there continues to be a need to further develop M\&E systems, which are currently operational in 33 per cent of countries, while a further 11 per cent of countries are either planning for or currently developing adaptation M\&E frameworks.
Knock-on effects: There is limited evidence in the material considered in this report that national-level adaptation planning is substantially stimulating the development of subnational and sectoral adaptation strategies and plans. On the other hand, NbS projects often provide clear signs of creating the enabling environment, business models and governance structures, as well as raising awareness and building capacity for scaling up pilot initiatives to subnational, national or regional levels.

Effectiveness of climate risk reduction: National-level data provide very few indications of future trends in adaptation (planning, financing, implementation) and associated levels of risk reduction, while recent Intergovernmental Panel on Climate Change (IPCC) reports indicate increasing levels of risk even under emission scenarios curtailing end-ofcentury global warming to 1.5 or $2^{\circ} \mathrm{C}$ (compared with preindustrial warming) (Intergovernmental Panel on Climate Change [IPCC] 2018; IPCC 2019; Nerille et al. 2019). This is particularly true of unique and sensitive ecosystems, such as warm-water coral reefs or arctic and alpine regions, some of which might lose their effectiveness in addressing climate risks in the context of NbS. This finding confirms the need for future AGRs to dive deeper into capturing the observed and expected outcomes of adaptation in order to determine whether we are actually succeeding in reducing current and future climate risks, and therefore on an effective adaptation trajectory.

Gender issues: While there are notable exceptions - not least in the context of $\mathrm{NbS}$, where gender issues and broader questions of equity and justice are explicitly mentioned in several initiatives - these aspects are generally not clearly detailed. As noted in chapter 3, for example, several countries highlight the importance of considering gender in adaptation planning. However, the extent to which gender dimensions are prioritized in national adaptation plans and policies is unclear.
Box 7.1 Main findings on the topical focus of this report: Nature-based solutions

Increasing ambition is essential for nature-based solutions (NbS) because they play a vital role in creating multiple co-benefits for disaster risk reduction, gender equality and sustainable livelihoods, as well as for building climate resilience. NbS support ecosystem services and complement decarbonization. However, biodiversity is impacted by a changing climate and effective adaptation needs to consider these aspects of vulnerability and how this in turn, affects social vulnerability.

$\mathrm{NbS}$ need to play a stronger role in planning, especially in NDCs and national adaptation plans (NAPs). The NbS finance base needs to be amplified, strengthened and diversified by deploying innovative mechanisms which combine different funding sources. The strengthening of financial systems and incentives is required to enable public and private investments in NbS. In addition, successful implementation of $\mathrm{NbS}$ requires effective governance and institutions to manage public goods, frequently related to secure land tenure and access rights. Traditional and common knowledge play a significant role in the development of $\mathrm{NbS}$ and their implementation, with youth, women, indigenous peoples and local communities being key stakeholders. The potential of NbS for adaptation can best be fully realized by limiting the risks of dangerous levels of warming and by scaling up ambition and action on protecting, conserving and restoring nature. 


\subsubsection{Elements constraining the interpretation of findings}

A more detailed assessment of observed and expected adaptation outcomes is often complicated by a diversity of conceptual, technical and scientific limitations and uncertainties, three of which are briefly described in this section.

Lack of clarity in adaptation goals: It is unclear what the global goal on adaptation concretely means in terms of climate risk reduction now and in the future. The current definition under article 7 of the Paris Agreement, which refers to "enhancing adaptive capacity, strengthening resilience and reducing vulnerability to climate change, with a view to contributing to sustainable development", was not designed to provide precise targets and therefore remains too general to guide the analysis of adaptation progress (Magnan and Ribera 2016). This results in the lack of a more precise 'vision' for what we want to achieve from global adaptation efforts and makes some conclusions difficult to interpret. However, with growing experience in adaptation, there is an expectation that reporting under the United Nations Framework Convention on Climate Change (UNFCCC) will continually become more informative and converge towards more clearly defined goals.

Limited comprehensive information available: A second set of limitations and uncertainties are related to technical and more substantive knowledge gaps. On the 'technical' side, for example, it remains challenging to get a sense of the scale of private finance dedicated to adaptation because databases are most often scattered and/or difficult to access. There is also a lack of comprehensive databases gathering information on adaptation planning and implementation in high-income countries because adaptation is frequently mainstreamed at subnational and sectoral levels (UNEP 2018). On the 'more substantive' side, scientific challenges also come into play. In particular, there are knowledge gaps in understanding the effectiveness of a wide range of climate adaptation measures and processes (for example, empowerment of indigenous peoples and women via NbS) in terms of reducing current and projected climate risks. This, in turn, limits our understanding of the contribution of national-level adaptation plans, strategies, frameworks or laws to societal resilience and climate risk reduction across sectors, territories and population groups. Another knowledge gap exists in the assessment of risk levels at national scales and under different warming scenarios, all over the world, so that comparing adaptation outputs observed today with current and future riskreduction outcomes remains highly complex.

Uncertainty surrounding the enabling conditions for adaptation: The lack of comprehensive information is further complicated by external factors that are not climate-related but can still influence climate risks and vulnerabilities. This is equally as applicable to changes in the political economy of nations as it is to geopolitical shifts or global shocks. While drawing on historical evidence can sometimes provide clues, the extent to which these external factors will affect both the adaptation efforts themselves and their expected benefits (through the consequences they have on societies' vulnerability to climate change), remains unknown. A perfect example and illustration of this is the COVID-19 pandemic, which has several profound implications for future adaptation efforts and results which are far from being well understood (box 7.2).

\subsection{Way forward: how to improve the assessment of global adaptation progress}

The AGR chapters and synthesizing sections above highlight several overarching challenges related to better assessing adaptation through framing and measuring adaptation progress, as introduced in chapter 2 . The final section of this report reflects on how to improve the assessment of adaptation progress in view of these challenges and briefly discusses next steps.

\section{Improving the framing of progress in adaptation}

Section 2.3 raises the importance of moving towards a comprehensive understanding of adaptation progress, to understand not only what is currently being done (i.e. adaptation outputs), but also future risk levels and adaptation outcomes now and in the future (figure 2.3). This, in turn, calls for further work in at least three areas:

i. Assessing and monitoring a set of key climate risks of global importance - i.e. risks that transcend regional and national context specificities and provide an overview of the range of critical climate changerelated threats to global society, across all latitudes, levels of development and types of climate hazards.

ii. Contrasting risk levels under various global warming and socioeconomic scenarios to highlight potential global-level risk reduction targets and further advance the understanding of adaptation goals. This is critical if we are to assess progress made in adaptation (progress against what?).

iii. Advancing scientific knowledge on how to measure the actual and future benefits to be expected from ambitious adaptation in terms of risk reduction over this century. This requires a better understanding of the potential effectiveness of a wide range of adaptation-related actions, policies and measures, for example, the degree to which policies and measures fulfil specific goals relating to risk reduction now ('observed outcomes') and in the future ('expected outcomes')

\section{Improving the measurement of adaptation progress}

Connected to improving the framing of adaptation progress is the question of how to actually measure it. This raises multiple methodological issues, four of which are described below. 
Box 7.2. The implications of the COVID-19 pandemic on global adaptation processes

This report was produced during the COVID-19 pandemic. Beyond the direct health impacts of the pandemic, the implementation of national lockdowns has led to severe socioeconomic shocks in most countries. As with climate change, early signs clearly indicate that the socioeconomic and health impacts of the COVID-19 pandemic are disproportionally affecting the most vulnerable countries and population groups (UNEP 2020; International Labour Organization, Food and Agriculture Organization of the United Nations, International Fund for Agricultural Development and World Health Organization 2020; United Nations Office of the High Representative for the Least Developed Countries, Landlocked Developing Countries and Small Island Developing States 2020; Kebede et al. 2020).

Initial evidence indicates that the pandemic and the stringent measures implemented to manage it will have significant implications for adaptation processes at all levels and will continue to do so long after the pandemic has passed. However, at the time of writing, developing a comprehensive and robust picture of how global adaptation processes will be affected by the pandemic is not possible as the available evidence is fragmented and largely anecdotal with robust data and analysis generally lacking. Nevertheless, drawing upon available evidence, this box outlines how the COVID-19 pandemic is affecting the different dimensions of the global adaptation processes discussed in this report in the short term, and how it is likely to alter the outlook for these processes in the longer term.

\section{Short-term implications}

In the short term, the acute need to manage the direct public health impacts of the virus and its subsequent economic fallout has seen adaptation and related topics (for example, climate mitigation and environmental sustainability) fall down the political agenda at all levels of governance (Hammill 2020). Concurrently, ongoing and scheduled adaptation planning and implementation processes at the global, national and local levels have seen large proportions of the human and financial resources (including bilateral and multilateral support) previously earmarked for them being reallocated towards efforts to manage the impacts of the virus (Adaptation Fund 2020; Johnson, Vera and Zühr 2020; Global Environment Facility [GEF] 2020a and 2020b; Hammer and Hallegatte 2020).

Meanwhile, on the ground, the logistical implications of strict restrictions on movement and physical distancing have presented challenges for adaptation planning and implementation processes, some instances of which are severe. The most high-profile example of this is arguably the postponement of COP26 from November 2020 to November 2021. However, on national and subnational levels, COVID-19 restrictions and the reallocation of resources are reported to be impeding important adaptation planning meetings and stakeholder consultations (Hammill 2020; National Adaptation Plan Global Support Programme [NAP-GSP] 2020), as well as requiring implementers and funders to adopt new modes of operating to deal with rapidly changing priorities and operational realities (Adaptation Fund 2020; GEF 2020b).

\section{Longer-term implications}

In the longer term, the socioeconomic consequences of the pandemic can be expected to have lasting implications for global adaptation processes well after the pandemic has passed.

Most prominently, the severe negative impacts of the pandemic on the global economy are likely to reduce the availability of adaptation finance in the long term (Quevedo, Peters and Cao 2020). Pandemicinduced pressure on public finances is expected to be disproportionately felt in developing countries, where governments are likely to face being simultaneously hit by reductions in domestic tax revenues and external finance (Organisation for Economic Co-operation and Development [OECD], 2020a) 1 .

Meanwhile, the high levels of uncertainty surrounding the global economic outlook has cast doubt on the viability of many countries' long-term adaptation plans, including their updated NDCs, as many of the assumptions upon which these plans and strategies are based (for example, the availability of domestic budget resources, borrowing headroom, access to international climate finance, and economic growth) are no longer sound (Hammer, Hallegatte and Banaji 2020; NDC Partnership 2020).

At the same time, changes in national and donor priorities as a result of the likely side-effects of a global recession, for example, widespread business failure and high unemployment, could see budgets allocated for implementing climate actions and plans come under threat, or redirected towards adaptation actions that are considered more likely to achieve outcomes associated with stimulating economic growth, for example, job creation (Johnson, Vera and Zühr 2020; Hammill 2020). 
- Recognizing that climate change poses a threat to humankind that is far greater than that posed by COVID-19, key intergovernmental organizations such as the United Nations (2020a; 2020b), the International Monetary Fund (2020) and the OECD (2020b), have called upon national governments to harness their COVID-19 recovery packages to create more sustainable, resilient and inclusive societies. Such calls highlight the idea that the unprecedented recovery packages being mobilized by national governments represent a unique opportunity to enhance climate resilience, restore ecosystems and reduce greenhouse gas emissions through, among other means, investing in NbS. These calls also warn against the inclusion of investments in, or support for, industries that increase climate vulnerability and undermine adaptation efforts within these recovery packages.

If implemented well, COVID-19 related recovery packages could facilitate economic recovery, provide jobs for the most vulnerable, reduce gender and wealth inequalities within and among countries, and improve health systems, on top of building enhanced climate resilience and reducing emissions (Hepburn et al. 2020; UNEP 2020). Analysis of economic stimulus packages announced to date, however, suggest that governments are largely forgoing this opportunity, with support particularly neglecting efforts to restore and conserve nature (UNEP 2020; Vivid Economics 2020).

While this suggests that stimulus packages thus far have largely targeted economic recovery and job retention with only limited attention paid to climate change and environmental sustainability, global recovery from COVID-19 is a long way off. To ensure that this opportunity is not missed, national governments need to make greater efforts to align future COVID-19 recovery plans with countries' pre-existing low-carbon and resilient development plans (Alcayna 2020; GCF 2020; Hammer, Hallegatte and Banaji 2020; Hammer and Hallegate 2020; Hepburn et al. 2020; Norton et al. 2020; Quevedo, Peters and Cao 2020). iv. Multiple sources of information exist that are separate pieces of a larger puzzle (for example, NDC and NAP databases, global risk information, Sendai monitoring data on risk reduction, Sustainable Development Goal progress reports and scientific literature). While considering a broad range of information can highlight complementarities across data sources, this also often unearths overlaps and inconsistencies, for example, in the background data used and the way these data are interpreted. One more example to that effect is that most of the existing initiatives use global datasets to describe vulnerability to climate change at the country level, but these datasets are increasingly recognized to contain biases, and therefore, conclusions drawn from them need to be taken with caution. Triangulating multiple sources of analysis is a potential solution to this issue.

v. Developing new complementary types of data is a necessary action in order to reflect adaptation outcomes and gaps directly at the global level (UNEP 2017; Magnan and Chalastani 2019). This could be particularly relevant for closing certain knowledge gaps, as illustrated by the potential for satellite imagery analysis to help measure the distance of built assets to the sea on coasts all around the world, and therefore provide one proxy of global exposure to sealevel changes, among others.

vi. Enhancing the accessibility of background information and data will help to provide transparency. While the definition of specific adaptation metrics is a well-known challenge (for examples, see UNEP 2017; Leiter and Pringle 2018; Berrang-Ford et al. 2019), existing and accessible data are not always easily usable.

vii. Comprehensive information on funding sources and flows will aid in tracking global cooperation on adaptation. Comparing funding and cost curves remains a complex undertaking, but this could provide useful/proxy information to understand progress made on addressing the adaptation challenges.

\section{The way forward}

This report has presented salient new and updated information related to planning, finance and implementation of adaptation actions and has begun setting criteria for improving the assessment of adaptation outcomes in view of several conceptual and methodological challenges. The results are very much a work in progress and will therefore require continued efforts to further hone in on how this relates to the global goal on adaptation, which is a dynamic concept closely linked to our efforts and success in limiting global warming to well below $2^{\circ} \mathrm{C}$ and avoiding catastrophic climate change. While, in hindsight, there is already some evidence that the adaptation gap is widening, at least in terms of adaptation finance to tackle rising adaptation costs, the analysis is restricted to extrapolation of current trends without recognition of future scenarios and how they might affect the gap. It will, therefore, require multiple editions of AGRs to further elucidate progress on adaptation, building on, triangulating and integrating an ever-growing body of information, including from global analyses and national reporting to the UNFCCC, as well as subnational, sectoral and non-state actor assessments. 


\section{References}

\section{Chapter 1}

Berrang-Ford, L., Biesbroek, R., Ford, J.D., Lesnikowski, A., Tanabe, A., Wang, F.M. et al. (2019). Tracking global climate change adaptation among governments. Nature Climate Change 9, 440-449. https://doi.org/10.1038/s41558-019-0490-0.

CarbonBrief (2020). State of the climate: 2020 on course to be warmest year on record, 23 October. https://www.carbonbrief. org/state-of-the-climate-2020-on-course-to-be-warmest-year-on-record. Accessed 27 November 2020.

Christiansen, L., Olhoff, A. and Dale, T. (2020). Understanding Adaptation in the Global Stocktake. Designing a Robust Stocktake Discussion Series. Copenhagen: UNEP DTU Partnership. https://www.climateworks.org/wp-content/uploads/2020/05/ Understanding-Adaptation-in-the-Global-Stocktake_iGST_UNEP-DTU.pdf.

Christiansen, L., Sanchez Martinez, G. and Naswa, P. (eds.) (2018). Adaptation Metrics: Perspectives on Measuring, Aggregating and Comparing Adaptation Results. Copenhagen: UNEP DTU Partnership. https://unepdtu.org/wp-content/ uploads/2018/03/udp-perspectives-adaptation-metrics-web-1.pdf.

United Nations Environment Programme (UNEP) (2014). The Adaptation Gap Report 2014. Nairobi. https://www. unenvironment. org/resources/adaptation-gap-report-2014.

United Nations Environment Programme (UNEP) (2017). The Adaptation Gap Report 2017. Nairobi. https://www.unenvironment. org/resources/adaptation-gap-report-2017.

Walton, D. and van Aalst, M.K. (2020). Climate-related Extreme Weather Events and COVID-19. A First Look at the Number of People Affected by Intersecting Disasters. Geneva: IFRC. https://media.ifrc.org/ifrc/document/climate-related-extremeweather-events-covid-19-first-look-number-people-affected-intersecting-disasters/.

World Meteorological Organization (WMO) (2020). September was the warmest on record, 15 October. https://public.wmo. int/en/media/news/september-was-warmest-record. Accessed 2 December 2020.

\section{Chapter 2}

Berrang-Ford, L., Biesbroek, R., Ford, J. D., Lesnikowski, A., Tanabe, A., Wang, F.M. et al. (2019). Tracking global climate change adaptation among governments. Nature Climate Change 9, 440-449. http://doi.org/10.1038/s41558-019-0490-0.

De Cian, E., Hof, A.F., Marangoni, G., Tavoni, M. and van Vuuren, D.P. (2016). Alleviating inequality in climate policy costs: an integrated perspective on mitigation, damage and adaptation. Environmental Research Letters 11(7), 074015. http://doi. org/10.1088/1748-9326/11/7/074015.

Gattuso, J.-P., Magnan, A.K., Bopp, L., Cheung, W.W.L., Duarte, C.M., Hinkel, J. et al. (2018). Ocean solutions to address climate change and its effects on marine ecosystems. Frontiers in Marine Sciences 5, 337. http://doi.org/10.3389/ fmars.2018.00337.

Hof, A., Elzen, M. and Vuuren, D. (2010). Including adaptation costs and climate change damages in evaluating post-2012 burden-sharing regimes. Mitigation and Adaptation Strategies for Global Change 15, 19-40. http://doi.org/10.1007/s11027009-9201-x.

Hsiang, S., Kopp, R., Jina, A., Rising, J., Delgado, M., Mohan, S. et al. (2017). Estimating economic damage from climate change in the United States. Science 356(6345), 1362-1369. http://doi.org/10.1126/science.aal4369.

Hurlbert, M., Krishnaswamy, J., Davin, E., Johnson, F.X., Mena, C.F., Morton, J. et al. (2019). Risk management and decisionmaking in relation to sustainable development. In Climate Change and Land: An IPCC Special Report on Climate Change, Desertification, Land Degradation, Sustainable Land Management, Food Security, and Greenhouse Gas Fluxes in Terrestrial Ecosystems. Shukla, P.R., Skea, J., Calvo Buendia, E., Masson-Delmotte, V., Pörtner, H.-O., Roberts, D.C. et al. (eds.). Cambridge: Cambridge University Press. Chapter 7, 673-800. https://www.ipcc.ch/srccl/.

Intergovernmental Panel on Climate Change (IPCC) (2014). Climate Change 2014: Impacts, Adaptation, and Vulnerability. Part A: Global and Sectoral Aspects. Contribution of Working Group II to the Fifth Assessment Report of the Intergovernmental Panel on Climate Change. Field, C. B., Barros, V. R., Dokken, D. J., Mach, K. J., Mastrandrea, M. D., Bilir, T. E. et al. (eds.). Cambridge: Cambridge University Press. https://www.ipcc.ch/report/ar5/wg2/.

Intergovernmental Panel on Climate Change (IPCC) (2018). Summary for policymakers. In Global Warming of $1.5^{\circ} \mathrm{C}$ : An IPCC Special Report on the Impacts of Global Warming of $1.5^{\circ} \mathrm{C}$ above Pre-industrial Levels and Related Global Greenhouse Gas Emission Pathways, in the Context of Strengthening the Global Response to the Threat of Climate Change, Sustainable 
Development, and Efforts to Eradicate Poverty. Masson-Delmotte, V., Zhai, P., Pörtner, H.-O., Roberts, D., Skea, J., Shukla, J.R. et al. (eds.). Cambridge: Cambridge University Press. https://www.ipcc.ch/sr15/chapter/spm/.

Magnan, A.K. and Chalastani, V.I. (2019). Towards a Global Adaptation Progress Tracker: first thoughts. IDDRI Working Papers No.1. https://www.iddri.org/sites/default/files/PDF/Publications/Catalogue\%20Iddri/Document\%20de\%20 travail/WP0119_global\%20adaptation\%20tracker_0.pdf.

Magnan, A.K., Schipper, E.L.F. and Duvat, V.K.E. (2020). Frontiers in climate change adaptation science: advancing guidelines to design adaptation pathways. Current Climate Change Reports 6, 166-177. https://doi.org/10.1007/s40641-02000166-8.

Melvin, A.M., Larsen, P., Boehlert, B., Neumann, J.E., Chinowsky, P., Espinet, X. et al. (2016). Climate change damages to Alaska public infrastructure and the economics of proactive adaptation. Proceedings of the National Academy of Sciences of the United States of America 114(2), E122-E131. https://doi.org/10.1073/pnas.1611056113.

O'Neill, B.C., Oppenheimer, M., Warren, R., Hallegatte, S., Kopp, R.E., Pörtner, H.-O. et al. (2017). IPCC reasons for concern regarding climate change risks. Nature Climate Change 7, 28-37. https://doi.org/10.1038/nclimate3179.

Oppenheimer, M., Campos, M., Warren, R., Birkmann, J., Luber, G., O’Neill, B. et al. (2014). Emergent risks and key vulnerabilities. In Climate Change 2014: Impacts, Adaptation, and Vulnerability. Part A: Global and Sectoral Aspects. Contribution of Working Group II to the Fifth Assessment Report of the Intergovernmental Panel on Climate Change. Field, C. B., Barros, V. R., Dokken, D. J., Mach, K. J., Mastrandrea, M. D., Bilir, T. E. et al. (eds.). Cambridge: Cambridge University Press. Chapter 19, 1039-1099. https://www.ipcc.ch/report/ar5/wg2/.

Oppenheimer, M., Glavovic, B.C., Hinkel, J., van de Wal, R., Magnan, A.K., Abd-Elgawad, A. et al. (2019). Sea level rise and implications for low-lying islands, coasts and communities. In IPCC Special Report on the Ocean and Cryosphere in a Changing Climate. Pörtner, H.-O., Roberts, D.C., Masson-Delmotte, V., Zhai, P., Tignor, M., Poloczanska, E. et al. (eds.). Cambridge: Cambridge University Press. https://www.ipcc.ch/srocc/chapter/chapter-4-sea-level-rise-andimplications-for-low-lying-islands-coasts-and-communities/.

United Nations Environment Programme (UNEP) (2014). The Adaptation Gap Report 2014. Nairobi. https://www. unenvironment.org/resources/adaptation-gap-report-2014.

United Nations Environment Programme (UNEP) (2017). The Adaptation Gap Report 2017. Nairobi. https://www. unenvironment.org/resources/adaptation-gap-report-2017.

United Nations Environment Programme (UNEP) (2020). Emissions Gap Report 2020. Nairobi. https://www.unenvironment. org/emissions-gap-report-2020.

Warren, R., Andrews, O., Brown, S., Forstenhaeusler, N., Gernaat, D., Goodwin, P. et al. (2018). Risks Associated with Global Warming of $1.5^{\circ} \mathrm{C}$ or $2^{\circ} \mathrm{C}$. Briefing Note. Tyndall Centre for Climate Change Research. https://tyndall.ac.uk/publications/ risks-associated-global-warming-15-or-2c.

\section{Chapter 3}

Dazé, A., Price-Kelly, H. and Rass, N. (2016). Vertical Integration in National Adaptation Plan (NAP) Processes: Guidance Note. Winnipeg: International Institute for Sustainable Development. https://www4.unfccc.int/sites/NAPC/Documents\%20 NAP/Supplements/Vertical-Integration-in-NAP-Processes-Guidance-Note.pdf.

European Commission (2018a). Horizontal assessment of the adaptation preparedness country fiches. Brussels. https:// ec.europa.eu/clima/sites/clima/files/adaptation/what/docs/horizontal_assessment_en.pdf.

European Commission (2018b). Adaptation preparedness scoreboard Country fiches. Accompanying the document Report from the Commission to the European Parliament and the Council on the implementation of the EU strategy on adaptation to climate change. Brussels. https://eur-lex.europa.eu/legal-content/EN/TXT/PDF/?uri=CELEX:52018SC0460\&from=EN. Kiribati, Secretariat of the Pacific Community (2019). Kiribati joint implementation plan for climate change and disaster risk management (KJIP) 2019-2028. https://www4.unfccc.int/sites/NAPC/Documents/Parties/Kiribati-JointImplementation-Plan-for-Climate-Change-and-Disaster-Risk-Management-2019-2028.pdf.

Least Developed Countries Expert Group (2012). National Adaptation Plans: Technical guidelines for the national adaptation plan process. Bonn: United Nations Framework Convention on Climate Change. https://unfccc.int/files/adaptation/ cancun_adaptation_framework/application/pdf/naptechguidelines_eng_high__res.pdf.

Least Developed Countries Expert Group (2015). Monitoring and assessing progress, effectiveness and gaps under the process to formulate and implement National Adaptation Plans: The PEG M\&E tool. Bonn: United Nations Framework Convention on Climate Change. https://unfccc.int/files/adaptation/application/pdf/50301_04_unfccc_monitoring_tool.pdf.

Mimura, N., Pulwarty, R.S., Duc, D.M., Elshinnawy, I., Redsteer, M.H., Huang, H., et al. (2014). Adaptation planning and implementation. In Climate Change 2014: Impacts, Adaptation, and Vulnerability. Part A: Global and Sectoral Aspects. Contribution of Working Group II to the Fifth Assessment Report of the Intergovernmental Panel on Climate Change. Cambridge and New York, NY: Cambridge University Press. Chapter 15, 869-898. https://www.ipcc.ch/report/ar5/wg2/. 
Nachmany, M., Byrnes, R. and Surminski, S. (2019). National laws and policies on climate change adaptation: a global review. Policy Brief. Grantham Research Institute on Climate Change and the Environment and Centre for Climate Change Economics and Policy. https://www.Ise.ac.uk/granthaminstitute/wp-content/uploads/2019/12/National-laws-andpolicies-on-climate-change-adaptation_A-global-review.pdf.

Saint Lucia, Department of Sustainable Development (2018). Saint Lucia's Adaptation Plan (NAP) 2018-2028. https://www4. unfccc.int/sites/NAPC/Documents/Parties/SLU-NAP-May-2018.pdf.

Umweltbundesamt (2015). Evaluation of the German strategy for adaption to climate change (DAS) -Reporting and closing indicator gaps. https://www.umweltbundesamt.de/en/publikationen/evaluation-of-the-german-strategy-for-adaption-to.

Umweltbundesamt (2020). 2019 Monitoring report on the German strategy for adaptation to climate change. Postfach. https:// www.umweltbundesamt.de/sites/default/files/medien/421/publikationen/das_2019_monitoring_report_bf.pdf.

United Nations Environment Programme (UNEP) (2017). The Adaptation Gap Report 2017. Nairobi. https://www. unenvironment. org/resources/adaptation-gap-report-2017.

United Nations Framework Convention on Climate Change (UNFCCC) (2016). Report of the Conference of the Parties on its twenty-first session, held in Paris from 30 November to 13 December 2015. Addendum. Part two: Action taken by the Conference of the Parties at its twenty-first session. 29 January. FCCC/CP/2015/10/Add.1. https://unfccc.int/resource/ docs/2015/cop21/eng/10a01.pdf.

United Nations Framework Convention on Climate Change (UNFCCC) (2019). Climate action and support trends, based on national reports submitted to the UNFCCC secretariat under the current reporting framework. Bonn. https://unfccc.int/ sites/default/files/resource/Climate_Action_Support_Trends_2019.pdf.

United Nations Framework Convention on Climate Change (UNFCCC) (2020a). Revised draft technical paper on approaches to reviewing the overall progress made in achieving the global goal on adaptation. 29 Jan. AC18/TP/5A. https://unfccc. int/sites/default/files/resource/ac18_gga.pdf.

United Nations Framework Convention on Climate Change (UNFCCC) (2020b). Progress in the process to formulate and implement national adaptation plans. 20 November. FCCC/SBI/2020/INF.13. https://unfccc.int/sites/default/files/ resource/sbi2020_inf13.pdf.

\section{Chapter 4}

Adaptation Fund Board (AFB) (2019). Assessment Report on Progress in the Implementation of the Adaptation Fund's Gender Policy and Gender Action Plan. 8 October. AFB/B.34/Inf.9. https://www.adaptation-fund.org/document/assessmentreport-on-progress-in-the-implementation-of-the-adaptation-funds-gender-policy-and-gender-action-plan/.

Bodnar, P., Brown, J. and Nakhooda, S. (2015). What counts: Tools to help define and understand progress towards the $\$ 100$ billion climate finance commitment. Washington, D.C.: World Resources Institute. https://files.wri.org/s3fs-public/ climate-finance-tools-workingpaper.pdf.

Chapagain, D., Baarsch, F., Schaeffer, M. and D'haen, S. (2020). Climate change adaptation costs in developing countries: insights from existing estimates. Climate and Development 12(10), 934-942. https://doi.org/10.1080/17565529.2020.1 711698

Climate Bonds Initiative (2019). Comparing China's Green Definitions with the EU Sustainable Finance Taxonomy (Part 1). https:// www.climatebonds.net/resources/reports/comparing-china\%E2\%80\%99s-green-definitions-eu-sustainable-financetaxonomy-part-1.

Climate Funds Update (2020). Data Dashboard. https://climatefundsupdate.org/data-dashboard/. Accessed 18 December 2020.

Climate Investment Funds (2020). Engagement of Women and Gender-Related Groups in the Climate Investment Funds: An Assessment. https://www.climateinvestmentfunds.org/sites/cif_enc/files/knowledge-documents/wedo_final_ report_7april2020.pdf.

Climate Policy Initiative (2019). Global Landscape of Climate Finance 2019, 7 November. https://www.climatepolicyinitiative. org/publication/global-landscape-of-climate-finance-2019/. Accessed 18 December 2020.

Cochran, I. and Pauthier, A. (2019). A framework for alignment with the Paris Agreement: Why, what and how for financial institutions? I4CE Discussion Paper. https://www.i4ce.org/download/framework-alignment-with-paris-agreement-whywhat-and-how-for-financial-institutions/.

European Commission (2018). Commission action plan on financing sustainable growth, 8 March. https://ec.europa.eu/info/ publications/180308-action-plan-sustainable-growth_en. Accessed 08 January 2021.

European Union (2020). Regulation (EU) 2020/852 of the European Parliament and of the Council of 18 June 2020 on the establishment of a framework to facilitate sustainable investment, and amending Regulation (EU) 2019/2088 (Text with EEA relevance). Brussels. http://data.europa.eu/eli/reg/2020/852/oj.

Fankhauser, S. (2010). The costs of adaptation. Wiley Interdisciplinary Reviews: Climate Change 1(1), 23-30. https://doi. org/10.1002/wcc.14. 
G20 Sustainable Finance Study Group (2018). Sustainable Finance Synthesis Report. http://unepinquiry.org/wp-content/ uploads/2018/11/G20_Sustainable_Finance_Synthesis_Report_2018.pdf.

Global Commission on Adaptation (GCA) (2019). Adapt Now: A Global Call for Leadership on Climate Resilience. Rotterdam and Washington, D.C.: Global Center on Adaptation and World Resources Institute. https://cdn.gca.org/assets/2019-09/ GlobalCommission_Report_FINAL.pdf.

Global Commission on Adaptation (GCA) (2020). Call to Action for a Climate-Resilient Recovery from COVID-19, 9 July. https:// cdn.gca.org/assets/2020-07/Global_Commission_Adapation_COVID_Resilience_Statement.pdf.

Green Climate Fund (GCF) (2011). Governing instrument for the Green Climate Fund. Incheon. https://www.greenclimate.fund/ document/governing-instrument.

International Development Finance Club (IDFC) (2019). IDFC Green Finance Mapping Report 2019. https://www.idfc.org/wpcontent/uploads/2019/12/idfc_report_final-2.pdf.

International Monetary Fund (IMF) (2019). Climate Change and Financial Risk. Finance \& Development, Vol. 56, No. 4. Washington DC. https://www.imf.org/external/pubs/ft/fandd/2019/12/pdf/climate-change-central-banks-and-financialrisk-grippa.pdf.

International Platform on Sustainable Finance (2020). Annual report of the International Platform on Sustainable Finance. https://ec.europa.eu/info/files/international-platform-sustainable-finance-annual-report-2020_en.

Mazzucato, M. (2013). The Entrepreneurial State: Debunking Public vs. Private Sector Myths. London: Anthem Press.

Multilateral Development Banks (MDB) (2013). Joint Report on MDB Climate Finance 2012. https://www. eib.org/attachments/ documents/joint_report_on_mdb_climate_finance_2012.pdf.

Multilateral Development Banks (MDB) (2014). Joint Report on MDB Climate Finance 2013. https://www.eib.org/attachments/ documents/joint_report_on_mdb_climate_finance_2013.pdf.

Multilateral Development Banks (MDB) (2015). 2014 Joint Report on Multilateral Development Banks' Climate Finance. https:// www.worldbank.org/content/dam/Worldbank/document/Climate/mdb-climate-finance-2014-joint-report-061615.pdf.

Multilateral Development Banks (MDB) (2016). 2015 Joint Report on Multilateral Development Banks' Climate Finance. http:// dx.doi.org/10.18235/0000806.

Multilateral Development Banks (MDB) (2017). 2016 Joint Report on Multilateral Development Banks' Climate Finance. http:// dx.doi.org/10.18235/0000806.

Multilateral Development Banks (2018). 2017 Joint Report on Multilateral Development Banks' Climate Finance. http://dx.doi. org/10.18235/0001336.

Multilateral Development Banks (2019). 2018 Joint Report on Multilateral Development Banks' Climate Finance. http://dx.doi. org/10.18235/0001736

Musgrove, P. (2011). Rewards for good performance or results: A short glossary of RBF - Updated March 2011. https://www. rbfhealth.org/resource/rewards-good-performance-or-results-short-glossary-rbf-updated-march-2011.

Network for Greening the Financial System (NGFS) (2019). A call for action: Climate change as a source of financial risk. https://www.banque-france.fr/sites/default/files/media/2019/04/17/ngfs_first_comprehensive_ report_-_17042019_0.pdf.

Network for Greening the Financial System (NGFS) (2020). Overview of Environmental Risk Analysis by Financial Institutions. https://www.ngfs.net/sites/default/files/medias/documents/overview_of_environmental_risk_ analysis_by_financial_institutions.pdf.

Organisation for Economic Co-operation and Development (OECD) (2015). Climate finance in 2013-14 and the USD 100 billion goal: A report by the OECD in collaboration with climate policy initiative. Paris. https://dx.doi. org/10.1787/9789264249424-en.

Organisation for Economic Co-operation and Development (OECD) (2019a). Aligning Development Co-operation and Climate Action: The Only Way Forward. Paris: OECD Publishing. https://doi.org/10.1787/5099ad91-en.

Organisation for Economic Co-operation and Development (OECD) (2019b). Results of the first survey on coefficients that Members apply to the Rio marker data when reporting to the UN Conventions on Climate Change and Biodiversity. Paris. http://www.oecd.org/dac/financing-sustainable-development/development-finance-topics/climate-change. htm.

Organisation for Economic Co-operation and Development (OECD) Development Assistance Committee (DAC) (2020). Climate-related Development Finance at the Activity Level. Climate Change: OECD DAC External Development Finance Statistics. http://www.oecd.org/dac/financing-sustainable-development/development-finance-topics/ climate-change.htm. Accessed 18 December 2020.

Organisation for Economic Co-operation and Development (OECD) (2020a). Climate Finance Provided and Mobilised by Developed Countries in 2013-18. Paris. https://www.oecd.org/environment/climate-finance-provided-andmobilised-by-developed-countries-in-2013-18-f0773d55-en.htm.

Organisation for Economic Co-operation and Development (OECD) Development Assistance Committee (2020b). Developing Sustainable Finance Definitions and Taxonomies. Paris. https://doi.org/10.1787/134a2dbe-en. 
Oxfam (2020). Climate Finance Shadow Report 2020: Assessing progress towards the $\$ 100$ billion commitment. Oxford. https://oxfamilibrary.openrepository.com/bitstream/handle/10546/621066/bp-climate-finance-shadow-report2020-201020-en.pdf.

Pauw, W.P., Castro, P., Pickering, J. and Bhasin, S. (2020). Conditional Nationally Determined Contributions in the Paris Agreement: Foothold for equity or Achilles heel? Climate Policy 20(4), 468-484. https://doi.org/10.1080/1469306 2.2019.1635874.

Pauw, W.P., Klein, R.J.T., Vellinga, P. and Biermann, F. (2016). Private finance for adaptation: do private realities meet public ambitions? Climatic Change 134(4), 489-503. https://doi.org/10.1007/s10584-015-1539-3.

Puri, J., Khan, A. and Asfaw, S. (2020). Climate and Money: Dealing with 'Impact Washing' and a Case for Climate Impact Bonds. In Global Handbook of Impact Investing: Solving Global Problems Via Smarter Capital Markets Towards A More Sustainable Society. Sarmento, E.D.M. and Herman, R.P. (eds.). John Wiley \& Sons.

Schalatek, L. (2019). Gender and Climate Finance. Washington, D.C.: Climate Funds Update. https://climatefundsupdate. org/wp-content/uploads/2019/11/CFF10-2019-ENG-DIGITAL.pdf.

Task Force on Climate-Related Financial Disclosures (TCFD) (2017). Implementing the Recommendations of the Task Force on Climate-related Financial Disclosures. Basel. https://assets.bbhub.io/company/sites/60/2020/10/FINALTCFD-Annex-Amended-121517.pdf.

Task Force on Climate-Related Financial Disclosures (TCFD) (2019). Task Force on Climate-Related Financial Disclosures: 2019 Status Report. Basel. https://www.fsb-tcfd.org/publications/tcfd-2019-status-report.

United Nations Development Programme (UNDP) (2019). Knowing what you spend: A guidance note for governments to track climate finance in their budgets, 3 July. https://www.undp.org/content/undp/en/home/librarypage/climateand-disaster-resilience-/knowing-what-you-spend.html. Accessed 8 January 2021.

United Nations Environment Programme (UNEP) (2016). Adaptation Finance Gap Report 2016. Nairobi. https://unepdtu. org/publications/the-adaptation-finance-gap-report/.

United Nations Environment Programme (UNEP) (2018). Adaptation Gap Report 2018. Nairobi. https://www.unep.org/ resources/adaptation-gap-report.

United Nations Framework Convention on Climate Change (UNFCCC) (2017). Establishment of a gender action plan. Decision 3/CP.23 FCCC/CP/2017/11/Add.1. https://unfccc.int/resource/docs/2017/cop23/eng/11a01.pdf\#page=13. Accessed 8 January 2021.

United Nations Framework Convention on Climate Change (UNFCCC) Standing Committee on Finance (SCF) (2016). 2016 Biennial assessment and overview of climate finance flows. Bonn. https://unfccc.int/topics/climate-finance/ workstreams/transparency-of-support-ex-post/biennial-assessment-and-overview-of-climate-finance-flows/thesecond-biennial-assessment-and-overview-of-climate-finance-flows-2016.

United Nations Framework Convention on Climate Change (UNFCCC) Standing Committee on Finance (SCF) (2018). 2018 Biennial assessment and overview of climate finance flows. Bonn. https://unfccc.int/topics/climate-finance/ workstreams/transparency-of-support-ex-post/biennial-assessment-and-overview-of-climate-finance-flowsbackground/biennial-assessment-and-overview-of-climate-finance-flows-2018.

Watson, C., Robertson, M., Ramdin, A. and Bailey, C. (2020). Assessment and overview of climate finance flows in Antigua and Barbuda 2014-2017. Bonn. United Nations Framework Convention on Climate Change. https://unfccc.int/sites/ default/files/resource/UNFCCC-AntiguaBarbuda-Report-web-DEF.pdf.

Weikmans, R. and Roberts, J.T. (2019). The international climate finance accounting muddle: Is there hope on the horizon? Climate and Development 11(2), 97-111. https://doi.org/10.1080/17565529.2017.1410087.

Weikmans, R., Roberts, J.T., Baum, J., Bustos, M.C. and Durand, A. (2017). Assessing the credibility of how climate adaptation aid projects are categorised. Development in Practice 27(4), 458-471. https://doi.org/10.1080/0961452 4.2017.1307325.

World Bank (2019). Fiscal Policies for Development and Climate Action. Pigato, M.A (ed.). Washington, D.C. https://www. worldbank.org/en/topic/macroeconomics/publication/fiscal-policies-for-development-and-climate-action.

\section{Chapter 5}

Adaptation Fund (2019). Results infographic, May 2019. https://www.adaptation-fund.org/pdfjs/web/viewer.html?file=https:// www.adaptation-fund.org/wp-content/uploads/2018/04/AF-infographic-Eng-May2019-WEB.pdf.

Berrang-Ford, L., Biesbroek, R., Ford, J.D., Lesnikowski, A., Tanabe, A., Wang, F.M. et al. (2019). Tracking global climate change adaptation among governments. Nature Climate Change 9, 440-449. https://doi.org/10.1038/s41558-019-0490-0.

Berrang-Ford, L. et al. (forthcoming). Mapping evidence of human adaptation to climate change. Submitted to Nature Climate Change.

Callaghan, M.W., Minx, J.C. and Fosters, P.M. (2020). A topography of climate change research. Nature Climate Change 10(2), 118-123. https://doi.org/10.1038/s41558-019-0684-5. 
Ford, J. and Berrang-Ford, L. (2016). The 4Cs of adaptation tracking: consistency, comparability, comprehensiveness, coherency. Mitigation and Adaptation Strategies for Global Change 21(6), 839-859. https://doi.org/10.1007/s11027-0149627-7.

Ford, J., Berrang-Ford, L., Biesbroek, R., Araos, M., Austin, S.E. and Lesnikowski, A. (2015). Adaptation tracking for a post-2015 climate agreement. Nature Climate Change 5(11), 967-969. https://doi.org/10.1038/nclimate2744.

Forsyth, T. (2018). Is resilience to climate change socially inclusive? Investigating theories of change processes in Myanmar. World Development 111, 13-26. https://doi.org/10.1016/j.worlddev.2018.06.023.

Global Environment Facility (GEF) (2020). Report of the Global Environment Facility to the Twenty-Sixth Session of the Conference of the Parties to the United Nations Framework Convention on Climate Change, 30 September 2020. https:// www.thegef.org/sites/default/files/documents/GEF_Report_UNFCCC_COP26.pdf.

Green Climate Fund (GCF) (2020). Annual portfolio performance report (2019). GCF/B.27/Inf.04, 23 October 2020. https://www. greenclimate.fund/sites/default/files/document/gcf-b27-inf04.pdf.

GIZ (2020). Tool for Assessing Adaptation in the NDCs (TAAN). Deutsche Gesellschaft für Internationale Zusammenarbeit (GIZ) GmbH. https://www.adaptationcommunity.net/nap-ndc/tool-assessing-adaptation-ndcs-taan/taan/. Accessed 8 January 2021.

Intergovernmental Panel on Climate Change (IPCC) (2018). Summary for Policymakers. In Global Warming of $1.5^{\circ} \mathrm{C}$. An IPCC Special Report on the impacts of global warming of $1.5^{\circ} \mathrm{C}$ above pre-industrial levels and related global greenhouse gas emission pathways, in the context of strengthening the global response to the threat of climate change, sustainable development, and efforts to eradicate poverty. Masson-Delmotte, V., Zhai, P., Pörtner, H.-O., Roberts, D., Skea, J., Shukla, J.R. et al. (eds.). Cambridge: Cambridge University Press. https://www.ipcc.ch/sr15/

Jones, L. (2019). A how-to guide for subjective evaluations of resilience, 25 September. Resilience Intel, Issue No.1. London: BRACED. http://www.braced.org/resources/i/A-how-to\%20guide-for-subjective-evaluations-of-resilience/. Accessed 8 January 2021.

Leiter, T. (2018). Assessing results of climate change adaptation projects in practice: learning from German Technical Development Cooperation. In Adaptation Metrics: Perspectives on Measuring, Aggregating and Comparing Adaptation Results (pp. 139155). Christiansen, L., Sanchez Martinez, G. and Naswa, P. (eds.). Copenhagen: UNEP DTU Partnership. https://unepdtu.org/publications/adaptation-metrics-perspectives-on-measuring-aggregating-and-comparingadaptation-results/.

Leiter, T., Olhoff, A., Al Azar, R., Barmby, V., Bours, D., Clement, V.W.C. et al. (2019). Adaptation Metrics: Current Landscape and Evolving Practices. Background paper for the Global Commission on Adaptation. Rotterdam and Washington, D.C. https://unepdtu.org/wp-content/uploads/2019/09/adaptation-metrics-current-landscape-and-evolving-practices.pdf Leiter, T. and Pringle, P. (2018). Pitfalls and potential of measuring adaptation through adaptation metrics. In Adaptation Metrics: Perspectives on Measuring, Aggregating and Comparing Adaptation Results (pp. 29-48). Christiansen, L., Sanchez Martinez, G. and Naswa, P. (eds.). Copenhagen: UNEP DTU Partnership. https://unepdtu.org/publications/adaptationmetrics-perspectives-on-measuring-aggregating-and-comparing-adaptation-results/.

Lesnikowski, A., Ford, J., Berrang-Ford, L., Barrera, M. and Heymann, S.J. (2015). How are we adapting to climate change? A global assessment. Mitigation and Adaptation Strategies for Global Change 20(2), 277-293. https://doi.org/10.1007/ s11027-013-9491-x.

Oberlack, C., Breu, T., Giger, M., Harari, N., Herweg, K., Mathez-Stiefel, S.-L. et al. (2019). Theories of change in sustainability science: Understanding how change happens. GAIA- Ecological Perspectives on Science and Society 28(2), 106-111. https://doi.org/10.14512/gaia.28.2.8.

Phillips, C.A., Caldas, A., Cleetus, R., Dahl, K.A., Declet-Barreto, J., Licker, R. et al. (2020). Compound climate risks in the COVID-19 pandemic. Nature Climate Change 10, 586-588. https://doi.org/10.1038/s41558-020-0804-2.

Schipper, L. (2020). Maladaptation: when adaptation to climate change goes very wrong. One Earth 3(4), 409-414. https://doi. org/10.1016/j.oneear.2020.09.014.

Thomas, K., Hardy, R.D., Lazrus, H., Mendez, M., Orlove, B., Rivera-Collazo, I. et al. (2018). Explaining differential vulnerability to climate change: A social science review. WIRES Climate Change 10(2), 1-18. https://doi.org/10.1002/wcc.565.

United Nations Environment Programme (UNEP) (2017). The Adaptation Gap Report 2017. Nairobi. https://www.unenvironment. org/resources/adaptation-gap-report-2017.

United Nations Environment Programme (UNEP) (2018). The Adaptation Gap Report 2018. Nairobi. https://www. unenvironment. org/resources/adaptation-gap-report.

United Nations Environment Programme (UNEP) (2020). The Emissions Gap Report 2020. Nairobi. https://www.unep.org/ emissions-gap-report-2020.

Von Engelhardt, J. and Jones, L. (2020). Using mobile phone surveys to track resilience and post-disaster recovery: a how-to guide. London: BRACED. http://www.braced.org/resources/i/using-mobile-phone-surveys-to-track-resilience.

Weikmans, R., Roberts, J.T., Baum, J., Bustos, M.C. and Durand, A. (2017). Assessing the credibility of how climate adaptation aid projects are categorised. Development in Practice 27(4), 458-471. https://doi.org/10.1080/09614524.2017.1307325. 


\section{Chapter 6}

Adaptation Fund (undated a). Enhancing climate resilience of rural communities living in protected areas of Cambodia. https://www.adaptation-fund.org/project/enhancing-climate-resilience-of-rural-communities-living-in-protectedareas-of-cambodia/. Accessed 27 August 2020.

Adaptation Fund (undated b). Ecosystem based approaches for reducing the vulnerability of food security to the impacts of climate change in the Chaco region of Paraguay. https://www.adaptation-fund.org/project/ecosystem-basedapproaches-reducing-vulnerability-food-security-impacts-climate-change-chaco-region-paraguay/. Accessed 17 December 2020.

Allen, C.D., Macalady, A.K., Chenchouni, H., Bachelet, D., McDowell, N., Vennetier, M. et al. (2010). A global overview of drought and heat-induced tree mortality reveals emerging climate change risks for forests. Forest Ecology and Management 259(4), 660-684. https://doi.org/10.1016/j.foreco.2009.09.001.

Almassy, D., Pinter, L., Rocha, S., Naumann, S., Davis, M., Abhold, K. et al. (2018). Urban Nature Atlas: A Database of NatureBased Solutions Across 100 European Cities. https://naturvation.eu/sites/default/files/result/files/urban_nature_ atlas_a_database_of_nature-based_solutions_across_100_european_cities.pdf.

Arkema, K.K., Verutes, G.M., Wood, S.A., Clarke-Samuels, C., Canto, M., Rosado, S. et al. (2015). Embedding ecosystem services in coastal planning leads to better outcomes for people and nature. Proceedings of the National Academy of Sciences of the United States of America 112(24), 7390-7395. https://doi.org/10.1073/pnas.1406483112.

Blue Forest Conservation (undated). Financial innovation for sustainable solutions. https://www.blueforestconservation. com/\#frb. Accessed 24 August 2020.

Buchner, B., Clark, A., Falconer, A., Macquarie, R., Meattle, C., Tolentino, R. et al. (2019). Global Landscape of Climate Finance 2019. London: Climate Policy Initiative. https://www.climatepolicyinitiative.org/wp-content/uploads/2019/11/2019Global-Landscape-of-Climate-Finance.pdf.

Buckley, R., Brough, P., Hague, L., Chauvenet, A., Fleming, C., Roche, E. et al. (2019). Economic value of protected areas via visitor mental health. Nature Communications 10, 5005. https://doi.org/10.1038/s41467-019-12631-6.

C40 Cities Climate Leadership Group and Nordic Sustainability (2019). Cities100: Medellín's interconnected green corridors. https://www.c40knowledgehub.org/s/article/Cities100-Medellin-s-interconnected-green-corridors?language=en_US. Accessed 30 October 2020.

Calliari, E., Staccione, A. and Mysiak, J. (2019). An assessment framework for climate-proof nature-based solutions. Science of The Total Environment 656, 691-700. https://doi.org/10.1016/j.scitotenv.2018.11.341.

Carbon Disclosure Project (CDP) (2016). CDP Cities 2016: Climate action from 533 global cities. London. https://6fefcbb86e61af1b2fc4-c70d8ead6ced550b4d987d7c03fcdd1d.ssl.cf3.rackcdn.com/cms/reports/ documents/000/001/171/original/CDP_Summary-Report_2016_FINAL.pdf?1597935546.

Chausson, A., Turner, B., Seddon, D., Chabaneix, N., Girardin, C.A., Kapos, V. et al. (2020). Mapping the effectiveness of naturebased solutions for climate change adaptation. Global Change Biology 26(11), 6134-6155. https://doi.org/10.1111/ gcb.15310.

City of New York (2019). City doubles size of largest green infrastructure program in nation, making NYC more resilient to global warming, 28 August. https://www1.nyc.gov/office-of-the-mayor/news/406-19/city-doubles-size-largest-greeninfrastructure-program-nation-making-nyc-more-resilient-to. Accessed 30 October 2020.

Climate Bonds Initiative (CBI) (2019). Green Bonds: The State of the Market 2018. https://www.climatebonds.net/files/reports/ cbi_gbm_final_032019_web.pdf.

Climate Bonds Initiative (CBI) (2020). Green Bonds: Global State of the Market 2019. https://www.climatebonds.net/files/ reports/cbi_sotm_2019_vol1_04d.pdf.

Climate Finance Advisors (2019). Driving Finance Today for the Climate Resilient Society of Tomorrow. Geneva: United Nations Environment Programme.http://www.unepfi.org/wordpress/wp-content/uploads/2019/07/GCA-Adaptation-Finance. pdf.

Climate Technology Center and Network (CTCN) (undated). Restoration of organic soils. https://www.ctc-n.org/technologies/ restoration-organic-soils. Accessed 27 August 2020.

Cohen-Shacham, E., Walters, G., Janzen, C., and Maginnis, S. (eds.) (2016). Nature-based Solutions to address global societal challenges. Gland: IUCN. https://portals.iucn.org/library/node/46191.

Conway, S. and Mazza, F. (2019). Restoration Insurance Service Company (RISCO): Lab Instrument Analysis. The Global Innovation Lab for Climate Finance. https://www.climatefinancelab.org/wp-content/uploads/2019/03/RISCO_ Instrument-analysis-1.pdf.

Cool Coalition (2020). El bosque metropolitano: Madrid announces urban forest plan to combat urban heat and pollution, 3 August. https://coolcoalition.org/el-bosque-metropolitano-madrid-announces-urban-forest-plan-to-combat-urbanheat-and-pollution/. Accessed 30 October 2020.

Cooper, G. and Trémolet, S. (2019). Investing in Nature: Private Finance for Nature-based Resilience. London: The Nature Conservancy and Environmental Finance. https://www.environmental-finance.com/content/research/investing-innature-private-finance-for-nature-based-resilience.html. 
Cooper, R. and Matthews, J.H. (2020). Water Finance and Nature-based Solutions. K4D Helpdesk Report 857. Brighton: Institute of Development Studies. https://opendocs.ids.ac.uk/opendocs/handle/20.500.12413/15592.

Costanza, R., d'Arge, R., De Groot, R., Farber, S., Grasso, M., Hannon, B. et al. (1997). The value of the world's ecosystem services and natural capital. Nature 387, 253-260. https://doi.org/10.1038/387253a0.

Costanza, R., De Groot, R., Braat, L., Kubiszewski, I., Fioramonti, L., Sutton et al. (2017). Twenty years of ecosystem services: how far have we come and how far do we still need to go? Ecosystem Services 28, 1-16. https://doi. org/10.1016/j.ecoser.2017.09.008.

Costanza, R., Pérez-Maqueo, O., Martinez, M.L., Sutton, P., Anderson, S.J., Mulder, K. (2008). The value of coastal wetlands for hurricane protection. Ambio 37(4), 241-248. https://doi.org/10.1579/0044-7447(2008)37[241:TV OCWF]2.0.CO;2.

Dazé, A., Price-Kelly, H. and Rass, N. (2016). Vertical Integration in National Adaptation Plan (NAP) Processes: A Guidance Note for Linking National and Sub-national Adaptation Processes. Winnipeg: International Institute for Sustainable Development. https://napglobalnetwork.org/wp-content/uploads/2016/11/Vertical-Integrationin-NAP-Processes-Guidance-Note.pdf.

De Mel, M. and Weerathunghe, C. (2011). Valuation of Ecosystem Services of the Maha Oya. Colombo: Environmental Foundation. http://www. mangrovesforthefuture.org/assets/Repository/Documents/Valuation-ofEcosystem-Services-of-the-Maha-Oya.pdf.

Deutsche Gesellschaft für Internationale Zusammenarbeit (GIZ) (2019). Towards a strategic approach to the diagnosis, response \& delivery of sustainable biodiversity financing solutions. Bonn.

Donatti, C., Harvey, C., Hole, D., Panfil, S. and Schurman, H. (2020). Indicators to measure the climate change adaptation outcomes of ecosystem-based adaptation. Climatic Change 158, 413-433. https://doi.org/10.1007/ s10584-019-02565-9.

Droste, N., Schröter-Schlack, C., Hansjürgens, B. and Zimmermann H. (2017). Implementing nature-based solutions in urban areas: financing and governance aspects. In Nature-based Solutions to Climate Change Adaptation in Urban Areas: Linkages between Science, Policy and Practice. Kabisch, N., Korn, H., Sadler, J. and Bonn N. (eds.). Cham: Springer. Chapter 18. 307-321. https://doi.org/10.1007/978-3-319-56091-5_18.

Epple, C., Thorley, J., Güisa, M., Calderón-Urquizo, A., Walcott, J., Väänänen, E., et al (2014). Promoting environmental and social benefits of REDD+ in Peru through spatial analysis. How maps can support the achievement of multiple policy goals. Cambridge: UNEP-WCMC. https://www.unep-wcmc.org/system/dataset_file_fields/ files/000/000/268/original/Peru_Report_141105_lowres_webversion.pdf?1415890986.

Estrella, M. and Saalismaa, N. (2013). Ecosystem-based disaster risk reduction (Eco-DRR): an overview. In The Role of Ecosystems in Disaster Risk Reduction. Renaud, F.G., Sudmeier-Rieux, K. and Estrella, M. (eds.). Tokyo: United Nations University Press. https://collections.unu.edu/view/UNU:1995.

European Environment Agency, European Climate Adaptation Platform (Climate-ADAPT) (undated). Lower Danube green corridor: floodplain restoration for flood protection (2014). https://climate-adapt.eea.europa.eu/ metadata/case-studies/lower-danube-green-corridor-floodplain-restoration-for-flood-protection. Accessed 17 December 2020.

European Investment Bank (EIB) (undated). Investing in Nature: Financing Conservation and Nature-based Solutions. https://www.eib.org/attachments/pj/ncff-invest-nature-report-en.pdf.

Food and Agriculture Organization of the United Nations (FAO) and United Nations Development Programme (UNDP) (2020). National Adaptation Plans - An Entry Point for Ecosystem-based Adaptation. Integrating Agriculture in National Adaptation Plans Programme Briefing Note. http://www.fao.org/3/ca9541en/ ca9541en.pdf.

Frantzeskaki, N. (2019). Seven lessons for planning nature-based solutions in cities. Environmental. Science \& Policy 93, 101-111. https://doi.org/10.1016/j.envsci.2018.12.033.

Graham, S., Barnett, J., Fincher, R., Mortreux, C. and Hurlimann, A. (2015). Towards fair local outcomes in adaptation to sea-level rise. Climatic Change, 130(3), 411-424. https://doi.org/10.1007/s10584-014-1171-7.

Global Commission on Adaptation (GCA) (2019). Adapt Now: A Global Call for Leadership on Climate Resilience. Rotterdam and Washington, D.C.: Global Center on Adaptation and World Resources Institute. https://cdn. gca.org/assets/2019-09/GlobalCommission_Report_FINAL.pdf.

Hamrick, K. (2016). State of Private Investment in Conservation 2016: A Landscape Assessment of an Emerging Market. Washington, D.C.: Forest Trends. https://www.forest-trends.org/wp-content/ uploads/2017/03/2016SOPICReport_FINAL_Full-REV.pdf.

Immerzeel, W.W., Lutz, A.F., Andrade, M., Bahl, A., Biemans, H., Bolch, T. et al. (2020). Importance and vulnerability of the world's water towers. Nature 577, 364-369. https://doi.org/10.1038/s41586-019-1822-y.

Inter-American Development Bank (IDB) (2019). Nature-Based Solutions: Increasing Private Sector Uptake for Climate-Resilience Infrastructure in Latin America and the Caribbean. Interamerican Development Bank Climate Change Division Discussion Paper No. IDB-DP-00724. https://dx.doi.org/10.18235/0002049. 
Inter-American Development Bank (IDB) (2020). Increasing Infrastructure Resilience with Nature-based Solutions (NbS): A 12-Step Technical Guidance Document for Project Developers. http://dx.doi.org/10.18235/0002325.

Intergovernmental Panel on Climate Change (IPCC) (2014). Annex II: Glossary. In Climate Change 2014: Synthesis Report. Contribution of Working Groups I, II and III to the Fifth Assessment Report of the Intergovernmental Panel on Climate Change. Mach, K.J., Planton, S., von Stechow, C. (eds.). Geneva. 117-130. https://www.ipcc.ch/report/ar5/syr/.

Intergovernmental Panel on Climate Change (IPCC) (2018). Summary for Policymakers. Global Warming of $1.5^{\circ} \mathrm{C}$. An IPCC Special Report on the impacts of global warming of $1.5^{\circ} \mathrm{C}$ above pre-industrial levels and related global greenhouse gas emission pathways, in the context of strengthening the global response to the threat of climate change, sustainable development, and efforts to eradicate poverty. Masson-Delmotte, V., Zhai, P., Pörtner, H.-O., Roberts, D., Skea, J., Shukla, J.R. et al. (eds.). Cambridge: Cambridge University Press. https://www.ipcc.ch/sr15/.

Intergovernmental Science-Policy Platform on Biodiversity and Ecosystem Services (IPBES) (2019). Global Assessment Report on Biodiversity and Ecosystem Services of the Intergovernmental Science-Policy Platform on Biodiversity and Ecosystem Services. Brondizio, E.S., Settele, J., Díaz, S., and Ngo H.T. (eds.). Bonn. https://www.ipbes.net/globalassessment.

Intergovernmental Science-Policy Platform on Biodiversity and Ecosystem Services (IPBES) (2020). IPBES Workshop on Biodiversity and Pandemics: Executive Summary. Bonn. https://ipbes.net/sites/default/files/2020-10/IPBES\%20 Pandemics\%20Workshop\%20Report\%20Executive\%20Summary\%20Final.pdf.

International Climate Initiative (2020a). Ecosystem based adaptation in mountain ecosystems, December. https://www. international-climate-initiative.com/en/details/project/ecosystem-based-adaptation-in-mountain-ecosystems-12 II+_012-256. Accessed 25 August 2020.

International Climate Initiative (2020b). Maintaining habitats in the Altai Sayan region, December. https://www.internationalclimate-initiative.com/en/details/project/maintaining-habitats-in-the-altai-sayan-region-08_II_039-238. Accessed 17 December 2020.

International Union for Conservation of Nature (IUCN) (undated a). EbA: strengthening the evidence and informing policy. https://www.iucn.org/theme/ecosystem-management/our-work/ecosystem-based-adaptation-and-climate-change/ eba-strengthening-evidence-and-informing-policy. Accessed 17 December 2020.

International Union for Conservation of Nature (IUCN) (undated b). Scaling up mountain EbA. https://www.iucn.org/theme/ ecosystem-management/our-work/ecosystem-based-approaches-climate-change-adaptation/scaling-mountaineba. Accessed 17 December 2020.

International Union for Conservation of Nature (IUCN) (2015). Tank Ecosystem Restoration. Programme on Restoring Traditional Cascading Tank Systems Technical Note \# 3. Colombo. https://www.iucn.org/sites/dev/files/content/ documents/tank_ecosystem_restoration_tn_3_feb11_2016.pdf.

International Union for Conservation of Nature (IUCN) (2018). Safeguarding Nature Through Finance. https://www.iucn.org/ sites/dev/files/information_paper___safeguarding_nature_through_finance.pdf.

International Union for Conservation of Nature (IUCN) (2020). Guidance for Using the IUCN Global Standard for Nature-based Solutions. A User-friendly Framework for the Verification, Design and Scaling up of Nature-based Solutions. First edition. Gland. https://doi.org/10.2305/IUCN.CH.2020.08.en.

Itaipú Binacional (2020). Mission. https://www.itaipu.gov.br/en/company/mission. Accessed 27 October 2020.

Kapos, V., Wicander, S., Salvaterra, T., Dawkins, K. and. Hicks, C. (2019). The Role of the Natural Environment in Adaptation. Rotterdam and Washington, D.C.: Global Commission on Adaption. https://cdn.gca.org/assets/2019-12/ RoleofNaturalEnvironmentinAdaptation_V2.pdf.

Kestrel Verifiers (2020). Verifier's Report: Milwaukee Metropolitan Sewerage District General Obligation Sewerage System Bonds Series 2020A (Green Bonds) -"Series 2020A Green Bonds". https://www.climatebonds. net/files/files/MMSDpre-issuance-verification.pdf.

Kovach, R.P., Gharrett, A.J. and Tallmon, D.A. (2012). Genetic change for earlier migration timing in a pink salmon population. Proceedings of the Royal Society B: Biological Sciences 279(1743), 3870-3878. https://doi.org/10.1098/rspb.2012.1158.

Lao People's Democratic Republic and United Nations Environment Programme (UNEP) (2019). SAP009: Building resilience of urban populations with ecosystem-based solutions in Lao PDR. Green Climate Fund. https://www. greenclimate.fund/ sites/default/files/document/funding-proposal-sap009-unep-lao-people-s-democratic-republic.pdf.

Lavorel, S., Colloff, M.J., Locatelli, B., Gorddard, R., Prober, S.M., Gabillet, M. et al. (2019). Mustering the power of ecosystems for adaptation to climate change. Environmental Science and Policy 92, 87-97. https://doi.org/10.1016/j. envsci.2018.11.010.

Lavorel, S., Colloff, M.J., Mcintyre, S., Doherty, M.D., Murphy, H.T., Metcalfe, D.J. et al. (2015). Ecological mechanisms underpinning climate adaptation services. Global Change Biology 21(1), 12-31. https://onlinelibrary.wiley.com/doi/ full/10.1111/gcb.12689.

Lazić, M. and Emerton, L. (2020). Sourcebook on Sustainable Financing for Biodiversity, Ecosystems \& Protected Areas. Eschborn and Bonn: Deutsche Gesellschaft für Internationale Zusammenarbeit. https://www.giz.de/en/downloads/ Sourcebook_sustainable_financing_biodiversit_final.pdf. 
Least Developed Countries Expert Group of the United Nations Framework Convention on Climate Change (2012). National Adaptation Plans: Technical Guidelines for the National Adaptation Plan Process. Bonn: United Nations Climate Change Secretariat. http://unfccc.int/files/adaptation/cancun_adaptation_framework/national_adaptation_plans/application/ pdf/naptechguidelines_eng_low_res.pdf.

Lo, S., Wu, C. and Lin, C. (2016). Financial support mechanisms and financing instruments for climate change adaptation. Journal of Environmental Protection 7(2), 242-252. https://doi.org/10.4236/jep.2016.72021.

Losada, I.J., Menéndez, P., Espejo, A., Torres, S., Díaz-Simal, P., Abad, S. et al. (2018). The Global Value of Mangroves for Risk Reduction. Berlin: The Nature Conservancy. https://doi.org/10.7291/V9DV1H2S.

Mekong River Commission (MRC) (2014). International Experiences on the Formulation and Implementation of Transboundary Climate Change Adaptation Strategies. Vientiane. http://mrcmekong.org/assets/Publications/Reports/Internationalexperiences-on-the-formulation-implt-of-tbr-CCA-strategies.pdf.

Menéndez, P., Losada, I.J., Torres-Ortega, S., Narayan, S., and Beck, M.W. (2020). The global flood protection benefits of mangroves. Scientific Reports 10, 3-11. https://doi.org/10.1038/s41598-020-61136-6.

Meyers, D., Bohorquez, J., Cumming, T., Emerton, L., van den Heuvel, O., Riva, M. et al. (2020). Conservation Finance: A Framework. Conservation Finance Alliance. https://doi.org/10.13140/RG.2.2.14186.88000.

Millennium Ecosystem Assessment (2005). Ecosystems and Human Well-being: Synthesis. Washington, D.C.: Island Press. http://www.millenniumassessment.org/documents/document.356.aspx.pdf.

Multihazard Mitigation Council (MMC) (2005). Natural Hazard Mitigation Saves: An Independent Study to Assess the Future Savings from Mitigation Activities. Volume 1-Findings, Conclusions, and Recommendations. Washington, D.C.: National Institute of Building Sciences. https://www.nibs.org/resource/resmgr/MMC/hms_vol1.pdf.

Narayan, S., Beck, M., Reguero, B., Losada, I., van Wesenbeeck, B., Pontee, N. et al. (2016). The effectiveness, costs and coastal protection benefits of natural and nature-based defenses. PLOS ONE 11(5), e0154735. https://doi.org/10.1371/ journal.pone.0154735.

New York State (NYS) (undated). Learn more about the living breakwaters project. https://stormrecovery.ny.gov/learn-moreabout-living-breakwaters-project. Accessed 30 June 2020.

NYC Parks (2015). NYC parks celebrates one millionth tree with Bronx community members, 24 November. https://www. nycgovparks.org/parks/joyce-kilmer-park/dailyplant/23507. Accessed 17 December 2020.

OneWorld Sustainable Investments and Oxford Policy Management (2018). Microfinance for Climate Adaptation: From Readiness to Resilience. Climate Investment Funds. https://www.climateinvestmentfunds.org/sites/cif_enc/files/ knowledge-documents/micro-finance_research_brief.pdf.

Organisation for Economic Co-operation and Development (OECD) (2020a). Nature-based solutions for adapting to waterrelated climate risks. Environment Policy Papers 21. Paris. https://doi.org/10.1787/2257873d-en.

Organisation for Economic Co-operation and Development (OECD) (2020b). Aid activities targeting Global Environmental Objectives. https://stats.oecd.org/Index.aspx?DataSetCode=RIOMARKERS. Accessed 20 August 2020.

Ozment, S., Ellison, G., and Jongman, B. (2019). Nature-Based Solutions for Disaster Risk Management. Washington, D.C.: World Bank Group. http://documents.worldbank.org/curated/en/253401551126252092/Booklet.

Pauw, W.P., Klein, R.J.T., Biermann, F. and Vellinga, P. (2016). Private finance for adaptation: do private realities meet public ambitions? Climatic Change 134(4), 489-503 https://doi.org/10.1007/s10584-015-1539-3.

Powell, N., Osbeck, M., Tan, S.B., and Toan, V.C. (2011). World Resources Report Case Study: Mangrove restoration and rehabilitation for climate change adaptation in Vietnam. Washington, D.C.: World Resources Report. https://www. researchgate.net/publication/235602091_Mangrove_restoration_and_rehabilitation_for_climate_change_ adaptation_in_Vietnam.

Quinn, A. (2018). Case Study 10.B: New York's Million Trees NYC Project. In Climate Change and Cities: Second Assessment Report of the Urban Climate Change Research Network. Rosenzweig, C., Solecki, W., Romero-Lankao, P., Mehrotra, S., Dhakal, S. and Ali Ibrahim, S. (eds.). Cambridge University Press, Annex 5. https://c4cmr518.caspio.com/ dp/29055000d441069aa8224d76905a/files/3545983. Accessed 17 December 2020.

Raymond, C.M., Berry, P., Breil, M., Nita, M.R., Kabisch, N., de Bel, M. et al. (2017). An Impact Evaluation Framework to Support Planning and Evaluation of Nature-based Solutions Projects. Wallingford: Centre for Ecology \& Hydrology. https://ec.europa.eu/research/environment/pdf/renaturing/eklipse_report1_nbs-02022017. pdf\#view=fit\&pagemode=none.

Reguero, B.G., Beck, M.W., Schmid, D., Stadtmüller, D., Raepple, J., Schüssele, S. et al. (2020). Financing coastal resilience by combining nature-based risk reduction with insurance. Ecological Economics 169, 106487. https://doi.org/10.1016/j. ecolecon.2019.106487.

Reid, H., Hou Jones, X., Porras, I., Hicks, C., Wicander, S., Seddon, N., et al. (2019). Is Ecosystem-based Adaptation Effective? Perceptions and Lessons Learned from 13 Project Sites. London: International Institute for Environment and Development. https://pubs.iied.org/pdfs/17651IIED.pdf.

Reynolds, A. (2019). Scientists work to build climate change resilience in Caribbean coral reef, 8 January. https://blogs. ei.columbia.edu/2019/01/08/climate-resilience-mesoamerican-reef/. Accessed 17 August 2020. 
Rizvi, A.R. (2014). Nature Based Solutions for Human Resilience: A Mapping Analysis of IUCN's Ecosystem Based Adaptation Projects. Washington, D.C.: International Union for Conservation of Nature. https://portals.iucn.org/library/sites/ library/files/documents/Rep-2014-008.pdf.

Rodríguez-de-Francisco, J.C. and Budds, J. (2015). Payments for environmental services and control over conservation of natural resources: the role of public and private sectors in the conservation of the Nima watershed, Colombia. Ecological Economics 117, 295-302. https://doi.org/10.1016/j.ecolecon.2014.05.003.

Royal Society for the Protection of Birds (undated). Medmerry Coastal Realignment: Success for People and Wildlife. UK. http://ww2.rspb.org.uk/Images/medmerry_tcm9-405348.pdf.

Rycerz, R., Bugler, W., Messling, L. and Wade, G. (2020). Itaipú Dam: How Natural Ecosystems Support One of the World's Largest Hydroelectric Dams. The Resilience Shift. https://www.resilienceshift.org/wp-content/uploads/2020/08/ Itaipu-Dam-case-study-Resilience-Shift.pdf.

Saintilan, N., Khan, N.S., Ashe, E., Kelleway, J.J., Rogers, K., Woodroffe, C. et al. (2020). Thresholds of mangrove survival under rapid sea level rise. Science 368(6495), 1118-1121. https://doi.org/10.1126/science.aba2656.

Scheffers, B.R., De Meester, L., Bridge, T.C., Hoffmann, A.A., Pandolfi, J.M., Corlett, R.T. et al. (2016). The broad footprint of climate change from genes to biomes to people. Science 354(6313), aaf7671. https://doi.org/10.1126/science.aaf7671.

Secretariat of the Convention on Biological Diversity (CBD) (2009). Connecting biodiversity and climate change mitigation and adaptation. Report of the Second Ad Hoc Technical Expert Group on Biodiversity and Climate Change. CBD Technical Series No. 41. Montreal. https://www.cbd.int/doc/publications/cbd-ts-41-en.pdf.

Secretariat of the Convention on Biological Diversity (CBD) (2010). Ecosystem approach: description, 17 March. https:// www.cbd.int/ecosystem/description.shtml. Accessed 29 October 2020.

Seddon, N., Chausson, A., Berry, P., Girardin, C.A., Smith, A. and Turner, B. (2020a). Understanding the value and limits of nature-based solutions to climate change and other global challenges. Philosophical Transactions of the Royal Society B 375(1794), 20190120. https://doi.org/10.1098/rstb.2019.0120.

Seddon, N., Daniels, E., Davis, R., Chausson, A., Harris, R., Hou-Jones, X. et al. (2020b). Global recognition of the importance of nature-based solutions to the impacts of climate change. Global Sustainability 3, e15. https://doi.org/10.1017/ sus.2020.8.

Settele, J., Scholes, R., Betts, R., Bunn, S., Leadley, P., Nepstad, D. et al. (2014). Terrestrial and inland water systems. In Climate Change 2014: Impacts, Adaptation, and Vulnerability. Part A: Global and Sectoral Aspects. Working Group II Contribution to the Fifth Assessment Report of the Intergovernmental Panel on Climate Change. Field, C.B., Barros, V.R., Dokken, D.J., Mach, K.J., Mastrandrea, M.D., Bilir, T.E. et al. (eds.). Cambridge and New York: Cambridge University Press. 271-359. https://www.ipcc.ch/site/assets/uploads/2018/02/WGIIAR5-PartA_FINAL.pdf.

Somarakis, G., Stagakis, S. and Chrysoulakis, N.(eds.) (2019). ThinkNature Nature-based Solutions Handbook. https://doi. org/10.26225/jerv-w202.

Terton, A. and Greenwalt, J. (2020). Building Resilience with Nature: Ecosystem-based Adaptation in National Adaptation Plan Processes: An Analysis. Winnipeg: International Institute for Sustainable Development. https://napglobalnetwork. org/wp-content/uploads/2020/11/napgn-en-2020-ecosystem-based-adaptation-in-national-adaptation-plans.pdf.

The Forum for Sustainable and Responsible Investment (US SIF) (2018). Report on US Sustainable, Responsible and Impact Investing Trends 2018. https://www.ussif.org/files/Trends/Trends\%202018\%20executive\%20summary\%20FINAL.pdf. Accessed 24 August 2020.

The Nature Conservancy (TNC) (2018). Strategies for Operationalizing Nature-based Solutions in the Private Sector. Arlington. https://www.nature.org/content/dam/tnc/nature/en/documents/NBSWhitePaper.pdf.

The Nature Conservancy (TNC) (undated). Water Funds Toolbox: New York City. https://waterfundstoolbox.org/new-yorkcity. Accessed 30 October 2020.

Thiele, T., Alleng, G., Biermann, A., Corwin, E., Crooks, S., Fieldhouse, P. et al. (2020). Blue Infrastructure Finance: A New Approach, Integrating Nature-based Solutions for Coastal Resilience. Gland: International Union for Conservation of Nature. https://bluenaturalcapital.org/wp2018/wp-content/uploads/2020/03/Blue-Infrastructure-Finance.pdf.

Thomas, K., Hardy, R.D., Lazrus, H., Mendez, M., Orlove, B., Rivera-Collazo, I. et al. (2019). Explaining differential vulnerability to climate change: a social science review. Wiley Interdisciplinary Reviews: Climate Change 10(2), e565. https://doi. org/10.1002/wcc.565.

Tonkonogy, B., Mazza, F. and Micale, V. (2018). Understanding and Increasing Finance for Climate Adaptation in Developing Countries. Climate Policy Initiative. https://www.climatepolicyinitiative.org/wp-content/uploads/2018/12/ Understanding-and-Increasing-Finance-for-Climate-Adaptation-in-Developing-Countries-1.pdf.

Trinomics and International Union for Conservation of Nature (IUCN) (2019). Approaches to Financing Nature-based Solutions in Cities. Working document prepared in the framework of the Horizon 2020 project GrowGreen. http:// growgreenproject.eu/wp-content/uploads/2019/03/Working-Document_Financing-NBS-in-cities.pdf.

UN Climate Action Summit (2019). Compendium of Contributions: Nature-based Solutions. Nairobi: United Nations Office Nairobi. https://wedocs.unep.org/bitstream/handle/20.500.11822/29988/Compendium_NBS.pdf.

United Nations Development Programme (UNDP) (undated). Payments for ecosystem services. https://www.sdfinance. undp.org/content/sdfinance/en/home/solutions/payments-for-ecosystem-services.html. Accessed 24 August 2020. 
United Nations Development Programme (UNDP) (2016). National Biodiversity Strategies and Action Plans: Natural Catalysts for Accelerating Action on Sustainable Development Goals. Interim Report. New York. https://www.undp.org/content/ undp/en/home/librarypage/environment-energy/ecosystems_and_biodiversity/nbsaps---natural-catalysts-forachieving-the-sdgs.html.

United Nations Development Programme (UNDP) (2019). A Call for Action: Raising Ambition for Climate Adaptation and Resilience. https://www.adaptation-undp.org/sites/default/files/uploaded-images/call_for_action_on_adaptation_ and_resilience.pdf. Accessed 30 December 2020.

United Nations Environment Programme (UNEP) (2019). Resolution adopted by the United Nations Environment Assembly on 15 March 2019. Promoting Gender Equality and the Human Rights and Empowerment of Women and Girls in Environmental Governance. 28 March. UNEP/EA.4/L.21. https://wedocs.unep.org/bitstream/handle/20.500.11822/28481/English. pdf.

United Nations Environment Programme (UNEP) (undated a). Gambia: Ecosystem-based Adaption 2017-2023. http:// wedocs.unep.org/bitstream/handle/20.500.11822/28428/EbA_Gambia. pdf? sequence=1\&isAllowed=y. Accessed 17 December 2020.

United Nations Environment Programme (UNEP) (undated b). Comoros: Ecosystem-based Adaptation 2017-2020. http:// wedocs.unep.org/bitstream/handle/20.500.11822/28424/ComorosEba. pdf?sequence=1\&isAllowed=y. Accessed 17 December 2020.

United Nations Environment Programme (UNEP) (undated c). Open Data. Building Climate Resilience through Rehabilitated Watersheds, Forests and Adaptive Livelihoods. https://open.unep.org/project/GEF-5694. Accessed 17 December 2020.

United Nations Environment Programme (UNEP) (undated d). United Nations Decade on Ecosystem Restoration: Strategy. https://www.decadeonrestoration.org/strategy. Accessed 11 June 2020.

United Nations Environment Programme (UNEP) (2018). The Adaptation Gap Report 2018. Nairobi. https://wedocs.unep. org/bitstream/handle/20.500.11822/27114/AGR_2018.pdf.

United Nations Framework Convention on Climate Change (UNFCCC) (2018). The Scope of Work Undertaken on Slow Onset Events (SOES) as Reported by Partners in the SOEs Database. https://unfccc.int/sites/default/files/resource/ activity_b_soe_assesment_feb_2018.pdf.

United Nations Framework Convention on Climate Change (UNFCCC) (2020). Report of the Conference of the Parties on its twenty-fifth session, held in Madrid from 2 to 15 December 2019. Addendum. Part two: Action taken by the Conference of the Parties at its twenty-fifth session. 16 March. FCCC/CP/2019/13/Add.1. https://unfccc.int/sites/default/files/ resource/cp2019_13a01E.pdf.

Urban Institute (undated). What is pay for success (PFS)? https://pfs.urban.org/pfs-101/content/what-pay-success-pfs. Accessed 27 August 2020.

World Bank (undated). World Bank Climate Finance 2018. Washington, D.C. http://pubdocs.worldbank.org/ en/744511553696049991/World-Bank-2018-CFData.pdf.

World Bank (2017). Implementing nature-based flood protection: Principles and implementation guidance. Washington, DC. http://documents1.worldbank.org/curated/en/739421509427698706/pdf/Implementing-nature-based-floodprotection-principles-and-implementation-guidance.pdf

World Bank Group (2020). Mobilizing Private Finance for Nature. Washington, D.C. http://pubdocs.worldbank.org/ en/916781601304630850/Finance-for-Nature-28-Sep-web-version.pdf.

World Wide Fund for Nature (WWF) (undated). Smart coasts: climate-smarting marine protected areas and coastal management in the Mesoamerican reef region. https://www.wwfca.org/en/smartcoastsmar.cfm. Accessed 13 August 2020

\section{Chapter 7}

Adaptation Fund (2020). Report on the Adaptation Fund's response to the Covid-19 pandemic and adaptive measures to mitigate its impact on the fund's portfolio. AFB/EFC.26.b/4. https://www.adaptation-fund.org/wp-content/ uploads/2020/10/AFB.EFC_.26.b.4_AF_COVID19_Response.pdf.

Alcayna, T. (2020). At what cost? How chronic gaps on adaptation finance expose the world's poorest people to climate chaos. Zurich: Flood Resilience Alliance. https://reliefweb.int/sites/reliefweb.int/files/resources/1087-PA-ZFRAAtWhatCost-V15c-WEB.pdf.

Berrang-Ford, L., Biesbroek, R., Ford, J.D., Lesnikowski, A., Tanabe, A., Wang, F.M. et al. (2019). Tracking global climate change adaptation among governments. Nature Climate Change 9(6), 440-449. https://doi.org/10.1038/s41558019-0490-0.

Global Environment Facility (GEF) (2020a). White paper on a GEF COVID-19 Response Strategy. GEF/C.59/Inf.14.17 November. https://www.thegef.org/sites/default/files/council-meeting-documents/EN_GEF_C.59_Inf.14_White Paper on a GEF COVID-19 Response Strategy_.pdf. 
Global Environment Facility (GEF) (2020b). The impact of COVID-19 on GEF project preparation and implementation: Overview of responses from across the GEF Partnership. 9 November. GEF/C.59/11. https://www.thegef.org/ sites/default/files/council-meeting-documents/EN_GEF.C59_11_Impact of COVID19 on Project Preparation and Implementation_0.pdf.

Green Climate Fund (GCF) (2020). At a Turning Point: Catalysing Climate Finance in the Era of COVID-19. [online video]. 10 July. https://www.greenclimate.fund/print/node/11045. Accessed 16 December 2020.

Hammer, S. and Hallegatte, S. (2020). Planning for the economic recovery from COVID-19: A sustainability checklist for policy makers, 14 April. https://blogs.worldbank.org/climatechange/planning-economic-recovery-covid-19coronavirus-sustainability-checklist-policymakers. Accessed 8 January 2021.

Hammer, S., Hallegatte, S. and Banaji, F. (2020). How countries' climate ambitions can support sustainable recovery from COVID-19 (Coronavirus), 5 May. https://blogs.worldbank.org/climatechange/how-countries-climate-ambitions-cansupport-sustainable-recovery-covid-19-coronavirus. Accessed 8 January 2021.

Hammill, A. (2020). How COVID-19 is reinforcing the need for climate adaptation in vulnerable countries, 1 August. https:// ndcpartnership.org/news/how-covid-19-reinforcing-need-climate-adaptation-vulnerable-countries. Accessed 8 January 2021.

Hepburn, C., O'Callaghan, B., Stern, N., Stiglitz, J. and Zenghelis, D. (2020). Will COVID-19 fiscal recovery packages accelerate or retard progress on climate change? Oxford Review of Economic Policy 36(Supplement_1), S359-S381. https://doi.org/10.1093/oxrep/graa015.

Hurlbert, M., Krishnaswamy, J., Davin, E., Johnson, F.X., Mena, C.F., Morton, J. et al. (2019). Risk management and decision making in relation to sustainable development. In Climate Change and Land: an IPCC Special Report on Climate Change, Desertification, Land Degradation, Sustainable Land Management, Food Security, and Greenhouse Gas Fluxes in Terrestrial Ecosystems. Shukla, P.R., Skea, J., Calvo Buendía, E., Masson-Delmotte, V. Pörtner, H.-O., Roberts, D. et al. (eds). Intergovernmental Panel on Climate Change. Chapter 7. 673-800. https://www.ipcc.ch/srccl/.

Intergovernmental Panel on Climate Change (IPCC) (2019). Summary for policymakers. In IPCC Special Report on the Ocean and Cryosphere in a Changing Climate. Pörtner, H.-O., Roberts, D.C, Masson-Delmotte, V., Zhai, P., Tignor, M., Poloczanska, E. et al. (eds.). Cambridge: Cambridge University Press. https://www.ipcc.ch/srocc/.

Intergovernmental Panel on Climate Change (IPCC) (2018). Summary for policymakers. In Global Warming of $1.5^{\circ} \mathrm{C}$. An IPCC Special Report on the Impacts of Global Warming of $1.5^{\circ} \mathrm{C}$ Above Pre-Industrial Levels and Related Global Greenhouse Gas Emission Pathways, in the Context of Strengthening the Global Response to the Threat of Climate Change, Sustainable Development, and Efforts to Eradicate Poverty. Masson-Delmotte, V., Zhai, P., Pörtner, H.-O., Roberts, D., Skea, J., Shukla, P.R. et al. (eds). Cambridge: Cambridge University Press. https://www.ipcc.ch/sr15/.

International Labour Organization (ILO), Food and Agriculture Organization of the United Nations (FAO), International Fund for Agricultural Development (IFAD) and World Health Organization (WHO) (2020). Impact of COVID-19 on people's livelihoods, their health and our food systems, 13 October. https://www. who.int/news/item/13-10-2020-impact-ofcovid-19-on-people's-livelihoods-their-health-and-our-food-systems. Accessed 16 December 2020.

International Monetary Fund (2020). Greening the recovery. Special series on fiscal policies to respond to COVID-19. https://www.imf.org/en/Topics/climate-change/green-recovery. J

Johnson, Z., Vera, I. and Zühr, R. (2020). How are donor countries responding to COVID-19? Early analyses and trends to watch, 13 May. https://donortracker.org/insights/how-are-donor-countries-responding-covid-19early-analyses-and-trends-watch. Accessed 8 January 2021.

Kebede, T.A., Stave, S.E. and Kattaa, M. (2020). Rapid assessment of the impacts of COVID-19 on vulnerable populations and small-scale enterprises in Iraq. International Labour Organization. https://www.ilo.org/wcmsp5/groups/ public/---arabstates/---ro-beirut/documents/publication/wcms_751209.pdf.

Leiter, T. and Pringle, P. (2018). Pitfalls and potential of measuring adaptation through adaptation metrics. In Adaptation Metrics: Perspectives on Measuring, Aggregating and Comparing Adaptation Results (pp. 29-48). Christiansen, L., Sanchez Martinez, G. and Naswa, P. (eds.). Copenhagen: UNEP DTU Partnership. https:// unepdtu.org/publications/adaptation-metrics-perspectives-on-measuring-aggregating-and-comparingadaptation-results/.

Magnan A.K. and Chalastani, V.I. (2019). Towards a global adaptation progress tracker: First thoughts. IDDRI Working Papers. 01/2019. https://www.iddri.org/sites/default/files/PDF/Publications/Catalogue\%20lddri/ Document\%20de\%20travail/WP0119_global\%20adaptation\%20tracker_0.pdf. Accessed 8 January 2021.

Magnan A.K. and Ribera, T. (2016). Global adaptation after Paris. Science 352(6291), 1280-1282. https://doi. org/10.1126/science.aaf5002.

National Adaptation Plan Global Support Programme (2020). The impacts of COVID-19 on adaptation planning in Asia LDCs, 29 July. https://www.globalsupportprogramme.org/nap-gsp-webinar-impacts-covid-19-adaptationplanning-asian-Idcs. Accessed 8 January 2021.

NDC Partnership (2020). Climate Action at the Heart of COVID-19 Recovery Plans [presentation]. 22 May. https:// issuu.com/ndcpartnership/docs/ndcp_covid_response_blog. Accessed 16 December 2020. 
Norton, R., Venkateswaran, K., Vaughan, A., McQuistan, C., Bachofen, C. and Hagon, K. (2020). Building Back Better: Ensuring COVID-19 response and recovery builds long-term resilience to climate impacts. Policy Brief. Zurich: Zurich Flood Resilience Alliance. https://europe.mercycorps.org/sites/default/files/2020-10/1033-PA-ZFRPPB-BuildingBackBetter\%20WEB.pdf.

Oppenheimer, M., Glavovic, B.C., Hinkel, J., van de Wal, R., Magnan, A.K., Abd-Elgawad, A. et al. (2019). Sea level rise and implications for low-lying islands, coasts and communities. In IPCC Special Report on the Ocean and Cryosphere in a Changing Climate. Pörtner, H.-O., Roberts, D.C, Masson-Delmotte, V., Zhai, P., Tignor, M., Poloczanska, E. et al. (eds.). Cambridge: Cambridge University Press. https://www.ipcc.ch/srocc/.

Organisation for Economic Co-operation and Development (OECD) (2020a). Impact of the Coronavirus (COVID-19) Crisis on Development Finance. http://www.oecd.org/coronavirus/policy-responses/the-impact-of-thecoronavirus-covid-19-crisis-on-development-finance-9de00b3b/.Organisation for Economic Co-operation and Development (OECD) (2020b). Building Back Better: A sustainable, resilient recovery after COVID-19. http://www. oecd.org/coronavirus/policy-responses/building-back-better-a-sustainable-resilient-recovery-after-covid-19$52 \mathrm{~b} 869 \mathrm{f5} /$.

Quevedo, A., Peters, K. and Cao, Y. (2020). The impact of COVID-19 on climate change and disaster resilience funding: Trends and signals. London and Zurich: ODI and Zurich Flood Resilience Alliance. https://www.odi.org/sites/ odi.org.uk/files/resource-documents/covid_and_resilience_funding_briefing_note_web_0.pdf.

United Nations (2020a). Climate change and COVID-19: UN urges nations to 'recover better', 22 April. https:// www.un.org/en/un-coronavirus-communications-team/un-urges-countries-\%E2\% $80 \% 98$ build-backbetter\%E2\%80\%99. Accessed 23 November 2020.

United Nations (2020b). International Mother Earth Day, 22 April. https://www.un.org/en/observances/earth-day/ message. Accessed 16 December 2020.

United Nations Environment Programme (UNEP) (2014). The Adaptation Gap Report 2014. Nairobi. https://www. unenvironment.org/resources/adaptation-gap-report-2014.

United Nations Environment Programme (UNEP) (2017). The Adaptation Gap Report 2017. Nairobi. https://www. unenvironment.org/resources/adaptation-gap-report-2017.

United Nations Environment Programme (UNEP) (2018). The Adaptation Gap Report 2018. Nairobi. https://www.unep. org/resources/adaptation-gap-report.

United Nations Environment Programme (UNEP) (2020). The Emissions Gap Report 2020. Nairobi. https://www. unenvironment.org/resources/adaptation-gap-report-2020.

United Nations Office of the High Representative for the Least Developed Countries, Landlocked Developing Countries and Small Island Developing States (2020). World's most vulnerable countries lack the capacity to respond to a global pandemic. https://www.un.org/ohrlls/news/world's-most-vulnerable-countries-lack-capacity-respondglobal-pandemic-credit-mfdelyas-alwazir. Accessed 8 January 2021.

Vivid Economics (2020). Green Stimulus Index. An assessment of the orientation of COVID-19 stimulus in relation to climate change, biodiversity and other environmental impacts. https://www.vivideconomics.com/wp-content/ uploads/2020/08/200820-GreenStimulusIndex_web.pdf. 


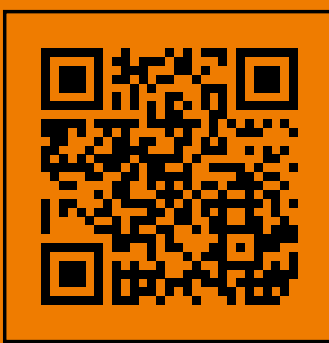

\section{UN environment programme}

United Nations Avenue, Gigiri

P.O. Box 30552, 00100 Nairobi, Kenya

Tel. +254 207621234

unep-publications@un.org

www.unep.org 